\title{
Proximal esophageal cancer
}

Citation for published version (APA):

de Vos-Geelen, J. (2021). Proximal esophageal cancer. [Doctoral Thesis, Maastricht University]. Maastricht University. https://doi.org/10.26481/dis.20210625jv

Document status and date:

Published: 01/01/2021

DOI:

10.26481/dis.20210625jv

Document Version:

Publisher's PDF, also known as Version of record

\section{Please check the document version of this publication:}

- A submitted manuscript is the version of the article upon submission and before peer-review. There can be important differences between the submitted version and the official published version of record.

People interested in the research are advised to contact the author for the final version of the publication, or visit the DOI to the publisher's website.

- The final author version and the galley proof are versions of the publication after peer review.

- The final published version features the final layout of the paper including the volume, issue and page numbers.

Link to publication

\footnotetext{
General rights rights.

- You may freely distribute the URL identifying the publication in the public portal. please follow below link for the End User Agreement:

www.umlib.nl/taverne-license

Take down policy

If you believe that this document breaches copyright please contact us at:

repository@maastrichtuniversity.nl

providing details and we will investigate your claim.
}

Copyright and moral rights for the publications made accessible in the public portal are retained by the authors and/or other copyright owners and it is a condition of accessing publications that users recognise and abide by the legal requirements associated with these

- Users may download and print one copy of any publication from the public portal for the purpose of private study or research.

- You may not further distribute the material or use it for any profit-making activity or commercial gain

If the publication is distributed under the terms of Article $25 \mathrm{fa}$ of the Dutch Copyright Act, indicated by the "Taverne" license above, 


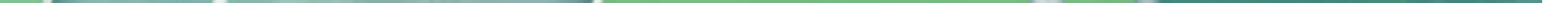




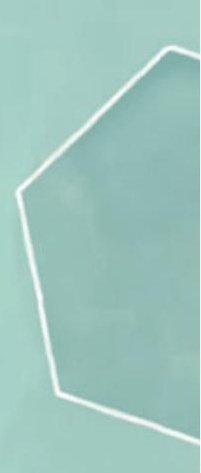




\section{Proximal esophageal cancer}


(C) copyright Judith de Vos-Geelen, Maastricht 2021

All rights reserved. No part of this publication may be reproduced or transmitted, in any form or by any means, electronic, mechanical, photocopying, recording or otherwise, without prior permission of the author or the publishers of the published chapters.

Cover: Evelien Jagtman

Layout: Tiny Wouters

Printing: Ridderprint

ISBN: 978-94-6416-402-2 


\title{
Proximal esophageal cancer
}

\author{
Proefschrift
}

ter verkrijging van de graad van doctor aan de Universiteit Maastricht, op gezag van de Rector Magnificus, Prof.dr. Rianne M. Letschert, volgens het besluit van het College van Decanen, in het openbaar te verdedigen op vrijdag 25 juni 2021 om 12:00 uur

door

Judith de Vos-Geelen 


\section{Promotor}

Prof. dr. V.C.G. Tjan-Heijnen

\section{Copromotores}

Dr. G.A.P. Nieuwenhuijzen, Catharina Ziekenhuis Eindhoven

Dr. ir. S.M.E. Geurts

Dr. F.J.P. Hoebers

\section{Beoordelingscommissie}

Prof. dr. M.L. Smidt (voorzitter)

Prof. dr. I.H.J.T. de Hingh

Prof. dr. M. Verheij, Radboud UMC

Dr. J.W. Wilmink, Amsterdam UMC, locatie AMC 



\section{Contents}

Chapter 1 General introduction and outline of the thesis

Chapter 2 Long-term survival improvement in esophageal cancer in

the Netherlands

European Journal of Cancer. 2018 May;94:138-147

Chapter 3 Trends in treatment and overall survival among patients with proximal esophageal cancer World Journal of Gastroenterology. 2019 Dec 21;25(47):6835-6846

Chapter 4 Cervical esophageal cancer: a gap in cancer knowledge Annals of Oncology. 2016 Sep;27(9):1664-1674

Chapter 5 A national study to assess outcomes of definitive chemoradiation regimens in proximal esophageal cancer Acta Oncologica. 2020 Aug;59(8):895-903

Chapter 6 Patterns of recurrence following definitive chemoradiation for patients with proximal esophageal cancer European Journal of Surgical Oncology. 2021 Feb 5:S0748-7983(21)00084-6

Chapter 7 General discussion and future perspectives

Chapter 8 Summary

Addendum Samenvatting

Impact paragraph 169

List of publications

Dankwoord

Curriculum vitae 



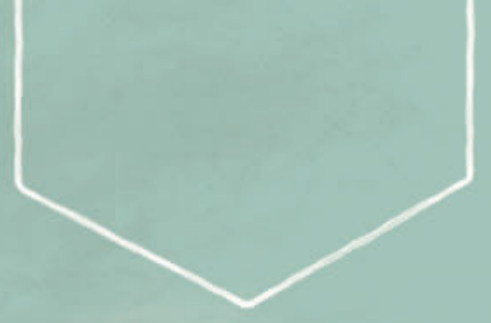

CHAPTER 1

General introduction and outline of the thesis 



\section{General aspects of esophageal cancer}

Esophageal cancer is the seventh most common cancer worldwide, with an estimated incidence of 572,034 cases around the world in 2018. ${ }^{1}$ Of all new cancer diagnoses in the Netherlands in 2018, 2\% were esophageal cancers, corresponding with 2,456 new patients. ${ }^{1}$ Although the absolute number of deaths has decreased, esophageal cancer is still the sixth leading cause of cancer-related mortality globally and in the Netherlands. ${ }^{1}$ Esophageal cancer is classified by histology as adenocarcinoma or squamous cell cancer. $^{2,3}$ In contrast to squamous cell cancer, adenocarcinoma incidence has increased several fold in Western countries in recent decades, ${ }^{4}$ occurs predominantly in the lower esophagus, and is associated with obesity, gastric reflux and the precursor state Barrett's esophagus. Esophageal squamous cell cancer is associated with a lower socioeconomic status, with smoking and alcohol exposure as the most notable risk factors in Western populations. ${ }^{3,4}$ Squamous cell cancer predominates in the proximal and mid-esophagus. Cancer of the proximal esophagus is an uncommon malignancy, as less than $5 \%$ of all esophageal cancers originate in the proximal esophagus. ${ }^{5}$ Proximal esophageal cancer shows similarities with head and neck squamous cell cancer in terms of location, histology, and molecular features. ${ }^{6}$ Due to its low incidence, literature is scarce and profound research of the distinct entity of proximal esophageal cancer challenging.

\section{Clinical presentation, diagnostic procedures and staging}

Esophageal adenocarcinomas and squamous cell cancers have comparable clinical features. Most common symptoms at the time of diagnosis are dysphagia (74\%), weight loss (57\%), and heartburn (21\%). ${ }^{7}$ Dyspnea, hoarseness, and (retrosternal, right upper abdominal or back) pain occur less often and may reflect the presence of locally advanced, unresectable disease.

Staging of esophageal cancer consists of an endoscopic evaluation of the esophageal mucosa, strictures or ulcerations of the esophagus. Beginning at the hypopharynx, the esophagus lies posterior to the trachea and the heart, passing through the posterior mediastinum and entering the stomach below the hiatus. For classification, staging, and reporting of cancer, the esophagus is divided into four regions because its treatment might vary between the anatomic sections. ${ }^{8}$ The location at endoscopy is measured from the incisors, separating the proximal esophagus from the mid thoracic, and distal part of the esophagus. The proximal esophagus can be subdivided into the cervical 
esophagus, commencing at the lower border of the cricoid cartilage and ending at the thoracic inlet, approximately $18 \mathrm{~cm}$ from the incisors, and the upper thoracic section, extending from the thoracic inlet unto the level of the tracheal bifurcation, which is approximately $24 \mathrm{~cm}$ from the incisors (Figure 1.1). ${ }^{8}$

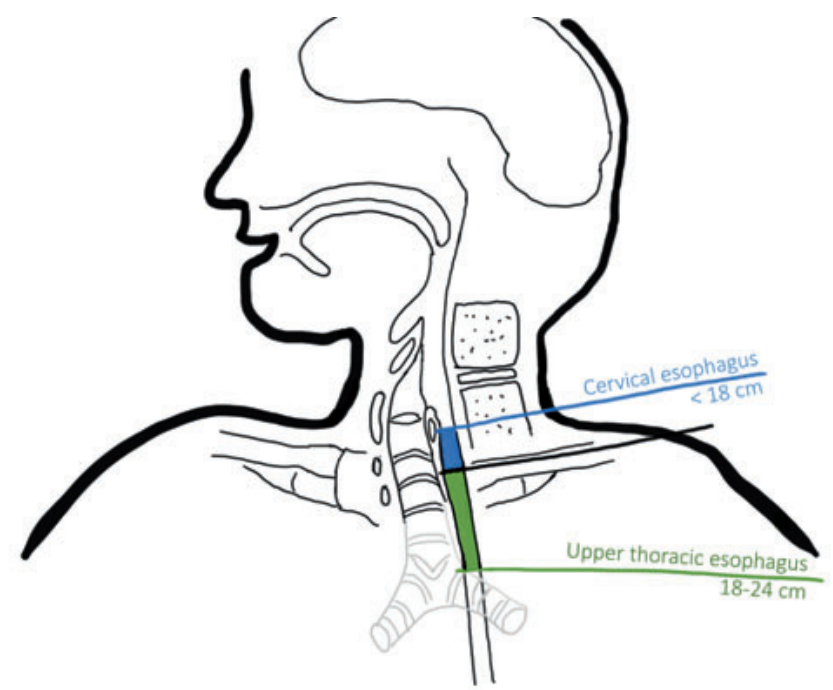

Figure 1.1 Anatomy of the proximal esophagus.

Biopsies are performed for histopathological examination. In addition to computed tomography (CT), Positron-emission tomography (PET) with fluorodeoxyglucose $\mathrm{F} 18$ (FDG) imaging is performed to assess occult nodal involvement and distant metastases. ${ }^{9}$ The use of endoscopic ultrasonography has improved the assessment of depth of tumor invasion and the accuracy of lymph node staging. ${ }^{10}$ Hence, an endoscopic ultrasound may be beneficial to obtain additional information in patients with an esophageal cancer without signs of distant metastasis.

A systematic usage of these diagnostic interventions establish a uniform American Joint Committee on Cancer (AJCC) staging, utilizing Tumor-Node-Metastasis (TNM) guidelines. $^{8,11,12}$ 


\section{Treatment}

For early-stage esophageal cancers endoscopic resection, i.e. endoscopic mucosal resection or endoscopic submucosal dissection, is appropriate. In higher stage disease treatment patterns frequently diverge due to multiple therapeutic options. In patients with more locally advanced disease, survival outcomes with surgery alone are poor and a multimodal approach, i.e. performing (neo)adjuvant chemo(radio)therapy, is recommended for patients who are deemed fit to undergo a resection. ${ }^{13-15}$ Esophageal squamous cell cancer is more sensitive to radiotherapy than adenocarcinoma, therefore definitive chemoradiation is an option for patients with esophageal squamous cell cancer. ${ }^{16,17}$ Survival outcomes of definitive chemoradiation are comparable to surgery with or without chemo(radio)therapy but in definitive chemoradiation higher rates of local recurrences and subsequent salvage esophagectomy are observed. ${ }^{18-22}$ Alternatively, patients can be treated by either neoadjuvant chemoradiation or perioperative chemotherapy, with treatment preferences varying worldwide. ${ }^{13,14,23}$ Long-term results from the Dutch phase 3 CROSS trial confirmed the clinical value of multimodality treatment for esophageal cancer with a 5-year overall survival rate of $47 \%$ for patients who underwent neoadjuvant carboplatin plus paclitaxel chemoradiation followed by surgery compared to $33 \%$ in the surgery alone group. ${ }^{24,25}$ Hence, this treatment approach is currently standard of care for operable patients with resectable esophageal cancer in the Netherlands.

As of 2006, surgical treatment for esophageal cancer was centralized due to the relatively low incidence of these high-risk surgical procedures. Concentration of esophageal cancer surgery has been associated with a significant reduction in postoperative morbidity and mortality, and improved long-term survival. ${ }^{26,27}$

\section{Management of proximal esophageal cancer}

Treatment guidelines for proximal esophageal cancers specifically are lacking and mainly based on research of esophageal cancer in general. Cancers of the proximal part of the esophagus are regarded as a distinct entity as these cancers are frequently locally advanced at diagnosis, infiltrating nearby vital structures, e.g. larynx and trachea. Thus, most patients present at an unresectable stage. In others, the surgical procedure comprising pharyngo-laryngo-esophagectomy is highly mutilating, with longterm consequences in terms of speech and swallowing. ${ }^{28}$ Hence, other less invasive strategies were implemented to prolong survival while maintaining as much quality of life as possible. A meta-analysis demonstrated that the addition of chemotherapy to 
radiotherapy significantly increased response and overall survival in patients with esophageal cancer. ${ }^{19}$ As a result, definitive chemoradiation is considered standard of care for patients with proximal esophageal cancer. ${ }^{13,14}$ Although there seems to be a general consensus concerning the need for definitive chemoradiation, there is significant diversity in the regimen of this multimodality approach. Physicians use either established schemes analogous to the treatment of locally advanced head and neck squamous cell cancer, or those used in the management of patients with lower esophageal cancer. The most frequently used chemoradiation regimen for head and neck squamous cell cancer is 70 Gy radiotherapy, with concurrent cisplatin. ${ }^{29,30}$ The definitive chemoradiation strategy for cancers of the lower part of the esophagus include radiation doses of 50-50.4 Gy. ${ }^{13,14}$ However, NCCN guidelines state that higher doses of radiotherapy (60-66 Gy) may be opportune for cancers in the proximal esophagus, although robust data to confirm this statement are lacking. ${ }^{31}$

The most optimal chemotherapeutic backbone in definitive chemoradiation for esophageal cancer is currently subject of debate. Chemoradiation schedules containing cisplatin and 5-fluorouracil chemotherapy have long been the standard. ${ }^{16,17}$ The CROSS trial $^{24}$ demonstrated a high pathologic complete response rate of $49 \%$ in patients with esophageal squamous cell cancer following neoadjuvant carboplatin plus paclitaxel with 41.4 Gy radiotherapy, which was higher than previously observed in cisplatinbased regimens. ${ }^{32-34}$ Furthermore, this chemoradiation schedule with carboplatin plus paclitaxel demonstrated an encouraging safety profile. These results have led to the use of carboplatin plus paclitaxel in definitive chemoradiation strategies for patients with esophageal cancer. No randomized data are available to establish a preferential radiation dose and chemotherapeutic backbone in the neoadjuvant or definitive setting for the treatment of non-metastatic (proximal) esophageal cancer. Hence, various strategies are implemented in (inter)national care.

\section{Follow-up and prognosis in proximal esophageal cancer}

Long-term survival in proximal esophageal cancer is only achieved in complete responders to definitive chemoradiation, with 3-year overall survival rates of $45-67 \%{ }^{35-}$ 38 Nonetheless, many patients suffer from recurrence with consequently a poor prognosis. ${ }^{35,38-43}$ Depending on location of disease recurrence, a minority of patients might benefit from salvage surgery, second course radiotherapy or palliative systemic therapies. $^{36,44-46}$ However, potential survival advantages should be comprehensively discussed with each individual patient considering high rates of morbidity or toxicity associated with these complex treatments. ${ }^{45,46}$ Recurrence patterns of proximal 
esophageal cancer and its treatment is still unclear. Whether or not follow-up after definitive chemoradiation for esophageal cancer is useful remains controversial. Hence, recommendations by NCCN and ESMO guidelines are inconsistent regarding follow-up strategies and duration of surveillance. ${ }^{13,14}$

\section{Outline of this thesis}

This thesis describes several projects all aimed to enhance understanding of treatment patterns and associated outcomes, identifying points of improvement, ultimately optimizing counseling and outcomes for all patients with proximal esophageal cancer.

First, in Chapter two it was described how tumor stage, treatment, and survival of esophageal cancer in the Netherlands evolved over time, and whether centralization of surgical care influenced outcome. The study results are based on the data of 35,760 patients with esophageal cancer selected from the Netherlands Cancer Registry. Subsequently, an in-depth study on proximal esophageal cancer was presented in Chapter three including 2,783 patients identified from the Netherlands Cancer Registry. Chapter four provides a review of the literature focusing on evidence of current diagnostic strategies and therapeutic options for patients with non-metastatic cervical esophageal cancer.

Based on the findings in this review, a nationwide retrospective cohort of 200 patients with cervical and upper thoracic, i.e. proximal, esophageal cancer treated with definitive chemoradiation in 11 centers in the Netherlands was assembled to examine patterns of chemoradiation regimens and associated outcomes. We evaluated the impact of four definitive chemoradiation schedules on safety and outcome (Chapter five), through collaboration within the Dutch Upper GI Cancer Group (DUCG) and the National Working Group Head Neck Cancer (NWHHT). Chapter six depicts the details on recurrence in complete responders following definitive chemoradiation for nonmetastatic proximal esophageal cancer $(\mathrm{N}=133)$. 


\section{Summary of research questions addressed in this thesis}

\section{Chapter Research question}

2 What were the trends in stage distribution, treatment, and outcome of esophageal cancer in a large population-based setting in the Netherlands in the period 1989-2014?

3 How did trends in treatment and overall survival in patients diagnosed with non-metastatic or metastatic proximal esophageal cancer in a nationwide registry progress between 1989 and 2014?

4 What is the current knowledge of diagnosis, treatment options, and its accompanied toxicity, for patients with non-metastatic cervical esophageal cancer?

$5 \quad$ How did the implementation of new chemoradiation regimens (carboplatin plus paclitaxel versus cisplatin-based, and low versus high dose radiotherapy affect) affect clinical practice, toxicity, and overall survival in patients with non-metastatic proximal esophageal cancer?

$6 \quad$ Where and when do first recurrences appear after achieving clinical complete response following definitive chemoradiation for non-metastatic proximal esophageal cancer? 


\section{References}

1. Ferlay J, et al. Global Cancer Observatory: Cancer Today. Lyon, France: International Agency for Research on Cancer. Available from: https://gco.iarc.fr/today (accessed November 23, 2020).

2. Pennathur A, et al. Oesophageal carcinoma. Lancet 2013;381(9864):400-12.

3. Siewert JR, Ott K. Are squamous and adenocarcinomas of the esophagus the same disease? Semin Radiat Oncol 2007;17(1):38-44.

4. The global, regional, and national burden of oesophageal cancer and its attributable risk factors in 195 countries and territories, 1990-2017: a systematic analysis for the Global Burden of Disease Study 2017. Lancet Gastroenterol Hepatol 2020;5(6):582-97.

5. Rice TW, et al. Worldwide esophageal cancer collaboration. Dis Esophagus 2009;22(1):1-8.

6. The Cancer Genome Atlas Research Network, Integrated genomic characterization of oesophageal carcinoma. Nature 2017;541(7636):169-75.

7. Daly JM, et al. Esophageal cancer: results of an American College of Surgeons Patient Care Evaluation Study. J Am Coll Surg 2000;190(5):562-72; discussion 572-3.

8. Greene FL, et al. AJCC Cancer Staging Manual, 6th Edition. Springer-Verlag New York, 2002.

9. Vyas S, et al. The role of integrated F-18-FDG-PET scanning in the detection of M1 disease in oesophageal adenocarcinoma and impact on clinical management. J Gastrointest Surg 2011;15(12): 2127-35.

10. van Vliet EP, et al. Staging investigations for oesophageal cancer: a meta-analysis. Br J Cancer 2008; 98(3):547-57.

11. Edge SB, Byrd DR, Compton CC. The AJCC Cancer Staging Manual, 7th edition. New York: Springer 2010: 143-65.

12. Rice TW, Patil DT, Blackstone EH. 8th edition AJCC/UICC staging of cancers of the esophagus and esophagogastric junction: application to clinical practice. Ann Cardiothorac Surg 2017;6(2):119-30.

13. Lordick F, et al. Oesophageal cancer: ESMO Clinical Practice Guidelines for diagnosis, treatment and follow-up. Ann Oncol 2016;27(suppl 5):v50-7.

14. Ajani JA, et al. Esophageal and Esophagogastric Junction Cancers, Version 2.2019, NCCN Clinical Practice Guidelines in Oncology. J Natl Compr Canc Netw 2019;17(7):855-83.

15. Sjoquist KM, et al. Survival after neoadjuvant chemotherapy or chemoradiotherapy for resectable oesophageal carcinoma: an updated meta-analysis. Lancet Oncol 2011;12(7):681-92.

16. Cooper JS, et al. Chemoradiotherapy of locally advanced esophageal cancer: long-term follow-up of a prospective randomized trial (RTOG 85-01). Radiation Therapy Oncology Group. JAMA 1999;281(17): 1623-7.

17. Herskovic A, et al. Combined Chemotherapy and Radiotherapy Compared with Radiotherapy Alone in Patients with Cancer of the Esophagus. N Engl J Med 1992;326(24):1593-8.

18. Crosby TD, et al. Definitive chemoradiation in patients with inoperable oesophageal carcinoma. $\mathrm{Br} J$ Cancer 2004;90(1):70-5.

19. Wong R, Malthaner R. Combined chemotherapy and radiotherapy (without surgery) compared with radiotherapy alone in localized carcinoma of the esophagus. Cochrane Database Syst Rev 2006(1): Cd002092.

20. Allum WH, et al. Guidelines for the management of oesophageal and gastric cancer. Gut 2011;60(11): 1449-72.

21. Stahl $\mathrm{M}$, et al. Chemoradiation with and without surgery in patients with locally advanced squamous cell carcinoma of the esophagus. J Clin Oncol 2005;23(10):2310-7.

22. Bedenne $\mathrm{L}$, et al. Chemoradiation followed by surgery compared with chemoradiation alone in squamous cancer of the esophagus: FFCD 9102. J Clin Oncol 2007;25(10):1160-8.

23. Kitagawa $Y$, et al. Esophageal cancer practice guidelines 2017 edited by the Japan Esophageal Society: part 1. Esophagus 2019;16(1):1-24.

24. van Hagen $\mathrm{P}$, et al. Preoperative chemoradiotherapy for esophageal or junctional cancer. N Engl J Med 2012;366(22):2074-84. 
25. Shapiro J, et al. Neoadjuvant chemoradiotherapy plus surgery versus surgery alone for oesophageal or junctional cancer (CROSS): long-term results of a randomised controlled trial. Lancet Oncol 2015;16(9): 1090-8.

26. van de Poll-Franse LV, et al. Impact of concentration of oesophageal and gastric cardia cancer surgery on long-term population-based survival. Br J Surg 2011;98(7):956-63.

27. Dikken JL, et al. Effect of hospital volume on postoperative mortality and survival after oesophageal and gastric cancer surgery in the Netherlands between 1989 and 2009. Eur J Cancer 2012;48(7):1004-13.

28. Archibald S, Young JE, Thoma A. Pharyngo-cervical esophageal reconstruction. Clin Plast Surg 2005; 32(3):339-46, vi.

29. Pignon JP, et al. Meta-analysis of chemotherapy in head and neck cancer (MACH-NC): an update on 93 randomised trials and 17,346 patients. Radiother Oncol 2009;92(1):4-14

30. Strojan $\mathrm{P}$, et al. Cumulative cisplatin dose in concurrent chemoradiotherapy for head and neck cancer: $\mathrm{A}$ systematic review. Head \& Neck 2016;38(S1):E2151-8.

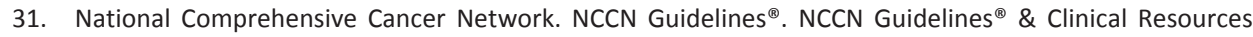
2018. Esophageal and Esophagogastric Junction Cancers (Version 2.2018). 2018 May 22, 2018; Available from: https://www.nccn.org/professionals/physician_gls/pdf/esophageal.pdf.

32. Bosset JF, et al. Chemoradiotherapy followed by surgery compared with surgery alone in squamous-cell cancer of the esophagus. N Engl J Med 1997;337(3):161-7.

33. Tepper J, et al. Phase III trial of trimodality therapy with cisplatin, fluorouracil, radiotherapy, and surgery compared with surgery alone for esophageal cancer: CALGB 9781. J Clin Oncol 2008;26(7):1086-92.

34. Lee $\mathrm{JL}$, et al. A single institutional phase III trial of preoperative chemotherapy with hyperfractionation radiotherapy plus surgery versus surgery alone for resectable esophageal squamous cell carcinoma. Ann Oncol 2004;15(6):947-54.

35. Gkika $\mathrm{E}$, et al. Long-term results of definitive radiochemotherapy in locally advanced cancers of the cervical esophagus. Dis Esophagus 2014;27(7):678-84.

36. Zenda S, et al. Multicenter Phase 2 Study of Cisplatin and 5-Fluorouracil With Concurrent Radiation Therapy as an Organ Preservation Approach in Patients With Squamous Cell Carcinoma of the Cervical Esophagus. Int J Radiat Oncol Biol Phys 2016;96(5):976-84.

37. Valmasoni M, et al. Cervical Esophageal Cancer Treatment Strategies: A Cohort Study Appraising the Debated Role of Surgery. Ann Surg Oncol 2018;25(9):2747-55.

38. Uno T, et al. Concurrent chemoradiation for patients with squamous cell carcinoma of the cervical esophagus. Dis Esophagus 2007;20(1):12-8.

39. Huang $\mathrm{SH}$, et al. Effect of concurrent high-dose cisplatin chemotherapy and conformal radiotherapy on cervical esophageal cancer survival. Int J Radiat Oncol Biol Phys 2008;71(3):735-40.

40. Zhang $P$, et al. Clinical efficacy and failure pattern in patients with cervical esophageal cancer treated with definitive chemoradiotherapy. Radiother Oncol 2015;116(2):257-61.

41. Herrmann E, et al. Outcome of proximal esophageal cancer after definitive combined chemo-radiation: a Swiss multicenter retrospective study. Radiat Oncol 2017;12(1):97.

42. Yamada K, et al. Treatment results of radiotherapy for carcinoma of the cervical esophagus. Acta Oncol 2006;45(8):1120-5.

43. Ludmir EB, et al. Incidence and prognostic impact of high-risk HPV tumor infection in cervical esophageal carcinoma. J Gastrointest Oncol 2014;5(6):401-7.

44. Schieman C, et al. Salvage resections for recurrent or persistent cancer of the proximal esophagus after chemoradiotherapy. Ann Thorac Surg 2013;95(2):459-63.

45. Markar S, et al. Salvage Surgery After Chemoradiotherapy in the Management of Esophageal Cancer: Is It a Viable Therapeutic Option? J Clin Oncol 2015;33(33):3866-73.

46. Sudo K, et al. Importance of surveillance and success of salvage strategies after definitive chemoradiation in patients with esophageal cancer. J Clin Oncol 2014;32(30):3400-5. 



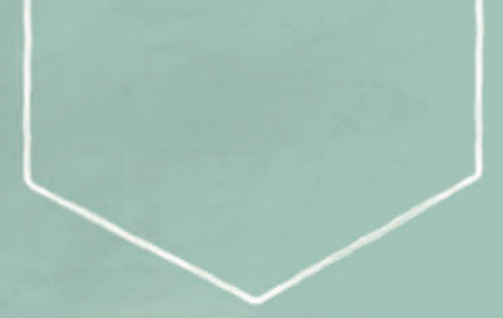

CHAPTER 2

Long-term survival improvement in esophageal cancer in the Netherlands

M. van Putten, J. de Vos-Geelen, G.A.P. Nieuwenhuijzen, P.D. Siersema V.E.P.P. Lemmens. C. Rosman, M.J.C. van der Sangen, R.H.A. Verhoeven European Journal of Cancer 2018;94:138-147 


\section{Abstract}

\section{Background}

Treatment for esophageal cancer has evolved due to developments including the centralization of surgery and introduction of neoadjuvant treatment. Therefore, this study evaluated trends in stage distribution, treatment and survival of esophageal cancer patients in the last 26 years in the Netherlands.

\section{Patients and methods}

Patients with esophageal cancer diagnosed in the period 1989-2014 were selected from the Netherlands Cancer Registry. Patients were divided into two groups: non-metastatic (M0) and metastatic (M1). Trends in stage distribution, treatment and relative survival rates were evaluated according to histology.

\section{Results}

Among all 35,760 patients, the percentage of an unknown tumor stage decreased from $34 \%$ to $10 \%$ during the study period, whereas the percentage of patients with metastatic disease increased from $21 \%$ to $34 \%$. Among surgically treated patients $32 \%$ underwent a resection in a high-volume hospital in 2005 which increased to $92 \%$ in 2014 . Use of neoadjuvant chemoradiotherapy increased in non-metastatic esophageal adenocarcinoma (EAC) and squamous cell carcinoma (ESCC) patients from respectively $4 \%$ and $2 \%$ in $2000-2004$ to $43 \%$ and $26 \%$ in $2010-2014$. Five-year relative survival increased from $8 \%$ to $22 \%$ for all patients; from $12 \%$ to $36 \%$ for non-metastatic EAC and from $9 \%$ to $27 \%$ for non-metastatic ESCC over 26 years. Median overall survival of metastatic patients improved from 18 to 22 weeks.

\section{Conclusion}

In the Netherlands, survival for esophageal cancer patients improved significantly, especially in the period 2005-2014 which might be the result of better treatment related to the centralization of surgery and introduction of neoadjuvant chemoradiotherapy. 


\section{Introduction}

Esophageal cancer is the sixth leading cause of cancer related mortality and eight most common cancer worldwide. ${ }^{1,2}$ It affects 456,000 people worldwide annually and the incidence is increasing rapidly. ${ }^{1}$ There are two major histological types, esophageal adenocarcinoma (EAC) and esophageal squamous cell carcinoma (ESCC) each with a distinct etiology and specific risk factors. ${ }^{3}$ Although ESCC accounts for approximately $90 \%$ of all cases of esophageal cancer worldwide, EAC has become the predominant type of esophageal cancer in Europe and Northern America during the past decades. ${ }^{1,4}$ Treatment of esophageal cancer has been subjected to paradigm shifts in the last two decades. Long-term results from the CROSS trial confirmed the clinical value of multimodality treatment for esophageal cancer with a 5-year overall survival difference of $14 \%$ in favor of patients who underwent neoadjuvant chemoradiotherapy followed by surgery compared with surgery alone. ${ }^{5,6}$ Furthermore, endoscopic treatment was introduced for treatment of early-stage tumors and definitive chemoradiotherapy is increasingly considered as a well-tolerated alternative for surgery in inoperable patients and especially in squamous cell esophageal cancer. ${ }^{7-10}$ Besides these major changes in treatment, improved diagnostic procedures facilitated a better patient selection. $^{11-14}$

Esophageal cancer surgery has been increasingly centralized in the Netherlands. As of 2006, surgical treatment for esophageal cancer was centralized in hospitals performing a minimum of 10 resections per year and since 2011 a minimum of 20 . Concentration of esophageal cancer surgery has been shown to be associated with improved long-term overall survival for surgically and non-surgically treated patients. ${ }^{15,16}$ As treatment for esophageal cancer has evolved over the last few decades due to several developments such as centralization of surgery and new treatment approaches, the aim of this study was to evaluate trends in treatment and survival of patients with esophageal cancer in the Netherlands.

\section{Methods}

\section{Netherlands Cancer Registry}

Data were obtained from the Netherlands Cancer Registry (NCR). This registry serves the total Dutch population of 16.9 million inhabitants. The NCR is based on the inclusion of all newly diagnosed malignancies in the Netherlands by the national automated pathological archive. Additional sources are the national registry of hospital 
discharge and radiotherapy institutions. Specially trained data managers of the NCR routinely extract information on diagnosis, tumor stage and treatment from the medical records. Information on vital status is obtained through annual linkage with the Municipal Administrative Database, in which all deceased and emigrated persons in the Netherlands are registered.

Patients with esophageal cancer (C15.0-C15.9) diagnosed in the period 1989-2014 were selected. Topography and morphology were coded according to the International Classification of Diseases for Oncology (ICD-O). ${ }^{17}$ ICD-O morphology codes were used to classify tumors as adenocarcinoma, squamous cell carcinoma and other or unknown histology. Subsite distribution was divided as: cervical (C15.0), proximal 1/3 (C15.3), middle 1/3 (C15.4), distal 1/3 (C15.5) and overlapping or not otherwise specified (C15.8, C15.9).

Tumor staging was performed according to the Union for International Cancer Control (UICC) TNM classification that was valid at the time of diagnosis. As tumor stage classification was comparable from TNM-4 to -6 but changed with the introduction of TNM-7, all patients were recoded (stage I to IV and unknown) according to TNM-6 in this study. Furthermore, M1a tumors according to TNM-5 and 6 were categorized as $\mathrm{N}+$ as most patients with a M1a tumor had a distal tumor with celiac lymph nodes which can be considered $\mathrm{N}+$ according to TNM-7. Pathologic tumor stage was assessed for stage distribution, or if not available, clinical tumor stage was noted. Patients with a cM1 or pM1 stage were classified as metastatic and all other patients as nonmetastatic.

\section{Treatment}

For non-metastatic patients, neoadjuvant chemoradiotherapy was defined as chemoradiotherapy followed by surgery. Definitive chemoradiotherapy was defined as chemoradiotherapy without a surgical resection as the intention of chemoradiotherapy was not registered during the study period. An endoscopic resection was defined as a local tumor excision, endoscopic mucosal resection or an endoscopic submucosal dissection.

For metastatic patients, a distinction was made between chemoradiotherapy, systemic treatment or radiotherapy as single modality. Systemic treatment included chemotherapy and targeted therapy. Symptom-related treatment was classified as no treatment. All other treatments were grouped as 'other' therapy and were described below Figures 2.3 and 2.4 . 


\section{Statistical analysis}

Differences in characteristics between patients were described according to period of diagnosis. Incidence and mortality rates were calculated as the number of new patients per 100,000 inhabitants per year, and age-standardized to European standardized rates. Survival time was defined as time from diagnosis to death or until February 1st 2017 for patients who were still alive. The median overall survival was estimated by using the Kaplan-Meier method for metastatic patients. Relative survival was estimated by using life tables of the general population to correct for age- and gender specific background mortality. The Ederer II method with age standardization to the most recent time period was used to compare relative survival between time periods. ${ }^{18,19}$ STATA version 14.1 was used for the survival analyses, and all other analyses were conducted using SAS version 9.4. $P$ values of $<0.05$ were considered statistically significant.

\section{Results}

Between January 1989 and December 2014, 35,760 patients were diagnosed with esophageal cancer in the Netherlands. Age-standardized incidence rates increased from 5 per 100,000 inhabitants in 1989 to 9 in 2014, whereas mortality rates increased to a lesser extent from 5 to 7 (Figure 2.1). The incidence of EAC increased especially in males, from 3 per 100,000 inhabitants in 1989 to 10 in 2014. Corresponding to the increase of EAC, the number of patients with a distal tumor increased. The median age was 69 (interquartile range 60-77) in 1989-1994 and remained similar over time (Table 2.1).

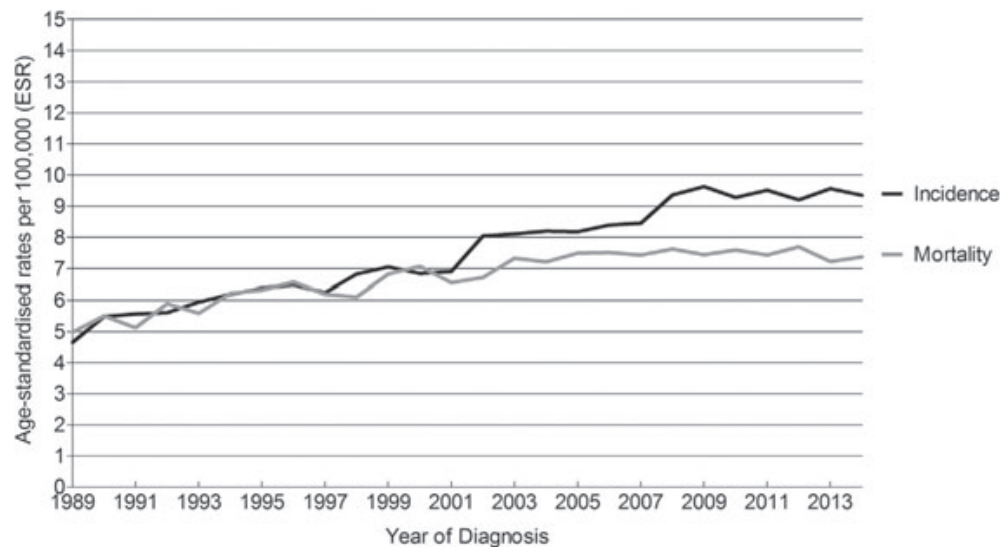

Figure 2.1 Incidence and mortality of esophageal cancer in the Netherlands, 1989-2014. 
The proportion of patients with an unknown tumor stage decreased from $34 \%$ to $10 \%$ in 1989-1994 and 2010-2014, with a corresponding decrease in the proportion of patients with a metastatic disease from $21 \%$ to $34 \%$ (Figure 2.2). Furthermore, the percentage of patients with a stage 0 tumor (pathologic or if not available clinical stage TO, NO, MO or TO, NX, MO) increased from 0\% in 2000-2004 to 6\% in 2010-2014.

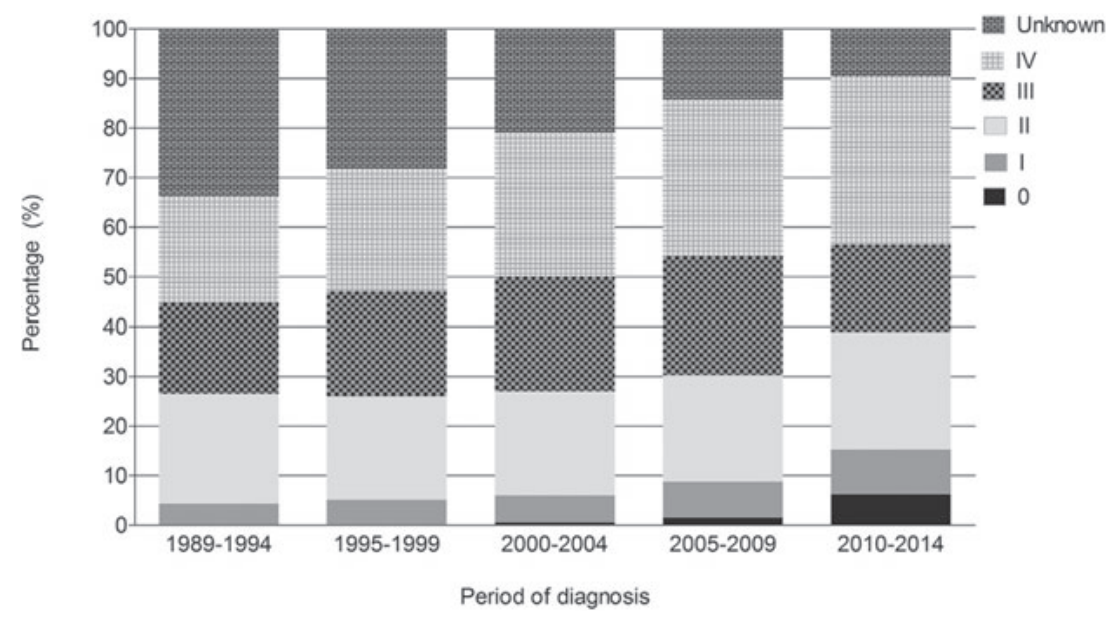

Figure 2.2 Stage distribution of all patients with esophageal cancer according to period of diagnosis $(\mathrm{N}=35,670)$. Pathological tumor stage was assessed, or if not available, clinical tumor stage was noted.

\section{Trends in treatment}

Among all patients, resection rates remained relatively stable with approximately $25 \%$ between 1989 and 2004 and 29\% between 2010 and 2014. Among non-metastatic EAC, the use of neoadjuvant chemoradiotherapy and surgery increased significantly from $4 \%$ in 2000-2004 to $43 \%$ in 2010-2014 and from $2 \%$ to $26 \%$ for non-metastatic ESCC (Figure $2.3 \mathrm{~A}$ and $\mathrm{B}$ ). During the same period, the use of definitive chemoradiotherapy increased as well from $8 \%$ in $2000-2004$ to $31 \%$ in 2010-2014 for non-metastatic ESCC, whereas this increase was less prominent for non-metastatic EAC (3\%-14\%). The use of endoscopic resection hardly increased for non-metastatic ESCC but increased for nonmetastatic EAC from $2 \%$ in 2000-2004 to $10 \%$ in 2010-2014. Furthermore, in 2005, 32\% of all resected patients underwent a resection in a high-volume hospital (performing $\geq 20$ procedures per year) which increased to 92\% in 2014 (Supplementary Figure S2.1). 


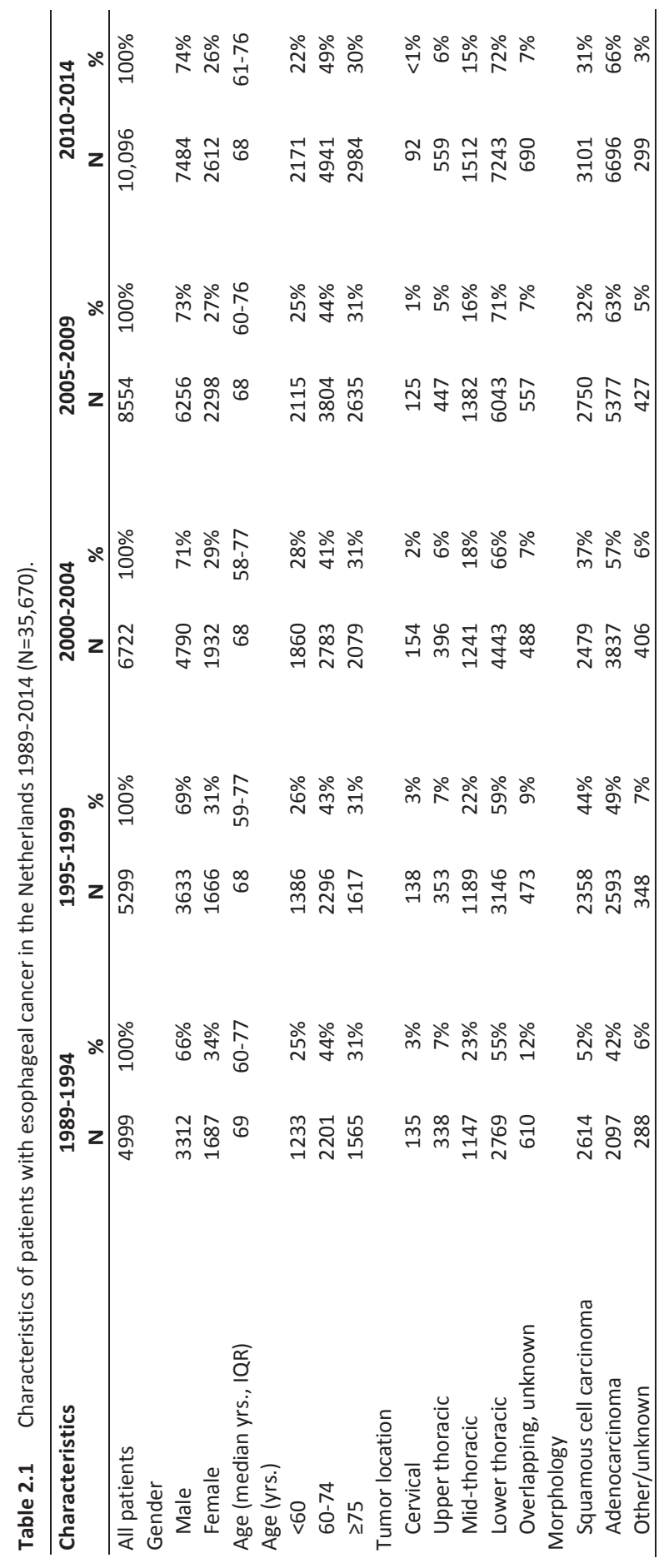


The proportion of patients with metastatic EAC who received systemic treatment as a single modality increased from $11 \%$ in $1989-1994$ to $28 \%$ in $2010-2014$, and the use of chemoradiotherapy increased from $1 \%$ to $15 \%$ in these time periods (Figure $2.4 \mathrm{~A}$ ). In contrast, the increase in chemoradiotherapy was more prominent among patients with metastatic ESCC (3\% in 1989-1994 and 21\% in 2010-2014), whereas the use of chemotherapy remained stable (approximately 11\%; Figure 2.4B).

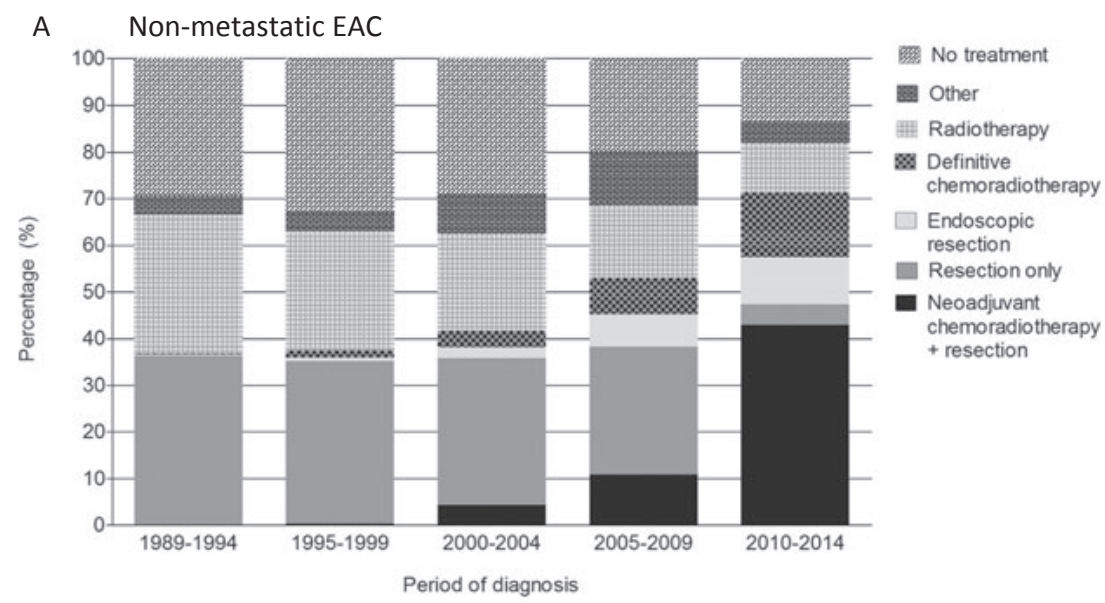

B Non-metastatic ESCC

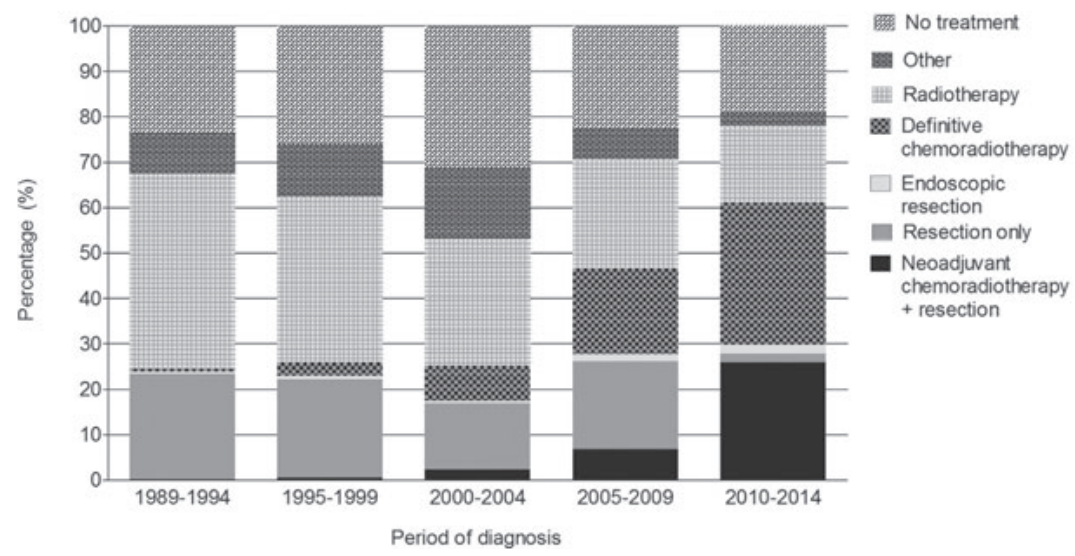

Figure 2.3 Treatment of patients with non-metastatic (MO) esophageal cancer in the Netherlands, according to histology and period of diagnosis (1989-2014; A; N=13,854, B; $N=10,125)$. Other treatment mainly included: systemic treatment as a single modality, and chemotherapy combined with surgery. EAC, esophageal adenocarcinoma; ESCC, esophageal squamous cell carcinoma. 
A Metastatic EAC

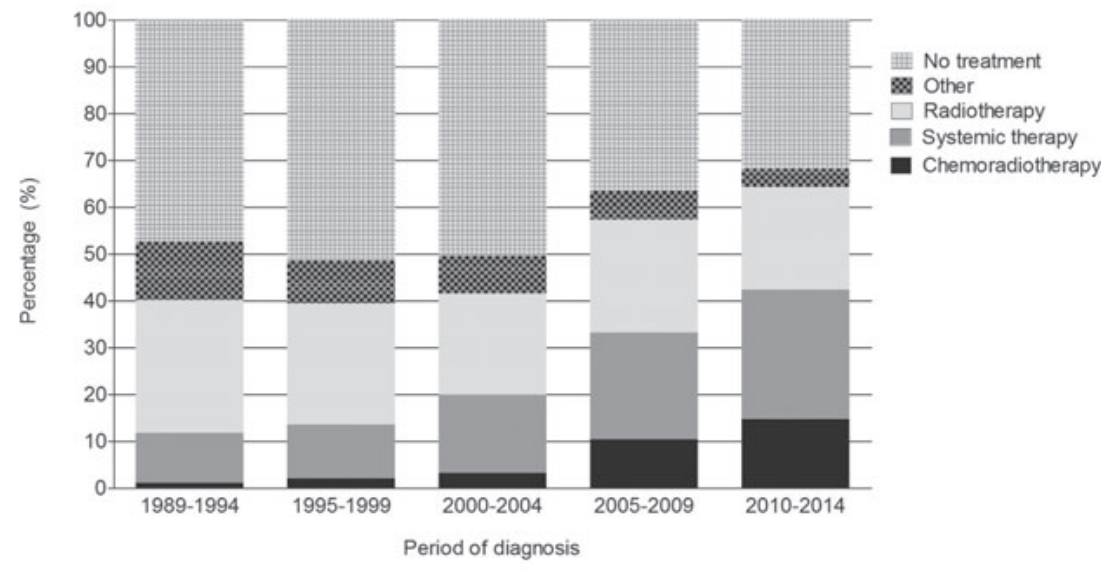

B Metastatic ESCC

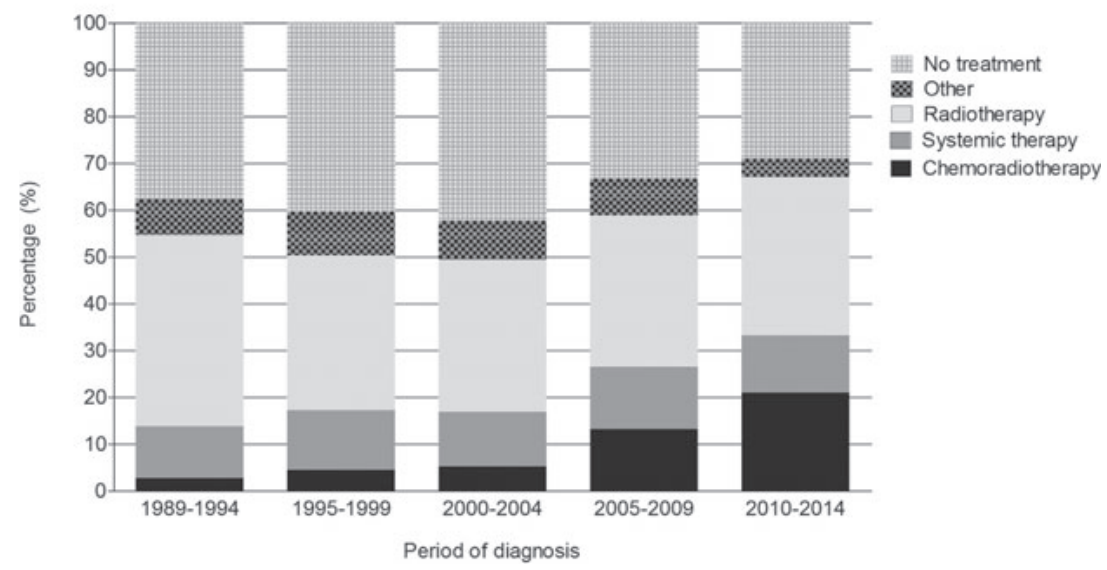

Figure 2.4 Treatment of patients with metastatic (M1) esophageal cancer in the Netherlands, according to histology and period of diagnosis (1989-2014; A; N=6746, B; N=3177). Other treatment mainly included: radiotherapy for metastases, metastasectomy and surgery alone, the latter especially in the earlier periods. EAC, esophageal adenocarcinoma; ESCC, esophageal squamous cell carcinoma.

\section{Survival}

The 5-year relative survival for all patients with esophageal cancer increased from $8 \%$ to $22 \%$ in 1989-2014 (Figure 2.5; Table 2.2A). The largest increases were observed in the last two periods. During these periods survival improved by $7 \%$ and $9 \%$ compared with the period before. Five-year relative survival tripled for both patients with non- 
metastatic EAC and ESCC, from $12 \%$ to $36 \%$ and $9 \%-27 \%$ in $1989-1994$ and $2010-2014$, respectively (Figure $2.6 \mathrm{~A}$ and $\mathrm{B}$ and Table $2.2 \mathrm{~B}$ ).

One-year relative survival for all patients with metastatic esophageal cancer increased from $15 \%$ to $22 \%$ in $1989-2014$ (Table $2.2 \mathrm{C}$ ). The one-year relative survival increased with 3\% in 2000-2004 for patients with metastatic ESCC and with 5\% in 2005-2009 for metastatic EAC. After these periods, relative survival remained stable (Figure 2.6C and $\mathrm{D}$ and Table 2.2C). Median overall survival for all metastatic patients increased with 4 weeks from 18 weeks in 1989-1994 to 22 weeks in 2010-2014.

Table 2.2 Five-year relative survival for all patients with (A) esophageal carcinoma, (B) non-metastatic (M0) esophageal carcinoma, (C) One-year relative survival for patients with metastatic (M1) esophageal carcinoma.

\begin{tabular}{|c|c|c|c|c|c|c|}
\hline \multirow[t]{2}{*}{ A } & \multicolumn{2}{|c|}{$\begin{array}{l}\text { All esophageal cancer } \\
\qquad \mathrm{N}=35,670\end{array}$} & \multicolumn{2}{|l|}{$\begin{array}{c}\text { All EAC } \\
N=20,600\end{array}$} & \multicolumn{2}{|l|}{$\begin{array}{c}\text { All ESCC } \\
\mathrm{N}=13,302 \\
\end{array}$} \\
\hline & Point estimate (\%) & SE & Point estimate (\%) & SE & Point estimate (\%) & SE \\
\hline \multicolumn{7}{|c|}{ Period of diagnosis } \\
\hline 1989-1994 & 8 & 0.4 & 9 & 0.7 & 8 & 0.6 \\
\hline 1995-1999 & 10 & 0.5 & 11 & 0.7 & 10 & 0.7 \\
\hline $2000-2004$ & 12 & 0.4 & 13 & 0.6 & 11 & 0.7 \\
\hline 2005-2009 & 16 & 0.4 & 18 & 0.6 & 15 & 0.7 \\
\hline 2010-2014 & 22 & 0.5 & 23 & 0.6 & 20 & 0.9 \\
\hline \multirow[t]{3}{*}{ B } & \multicolumn{2}{|c|}{ M0 esophageal cancer } & \multicolumn{2}{|l|}{ MO EAC } & \multicolumn{2}{|l|}{ MO ESCC } \\
\hline & \multicolumn{2}{|c|}{$\mathrm{N}=25,214$} & \multicolumn{2}{|l|}{$\mathrm{N}=13,854$} & \multicolumn{2}{|l|}{$\mathrm{N}=10,125$} \\
\hline & Point estimate (\%) & SE & Point estimate (\%) & SE & Point estimate (\%) & SE \\
\hline 1989-1994 & 10 & 0.5 & 12 & 0.9 & 9 & 0.7 \\
\hline 1995-1999 & 13 & 0.6 & 15 & 1.0 & 12 & 0.9 \\
\hline $2000-2004$ & 16 & 0.6 & 18 & 0.8 & 14 & 0.9 \\
\hline 2005-2009 & 23 & 0.6 & 27 & 0.8 & 19 & 1.0 \\
\hline 2010-2014 & 32 & 0.7 & 36 & 0.9 & 27 & 1.2 \\
\hline \multirow[t]{3}{*}{$\mathrm{C}$} & \multicolumn{2}{|c|}{ M1 esophageal cancer } & \multicolumn{2}{|l|}{ M1 EAC } & \multicolumn{2}{|l|}{ M1 ESCC } \\
\hline & \multicolumn{2}{|l|}{$\mathrm{N}=10,456$} & \multicolumn{2}{|l|}{$N=6746$} & \multicolumn{2}{|l|}{$\mathrm{N}=3177$} \\
\hline & Point estimate (\%) & SE & Point estimate (\%) & SE & Point estimate (\%) & SE \\
\hline \multicolumn{7}{|c|}{ Period of diagnosis } \\
\hline 1989-1994 & 15 & 1.1 & 14 & 1.5 & 16 & 1.7 \\
\hline 1995-1999 & 14 & 1.0 & 14 & 1.3 & 17 & 1.9 \\
\hline 2000-2004 & 17 & 0.9 & 16 & 1.1 & 22 & 1.8 \\
\hline 2005-2009 & 21 & 0.8 & 22 & 1.0 & 22 & 1.5 \\
\hline 2010-2014 & 22 & 0.7 & 22 & 0.8 & 23 & 1.4 \\
\hline
\end{tabular}

$\mathrm{SE}$, standard error; EAC, esophageal adenocarcinoma; ESCC, esophageal squamous cell carcinoma. 


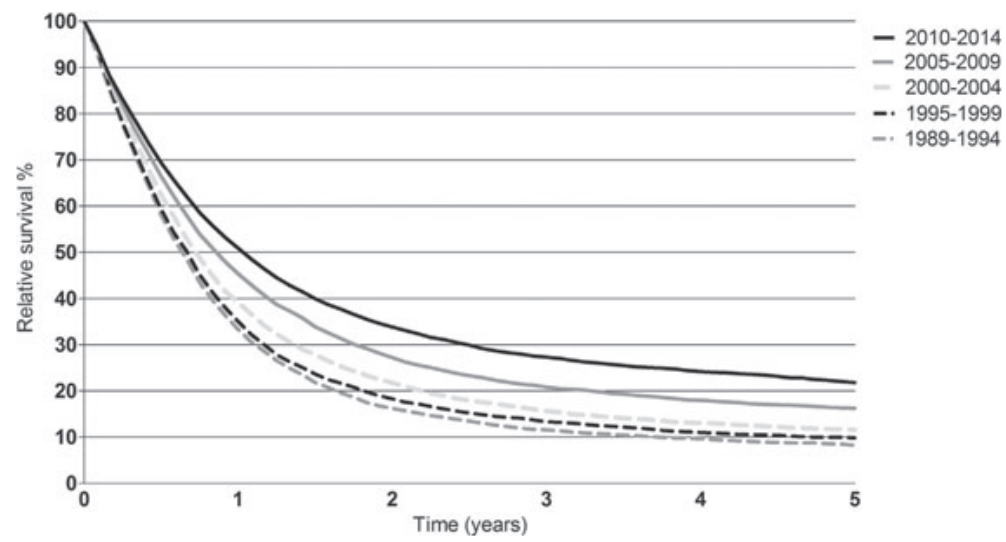

Figure 2.5 Relative survival of all patients with esophageal cancer $(N=35,670)$.

\section{Discussion}

This large population-based nationwide study observed progress against esophageal cancer in the last 26 years in the Netherlands, as the incidence increased and mortality decreased, suggesting an improvement in survival. Relative survival rates more than doubled for all patients and tripled for non-metastatic patients, particularly in the last two study periods. Moreover, an improvement in survival of metastatic patients was also observed.

The rising incidence in esophageal cancer can be attributed to a rise in EAC, especially among males. EAC and ESCC have a distinct etiology and specific risk factors. ESCC has been associated with tobacco smoking, overconsumption of alcohol and low intake of fruit and vegetables, whereas EAC has been associated with obesity, gastro-esophageal reflux disease and Barrett's esophagus. ${ }^{2,20}$ The increase in EAC among males may be attributed to the increase in obesity and especially abdominal (visceral) fat, which is more common among males and the strongest risk factor for Barrett's esophagus and EAC. ${ }^{2}$ Globally, the incidence of EAC is highest in Western industrialized countries, while the incidence of ESCC is highest in Asia, East Africa and South America. ${ }^{4}$ 


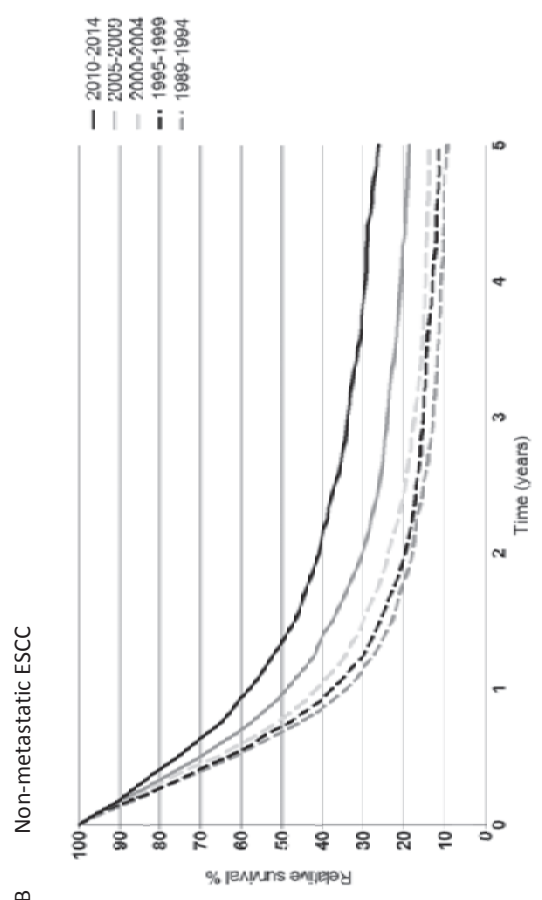

$\infty$

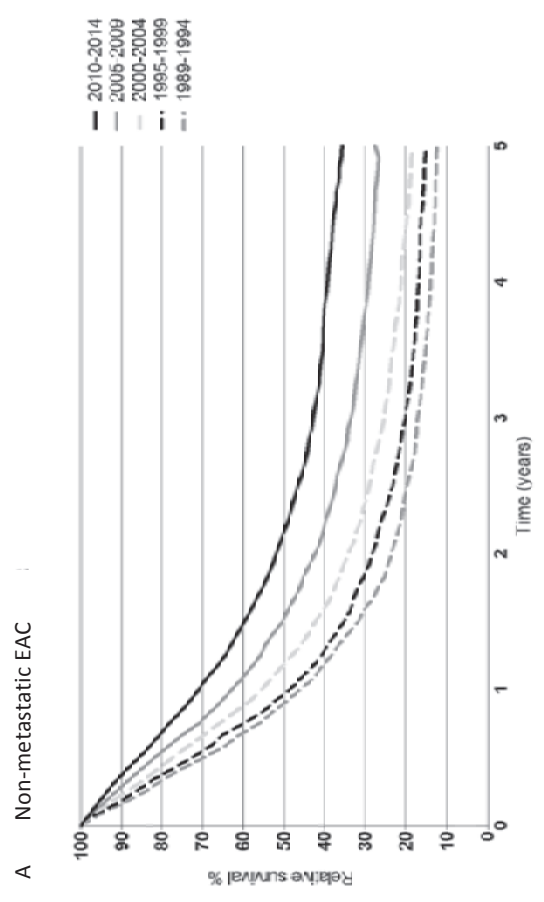

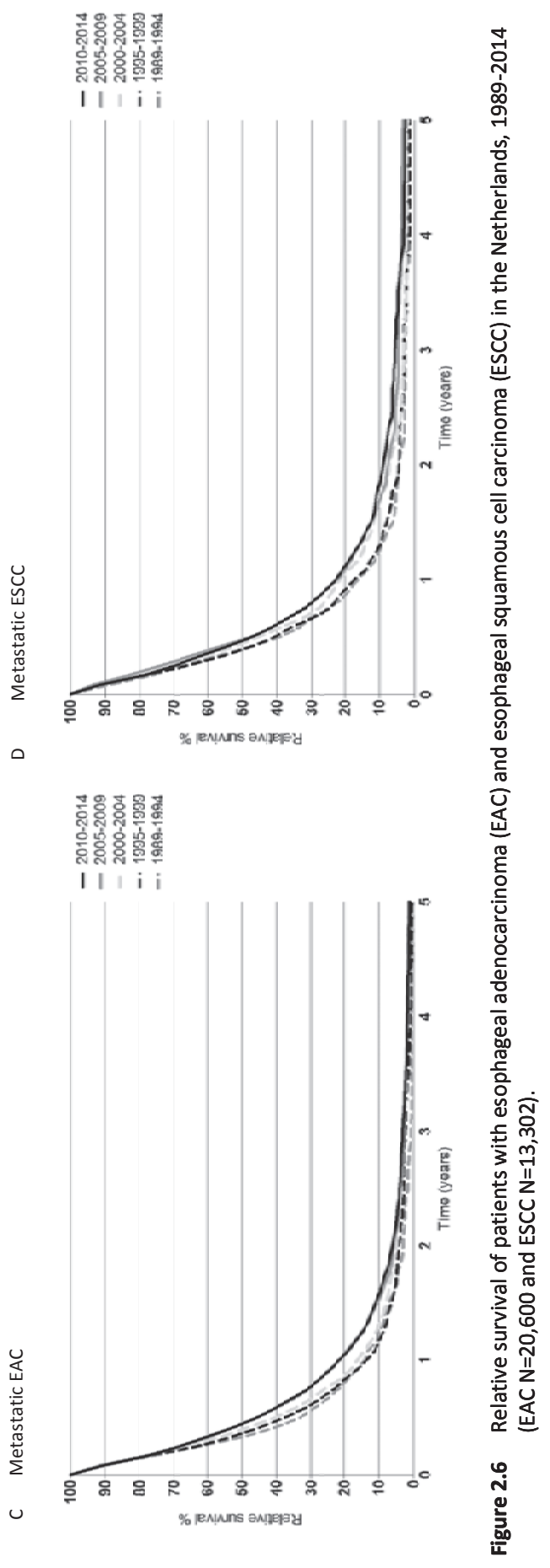


The widening gap between incidence and mortality for esophageal cancer suggesting an improvement in survival. ${ }^{21}$ There are several reasons why survival may artificially increase, such as improved detection (i.e. screening) and changes in incidence and underlying proportional changes in age, morphology and stage distribution. As screening programs are not the case for esophageal cancer in the Netherlands and survival improved for non-metastatic and metastatic patients as well as for both morphology subgroups, changes in survival may reflect improved staging and treatment.

During the study period, relative survival also increased for patients with gastric cardia cancer, which is related to distal EAC, from 11\% in 1989-1994 to $17 \%$ in $2010-2014$. Survival especially improved in the last two periods. However, survival for gastric cardia cancer increased to a lesser extent compared to esophageal cancer. An explanation may be that multimodality treatment has been administered less frequently in gastric cardia cancer as compared to esophageal cancer. ${ }^{22}$ Moreover, gastric cardia cancer patients can be treated with an esophagectomy or gastrectomy which latter procedure is centralized more recently. Therefore, it is expected that survival will further increase in the next decade.

There are several possible explanations for the improvement in survival of patients with non-metastatic esophageal cancer. First, the introduction of neoadjuvant chemoradiotherapy in a multimodality treatment for esophageal cancer has contributed to better survival rates for resected patients by down staging of the tumor and an improved loco regional and distant disease control. ${ }^{5,6}$ The results from the CROSS trial have led to a successful implementation of neoadjuvant chemoradiotherapy as preferred treatment for resectable patients with esophageal cancer in the Netherlands. Nowadays, nearly all Dutch patients that undergo surgery receive neoadjuvant chemoradiotherapy. The down staging effect of chemoradiotherapy possibly resulted in an increasing number of patients with a pathological complete response (stage 0) or stage I and II as shown in Figure 2.2.

Second, centralization of esophageal cancer surgery may have further contributed to the improved survival in the most recent periods for non-metastatic patients. Many population-based studies have shown that centralization improves surgical experience, decreases postoperative complications and mortality. ${ }^{15,23-26}$ Furthermore, centralization also seems to improve patient selection as survival also improved for nonsurgically treated patients. ${ }^{15,27}$

Third, survival may have improved due to better diagnostic procedures, resulting in improved patient selection. With the introduction of high-quality computed tomography (CT) scanners, endoscopic ultrasonography (EUS), endobronchial ultrasonography (EBUS) and Positron Emission Tomography-Computed Tomography 
(PETCT), staging has become more accurate. ${ }^{13,14,28,29}$ The higher proportion of patients diagnosed with an advanced tumor stage over time - instead of unknown - in the present study indicates stage migration due to improved diagnostic techniques. However, since the survival of all patients increased the influence of stage migration can only partly explain the increased survival.

Finally, the increased use of definitive chemoradiotherapy might have improved survival especially for patients with ESCC. Compared with neoadjuvant chemoradiotherapy followed by surgery, definitive chemoradiotherapy has been associated with an equivalent survival of patients with ESCC but higher rates of local relapse in two RCTs. ${ }^{10,30}$ As not each patient is fit for surgery, definitive chemoradiotherapy can be a well-tolerated alternative, especially in ESCC patients. ${ }^{31}$

The median overall survival of metastatic esophageal cancer patients improved from 18 to 22 weeks (22\%) during the last 26 years. Similar findings have been reported by two other Dutch studies. ${ }^{32,33}$ The prolonged survival in metastatic patients may be the result of major changes in treatment but also of stage migration due to improved diagnostic techniques, which facilitates detection of metastases at an earlier stage. ${ }^{12}$

Survival of patients with esophageal cancer also improved in countries outside the Netherlands. The EUROCARE-5 study showed that the largest improvements in 5-year relative survival were observed in Ireland, the UK and Central Europe in the period 2005-2007 compared with 1999-2001 ranging from 4 to $5 \% .{ }^{34}$ The changes in survival between Belgium and the Netherlands are comparable. ${ }^{35}$ Limited improvements were observed in Eastern and Southern Europe. ${ }^{34}$ The average European 5-year relative survival of $12 \%$ in 2000-2007 was somewhat lower compared with the 5-year relative survival of $16 \%$ in 2005-2009 in the Netherlands. Furthermore, the improvement in 5 -year relative survival rates in the Netherlands was comparable to the improvement seen in the United States. ${ }^{36}$

This study has some limitations. First, information about the intention of chemoradiotherapy (curative or palliative) was not available. Therefore, among nonmetastatic esophageal cancer patients, it was assumed that patients underwent chemoradiotherapy with curative intention (neoadjuvant or definitive). Second, the group of MO patients who underwent definitive chemoradiotherapy may be heterogeneous, consisting of patients who indeed underwent definitive chemoradiotherapy, patients not fit enough to undergo surgery after neoadjuvant chemoradiotherapy and some patients with a complete clinical response after neoadjuvant chemoradiotherapy who may have refused surgery. Third, possible incompleteness of registration of endoscopic resections in the earlier period could have led to an underestimation of endoscopically treated patients. The strength of this study is its unique nationwide population-based design resulting in a large and representative 
study population with real-world data about treatment patterns and survival in the past 26 years in the Netherlands.

In conclusion, the significant improvement in survival of esophageal cancer patients especially after 2005 reflects the possibly improved staging, better patient selection and evolving therapeutic options including neoadjuvant treatment and centralization of esophageal cancer surgery. Further improvement may be achieved by earlier detection and treatment of (pre) malignant lesions and by use of more effective personalized systemic treatment. ${ }^{37}$ 


\section{References}

1. Ferlay J, Soerjomataram I, Dikshit R, Eser S, Mathers C, Rebelo M, et al. Cancer incidence and mortality worldwide: sources, methods and major patterns in GLOBOCAN 2012. Int J Cancer 2015;136(5): E359-86.

2. Smyth EC, Lagergren J, Fitzgerald RC, Lordick F, Shah MA, Lagergren P, et al. Oesophageal cancer. Nat Rev Dis Primers 2017;3:17048.

3. Pennathur A, Gibson MK, Jobe BA, Luketich JD. Oesophageal carcinoma. Lancet 2013;381(9864):400-12.

4. Arnold M, Soerjomataram I, Ferlay J, Forman D. Global incidence of oesophageal cancer by histological subtype in 2012. Gut 2015;64(3):381-7.

5. van Hagen P, Hulshof MC, van Lanschot JJ, Steyerberg EW, van Berge Henegouwen MI, Wijnhoven BP, et al. Preoperative chemoradiotherapy for esophageal or junctional cancer. N Engl J Med 2012;366(22):2074-84.

6. Shapiro J, van Lanschot JJ, Hulshof MC, van Hagen $\mathrm{P}$, van Berge Henegouwen MI, Wijnhoven $\mathrm{BP}$, et al. Neoadjuvant chemoradiotherapy plus surgery versus surgery alone for oesophageal or junctional cancer (CROSS): long-term results of a randomised controlled trial. Lancet Oncol 2015;16(9):1090-8.

7. Crosby TD, Brewster AE, Borley A, Perschky L, Kehagioglou P, Court J, et al. Definitive chemoradiation in patients with inoperable oesophageal carcinoma. Br J Cancer 2004;90(1):70-5.

8. Wong R, Malthaner R. Combined chemotherapy and radiotherapy (without surgery) compared with radiotherapy alone in localized carcinoma of the esophagus. Cochrane Database Syst Rev 2006;1: Cd002092.

9. Allum WH, Blazeby JM, Griffin SM, Cunningham D, Jankowski JA, Wong R, et al. Guidelines for the management of oesophageal and gastric cancer. Gut 2011;60(11):1449-72.

10. Stahl M, Stuschke M, Lehmann N, Meyer HJ, Walz MK, Seeber S, et al. Chemoradiation with and without surgery in patients with locally advanced squamous cell carcinoma of the esophagus. J Clin Oncol 2005;23(10):2310-7.

11. Blom RL, Schreurs WM, Belgers HJ, Oostenbrug LE, Vliegen RF, Sosef MN. The value of postneoadjuvant therapy PET-CT in the detection of interval metastases in esophageal carcinoma. Eur J Surg Oncol 2011;37(9):774-8.

12. Rustgi A, El-Serag HB. Esophageal carcinoma. N Engl J Med 2015;372(15):1472-3.

13. Findlay JM, Bradley KM, Maile EJ, Braden B, Maw J, Phillips-Hughes J, et al. Pragmatic staging of oesophageal cancer using decision theory involving selective endoscopic ultrasonography, PET and laparoscopy. Br J Surg 2015;102(12):1488-99.

14. Puli SR, Reddy JB, Bechtold ML, Antillon D, Ibdah JA, Antillon MR. Staging accuracy of esophageal cancer by endoscopic ultrasound: a meta-analysis and systematic review. World J Gastroenterol 2008;14(10):1479-90.

15. van de Poll-Franse LV, Lemmens VE, Roukema JA, Coebergh JW, Nieuwenhuijzen GA. Impact of concentration of oesophageal and gastric cardia cancer surgery on long-term population-based survival. Br J Surg 2011;98(7):956-63.

16. Dikken JL, Dassen AE, Lemmens VE, Putter H, Krijnen P, van der Geest L, et al. Effect of hospital volume on postoperative mortality and survival after oesophageal and gastric cancer surgery in The Netherlands between 1989 and 2009. Eur J Cancer 2012;48(7):1004-13.

17. Fritz A, Percy C, Jack A, Shanmugaratnam K, Sobin L, Parkin DM, et al. International classification of diseases for oncology. 3rd ed. Geneva: World Health Organization; 2000.

18. Lambert PC, Dickman PW, Rutherford MJ. Comparison of different approaches to estimating age standardized net survival. BMC Med Res Methodol 2015;15:64.

19. Hakulinen T, Seppa K, Lambert PC. Choosing the relative survival method for cancer survival estimation. Eur J Cancer 2011;47(14):2202-10.

20. Lepage C, Remontet L, Launoy G, Tretarre B, Grosclaude P, Colonna M, et al. Trends in incidence of digestive cancers in France. Eur J Cancer Prev 2008;17(1):13-7. 
21. Cho H, Mariotto AB, Schwartz LM, Luo J, Woloshin S. When do changes in cancer survival mean progress? The insight from population incidence and mortality. J Natl Cancer Inst Monogr 2014;2014(49):187-97.

22. Koeter M, Parry K, Verhoeven RH, Luyer MD, Ruurda JP, van Hillegersberg R, et al. Perioperative treatment, not surgical approach, influences overall survival in patients with gastroesophageal junction tumors: a nationwide, populationbased study in The Netherlands. Ann Surg Oncol 2016;23(5):1632-8.

23. Anderson O, Ni Z, Moller H, Coupland VH, Davies EA, Allum WH, et al. Hospital volume and survival in oesophagectomy and gastrectomy for cancer. Eur J Cancer 2011;47(16):2408-14.

24. Pasquer A, Renaud F, Hec F, Gandon A, Vanderbeken M, Drubay V, et al. Is centralization needed for esophageal and gastric cancer patients with low operative risk?: A nationwide study. Ann Surg 2016;264(5):823-30.

25. Henneman D, Dikken JL, Putter H, Lemmens VE, Van der Geest LG, van Hillegersberg R, et al. Centralization of esophagectomy: how far should we go? Ann Surg Oncol 2014;21(13):4068-74.

26. Derogar M, Sadr-Azodi O, Johar A, Lagergren P, Lagergren J. Hospital and surgeon volume in relation to survival after esophageal cancer surgery in a population-based study. J Clin Oncol 2013;31(5):551-7.

27. Lemmens VE, Bosscha K, van der Schelling G, Brenninkmeijer S, Coebergh JW, de Hingh IH. Improving outcome for patients with pancreatic cancer through centralization. Br J Surg 2011;98(10):1455-62.

28. van Vliet EP, Heijenbrok-Kal MH, Hunink MG, Kuipers EJ, Siersema PD. Staging investigations for oesophageal cancer: a meta-analysis. Br J Cancer 2008;98(3):547-57.

29. Kim TJ, Kim HY, Lee KW, Kim MS. Multimodality assessment of esophageal cancer: preoperative staging and monitoring of response to therapy. Radiographics 2009;29(2):403-21.

30. Bedenne L, Michel P, Bouche O, Milan C, Mariette C, Conroy T, et al. Chemoradiation followed by surgery compared with chemoradiation alone in squamous cancer of the esophagus: FFCD 9102. J Clin Oncol 2007;25(10):1160-8.

31. Lordick F, Mariette C, Haustermans K, Obermannova R, Arnold D, Committee EG. Oesophageal cancer: ESMO clinical practice guidelines for diagnosis, treatment and follow-up. Ann Oncol 2016;27(Suppl. 5):v50-7.

32. Bernards N, Haj Mohammad N, Creemers GJ, Rozema T, Roukema JA, Nieuwenhuijzen GA, et al. Improvement in survival for patients with synchronous metastatic esophageal cancer in the south of The Netherlands from 1994 to 2013. Acta Oncol 2016;55(9-10):1161-7.

33. Dikken JL, Lemmens VE, Wouters MW, Wijnhoven BP, Siersema PD, Nieuwenhuijzen GA, et al. Increased incidence and survival for oesophageal cancer but not for gastric cardia cancer in The Netherlands. Eur J Cancer 2012;48(11):1624-32.

34. Anderson LA, Tavilla A, Brenner H, Luttmann S, Navarro C, Gavin AT, et al. Survival for oesophageal, stomach and small intestine cancers in Europe 1999-2007: results from EUROCARE- 5. Eur J Cancer 2015;51(15):2144-57.

35. Stordeur S, Vlayen J, Vrijens F, Camberlin C, De Gendt C, Van Eycken E, et al. Quality indicators for oesophageal and gastric cancer: a population-based study in Belgium, 2004-2008. Eur J Cancer Care (Engl) 2015;24(3):376-86.

36. Siegel RL, Miller KD, Jemal A. Cancer statistics, 2016. CA Cancer J Clin 2016;66(1):7-30.

37. Oppedijk V, van der Gaast A, van Lanschot JJ, van Hagen P, van Os R, van Rij CM, et al. Patterns of recurrence after surgery alone versus preoperative chemoradiotherapy and surgery in the CROSS trials. J Clin Oncol 2014;32(5):385-91. 


\section{Supplemental material}

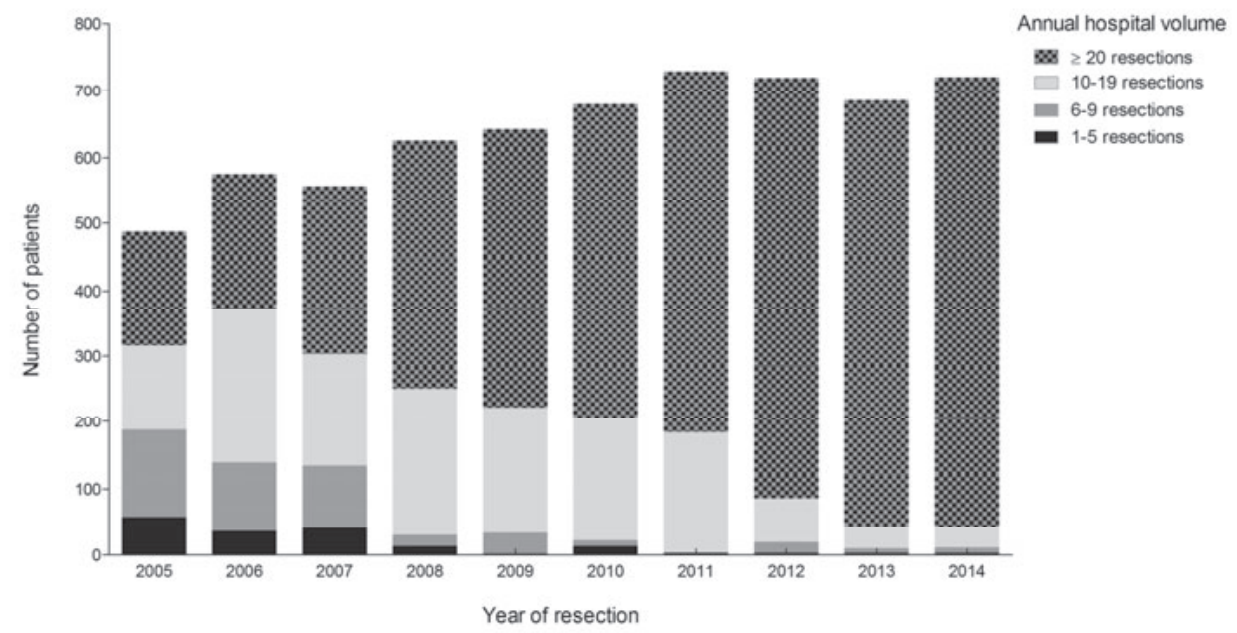

Figure S2.1 Number of esophageal cancer resections per hospital volume category in the period 2005-2014. 



\section{Abstract}

\section{Background}

The management of proximal esophageal cancer differs from that of tumors located in the mid and lower part of the esophagus due to the close vicinity of vital structures. Non-surgical treatment options like radiotherapy and definitive chemoradiation (CRT) have been implemented. The trends in (non-)surgical treatment and its impact on overall survival (OS) in patients with proximal esophageal cancer are unclear, related to its rare disease status. To optimize treatment strategies and counseling of patients with proximal esophageal cancer, it is therefore essential to gain more insight through real-life studies.

\section{Aim}

To establish trends in treatment and OS in patients with proximal esophageal cancer.

\section{Methods}

In this population-based study, patients with proximal esophageal cancer diagnosed between 1989 and 2014 were identified in the Netherlands Cancer Registry. The proximal esophagus consists of the cervical esophagus and the upper thoracic section, extending to $24 \mathrm{~cm}$ from the incisors. Trends in radiotherapy, chemotherapy, and surgery, and OS were assessed. Analyses were stratified by presence of distant metastasis. Multivariable Cox proportional hazards regression analyses was performed to assess the effect of period of diagnosis on OS, adjusted for patient, tumor, and treatment characteristics.

\section{Results}

In total, 2783 patients were included. Over the study period, the use of radiotherapy, resection, and CRT in non-metastatic disease changed from 53\%, 23\%, and 1\% in $1989-1994$ to $21 \%, 9 \%$, and $49 \%$ in 2010-2014, respectively. In metastatic disease, the use of chemotherapy and radiotherapy increased over time. Median OS of the total population increased from 7.3 mo [95\% confidence interval (Cl): 6.4-8.1] in 1989-1994 to 9.5 mo (95\% Cl: 8.1-10.8) in 2010-2014 (logrank $\mathrm{P}<0.001)$. In non-metastatic disease, 5 -year OS rates improved from $5 \%(95 \% \mathrm{Cl}: 3 \%-7 \%)$ in 1989-1994 to $13 \%$ (95\% Cl: $9 \%-17 \%$ ) in 2010-2014 (logrank $P<0.001)$. Multivariable regression analysis demonstrated a significant treatment effect over time on survival. In metastatic disease, median OS was $3.8 \mathrm{mo}(95 \% \mathrm{Cl}: 2.5-5.1)$ in 1989-1994, and $5.1 \mathrm{mo}(95 \% \mathrm{Cl}: 4.3-5.9)$ in 2010-2014 (logrank $P=0.26$ ).

\section{Conclusion}

OS significantly improved in non-metastatic proximal esophageal cancer, likely to be associated with an increased use of CRT. Patterns in metastatic disease did not change significantly over time. 


\section{Introduction}

Esophageal cancer is the seventh most common cancer worldwide. ${ }^{1}$ Although the absolute number of deaths has decreased, esophageal cancer is still the sixth leading cause of cancer-related mortality globally. ${ }^{1}$ Surgical treatment of patients with esophageal cancer, and in particular treatment of cancer located in the proximal part of the esophagus, is challenging because of the close proximity to vital structures. The proximal part of the esophagus consists of the cervical and the upper thoracic segment. Proximal esophageal cancer is relatively uncommon, accounting for $10 \%$ of all esophageal cancer cases. $^{2}$

The management of proximal esophageal cancer differs from that of tumors located in the mid and lower part of the esophagus. Patients with proximal esophageal cancer often present with locally advanced disease, for which potentially curative surgery would require extensive mutilating resections, with a high risk of major complications and a significant impact on patients quality of life. To prolong survival and improve quality of life, non-surgical treatment options like radiotherapy and definitive chemoradiation (CRT) have been explored since the 1990s, following promising treatment results of cancers in the thoracic esophagus, hypopharynx, and non-smallcell lung cancer. ${ }^{3-6}$ In a meta-analysis in 2006, Wong et al. showed that the addition of chemotherapy to radiotherapy for the definitive treatment of esophageal cancer significantly increased response and overall survival (OS) rates. ${ }^{7}$

Therefore, definitive CRT is recommended as treatment modality for patients with nonmetastatic proximal esophageal cancer. ${ }^{8,9}$ However, only four of the 19 studies in the aforementioned meta-analysis incorporated patients with proximal esophageal cancers, limiting the extrapolation of these findings to the proximal esophagus.

Separate OS rates for patients with proximal esophageal cancer are largely lacking from clinical trials, due to exclusion of this subpopulation or related to its rare disease status. To optimize treatment strategies and counseling of patients with proximal esophageal cancer, it is therefore essential to gain more insight in patient characteristics, provided therapies and OS through real-life studies.

The aim of this population-based cohort study was to establish the trends in treatment and OS in patients diagnosed with non-metastatic or metastatic proximal esophageal cancer in a nationwide registry between 1989 and 2014. 


\section{Materials and methods}

\section{Patients}

All patients with a tumor located in the cervical or upper thoracic esophagus diagnosed between 1989 and 2014 were identified in the Netherlands Cancer Registry (NCR). The NCR is a population-based cancer registry of all residents of the Netherlands. The NCR is linked to the national automated pathological archive, which leads to the automatic inclusion of all newly diagnosed malignancies in the Netherlands. Additional data sources linked to the NCR are the national hospital discharge register and registers of radiotherapy institutions. Information on vital status was obtained through annual linkage with the Municipal Administrative Database, in which all deceased or emigrated individuals in the Netherlands are registered. This study was approved by the Privacy Review Board of the NCR and the need for a separate approval from an ethics committee in the Netherlands was waived.

\section{Definitions}

Topography and histology were coded according to the International Classification of Diseases for Oncology (ICD-O). ${ }^{10}$ ICD-O histology codes were used to classify tumors as squamous cell carcinoma (SCC), adenocarcinoma, and other origin. Cancers of the proximal esophagus can be subdivided in cancers originating in the cervical esophagus (CEC, ICD-O C15.0), commencing at the lower border of the cricoid cartilage and ending at the thoracic inlet, approximately $18 \mathrm{~cm}$ from the incisors, and cancers in the upper thoracic section (UTEC, ICD-O C15.3), extending from the thoracic inlet to the level of the tracheal bifurcation, which is approximately $24 \mathrm{~cm}$ from the incisors. ${ }^{11}$

Tumor staging was registered according to the Union for International Cancer Control TNM classification that was valid at the time of diagnosis. As the classification of tumor stage (cT) was reasonably comparable from the TNM-4 to -6 , but changed with the introduction of the 7th edition in 2010, we converted all tumor and lymph node stages according to TNM-6th edition. Patients with a cM1a tumor according to TNM-6th edition, defined as cervical lymph node involvement, were categorized as having a positive lymph node status (cN+). Patients with unknown metastatic status (cMx) were included in the non-metastatic group.

All treatments for the primary disease stage were registered. Treatment categories included resection, neoadjuvant treatment and resection, radiotherapy, chemotherapy, radiotherapy and chemotherapy, other treatment, and no (anti-cancer) treatment. Resection included patients who received a surgical resection or an endoscopic excision $(\mathrm{N}=20)$. The group of "neoadjuvant and resection" comprised patients who underwent 
a resection, preceded by radiotherapy, chemotherapy or with concurrent CRT. The group "radiotherapy and chemotherapy" included patients who were treated with sequential or concurrent radiotherapy and chemotherapy, without any resection. Other treatments were not otherwise specified (palliative) treatments. "Other treatment" and "no (anti-cancer) treatment" were summarized as "no localized treatment". Type of surgical treatment and details on chemotherapy or radiotherapy were not collected by the data clerks of the NCR. Five-year periods of diagnosis were defined: 1989-1994, 1995-1999, 2000-2004, 2005-2009, and 2010-2014.

\section{Statistical analysis}

OS was calculated by period of diagnosis using the Kaplan-Meier method and a comparison between groups was made using the log-rank test. OS was defined as the time from diagnosis to death from any cause, censored at last follow-up date or until February 1, 2017. The median follow-up time was calculated using the reverse Kaplan Meier method (death censored). Multivariable Cox proportional hazards regression analyses were performed to assess the effect of period of diagnosis on OS, adjusted for age, histological type, tumor location, CT category, cN category, and treatment modality. Variance inflation factors were calculated to assess the degree of multicollinearity among the independent variables in the Cox proportional hazard model. Analyses were stratified by the presence of metastatic disease (cM0 vs. cM1), tumor location (CEC vs. UTEC), and histological type (SCC vs. adenocarcinoma). As the interaction analysis did not show any difference in OS between tumor location, i.e., cervical or upper thoracic site, and histology, results are presented by presence or absence of metastatic disease.

The statistical review of the study was performed by two senior epidemiologists.

\section{Results}

\section{Study population}

We identified 2783 patients diagnosed with proximal esophageal cancer in the Netherlands between 1989 and 2014 (Table 3.1). The median follow-up time of all patients was 103 mo [95\% confidence interval (Cl): 91-117 mo]. Fifty-six percent of patients were male, and $47 \%$ were between 60 and 74 years old at the time of diagnosis. In total, $81 \%$ of cancers were SCC. Two percent of the patients were diagnosed with clinical stage 1, 20\% with stage 2, $28 \%$ with stage 3, 21\% with stage 4, and $29 \%$ with unknown stage disease. The number of patients with unknown stage 
disease decreased over time. In 2010-2014, $27 \%$ of patients had been diagnosed with another malignancy prior to the diagnosis of proximal esophageal cancer (data not shown).

Table 3.1 Patient and tumor characteristics by time period of diagnosis, $\mathrm{N}$ (\%).

\begin{tabular}{|c|c|c|c|c|c|c|}
\hline Characteristics & $\begin{array}{c}\text { Total } \\
(\mathrm{N}=2783)\end{array}$ & $\begin{array}{c}1989-1994 \\
(\mathrm{~N}=484)\end{array}$ & $\begin{array}{c}1995-1999 \\
(N=499)\end{array}$ & $\begin{array}{c}2000-2004 \\
(N=552)\end{array}$ & $\begin{array}{c}2005-2009 \\
(N=583)\end{array}$ & $\begin{array}{c}2010-2014 \\
(N=665)\end{array}$ \\
\hline \multicolumn{7}{|l|}{ Sex } \\
\hline Male & $1562(56)$ & $259(54)$ & $263(53)$ & $308(56)$ & 344 (59) & $388(58)$ \\
\hline Female & $1221(44)$ & $225(46)$ & $236(47)$ & $244(44)$ & $239(41)$ & $277(42)$ \\
\hline \multicolumn{7}{|l|}{ Age (yr) } \\
\hline$<60$ & $725(26)$ & $140(29)$ & $148(30)$ & $178(32)$ & $128(22)$ & $131(20)$ \\
\hline $60-74$ & 1304 (47) & $194(40)$ & $219(44)$ & $223(40)$ & $301(52)$ & $367(55)$ \\
\hline$\geq 75$ & $754(27)$ & $150(31)$ & $132(26)$ & $151(27)$ & $154(26)$ & $167(25)$ \\
\hline \multicolumn{7}{|l|}{ Histology } \\
\hline $\mathrm{SCC}$ & $2248(81)$ & $382(79)$ & $390(78)$ & $440(80)$ & $480(82)$ & $556(84)$ \\
\hline Adenocarcinoma & $320(11)$ & $62(13)$ & $63(13)$ & $70(13)$ & $61(10)$ & $64(10)$ \\
\hline Other & $215(8)$ & $40(8)$ & $46(9)$ & $42(8)$ & $42(7)$ & $45(7)$ \\
\hline \multicolumn{7}{|l|}{ Tumor location } \\
\hline CEC & $648(23)$ & $138(29)$ & $138(28)$ & $154(28)$ & $126(22)$ & $92(14)$ \\
\hline UTEC & $2135(77)$ & $346(71)$ & $361(72)$ & $398(72)$ & $457(78)$ & $573(86)$ \\
\hline \multicolumn{7}{|l|}{ cT classification } \\
\hline cT1 & $81(3)$ & $17(4)$ & $16(3)$ & $12(2)$ & $16(3)$ & $20(3)$ \\
\hline cT2 & $236(8)$ & $12(2)$ & $16(3)$ & $36(7)$ & $48(8)$ & 124 (19) \\
\hline cT3 & $447(16)$ & $36(7)$ & $39(8)$ & $79(14)$ & 109 (19) & $184(28)$ \\
\hline cT4 & $665(24)$ & $115(24)$ & $123(25)$ & $161(29)$ & $147(25)$ & $119(18)$ \\
\hline cTx & 1354 (49) & $304(63)$ & $305(61)$ & $264(48)$ & $263(45)$ & $218(33)$ \\
\hline \multicolumn{7}{|l|}{ cN classification } \\
\hline $\mathrm{cNO}$ & $892(32)$ & $172(36)$ & $173(35)$ & $189(34)$ & $157(27)$ & $201(30)$ \\
\hline $\mathrm{cN}+$ & $1193(43)$ & $119(25)$ & $158(32)$ & $208(38)$ & $313(54)$ & 395 (59) \\
\hline $\mathrm{cNx}$ & $698(25)$ & $193(40)$ & $168(34)$ & $155(28)$ & 113 (19) & $69(10)$ \\
\hline \multicolumn{7}{|l|}{ cM classification } \\
\hline $\mathrm{cMO}$ & $1752(63)$ & $311(64)$ & $314(63)$ & $316(57)$ & 344 (59) & $467(70)$ \\
\hline cM1 & $589(21)$ & $79(16)$ & $88(18)$ & $96(17)$ & $135(23)$ & $191(29)$ \\
\hline $\mathrm{cMx}$ & $442(16)$ & 94 (19) & $97(19)$ & $140(25)$ & $104(18)$ & $7(1)$ \\
\hline \multicolumn{7}{|l|}{ TNM stage } \\
\hline 1 & $64(2)$ & $14(3)$ & $14(3)$ & $9(2)$ & $14(2)$ & $13(2)$ \\
\hline 2 & $565(20)$ & $80(17)$ & $72(14)$ & $100(18)$ & $125(22)$ & $188(28)$ \\
\hline 3 & $763(27)$ & $102(21)$ & $126(25)$ & $173(31)$ & $174(30)$ & $188(28)$ \\
\hline 4 & $589(21)$ & $79(16)$ & $88(18)$ & $96(17)$ & $135(23)$ & $191(29)$ \\
\hline Unknown & $802(29)$ & $209(43)$ & $199(40)$ & $174(32)$ & $135(23)$ & $85(13)$ \\
\hline
\end{tabular}

Percentages may not add up to 100 percent because of rounding. SCC: Squamous cell carcinoma; CEC: Cervical esophageal cancer; UTEC: Upper thoracic esophageal cancer.

\section{Trends in treatment in patients with proximal esophageal cancer}

In patients with non-metastatic disease, the proportion of patients treated with CRT alone increased from $1 \%$ in $1989-1994$ to $49 \%$ in 2010-2014 (Figure 3.1A). Resection without neoadjuvant treatment was performed in 17\% of patients in 1989-1994 and in 
$2 \%$ of patients in 2010-2014. The proportion of patients treated with neoadjuvant therapy and resection was relatively constant over time, varying between $3 \%$ and $7 \%$. The proportion of patients with non-metastatic proximal esophageal cancer that did not undergo any form of treatment varied between $15 \%$ and $22 \%$, without a clear trend over time.

For patients with metastatic disease, only minor variations in treatment were observed (Figure 3.1B). Forty-four percent of patients were treated with radiotherapy alone in 1989-1994, which slightly decreased to $37 \%$ in $2010-2014$. Over time, multimodal treatment of chemotherapy and radiotherapy, concurrent or sequential, was administered more frequently: In 3\% of patients in 1989-1994 and 23\% of patients in 2010-2014. Chemotherapy alone was given to 7\%-12\% of patients in all time periods. The proportion of patients diagnosed with metastatic proximal esophageal cancer who did not undergo any form of anti-cancer treatment decreased from 33\% in 1989-2004 to $24 \%$ in $2010-2014$.

A

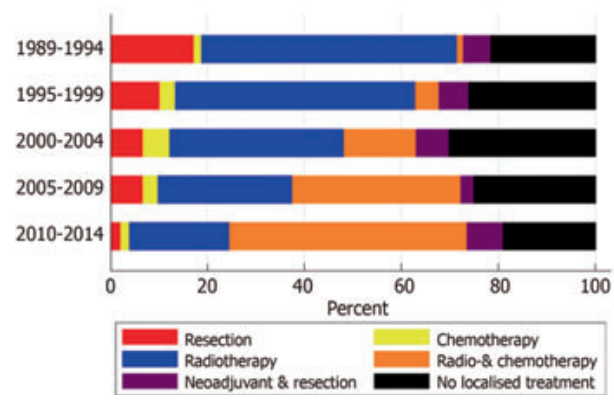

B

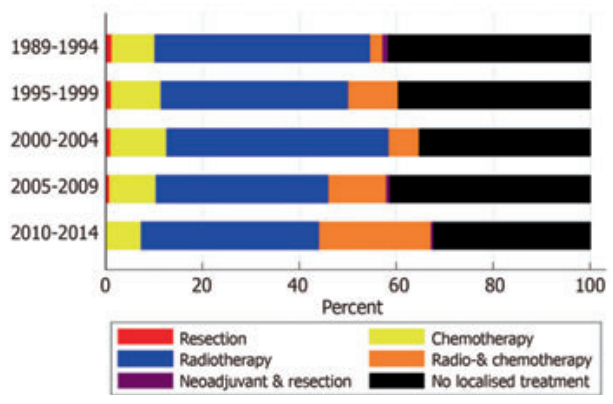

Figure 3.1 Treatment of patients with proximal esophageal cancer in the Netherlands between 1989 and 2014. A: Patients with non-metastatic proximal esophageal cancer; B: Patients with metastatic proximal esophageal cancer.

\section{Trends in survival in patients with proximal esophageal cancer}

The median OS of the total population of patients with proximal esophageal cancer was $8.0 \mathrm{mo}(95 \% \mathrm{Cl}: 7.6-8.5 \mathrm{mo})$. Median OS increased over the study period, from $7.3 \mathrm{mo}$ (95\% Cl: $6.4-8.1 \mathrm{mo})$ in $1989-1994$, to $9.5 \mathrm{mo}(95 \% \mathrm{Cl}: 8.1-10.8 \mathrm{mo})$ in $2010-2014$ (logrank $P<0.001$ ) (Figure 3.2). In patients with non-metastatic proximal esophageal cancer, 1 - and 5-year OS rates improved from $30 \%$ (95\% $\mathrm{Cl}: 26 \%-34 \%)$ and $5 \%(95 \% \mathrm{Cl}$ : $3 \%-7 \%)$ in $1989-1994$, to $44 \%(95 \% \mathrm{Cl}: 40 \%-48 \%)$ and $13 \%(95 \% \mathrm{Cl}: 9 \%-17 \%)$ in $2010-$ 2014, respectively (logrank $P<0.001$ ) (Figure $3.3 \mathrm{~A}$ ). Median OS of patients with non- 
metastatic proximal esophageal cancer was $8.0 \mathrm{mo}(95 \% \mathrm{Cl}: 7.0-8.9 \mathrm{mo})$ in $1989-1994$ and $13.3 \mathrm{mo}$ (95\% Cl: $11.1-15.5 \mathrm{mo})$ in 2010-2014. Patients with stage 1 disease showed the most favorable outcome with a 1- and 5-year OS rate of $70 \%(95 \% \mathrm{Cl}: 57 \%-80 \%)$ and $22 \%$ (95\% Cl 13\%-34\%), compared with 50\% (95\% Cl: 46\%-54\%) and 15\% (95\% $\mathrm{Cl}: 12 \%-$ $18 \%)$ in stage 2 , and $35 \%(95 \% \mathrm{Cl}: 32 \%-38 \%)$ and $10 \%(95 \% \mathrm{Cl}: 8 \%-13 \%)$ in stage 3 disease, respectively (logrank $P<0.001$ ) (Supplementary Figure S3.1).

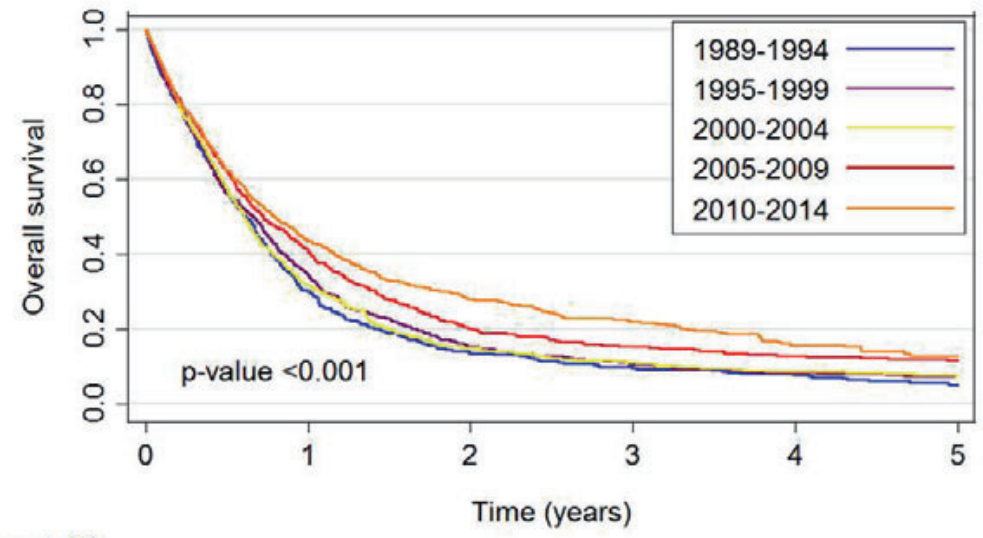

$\begin{array}{rr}\text { Number at risk } & \\ 1989-1994 & 475 \\ 1995-1999 & 498 \\ 2000-2004 & 550 \\ 2005-2009 & 579 \\ 2010-2014 & 664\end{array}$

141
172
174
238
290

63
75
82
116
154

45
52
60
88
84

$\begin{array}{ll}36 & 23 \\ 40 & 36 \\ 47 & 40 \\ 73 & 67 \\ 38 & 17\end{array}$

Figure 3.2 Overall survival by 5-year period of diagnosis of patients with proximal esophageal cancer in the Netherlands between 1989 and 2014, irrespective of stage at diagnosis.

In patients with non-metastatic proximal esophageal cancer, univariable analysis showed that period of diagnosis, age, histological type, cT, cN, and treatment were all associated with OS (Table 3.2). OS was similar for patients diagnosed with CEC or UTEC. Multivariable Cox regression analysis adjusted for age, histological type, tumor location, CT, and cN demonstrated an OS benefit for patients diagnosed in 2005-2009 [Hazard ratio $(H R)=0.77, P<0.001$ ] or 2010-2014 (HR=0.72, $P<0.001)$ when compared with patients diagnosed in 1989-1994. However, the time period effect disappeared after additional inclusion of treatment modality in the multivariable model. All treatment modalities had a statistically significant effect on OS compared with no localized treatment $(P<0.001)$. Patients with non-metastatic proximal esophageal cancer treated with surgery with or without neoadjuvant therapy or treated with definitive CRT 
showed 5 -year OS rates of $31 \%(95 \% \mathrm{Cl}: 23 \%-40 \%), 21 \%(95 \% \mathrm{Cl}: 16 \%-28 \%)$, and $22 \%$ (95\% Cl: 19\%-26\%), respectively (logrank $P=0.32$ ) (Supplementary Figure S3.2).

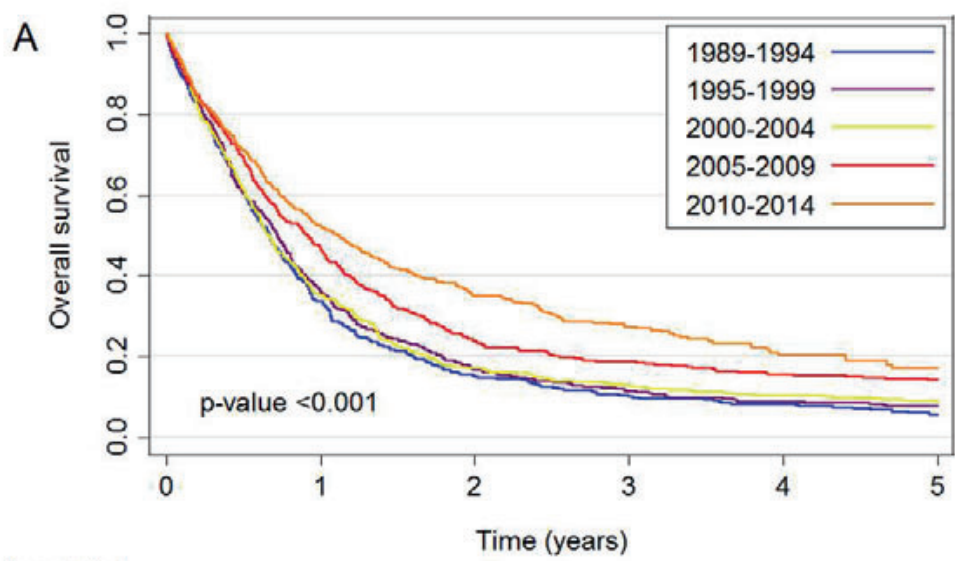

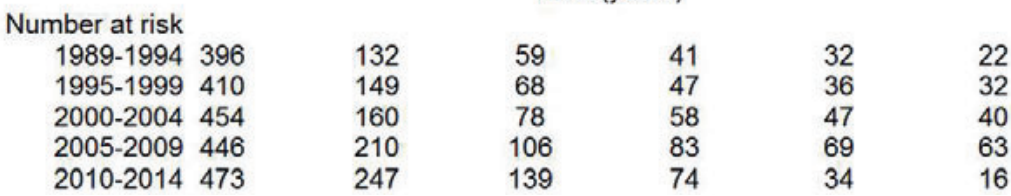
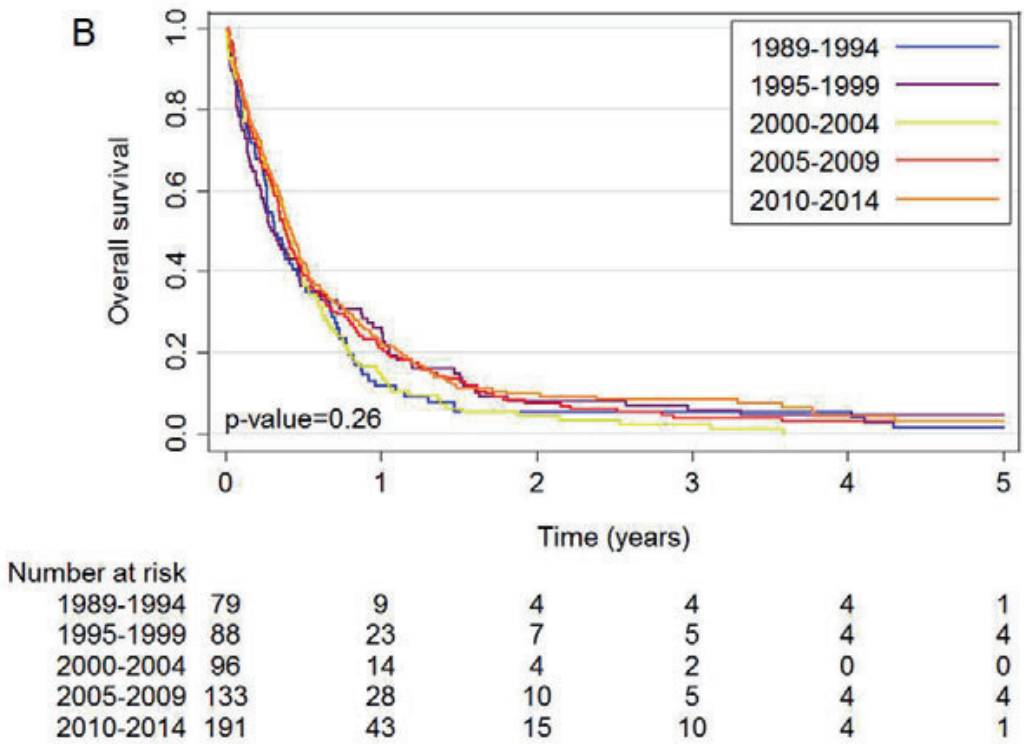

$\begin{array}{cc}9 & 4 \\ 23 & 7 \\ 14 & 4 \\ 28 & 10 \\ 43 & 15\end{array}$

$\begin{array}{ccc}4 & 4 & 1 \\ 5 & 4 & 4 \\ 2 & 0 & 0 \\ 5 & 4 & 4 \\ 10 & 4 & 1\end{array}$

Figure 3.3 Overall survival by 5-year period of diagnosis of patients with proximal esophageal cancer in the Netherlands between 1989 and 2014. A: Patients with non-metastatic proximal esophageal cancer; B: Patients with metastatic proximal esophageal cancer. 
In patients with metastatic disease, OS did not change significantly over time (logrank $P=0.26)$ (Figure 3.3B). Median OS was $3.8 \mathrm{mo}(95 \% \mathrm{Cl}: 2.5-5.1 \mathrm{mo})$ in $1989-1994$ and $5.1 \mathrm{mo}(95 \% \mathrm{Cl}: 4.3-5.9 \mathrm{mo})$ in $2010-2014$. One-year OS rate was $12 \%$ (95\% Cl: $6 \%-20 \%)$ in $1989-1994$ and $23 \%$ (95\%Cl: $17 \%-29 \%)$ in 2010-2014.

Table 3.2 Univariable and multivariable hazard ratios for overall survival of patients diagnosed with nonmetastatic proximal esophageal cancer $(\mathrm{N}=2194)$.

\begin{tabular}{|c|c|c|c|c|c|c|c|}
\hline \multirow[b]{2}{*}{ Characteristics } & \multirow[b]{2}{*}{$\mathbf{N}$} & \multicolumn{2}{|c|}{ Univariable analysis } & \multicolumn{2}{|c|}{ Multivariable analysis } & \multicolumn{2}{|c|}{ Multivariable analysis } \\
\hline & & HR $(95 \% \mathrm{Cl})$ & $P$ value & HR $(95 \% \mathrm{Cl})$ & $P$ value & HR $(95 \% \mathrm{Cl})$ & $P$ value \\
\hline \multicolumn{8}{|l|}{ Period } \\
\hline 1989-1994 & 405 & Ref. & & Ref. & & Ref. & \\
\hline 1995-1999 & 411 & $0.92(0.80-1.05)$ & 0.21 & $0.91(0.79-1.05)$ & 0.18 & $0.85(0.74-0.98)$ & 0.03 \\
\hline $2000-2004$ & 456 & $0.92(0.81-1.06)$ & 0.24 & $0.97(0.85-1.12)$ & 0.71 & $0.94(0.82-1.08)$ & 0.39 \\
\hline 2005-2009 & 448 & $0.73(0.63-0.83)$ & $<0.001$ & $0.77(0.67-0.89)$ & $<0.001$ & $0.88(0.76-1.02)$ & 0.09 \\
\hline $2010-2014$ & 474 & $0.59(0.51-0.68)$ & $<0.001$ & $0.72(0.62-0.85)$ & $<0.001$ & $0.94(0.79-1.10)$ & 0.43 \\
\hline \multicolumn{8}{|l|}{ Age } \\
\hline$<60 \mathrm{yr}$ & 562 & Ref. & & Ref. & & Ref. & \\
\hline $60-74 \mathrm{yr}$ & 1002 & $1.06(0.95-1.18)$ & 0.30 & $1.11(0.99-1.23)$ & 0.08 & $0.97(0.86-1.08)$ & 0.53 \\
\hline$\geq 75 \mathrm{yr}$ & 630 & 1.50 (1.33-1.69) & $<0.001$ & $1.51(1.34-1.71)$ & $<0.001$ & $1.00(0.87-1.14)$ & 0.95 \\
\hline \multicolumn{8}{|l|}{ Histology } \\
\hline SCC & 1797 & Ref. & & Ref. & & Ref. & \\
\hline$A C$ & 242 & $1.07(0.93-1.23)$ & 0.37 & $0.97(0.84-1.12)$ & 0.64 & $0.88(0.76-1.02)$ & 0.09 \\
\hline Other & 155 & 1.47 (1.24-1.74) & $<0.001$ & $1.22(1.03-1.44)$ & 0.02 & $1.11(0.93-1.31)$ & 0.25 \\
\hline \multicolumn{8}{|l|}{ Tumor location } \\
\hline UTEC & 1672 & Ref. & & Ref. & & Ref. & \\
\hline CEC & 522 & $0.97(0.88-1.08)$ & 0.59 & $0.89(0.80-0.98)$ & 0.02 & $0.95(0.86-1.06)$ & 0.37 \\
\hline \multicolumn{8}{|l|}{ cT category } \\
\hline cT1-3 & 642 & Ref. & & Ref. & & Ref. & \\
\hline cT4 & 506 & $2.03(1.79-2.30)$ & $<0.001$ & 1.93 (1.69-2.19) & $<0.001$ & $1.62(1.42-1.85)$ & $<0.001$ \\
\hline cTx & 1046 & 1.75 (1.57-1.94) & $<0.001$ & 1.50 (1.33-1.69) & $<0.001$ & $1.25(1.11-1.41)$ & $<0.001$ \\
\hline \multicolumn{8}{|l|}{ cN category } \\
\hline cNO & 825 & Ref. & & Ref. & & Ref. & \\
\hline $\mathrm{cN}+$ & 811 & $1.29(1.16-1.43)$ & $<0.001$ & $1.44(1.29-1.60)$ & $<0.001$ & $1.35(1.21-1.50)$ & $<0.001$ \\
\hline $\mathrm{cNx}$ & 558 & $2.06(1.84-2.30)$ & $<0.001$ & $1.78(1.59-2.00)$ & $<0.001$ & $1.37(1.22-1.55)$ & $<0.001$ \\
\hline \multicolumn{8}{|l|}{ Treatment } \\
\hline $\begin{array}{l}\text { No localized } \\
\text { treatment }\end{array}$ & 538 & Ref. & & & & Ref. & \\
\hline Resection & 183 & $0.19(0.16-0.22)$ & $<0.001$ & & & $0.22(0.18-0.26)$ & $<0.001$ \\
\hline $\begin{array}{l}\text { Neoadjuvant } \\
\text { and resection }\end{array}$ & 126 & $0.15(0.12-0.18)$ & $<0.001$ & & & $0.17(0.13-0.21)$ & $<0.001$ \\
\hline $\begin{array}{l}\text { Radio- and } \\
\text { chemotherapy }\end{array}$ & 480 & $0.17(0.14-0.19)$ & $<0.001$ & & & $0.19(0.16-0.22)$ & $<0.001$ \\
\hline Chemotherapy & 67 & $0.38(0.29-0.49)$ & $<0.001$ & & & $0.39(0.30-0.50)$ & $<0.001$ \\
\hline Radiotherapy & 800 & $0.38(0.34-0.42)$ & $<0.001$ & & & $0.40(0.36-0.46)$ & $<0.001$ \\
\hline
\end{tabular}

${ }^{1}$ Additionally adjusted for treatment category. SCC: Squamous cell carcinoma; AC: Adenocarcinoma; CEC: Cervical esophageal cancer; UTEC: Upper thoracic esophageal cancer; HR: Hazard ratio; Cl: Confidence interval. 


\section{Discussion}

In the Netherlands, median OS of patients with proximal esophageal cancer significantly increased by approximately two mo between 1989 and 2014. In patients with nonmetastatic proximal esophageal cancer, 5-year OS almost tripled to 13\% in 2010-2014, although the absolute long-term outcome remains poor. Multivariable analysis showed that improvements in treatment over time might have led to this survival benefit. The improvement is likely to be attributable to the implementation of CRT in the late nineties, accounting for almost $50 \%$ of treatment choices in non-metastatic proximal esophageal cancer nowadays. The proportion of patients who did not receive any anticancer treatment remained remarkably high, being one in five patients with nonmetastatic and one in four patients with metastatic proximal esophageal cancer, which may be a reflection of the poor performance status of these patients.

We observed that in the patients with non-metastatic proximal esophageal cancer $(\mathrm{N}=2194)$, the median OS improved from $8 \mathrm{mo}$ in 1989-1994 to 13 mo in 2010-2014, with comparable OS between CEC and UTEC. Considering OS in patients with metastatic disease did not improve significantly over time, stage migration was not expected to be a major contributor to the improved survival in the non-metastatic group. A Surveillance, Epidemiology, and End Results (SEER) data-based study in 362 patients with non-metastatic CEC diagnosed between 1998 and 2008 showed a longer median OS, i.e., 14 mo. ${ }^{12}$ The shorter median survival observed in our study may partly be explained by the inclusion of patients with a history of previous malignancies, whereas the SEER data-based study excluded these patients. In addition, we included patients with unknown metastatic status in the group of patients with non-metastatic disease, which could have led to an underestimation of the OS in the non-metastatic patient group.

Our study showed a reduction of surgical approaches from $23 \%$ in the earliest time period to $10 \%$ in the most recent period. The aforementioned SEER population-based study showed similar results, where only $11 \%$ of patients with cervical esophageal cancer underwent surgery and 79\% radiotherapy (chemotherapy data were not available). ${ }^{12}$ These findings confirm a different approach in the management of proximal esophageal cancer in specific as compared with cancers from all sites of the esophagus. In the latter group the proportion of patients treated with surgery remained relatively stable over time, from 25\% between 1989 and 2004, to 29\% between 2010 and $2014 .^{2}$

Considering bias by indication, we hypothesized that patients with resectable tumors, undergoing surgery, might show a superior outcome when compared with CRT. However, in the current population-based study, we observed a comparable OS in 
patients treated with surgery vs. those treated with definitive CRT which is consistent with a recent observational study in 148 patients with cervical esophageal cancer. ${ }^{13}$ The current study showed that period effect in the multivariable model disappeared after including treatment modality. These findings suggest that improvements in the (nonsurgical) treatment had a substantial effect on the observed improvement in OS. However progress in OS may also have partly occurred due to advancements in the management of non-cancer related high mortality disorders, e.g., cardiovascular disease. ${ }^{14}$ Figures from Statistics Netherlands show that the remaining life expectancy for, for example, an average 65 year old person was 17 years in 1989 and 20 years in 2014. ${ }^{15}$ Whether this increase in life expectancy is also seen in the high-risk population presented in our study is unknown.

In patients with metastatic proximal esophageal cancer, we did not observe any significant improvements in OS over time. These findings are in contrast to previous population-based studies, observing an increased survival over the years in the total group of patients with metastatic esophageal cancer patients, including $10 \%$ of cancers originating from the proximal esophagus. ${ }^{16,17}$ This difference in the trend in OS may be explained by the more prominent increased use of systemic therapy in metastatic adenocarcinomas, ${ }^{2}$ which are more common in the distal part of the esophagus. ${ }^{18}$ For example, in patients with HER2 amplified adenocarcinomas of the distal esophagus, HER2 directed therapies have led to a survival benefit. ${ }^{19}$ In metastatic SCC, palliative systemic therapy is scarcely applied. ${ }^{2}$ A recent meta-analysis, however, showed that systemic therapy in patients with metastatic SCC improved OS and quality of life, and is considered standard of care. ${ }^{20}$ The outcomes of patients with metastatic SCC is expected to improve in the coming decades, because the pace of development of cancer immunotherapies is accelerating. Recent studies show clinical evidence of efficacy of immune checkpoint inhibitors in SCC of the esophagus, ${ }^{21,22}$ and are expected to be approved for implementation in clinical practice.

Furthermore, since proximal esophageal cancer is extremely rare, development of highvolume expert centers is challenging. Centralization of surgery in esophageal cancer has led to an increased survival in resectable esophageal cancer. ${ }^{23} \mathrm{~A}$ recent Dutch study showed that center volume of palliative systemic therapy for metastatic esophagogastric cancer was associated with improved survival, suggesting a volumeoutcome relationship. ${ }^{24}$ Giving the low incidence rate and the challenging performance status of these patients, this could be a plea for centralization of care for patients with proximal esophageal cancer.

The retrospective nature of this study is inherent with some limitations mainly attributable to the availability of information. Coding of the tumor was being performed on the basis of topography, extracted from the medical records depending 
on input of physicians and interpretation of administrators, posing a risk of misclassification. The NCR does not include information on treatment techniques, schedules, and its related toxicities, causing interpretation adversity. Furthermore, data regarding risk factors, e.g., smoking behavior and alcohol consumption, comorbidity, performance status, and disease specific cause of death were not available, resulting in a risk of residual confounding. However, our multivariable model showed that the period effect almost completely disappeared after including treatment modalities to the multivariable model, implicating that there are no major confounders missing.

The strength of our study is that it is a large population-based cohort. This nationwide cohort of patients with proximal esophageal cancer in the Netherlands represents daily clinical practice, reflecting real-life treatment and survival. Moreover, the follow-up period can be considered long, given the relatively short survival time of patients with proximal esophageal cancer.

In conclusion, this nationwide study in patients with proximal esophageal cancer showed an increasing use of definitive CRT over the study period, with improved survival in non-metastatic disease, although long-term result is still rather poor.

\section{Highlights}

\section{Research background}

Proximal esophageal cancer is a rare disease, accounting for only $10 \%$ of all esophageal cancers. Nearby vital structures are involved in almost all proximal esophageal cancers at diagnosis, and as such surgical treatment is mutilating with major implications for quality of life of patients. Definitive chemoradiation (CRT) is an alternative treatment option, but survival data are scarce, restricting patient counseling.

\section{Research motivation}

To optimize treatment strategies and counseling of patients with proximal esophageal cancer, it is therefore essential to gain more insight in patient characteristics, provided therapies and outcome through real-life studies.

\section{Research objectives}

The aim of this population-based cohort study was to establish the trends in treatment and overall survival (OS) in patients diagnosed with non-metastatic or metastatic proximal esophageal cancer in a nationwide registry between 1989 and 2014. 


\section{Research methods}

All patients with a tumor located in the cervical or upper thoracic esophagus diagnosed between 1989 and 2014 were identified in the Netherlands Cancer Registry (NCR). The NCR is a population-based cancer registry of all residents of the Netherlands. Trends in radiotherapy, chemotherapy, and surgery, and OS were assessed. Analyses were stratified by presence of distant metastasis. Multivariable Cox proportional hazards regression analyses was performed to assess the effect of period of diagnosis on OS, adjusted for patient, tumor, and treatment characteristics.

\section{Research results}

Median OS of patients with proximal esophageal cancer significantly increased by approximately two mo between 1989 and 2014. In patients with non-metastatic proximal esophageal cancer, 5-year OS almost tripled to $13 \%$ in 2010-2014, although the absolute long-term outcome remains poor. Multivariable analysis showed that improvements in treatment over time have led to this survival benefit. The improvement is likely to be attributable to the implementation of CRT in the late nineties, accounting for almost $50 \%$ of treatment choices in non-metastatic proximal esophageal cancer nowadays, as shown in the current study. In metastatic disease, median OS did not change significantly between 1989 and 2014.

\section{Research conclusions}

Surgical treatment for proximal esophageal cancer has been substituted by definitive CRT in the more recent years, and was likely to be associated with significant survival improvement of patients with non-metastatic proximal esophageal cancer. (Long-term) survival data of patients with (non-)metastatic proximal esophageal cancer are provided from a large national database, representing daily clinical practice.

\section{Research perspectives}

Our findings give insights in real-life survival of patients with proximal esophageal cancer, providing crucial support for patient counseling. Future research should focus on outcome between different CRT regimens, to optimize non-surgical treatment. 


\section{References}

1. Ferlay J, Ervik M, Lam F, Colombet M, Mery L, Piñeros M, Znaor A, Soerjomataram I, Bray F. Global Cancer Observatory: Cancer Today. Lyon, France: International Agency for Research on Cancer. 27 Feb 2019. Available from: https://gco.iarc.fr/today

2. van Putten M, de Vos-Geelen J, Nieuwenhuijzen GAP, Siersema PD, Lemmens VEPP, Rosman C, van der Sangen MJC, Verhoeven RHA. Long-term survival improvement in oesophageal cancer in the Netherlands. Eur J Cancer 2018;94:138-47.

3. Cooper JS, Guo MD, Herskovic A, Macdonald JS, Martenson JA, Al-Sarraf M, Byhardt R, Russell AH, Beitler JJ, Spencer S, Asbell SO, Graham MV, Leichman LL. Chemoradiotherapy of locally advanced esophageal cancer: long-term follow-up of a prospective randomized trial (RTOG 85-01). Radiation Therapy Oncology Group. JAMA 1999;281:1623-7.

4. al-Sarraf M, Martz K, Herskovic A, Leichman L, Brindle JS, Vaitkevicius VK, Cooper J, Byhardt R, Davis L, Emami B. Progress report of combined chemoradiotherapy versus radiotherapy alone in patients with esophageal cancer: an intergroup study. J Clin Oncol 1997;15:277-84

5. Pignon JP, Bourhis J, Domenge C, Designé L. Chemotherapy added to locoregional treatment for head and neck squamous-cell carcinoma: three meta-analyses of updated individual data. MACH-NC Collaborative Group. Meta-Analysis of Chemotherapy on Head and Neck Cancer. Lancet 2000;355: 949-55

6. Pritchard RS, Anthony SP. Chemotherapy plus radiotherapy compared with radiotherapy alone in the treatment of locally advanced, unresectable, non-small-cell lung cancer. A meta-analysis. Ann Intern Med 1996; 125: 723-9.

7. Wong R, Malthaner R. Combined chemotherapy and radiotherapy (without surgery) compared with radiotherapy alone in localized carcinoma of the esophagus. Cochrane Database Syst Rev 2006;CD002092.

8. Lordick F, Mariette C, Haustermans K, Obermannová R, Arnold D; ESMO Guidelines Committee. Oesophageal cancer: ESMO Clinical Practice Guidelines for diagnosis, treatment and follow-up. Ann Oncol 2016;27:v50-7.

9. Ajani JA, D'Amico TA, Baggstrom M, Bentrem DJ, Chao J, Corvera C, Das P, Denlinger CS, Enzinger PC, Fanta P, Farjah F, Gerdes H, Gibson M, Glasgow RE, Hayman JA, Hochwald S, Hofstetter WL, Ilson DH, Jaroszewski D, Johung KL, Keswani RN, Kleinberg LR, Leong S, Linn C, Ly QP, Matkowskyj KA, Mulcahy MF, Paluri RK, Perry KA, Pimiento J, Poultsides GA, Strong VE, Washingon MK, Weksler B, Wiesner G, Willett CG, Wright CD, Gurski L, McMillian N, Pluchino LA. Esophageal and Esophagogastric Junction Cancers, Version 2.2018; 2018 [cited 2019 Dec 4]. Database: National Comprehensive Cancer Network [Internet]. Available from: https://www.nccn.org

10. Fritz A, Percy C, Jack A, Shanmugaratnam K, Sobin L, Parkin DM, Whelan S, editors. International Classification of Diseases for Oncology. 3rd ed. Geneva: World Health Organization. 2000

11. Greene FL, Balch CM, Haller DG, Morrow M. AJCC Cancer Staging Manual, 6th ed. New York: SpringerVerlag. AJCC Cancer Staging Manual, 6th ed. New York: Springer-Verlag 2002;91-9.

12. Grass GD, Cooper SL, Armeson K, Garrett-Mayer E, Sharma A. Cervical esophageal cancer: a populationbased study. Head Neck 2015;37:808-14.

13. Valmasoni M, Pierobon ES, Zanchettin G, Briscolini D, Moletta L, Ruol A, Salvador R, Merigliano S. Cervical Esophageal Cancer Treatment Strategies: A Cohort Study Appraising the Debated Role of Surgery. Ann Surg Oncol 2018;25:2747-55.

14. GBD 2017 Causes of Death Collaborators. Global, regional, and national age-sex-specific mortality for 282 causes of death in 195 countries and territories, 1980-2017: a systematic analysis for the Global Burden of Disease Study 2017. Lancet 2018;392:1736-88.

15. Statistics Netherlands. 2019 May 17 [cited 14 Nov 2019]. Available from: https://opendata.cbs.nl/statline/\#/CBS/nl/dataset/37360ned/table?ts=1573737810723.

16. Bernards N, Haj Mohammad N, Creemers GJ, Rozema T, Roukema JA, Nieuwenhuijzen GA, van Laarhoven HW, van der Sangen M, Lemmens VE. Improvement in survival for patients with 
synchronous metastatic esophageal cancer in the south of the Netherlands from 1994 to 2013. Acta Oncol 2016;55:1161-7.

17. Dikken JL, Lemmens VE, Wouters MW, Wijnhoven BP, Siersema PD, Nieuwenhuijzen GA, van Sandick JW, Cats A, Verheij M, Coebergh JW, van de Velde CJ. Increased incidence and survival for oesophageal cancer but not for gastric cardia cancer in the Netherlands. Eur J Cancer 2012;48:1624-32.

18. Smyth EC, Lagergren J, Fitzgerald RC, Lordick F, Shah MA, Lagergren P, Cunningham D. Oesophageal cancer. Nat Rev Dis Primers 2017;3:17048.

19. Bang YJ, Van Cutsem E, Feyereislova A, Chung HC, Shen L, Sawaki A, Lordick F, Ohtsu A, Omuro Y, Satoh T, Aprile G, Kulikov E, Hill J, Lehle M, Rüschoff J, Kang YK; ToGA Trial Investigators. Trastuzumab in combination with chemotherapy versus chemotherapy alone for treatment of HER2-positive advanced gastric or gastro-oesophageal junction cancer (ToGA): a phase 3, open-label, randomised controlled trial. Lancet 2010;376:687-97.

20. Janmaat VT, Steyerberg EW, van der Gaast A, Mathijssen RH, Bruno MJ, Peppelenbosch MP, Kuipers EJ, Spaander MC. Palliative chemotherapy and targeted therapies for esophageal and gastroesophageal junction cancer. Cochrane Database Syst Rev 2017;11:CD004063

21. Kudo T, Hamamoto Y, Kato K, Ura T, Kojima T, Tsushima T, Hironaka S, Hara H, Satoh T, Iwasa S, Muro K, Yasui H, Minashi K, Yamaguchi K, Ohtsu A, Doki Y, Kitagawa Y. Nivolumab treatment for oesophageal squamous-cell carcinoma: an open-label, multicentre, phase 2 trial. Lancet Oncol 2017;18:631-9.

22. Kojima T, Muro K, Francois E, Hsu CH, Moriwaki T, Kim SB, Lee SH, Bennouna J, Kato K, Lin S, Qin SQ, Ferreira P, Doi T, Adenis A, Enzinger PC, Shah MA, Wang R, Bhagia P, Kang SP, Metges JP. Pembrolizumab versus chemotherapy as second-line therapy for advanced esophageal cancer: The phase 3 KEYNOTE-181 study. 2019 Gastrointestinal Cancers Symposium; 2019 Jan 17-19; San Francisco, United States. American Society of Clinical Oncology.

23. Dikken JL, Dassen AE, Lemmens VE, Putter H, Krijnen P, van der Geest L, Bosscha K, Verheij M, van de Velde CJ, Wouters MW. Effect of hospital volume on postoperative mortality and survival after oesophageal and gastric cancer surgery in the Netherlands between 1989 and 2009. Eur J Cancer 2012; 48:1004-13.

24. Haj Mohammad N, Bernards N, van Putten M, Lemmens VEPP, van Oijen MGH, van Laarhoven HWM. Volume-outcome relation in palliative systemic treatment of metastatic oesophagogastric cancer. Eur J Cancer 2017;78:28-36. 


\section{Supplemental material}

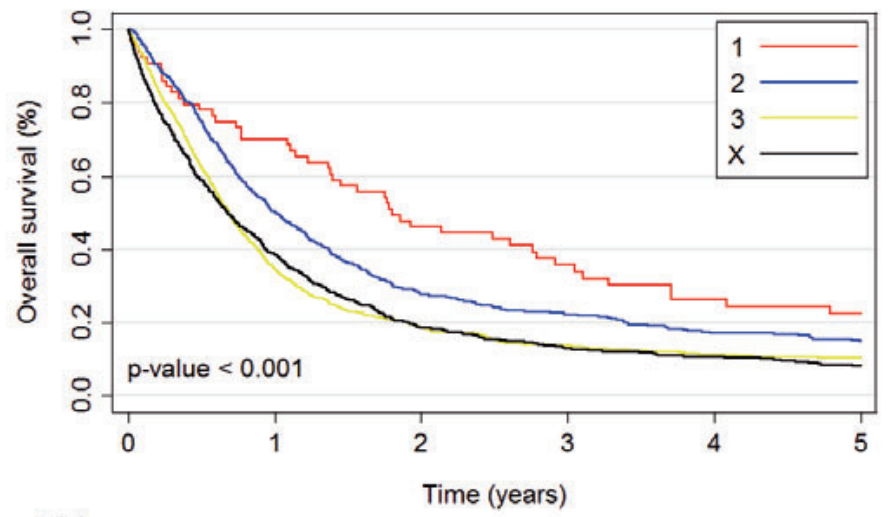

\section{Number at risk}

$\begin{array}{ccccccc}\text { Stage 1 } & 64 & 44 & 28 & 19 & 14 & 11 \\ \text { Stage 2 } & 565 & 285 & 143 & 96 & 62 & 46 \\ \text { Stage 3 } & 762 & 265 & 134 & 88 & 65 & 60 \\ \text { Stage X } 788 & 304 & 145 & 100 & 77 & 56\end{array}$

Figure S3.1 Overall survival of patients with proximal esophageal cancer in the Netherlands between 1989 and 2014 , stratified by stage of disease at diagnosis.

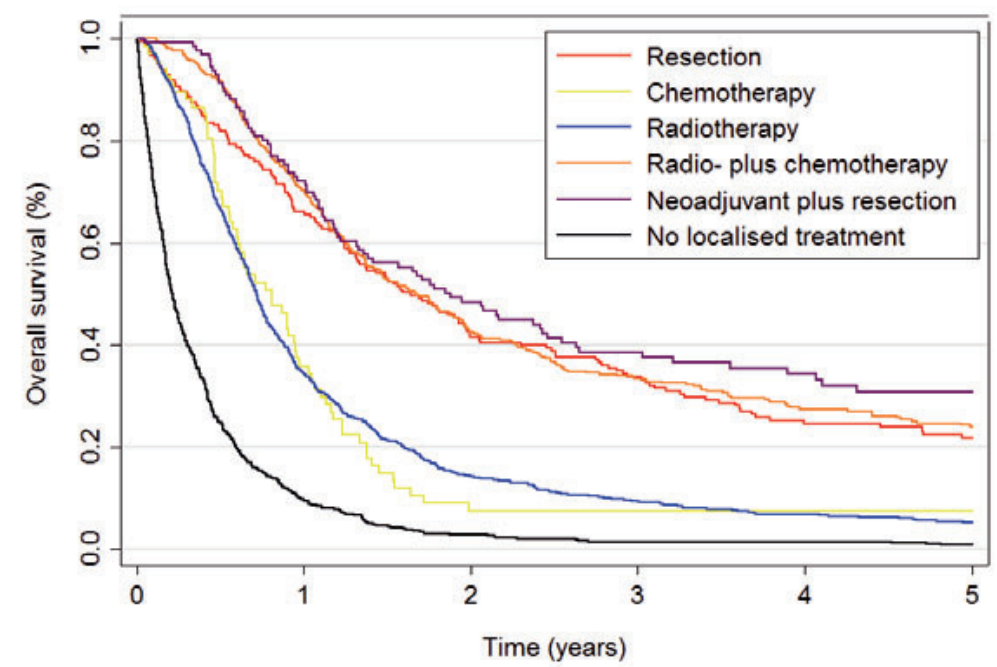

Figure S3.2 Overall survival of patients with non-metastatic proximal esophageal cancer in the Netherlands between 1989 and 2014, stratified by treatment modalities. 



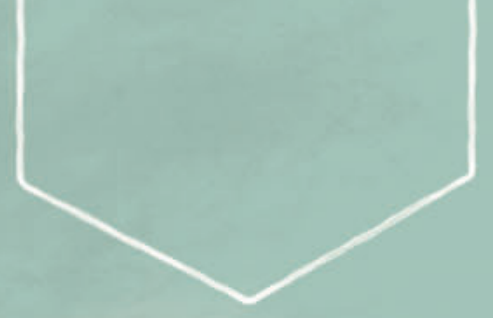

CHAPTER 4

Cervical esophageal cancer:

a gap in cancer knowledge

A. Hoeben, J. Polak, L. van de Voorde, F. Hoebers, H.I. Grabsch, J. de Vos-Geelen Annals of Oncology 2016;27:1664-1674 


\section{Abstract}

\section{Background}

The aim of this systematic review is to provide an overview of the diagnosis, treatment options and treatment-related complications of cervical esophageal carcinoma (CEC) and to subsequently provide recommendations to improve quality of care.

\section{Design}

Studies were identified in PubMed, EMBASE and Web of Science. A total of 107 publications fulfilled the inclusion criteria and were included.

\section{Results}

CEC is uncommon, accounting for $2 \%-10 \%$ of all esophageal carcinomas. These tumors are often locally advanced at presentation and have a poor prognosis, with a 5-year overall survival of $30 \%$. Tobacco and alcohol consumption seem to be the major risk factors for developing CEC. Surgery is usually not possible due to the very close relationship to other organs such as the larynx, trachea and thyroid gland. Therefore, the current standard of care is definitive chemoradiation (dCRT) with curative intent. Treatment regimens used to treat CEC are adapted by established regimens in lower esophageal squamous cell carcinoma and head and neck squamous cell carcinoma. However, dCRT may be accompanied by severe side-effects and complications. Several diagnostic and predictive markers have been studied, but currently, there is no other biomarker than clinical stage to determine patient management. Suggestions to improve patient outcomes are to determine the exact radiation dose needed for adequate locoregional control and to combine radiotherapy with optimal systemic therapy backbone.

\section{Conclusion}

CEC remains unchartered territory for many practicing physicians and patients with CEC have a poor prognosis. To improve the outcome for CEC patients, future studies should focus on the identification of new diagnostic biomarkers or targets for radiosensitizers, amelioration of radiation schedules, optimal combination of chemotherapeutic agents and/or new therapeutic targets. 


\section{Introduction}

The cervical esophagus is the short part of the esophagus between the lower border of the cricoid cartilage and the thoracic inlet (suprasternal notch), $\sim 18 \mathrm{~cm}$ from the incisor teeth. ${ }^{1}$ Carcinoma of the cervical esophagus (CEC), usually squamous cell carcinoma (SCC), is uncommon, with 5 new cases per 1 million person years in the United States ${ }^{2}$ and accounts for $2 \%-10 \%$ of all esophageal carcinomas. ${ }^{3}$ The highest rates of SCC are found in Eastern Asia and Southern Africa, and the lowest rates in Western Africa and Central America. ${ }^{4}$ The management of CEC differs from that of cancers of the lower two-thirds of the esophagus because CECS are often locally advanced at the time of diagnosis infiltrating nearby anatomical structures including, for example, the cricoid, thyroid cartilage or thyroid gland. Moreover, patients with CEC often present with lymph node metastases. ${ }^{1}$ Most CECs are not treatable by surgery, as this would involve mutilating resections including pharyngo-laryngo-esophagectomy (PLE). Therefore, definitive chemoradiation ( $\mathrm{dCRT}$ ) is the standard treatment modality recommended by the National Comprehensive Cancer Network (NCCN) and European Society for Medical Oncology (ESMO) guidelines. ${ }^{5,6}$ dCRT usually consists of 50.4 Gy in 1.8 Gy per fraction per day. Higher doses up to 60-66 Gy may be appropriate if no surgery is planned. Concurrent chemotherapy generally consists of cisplatin and 5-fluorouracil (5-FU), oxaliplatin and 5-FU or carboplatin and paclitaxel. ${ }^{5}$ As CECs behave very aggressively, as they grow in an area of abundant lymphatic drainage and fail to produce early symptoms, and easily and frequently extend toward the hypopharynx, these tumors are sometimes treated with schedules for locally advanced head and neck squamous cell carcinoma (LAHNSCC), which consists of 70 Gy in 35 fractions and cisplatin $100 \mathrm{mg} / \mathrm{m}^{2}$ on day 1, 22 and 43 of radiotherapy (RT) (NCCN guidelines for head and neck cancers ${ }^{7}$ ). dCRT is related to life-threatening adverse events in $5 \%-10 \%$ of patients ${ }^{8,9}$; thus, further research is needed to define the optimal treatment schedule with adequate survival and acceptable toxicity. In this literature review, we will provide an overview of the current knowledge and controversies surrounding CEC with respect to histopathology, genetic factors, etiology, diagnosis, treatment, toxicity and local disease control rate and survival and we will provide recommendations for future studies regarding potential curative treatment options, based on the current literature. 


\section{Methods}

\section{Literature search strategy}

In May 2015, the PubMed, Web of Science and EMBASE databases were searched for relevant evidence. The literature search strategy is detailed in Supplementary Data Section 4.1. The reference lists from included articles were also searched for additional relevant studies.

\section{Study inclusion and exclusion criteria}

Language was restricted to English. Articles published during the last three decades were selected. Studies were included if they comprised a minimum of five patients diagnosed with cancer in the cervical esophagus and treated with curative intent. Studies were excluded if patients had distant metastasis and were treated with palliative intent. Only studies published as abstracts were excluded.

\section{Literature search results}

The initial search in the three databases yielded 639 articles. Based on reading the titles and abstracts, 488 articles were excluded. Using Endnote (Version X6, Thomson Reuters) and manual screening, 63 duplicate articles were excluded. Eighty eight original articles and reviews were further screened. Thirty articles were excluded based on our predefined exclusion criteria leaving 58 full publications for inclusion in this review. During the manual search of the reference lists of the included articles, a further 49 relevant publications were identified, resulting in 107 articles that formed the basis of this review (for details, see flowchart in Supplementary Figure S4.1).

\section{Histopathology and genetic factors}

SCC accounts for $95 \%$ of cervical esophageal malignancies. ${ }^{10}$ Very little is known about SCC precursor lesions and genetic factors predisposing for CEC in particular. The malignant transformation to SCC involves basal cell hyperplasia, low- and high-grade dysplasia and invasive carcinoma. Squamous dysplasia is a well-described histological precursor lesion of esophageal SCC. ${ }^{11-14}$ Dysplasia is thought to be caused by molecular alterations. ${ }^{15}$ Early detection of molecular alterations, endoscopic and histological features of squamous dysplasia is necessary to identify SCC at an early stage. ${ }^{16-19}$ 
Modern endoscopy techniques, like micro-endoscopy, lugol staining and the use of biomarkers, have the potential to increase early detection. ${ }^{17-19}$

Genetic alterations in CEC are currently poorly understood and to the best of our knowledge, there are no studies investigating only genetic alterations in carcinomas located in the cervical esophagus. Several genes have been shown to be down- or upregulated in (pre)malignant lesions of esophageal sCC. ${ }^{11,20-29}$ The most common genetic alterations consist of allelic losses at chromosomes 3p, 5q, 9p, 9q, 3q, 17p, 17q, $18 q$ and mutations of $p 53, R B 1$ (retinoblastoma protein), ALDH2 (aldehyde dehydrogenase-2 gene), MTHFR (methylene tetrahydrofolate reductase gene), EGR1 (early growth response gene-1), CCND1 (cyclin D1) and $C M Y C .^{30-34}$ A recent work by the Cancer Genome Atlas Initiative provides comprehensive molecular profiling data of squamous cancers of the esophagus that may also facilitate future research for diagnostic and therapeutic molecular targets in CEC. ${ }^{35}$ There is an urgent clinical need for further research to investigate the potential usefulness of genetic and protein alterations for early diagnosis of CEC.

\section{Etiology and risk factors}

Tobacco and alcohol consumption are well-known risk factors for CEC. ${ }^{10,15,34,36}$ Mutations in $A D H$ (alcohol-dehydrogenase) $1 B$ and $A L D H-2$, both enzymes involved in alcohol metabolism, have been related to the occurrence of neoplasia in the upper

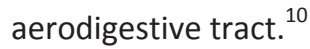

The variable geographic incidence of CEC with high-risk regions in Iran, Central Asia, Mongolia, Northern China and Eastern Cape South Africa suggests a potential influence of nutritional and environmental factors. The role of family history has not been clarified yet. ${ }^{34,37}$ Occupational factors have been difficult to evaluate independently because esophageal carcinomas often occur in unqualified workers in industry and agriculture, who are often also frequent tobacco and/or alcohol consumers. High exposure to polycyclic aromatic hydrocarbons (PAHs) has also been associated with a high risk of esophageal cancer. ${ }^{38}$

Studies investigating the potential association between human papilloma virus (HPV) infection and CEC incidence have conflicting results. Geographical locations with a high incidence of esophageal SCC tend to also have a higher incidence of HPV infection in patients with esophageal SCC (more than $10 \%$ of esophageal SCC cases are related to HPV infection). ${ }^{39-41}$ The main strains involved in esophageal cancer appear to be HPV 16 and $18 .^{40}$ 


\section{Diagnosis and staging}

Endoscopy and biopsy are the first choice of examination if a CEC is suspected. Recommendations regarding the minimum number of biopsies vary between countries, ranging from 1 up to $8 .^{42}$ Endoscopic ultrasonography (EUS) is considered to be the best technique to assess the depth of tumor infiltration and lymph node status and can be combined with fine needle aspiration cytology. ${ }^{3,43,44}{ }^{18}$ Fluorodeoxyglucose-positronemission-tomography-computed-tomography (18F-FDG-PET CT) is highly recommended to detect potential tumor invasion into adjacent structures and lymph node or distant metastases. ${ }^{44}$ Bronchoscopy, with endobronchial ultrasound and biopsy, can be used to assess infiltration in adjacent structures, e.g. trachea. ${ }^{45}$

Most CECs are locally advanced at the time of diagnosis, with $55 \%$ being TNM stage III or IV tumors and $27 \%$ stage II tumors. ${ }^{1,46-49}$ An overview of the current TNM staging can be found in Supplementary Table S4.1.

\section{Treatment}

Historically, surgery has been the standard treatment for CEC. Mostly, a PLE was carried out, a procedure that includes the resection of the larynx and has a huge impact on quality of life. ${ }^{50}$ Nonetheless, during the last decades, the outcome for patients who underwent surgery for CEC has improved due to the newly developed surgical strategies, such as minimally invasive surgery and neoadjuvant (chemo)radiotherapy. ${ }^{51}$ Furthermore, reconstruction methods like free jejunal graft, gastric pull-up or deltopectoral or pectoralis major myocutaneus flap have been introduced. ${ }^{50,52-62}$ Despite these efforts, surgical treatment still has a great risk of major complications and a high morbidity and mortality rate. ${ }^{57,63-68}$

To improve survival and quality of life, non-invasive treatment options like RT and dCRT have been explored. The Radiation Therapy Oncology Group (RTOG) compared dCRT versus RT alone for the treatment of patients with thoracic esophageal cancer and found that dCRT significantly increased 5-year overall survival (OS) compared with RT alone, $26 \%$ versus $0 \%{ }^{8}$ Although this study included only patients with thoracic esophageal cancer, the study results form the basis of the current non-surgical treatment of patients with esophageal cancer, including CEC. An update of the original RTOG 85-01 trial by al-Sarraf et al. ${ }^{69}$ reports higher survival rates of patients treated with dCRT compared with RT alone in the treatment of locally advanced esophageal cancer. Another study carried out in patients with cervical and upper thoracic esophageal cancer showed less favorable results than the RTOG study, reporting 5-year 
OS of $18.6 \%$ in patients treated with dCRT. ${ }^{70}$ Other studies reported a 5 -year OS of $\sim 30 \%$ for CEC patients treated with $\mathrm{dCRT}^{46,71}$ which is comparable with OS after surgery alone (24\%-47\%). ${ }^{56,58,63,66,72-74}$ In comparison with other SCCs in the head and neck region, 5-year OS of patients with CEC is relatively low, ${ }^{10}$ while it is comparable with 5 -year OS in patients with SCC located in other parts of the esophagus, which is $26 \%{ }^{8}$ dCRT may cause high rates of toxicity in CEC patients. Common toxic effects include dysphagia, dehydration, mucositis, esophagitis, dermatitis and fatigue. An additional side-effect of chemotherapy is bone marrow suppression. ${ }^{8,9,47-49,71,75,76}$ Moreover, late toxic effects like strictures and fistulas may occur. ${ }^{48,71,77}$ In the following, we will describe the currently available organ-sparing treatment options for locally advanced CEC, which combine RT with chemotherapy.

\section{Systemic therapy used within concurrent treatment regimens for CEC}

Several chemotherapeutic regimens are used, adapted by established regimens in lower esophageal SCC and head and neck squamous cell carcinoma (HNSCC). High-dose cisplatin-based chemotherapy, consisting of $100 \mathrm{mg} / \mathrm{m}^{2}$ on day 1,22 and 43 of RT, is currently considered one of the treatment options for patients with CEC based on increased cure rates that were observed with high-dose cisplatin in patients with head and neck cancer. ${ }^{7,46}$ However, no difference was seen in OS, disease-free survival (DFS) or locoregional recurrence-free survival (LRFS) comparing CEC patients treated with high-dose cisplatin with a concurrent RT dose of 70 Gy versus low-dose cisplatin combined with 5-FU or mitomycin C, concurrently administered with an RT schedule of 54 Gy (Table 4.1). ${ }^{46}$

SCC of the lower esophagus is often treated with a combination of cisplatin and 5-FU, ${ }^{82}$ a key factor in the treatment of gastroesophageal cancer. ${ }^{84}$ In CEC, the combination of cisplatin and 5-FU has shown acceptable cure and survival rates ${ }^{9,46-48,71}$ (Table 4.1), but combination therapy can lead to higher toxicity rates when compared with cisplatin alone. Bleiberg et al. ${ }^{80}$ randomized patients with advanced esophageal SCC to either receive cisplatin $\left(100 \mathrm{mg} / \mathrm{m}^{2}\right)$ and continuous $5-\mathrm{FU}\left(1000 \mathrm{mg} / \mathrm{m}^{2} /\right.$ day $)$ from day 1 to 5 or cisplatin alone $\left(100 \mathrm{mg} / \mathrm{m}^{2}\right)$ and found higher 2 -year OS rates $(18 \%$ and $9 \%$, respectively), but also higher toxicity rates in the cisplatin/5-FU group (16\% treatmentrelated deaths in the cisplatin/5-FU group versus $0 \%$ in the cisplatin alone group).

Other chemotherapeutic regimens have been studied with comparable results. ${ }^{78,81}$ Conroy et al. ${ }^{78}$ studied the role of FOLFOX regimen: 5 -FU (bolus $400 \mathrm{mg} / \mathrm{m}^{2}$, followed by infusional 5-FU $1600 \mathrm{mg} / \mathrm{m}^{2}$ over $46 \mathrm{~h}$ ) plus leucovorin $\left(200 \mathrm{mg} / \mathrm{m}^{2}\right)$ and oxaliplatin $\left(85 \mathrm{mg} / \mathrm{m}^{2}\right)$ in patients with adeno-, squamous cell or adenosquamous carcinoma. They compared the FOLFOX regimen with standard cisplatin/5-FU and found more 
treatment-related deaths in the cisplatin/5-FU group (4.5\% in the cisplatin/5-FU group versus $0.7 \%$ in the FOLFOX group). Three-year OS was $19.9 \%$ [95\% confidence interval (CI) 10.8-31.0] in the FOLFOX group and 26.9\% (95\% Cl 16.9-37.8) in the cisplatin/5-FU group. Ruppert et al. $^{81}$ identified carboplatin-/paclitaxel-based chemotherapy, a regimen already used in SCC of the lower esophagus, as a useful alternative to the cisplatin-based regimen. Van Hagen et al. ${ }^{85}$ studied the role of neoadjuvant carboplatin AUC 2 and paclitaxel $50 \mathrm{mg} / \mathrm{m}^{2}$ for 5 weeks and concurrent RT (41.4 Gy in 23 fractions), followed by surgery in esophageal and esophagogastric junction SCC, adenocarcinoma and large-cell undifferentiated carcinoma and found a pathological complete response (pCR) in $49 \%$ of patients with SCC. There was only one treatment-related death among the patients $(\mathrm{N}=171)$ that were treated with neoadjuvant chemoradiation, which indicates the great tolerance of this regimen. Three-year OS in this group was 58\%, compared with $44 \%$ in the group that received surgery alone. Moreover, Blom et al. ${ }^{86}$ found in patients treated with chemoradiation before surgery, that the combination of carboplatin/paclitaxel/41.4 Gy had a lower percentage of treatment-related deaths (1.1\% versus $4.1 \%)$ and a comparable 3 -year OS rate (57\% versus $61 \%)$ compared with the cisplatin/5-FU/50.4 Gy regimen. Hence, low-dose cisplatin, FOLFOX and carboplatin/paclitaxel (especially in combination with a low RT dose of $41.4 \mathrm{~Gy}$ ) are useful alternatives to a high-dose cisplatin-based chemotherapy.

The role of epidermal growth factor receptor (EGFR), targeting therapy using cetuximab, an established radiosensitizer in $\mathrm{HNSCC}^{7}$ seems to be not that prominent in CEC. On the basis of the results of the SCOPE1 trial, a multicenter phase II/II trial, randomizing 258 patients between standard dCRT and dCRT combined with cetuximab, the use of cetuximab cannot be recommended due to treatment-limiting toxicity. ${ }^{79}$ Likewise, the randomized phase III RTOG 0436 trial that compared OS between patients treated with dCRT with or without cetuximab, ${ }^{87}$ and the COG trial, in which esophageal cancer patients who had progressed under chemotherapy were randomly assigned to either gefitinib or placebo, ${ }^{88}$ did not find an improvement in OS when an anti-EGFR target was added. This is in contrast to the study by Lorenzen et al., ${ }^{89}$ which was published before the SCOPE 1 trial, but included only 62 patients. They reported a $75 \%$ disease control rate in the group randomized to standard chemotherapy combined with cetuximab (CET-CF), compared with $57 \%$ in the group randomized to standard chemotherapy alone (CF). This study also found a difference in survival rates, with a median OS of 9.5 and 5.5 months for CET-CF and CF, respectively, and therefore concluded that the addition of cetuximab to standard chemotherapy might be a useful therapeutic approach in patients with advanced (metastatic) esophageal SCC. Recently, the subsequent phase III REAL3 trial had to be closed early due to a lack of efficacy. ${ }^{90}$ These findings seem to indicate that the use of cetuximab is not recommended in patients with CEC. 


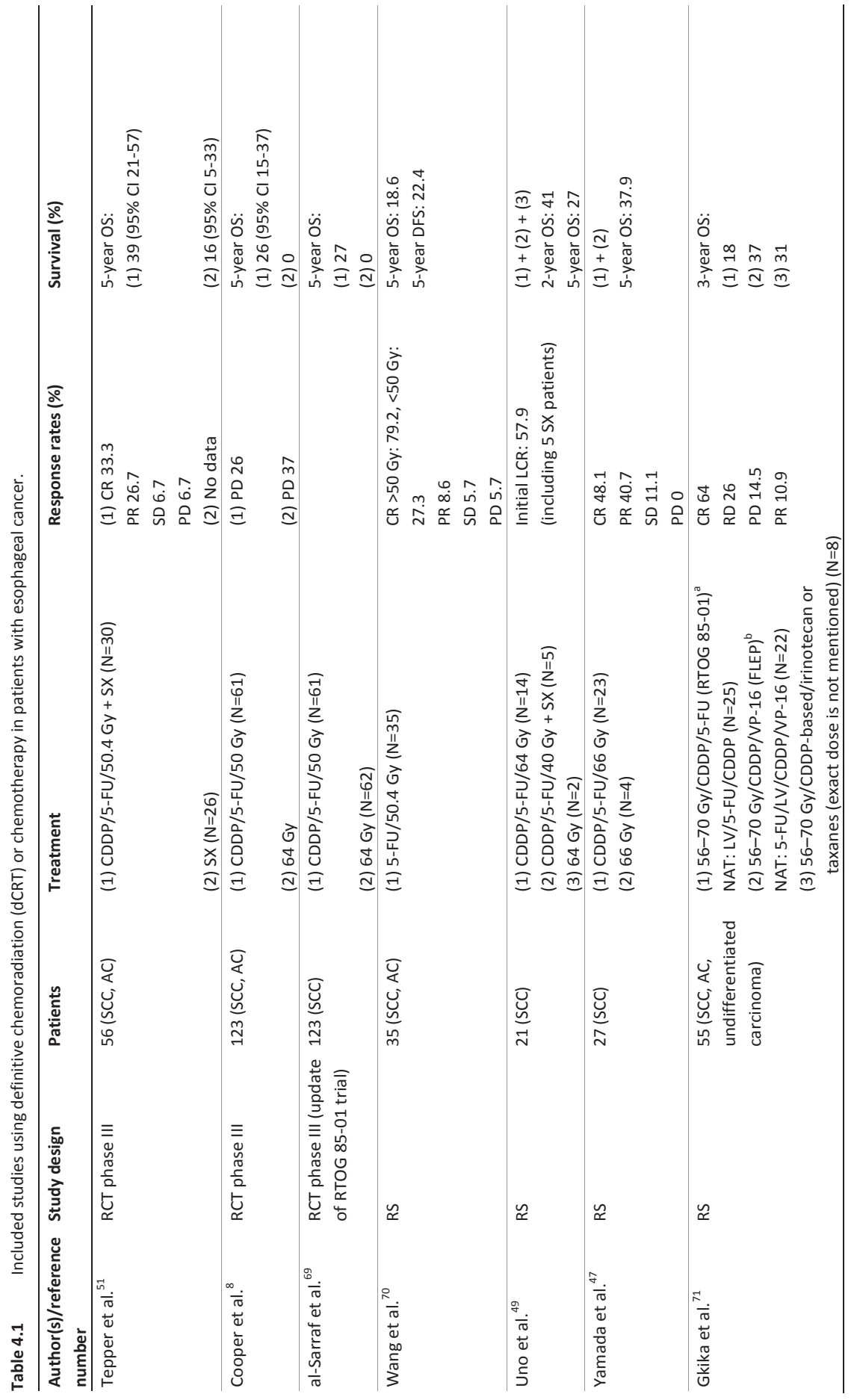




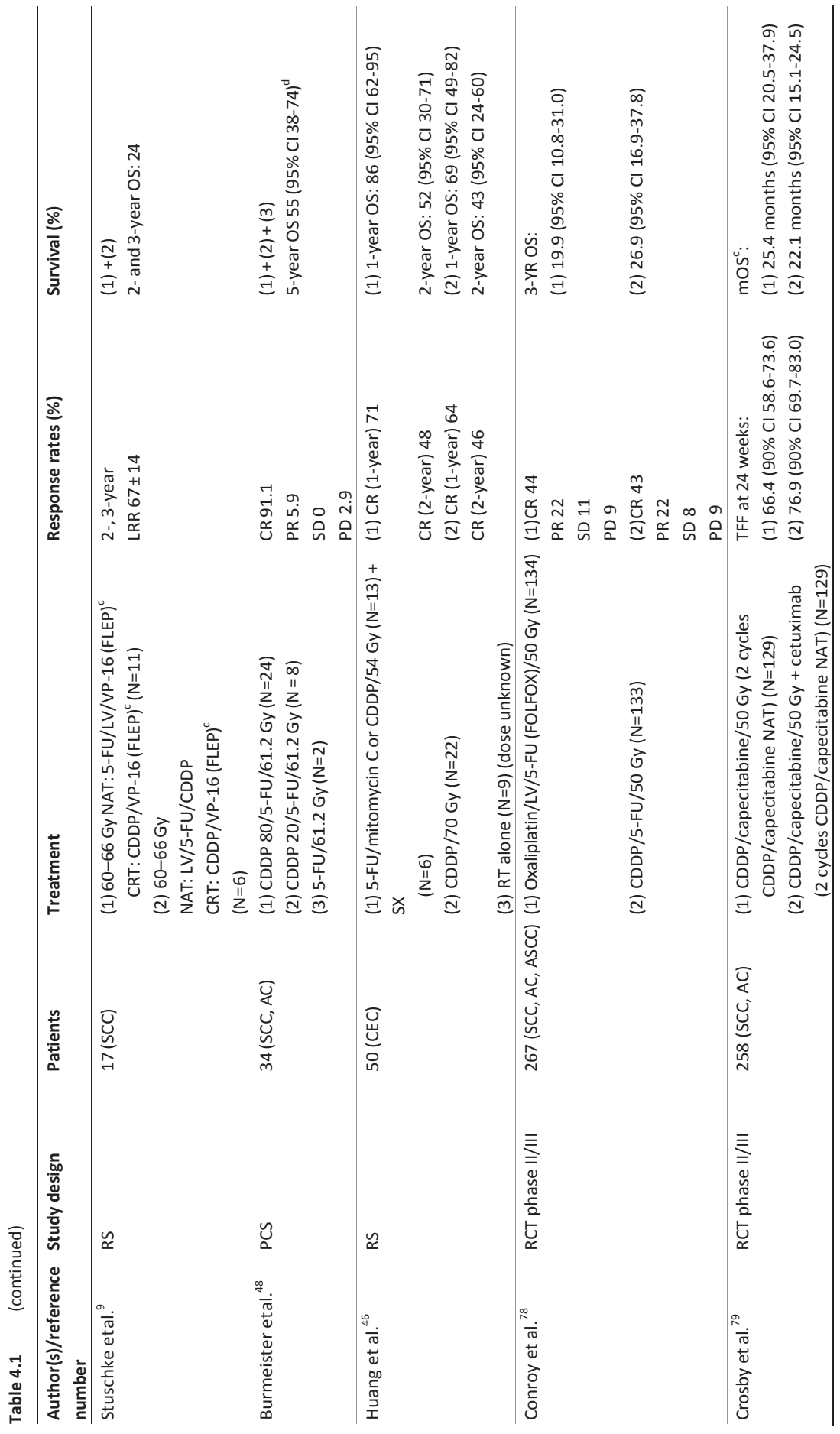




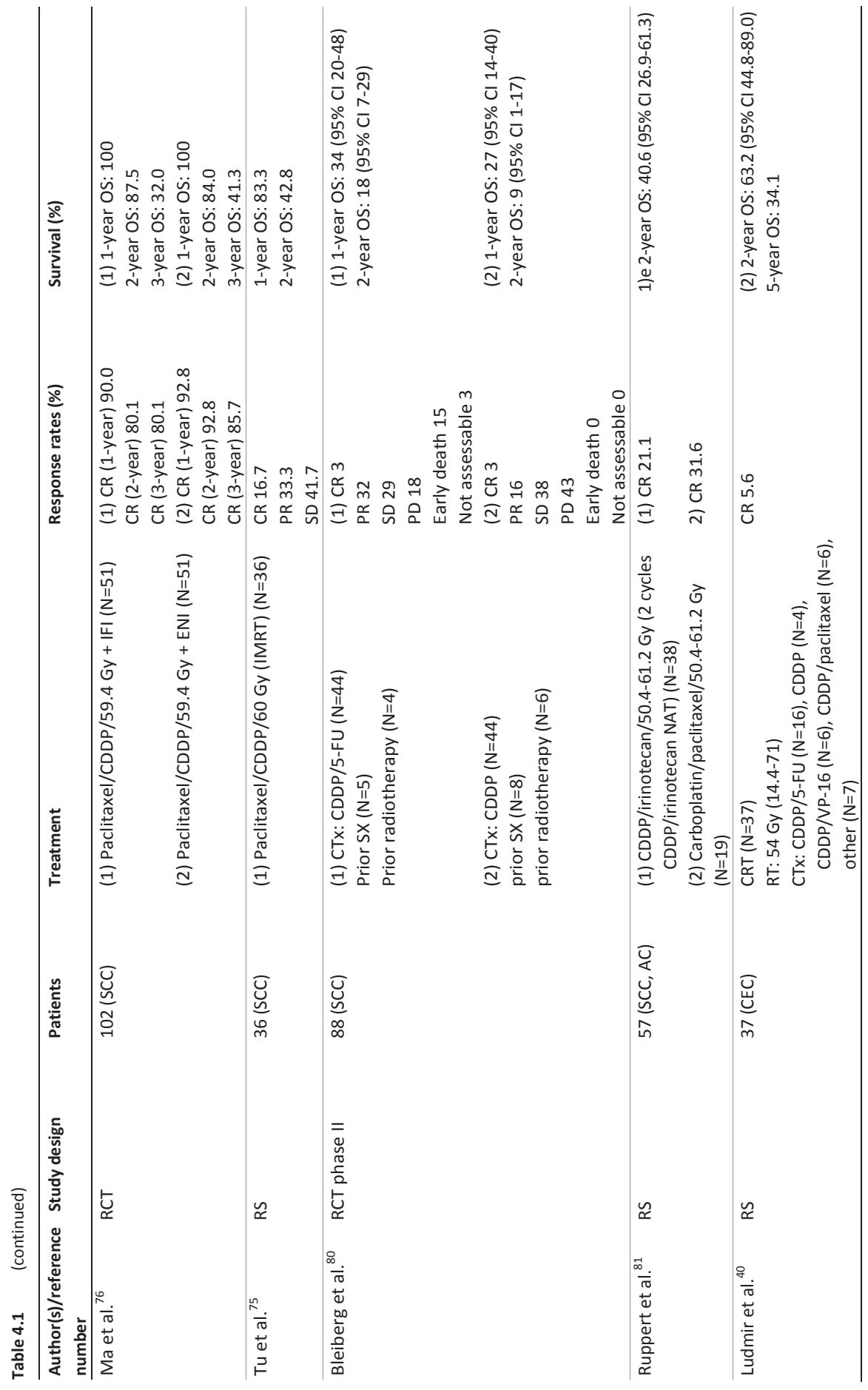




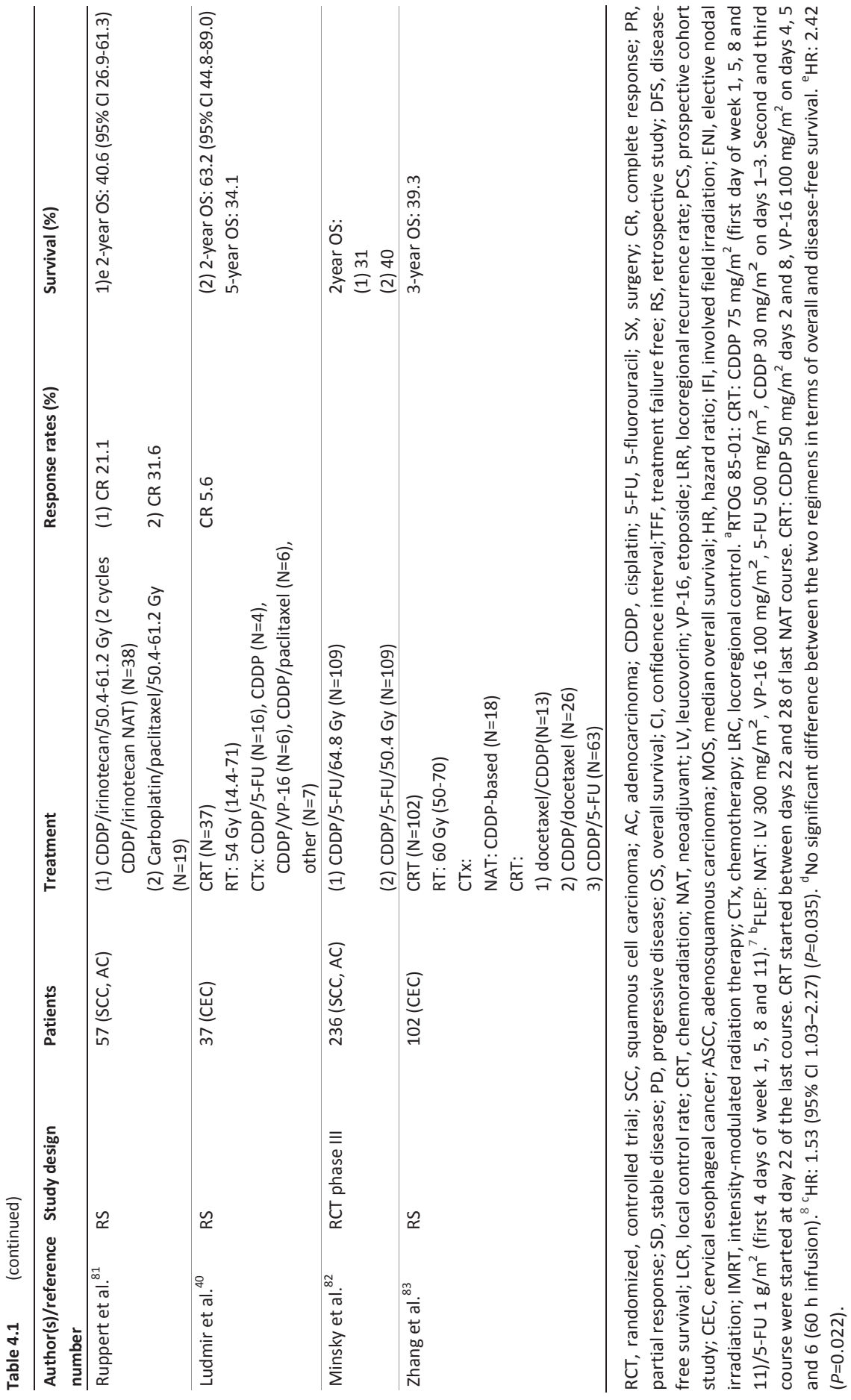




\section{RT used within concurrent treatment regimens for CEC}

The standard of care regarding dCRT for patients with esophageal cancer is $50.4 \mathrm{~Gy}$ with concurrent chemotherapy. In the case of CEC, there exists some tendency to increase the radiation dose of 60-70 Gy to the primary tumor and $\sim 40-45$ Gy to elective lymph node regions, analogous to the treatment of LAHNSCC. ${ }^{91}$ The randomized phase III INT-0123/RTOG 94-05 trial investigated the effect of dose escalation from 50.4 to $64.8 \mathrm{~Gy}$ of RT combined with chemotherapy in esophageal cancer from all anatomical locations. $^{82}$ There was no increase in survival or local/regional control for the high-dose arm. In CEC, there has been a tendency to use higher doses of radiation than the standard dose of $50.4 \mathrm{~Gy}$, up to 66-70 Gy. ${ }^{9,47,48,55,83,92}$ In retrospective studies, there are some indications that higher dose of radiation might be associated with improved outcome in esophageal cancer; Zhang et al. ${ }^{93}$ investigated local disease control and survival rates in patients with stage II-III esophageal cancer treated either with highdose RT (>51 Gy) or with low-dose RT ( $\leq 51 \mathrm{~Gy}$ ) and found a positive correlation between radiation dose and locoregional control rate and survival. Comparable results regarding the association between a higher radiation dose and survival were published by Sun. ${ }^{94}$ On the other hand, Huang et al. ${ }^{46}$ concluded that when using conventionally fractionated RT (70 Gy) rather than hypofractionated RT (54 Gy), the addition of prophylactic nodal RT and a change to high-dose cisplatin chemotherapy did not result in improved outcome in CEC patients. Currently, the ARTDECO study, in which differences in local tumor control, survival and grade 3 and 4 toxicity are measured between patients with inoperable esophageal cancer treated with a total RT dose of $61.6 \mathrm{~Gy}$ in combination with carboplatin/paclitaxel and in patients with similar tumor characteristics treated with a total RT dose of 50.4 Gy with the same concurrent chemotherapy regimen, is ongoing. ${ }^{95}$

Administering an adequate RT dose to the tumor is often challenging because of the close proximity of the cervical esophagus to vital structures such as the spinal cord and lungs. Modern RT techniques, such as intensity-modulated radiation therapy (IMRT) and simultaneous integrated boost (SIB), in which the intensity of the radiation can be changed during treatment, enable a higher dose to the tumor and a reduced dose to adjacent structures. Studies suggest that these techniques may be useful in the treatment of CEC. ${ }^{75,91,96,97}$ Volume-modulated arc RT, a rotational radiation treatment technique, allows to deliver a more conformal dose to the tumor and improved sparing of nearby organs at risk, providing an alternative CEC treatment option. ${ }^{98,99}$

No consensus has been reached so far regarding elective lymph node irradiation (ENI). According to some authors, the omission of ENI did not have a significant effect on the failure rate of non-irradiated lymph nodes and OS, but would delay cervical nodal 
progression, ${ }^{76,100,101}$ while others do recommend elective irradiation of neck and upper mediastinal lymph node stations. ${ }^{102-104}$ Patients who have not been treated with ENI might need salvage treatment more frequently than those treated with ENI. However, the latter group of patients might experience more frequently and more severe treatment-related toxicity, because of the larger radiation field. ${ }^{76,105}$ There are no guidelines recommending the treatment of paratracheal lymph nodes, despite the fact that the lymphatic drainage of the cervical esophagus is primarily to the paratracheal nodes and $43 \%$ of CEC patients have paratracheal lymph node metastases. ${ }^{106,107}$

\section{Local disease control rate and survival}

The local disease control rate depends mainly on the depth of tumor invasion, lymph node status and type of treatment. ${ }^{8,46,47,49,76,81}$ Locoregional recurrence rates in CEC patients treated with dCRT, range from $13.7 \%$ to $42 \%$ within $0-8.7$ years ${ }^{46,76,101}$ compared with $51 \%-74.1 \%$ within $0-4$ years in patients treated with RT alone ${ }^{47,100}$ and $15.6 \%-48.6 \%$ within $0-15$ years in surgically treated patients. ${ }^{53,56,63,66}$

Local failure is an important prognostic factor for survival. Uno et al. ${ }^{49}$ found that after $\mathrm{dCRT}$, none of the patients with initial local failure as determined by endoscopic examination, survived more than 20 months compared with 2- and 5-year survival rates of $60 \%$ and $40 \%$, respectively, in patients with initial local control. Local recurrences can be treated by salvage surgery, which potentially has a high morbidity rate, but is the only chance for relatively long-term survival. ${ }^{108}$ Otherwise, palliative treatment options have to be considered.

Survival rates of patients with CEC remain poor, due to a delayed diagnosis, poor performance status of many patients, particularly anatomic characteristics of the viscera associated with high malignancy potential, frequent occurrence of locoregional and distant metastases and $12 \%-30 \%$ increased risk of synchronous or metachronous lesions. ${ }^{9,46,109}$ Yamada et al. ${ }^{47}$ found that performance status and tumor length $(\leq 6$ or $>6$ $\mathrm{cm}$ ) were factors that were significantly related to survival.

\section{Discussion and recommendations}

CEC is a very rare disease and often locally advanced at the time of diagnosis resulting in limited locoregional disease control and poor survival. Dysplasia is a known precursor lesion of SCC ${ }^{11-14}$ and can be diagnosed by endoscopic biopsy improving the detection of patients at high risk of malignant transformation. Detection of genetic changes could 
also be an effective manner of diagnosing early tumors, but unfortunately the molecular changes in CEC and its precursor lesions remain to be clarified.

Owing to the presence of locally advanced disease at the time of diagnosis and the cancer being close to vital structures such as the larynx, upper airway and spinal cord, non-surgical management seems to be the current preferred therapeutic option. Our review suggests that the best results with respect to locoregional disease control and survival can be achieved with dCRT, however, at the costs of higher incidence of toxicity compared with RT alone. Despite the introduction of $\mathrm{dCRT}$, survival rates remain relatively low and patients require optimal clinical support to retain food intake and exercise to maintain good quality of life and to achieve best patient outcome. ${ }^{110}$

Several different chemoradiation schedules and techniques have been investigated in the past, but no consensus has been reached regarding the optimal treatment for CEC patients. High-dose RT (60-70 Gy) and concurrent cisplatin, similar to the established treatment regimen in locally advanced head and neck SCC (HNSCC), could be an option; however, there is no level I evidence to support this approach. Although thoracic esophageal SCCs, defined by being localized caudal of the suprasternal notch, develop only few centimeters distal from cervical SCC, the commonly used dCRT schedule for thoracic esophageal SCCs consists of a lower radiation dose (50.4 Gy) combined with cisplatin/5-fluorouracil (5-FU), oxaliplatin/5-FU or carboplatin/paclitaxel regimen. ${ }^{6} \mathrm{~A}$ possible rationale for the use of a lower radiation dose is the very close proximity of vital structures in the mediastinum and the lungs. In the CROSS study on preoperative chemoradiation, Van Hagen et al. $^{85}$ found a pCR of $49 \%$ after neoadjuvant chemoradiation (41.4 Gy and concurrent carboplatin/paclitaxel) in esophageal SCC of which $2 \%$ were located in the proximal third of the esophagus. The study by Blom et al. ${ }^{86}$ suggests this regimen is as effective as dCRT consisting of an RT dose of $50.4 \mathrm{~Gy}$ and cisplatin/5-FU, and has a more favorable toxicity profile. ${ }^{86}$ Therefore, we could hypothesize that the currently used high radiation dose in CEC is potentially unnecessary as it does not seem to result in higher complete response (CR) rates and outcome in SCC of the lower esophagus. ${ }^{82}$ While the use of a high RT dose of $61.6 \mathrm{~Gy}$ concurrently with chemotherapy in patients with inoperable/unresectable esophageal cancer is currently studied in the ARTDECO study, ${ }^{95}$ it could also be of potential interest to study the effect of lower dose RT in CEC alone, which may be accompanied by lower toxicity rates.

However, high toxicity rates in CEC patients ${ }^{8,9}$ might not only be a result of a high radiation dose, but could also be an effect of a relatively large radiation field, ${ }^{105}$ especially when combined with concurrent chemotherapy. A reduction in toxicity rates may be expected by applying modern state-of-the-art radiation techniques like IMRT, lowering the dose to normal structures. However, the current literature is inconclusive; 
some studies propose that only an irradiation volume covering the gross volume is appropriate and accompanied with lower toxicity rates, ${ }^{76,100}$ while others recommend consideration of ENI, especially in the case of nodal stage N1 and higher. ${ }^{5,101}$ Given the reported incidence of metastases in surrounding lymph nodes ( $50 \%$ of all CECs), especially in the neck (levels II, III and the supraclavicular lymph nodes) and upper mediastinum, ${ }^{103,106}$ we recommend that ENI of cervical, supraclavicular and paratracheal lymph nodes should be considered in CEC invading the hypopharynx. In more distally located CEC, which are located close to the suprasternal notch, ENI of mediastinal and paratracheal lymph nodes should be considered. ${ }^{104}$ We anticipate that radiation techniques will improve in the near future enabling the discovery and use of newer techniques (e.g. dose painting, in which a non-uniform radiation dose distribution is applied to the target volume based on functional or molecular imaging), where only the radiation dose needed for adequate locoregional disease control is applied, hopefully minimizing the rate of adverse events.

With respect to systemic therapy, a cisplatin-based schedule is currently often used, since this has shown to be effective in the treatment of HNSCC. Current guidelines are inconclusive regarding the most adequate chemotherapy treatment regimen and cisplatin/5-FU, oxaliplatin/5-FU or carboplatin/paclitaxel are equally recommended. ${ }^{5}$ Since the combination of carboplatin and paclitaxel is proven to be effective with acceptable adverse event rates in the (neoadjuvant) treatment of lower esophageal SCC, ${ }^{81,85}$ future studies might want to compare the combination of carboplatin/ paclitaxel with current cisplatin-based schedules. When molecular profiles of CEC including driver oncogenes and potential therapeutic targets will become apparent, the use of targeted agents, e.g. as radiosensitizers, might become worthwhile to investigate in future clinical trials. Furthermore, future research should focus on identifying a dCRT design with adequate survival and acceptable toxicity rates. It is of clinical interest to establish whether CECs are best treated with head and neck cancer protocols or regimens established in lower esophageal SCC. As patients with CECs treated according to the head and neck cancer protocol have a worse prognosis compared with patients with $\mathrm{HNSCC}^{72,74,107}$ it could be interesting to study the potential underlying molecular differences between these two types of SCCs.

\section{Recommendations}

Future studies that focus on early detection of CEC precancerous conditions, molecular changes and on identification of biomarkers for detection of early disease or as targets for radiosensitizers would be desirable for the future. However, since CEC is rare in 
Western countries, it is improbable that screening will impact on this disease outside high-risk areas.

Taking the survival data and toxicity profiles of the different dCRT regimens in consideration, the optimal treatment regimen for CEC patients is not yet defined.

Future studies should focus on whether CEC is best treated according to a head and neck cancer or esophageal cancer protocol.

We recommend that ENI of cervical, supraclavicular and paratracheal lymph nodes should be considered.

Finally, one should be aware that patients will need optimal clinical support to retain food intake and exercise to optimize patient outcome and quality of life.

\section{Conclusion}

CEC remains unchartered territory for many practicing physicians. Treatment of cancers at this site is often difficult because of the cervical location and most tumors are locally advanced with invasion of surrounding vital structures. To improve survival outcome and reduce morbidity and mortality rates, future studies should focus on earlier detection of these cancers and improving treatment design by investigating innovative radiation schedules and identifying the optimal backbone of systemic therapy. 


\section{References}

1. Grass GD, Cooper SL, Armeson K et al. Cervical esophageal cancer: a population-based study. Head Neck 2015;37:808-14.

2. Davies L, Welch HG. Epidemiology of head and neck cancer in the United States. Otolaryngol Head Neck Surg 2006;135(3):451-7.

3. Lee DJ, Harris A, Gillette A et al. Carcinoma of the cervical esophagus: diagnosis, management, and results. South Med J 1984;77(11):1365-7.

4. Torre LA, Bray F, Siegel RL et al. Global cancer statistics, 2012. CA Cancer J Clin 2015;65(2):87-108.

5. National Comprehensive Cancer Network. Clinical practice guidelines in oncology (NCCN Guidelines). Esophageal and Esophagogastric Junction Cancers 2015. NCCN.org.

6. European Society for Medical Oncology: clinical practice guidelines, in Oesophageal cancer: ESMO Clinical Practice Guidelines for diagnosis, treatment and follow-up. Ann Oncol 2013;24(Suppl 6):vi51-6.

7. National Comprehensive Cancer Network. Clinical practice guidelines in oncology (NCCN Guidelines). Head and Neck Cancers 2015: NCCN.org.

8. Cooper JS, Guo MD, Herskovic A et al. Chemoradiotherapy of locally advanced esophageal cancer: longterm follow-up of a prospective randomized trial (RTOG 85-01). Radiation Therapy Oncology Group. JAMA 1999;281(17):1623-7.

9. Stuschke $\mathrm{M}$, Stahl M, Wilke $\mathrm{H}$ et al. Induction chemotherapy followed by concurrent chemotherapy and high-dose radiotherapy for locally advanced squamous cell carcinoma of the cervical oesophagus. Oncology 1999;57(2):99-105.

10. Popescu CR, Bertesteanu SV, Mirea D et al. The epidemiology of hypopharynx and cervical esophagus cancer. J Med Life 2010;3(4):396-401.

11. Taylor PR, Abnet CC, Dawsey SM. Squamous dysplasia-the precursor lesion for esophageal squamous cell carcinoma. Cancer Epidemiol Biomarkers Prev 2013;22(4):540-52.

12. Lewin KJ. Malignant and premalignant lesions of the esophagus. Keio J Med 1992;41(3):177-83.

13. Sugimachi K, Sumiyoshi K, Nozoe T et al. Carcinogenesis and histogenesis of esophageal carcinoma. Cancer 1995;75(6 Suppl):1440-5.

14. Qiu SL, Yang GR. Precursor lesions of esophageal cancer in high-risk populations in Henan Province, China. Cancer 1988;62(3):551-7.

15. Popescu B, Popescu CR, Grigore R et al. Morphology and morphopathology of hypopharyngoesophageal cancer. Rom J Morphol Embryol 2012;53(2):243-8.

16. Dawsey SM, Wang GQ, Weinstein WM et al. Squamous dysplasia and early esophageal cancer in the Linxian region of China: distinctive endoscopic lesions. Gastroenterology 1993;105(5):1333-40.

17. Shin D, Protano MA, Polydorides $A D$ et al. Quantitative analysis of high-resolution microendoscopic images for diagnosis of esophageal squamous cell carcinoma. Clin Gastroenterol Hepatol 2015;13(2): 272-9.e2.

18. Kaneko K, Katagiri A, Konishi $\mathrm{K}$ et al. Study of p53 gene alteration as a biomarker to evaluate the malignant risk of Lugol-unstained lesion with non-dysplasia in the oesophagus. Br J Cancer 2007;96(3): 492-8.

19. Carvalho R, Areia M, Brito D et al. Diagnostic accuracy of lugol chromoendoscopy in the oesophagus in patients with head and neck cancer. Rev Esp Enferm Dig 2013;105(2):79-83.

20. Xue LY, Hu N, Song YM et al. Tissue microarray analysis reveals a tight correlation between protein expression pattern and progression of esophageal squamous cell carcinoma. BMC Cancer 2006;6:296.

21. Wang LD, Hong JY, Qiu SL et al. Accumulation of p53 protein in human esophageal precancerous lesions: a possible early biomarker for carcinogenesis. Cancer Res 1993;53(8):1783-7.

22. Zhou Q, Dong Wang L, Du F et al. Changes of TGFbeta1 and TGFbetaRIl expression in esophageal precancerous and cancerous lesions: a study of a highrisk population in Henan, northern China. Dis Esophagus 2002;15(1):74-9.

23. Yang L, Wang LS, Chen XL et al. Hedgehog signaling activation in the development of squamous cell carcinoma and adenocarcinoma of esophagus. Int J Biochem Mol Biol 2012;3(1):46-57. 
24. Bai $P$, Xiao X, Zou J et al. Expression of p14(ARF), p15(INK4b), p16(INK4a) and skp2 increases during esophageal squamous cell cancer progression. Exp Ther Med 2012;3(6):1026-32.

25. Chen $H$, Wang LD, Guo $M$ et al. Alterations of $\mathrm{p} 53$ and PCNA in cancer and adjacent tissues from concurrent carcinomas of the esophagus and gastric cardia in the same patient in Linzhou, a high incidence area for esophageal cancer in northern China. World J Gastroenterol 2003;9(1):16-21.

26. Kimos MC, Wang S, Borkowski $A$ et al. Esophagin and proliferating cell nuclear antigen (PCNA) are biomarkers of human esophageal neoplastic progression. Int J Cancer 2004;111(3):415-7.

27. Roye GD, Myers RB, Brown D et al. CD44 expression in dysplastic epithelium and squamous-cell carcinoma of the esophagus. Int J Cancer 1996;69(4):254-8.

28. Xia $\mathrm{M}$, Zhao $\mathrm{MQ}, \mathrm{Wu} \mathrm{K}$ et al. Investigations on the clinical significance of FOXP3 protein expression in cervical oesophageal cancer and the number of FOXP3+ tumour-infiltrating lymphocytes. J Int Med Res 2013;41(4):1002-8.

29. Yang YF, Li H, Xu XQ et al. An expression of squamous cell carcinoma antigen 2 in peripheral blood within the different stages of esophageal carcinogenesis. Dis Esophagus 2008;21(5):395-401.

30. Wu MY, Liang YR, Wu XY, Zhuang CX. Relationship between Egr-1 gene expression and apoptosis in esophageal carcinoma and precancerous lesions. World J Gastroenterol 2002;8(6):971-5.

31. Li QD, Li H, Wang MS et al. Multi-susceptibility genes associated with the risk of the development stages of esophageal squamous cell cancer in Feicheng County. BMC Gastroenterol 2011;11:74.

32. Yasuda $M$, Kuwano $H$, Watanabe $M$ et al. p53 expression in squamous dysplasia associated with carcinoma of the oesophagus: evidence for field carcinogenesis. Br J Cancer 2000;83(8):1033-8.

33. Montesano R, Hollstein M, Hainaut P. Genetic alterations in esophageal cancer and their relevance to etiology and pathogenesis: a review. Int J Cancer 1996;69(3):225-35.

34. Morita M, Saeki H, Mori M et al. Risk factors for esophageal cancer and the multiple occurrence of carcinoma in the upper aerodigestive tract. Surgery 2002;131(1 Suppl):S1-6.

35. Zhan C, Yan L, Wang L et al. Landscape of expression profiles in esophageal carcinoma by The Cancer Genome Atlas data. Dis Esophagus 2015; doi:10.1111/dote.12416.

36. Pandeya N, Williams G, Green AC et al. Alcohol consumption and the risks of adenocarcinoma and squamous cell carcinoma of the esophagus. Gastroenterology 2009;136(4):1215-24, e1-2.

37. Morita M, Kuwano $\mathrm{H}$, Nakashima $\mathrm{T}$ et al. Family aggregation of carcinoma of the hypopharynx and cervical esophagus: special reference to multiplicity of cancer in upper aerodigestive tract. Int J Cancer 1998;76(4):468-71.

38. van Gijssel HE, Schild LJ, Watt DL et al. Polycyclic aromatic hydrocarbon-DNA adducts determined by semiquantitative immunohistochemistry in human esophageal biopsies taken in 1985. Mutat Res 2004; 547(1-2):55-62.

39. Guo F, Liu Y, Wang $X$ et al. Human papillomavirus infection and esophageal squamous cell carcinoma: a case-control study. Cancer Epidemiol Biomarkers Prev 2012;21(5):780-5.

40. Ludmir EB, Palta M, Zhang $X$ et al. Incidence and prognostic impact of high-risk HPV tumor infection in cervical esophageal carcinoma. J Gastrointest Oncol 2014;5(6):401-7.

41. Syrjanen KJ. HPV infections and oesophageal cancer. J Clin Pathol 2002;55(10):721-8.

42. Nederlandse Vereniging van Maag-Darm-Leverartsen: richtlijn oesofaguscarcinoom. 2010; http://www.oncoline.nl/oesofaguscarcinoom (4 May 2016, date last accessed).

43. Laterza E, de Manzoni G, Guglielmi A et al. Endoscopic ultrasonography in the staging of esophageal carcinoma after preoperative radiotherapy and chemotherapy. Ann Thorac Surg 1999;67(5):1466-9.

44. Hermans R. Imaging of hypopharyngeal and cervical oesophageal cancer. Cancer Imaging 2004;4(1): 7-9.

45. Riedel M, Hauck RW, Stein HJ et al. Preoperative bronchoscopic assessment of airway invasion by esophageal cancer: a prospective study. Chest 1998;113(3):687-95.

46. Huang SH, Lockwood G, Brierley J et al. Effect of concurrent high-dose cisplatin chemotherapy and conformal radiotherapy on cervical esophageal cancer survival. Int J Radiat Oncol Biol Phys 2008:71(3): 735-40.

47. Yamada K, Murakami M, Okamoto $\mathrm{Y}$ et al. Treatment results of radiotherapy for carcinoma of the cervical esophagus. Acta Oncol 2006;45(8):1120-5. 
48. Burmeister BH, Dickie G, Smithers BM et al. Thirty-four patients with carcinoma of the cervical esophagus treated with chemoradiation therapy. Arch Otolaryngol Head Neck Surg 2000:126(2):205-8.

49. Uno $\mathrm{T}$, Isobe $\mathrm{K}$, Kawakami $\mathrm{H}$ et al. Concurrent chemoradiation for patients with squamous cell carcinoma of the cervical esophagus. Dis Esophagus 2007;20(1):12-8.

50. Archibald S, Young JE, Thoma A. Pharyngo-cervical esophageal reconstruction. Clin Plast Surg 2005; 32(3):339-46, vi.

51. Tepper J, Krasna MJ, Niedzwiecki D et al. Phase III trial of trimodality therapy with cisplatin, fluorouracil, radiotherapy, and surgery compared with surgery alone for esophageal cancer: CALGB 9781. J Clin Oncol 2008;26(7):1086-92.

52. Bottger T, Bumb P, Dutkowski $P$ et al. Carcinoma of the hypopharynx and the cervical oesophagus: a surgical challenge. Eur J Surg 1999;165(10):940-6.

53. Kadota $H$, Sakuraba M, Kimata $Y$ et al. Larynx-preserving esophagectomy and jejunal transfer for cervical esophageal carcinoma. Laryngoscope 2009;119(7):1274-80.

54. Cao Z, Ye Q, Qian X et al. End-to-end anastomosis after segmental esophagectomy for early stage cervical esophageal carcinoma. Ann Thorac Surg 2013;95(5):1815-7.

55. Tong DK, Law S, Kwong DL et al. Current management of cervical esophageal cancer. World J Surg 2011; 35(3):600-7.

56. Miyata H, Yamasaki M, Takahashi T et al. Larynx-preserving limited resection and free jejunal graft for carcinoma of the cervical esophagus. World J Surg 2013;37(3):551-7.

57. Shuangba $\mathrm{H}$, Jingwu $\mathrm{S}$, Yinfeng $\mathrm{W}$ et al. Complication following gastric pull-up reconstruction for advanced hypopharyngeal or cervical esophageal carcinoma: a 20-year review in a Chinese institute. Am J Otolaryngol 2011;32(4):275-8.

58. Sun F, Li X, Lei D et al. Surgical management of cervical esophageal carcinoma with larynx preservation and reconstruction. Int J Clin Exp Med 2014;7(9):2771-8.

59. Zhao D, Gao X, Guan L et al. Free jejunal graft for reconstruction of defects in the hypopharynx and cervical esophagus following the cancer resections. J Gastrointest Surg 2009;13(7):1368-72.

60. Cahow CE, Sasaki CT. Gastric pull-up reconstruction for pharyngo-laryngoesophagectomy. Arch Surg 1994;129(4):425-9; discussion 429-30.

61. Puttawibul P, Pornpatanarak C, Sangthong B et al. Results of gastric pull-up reconstruction for pharyngolaryngo-oesophagectomy in advanced head and neck cancer and cervical oesophageal squamous cell carcinoma. Asian J Surg 2004;27(3):180-5.

62. Wu JX, Yu L, Li JY et al. Gasless laparoscopically assisted transhiatal esophagectomy for upper esophageal carcinoma. Ann Surg Oncol 2015;22(3):1015-9.

63. Ott K, Lordick F, Molls $\mathrm{M}$ et al. Limited resection and free jejunal graft interposition for squamous cell carcinoma of the cervical oesophagus. Br J Surg 2009;96(3):258-66.

64. Adelstein DJ, Rice TW, Tefft $\mathrm{M}$ et al. Aggressive concurrent chemoradiotherapy and surgical resection for proximal esophageal squamous cell carcinoma. Cancer 1994;74(6):1680-5.

65. Chou SH, Li HP, Lee JY et al. Radical resection or chemoradiotherapy for cervical esophageal cancer? World J Surg 2010;34(8):1832-9.

66. Daiko H, Hayashi R, Saikawa $M$ et al. Surgical management of carcinoma of the cervical esophagus. J Surg Oncol 2007;96(2):166-72.

67. Ferahkose Z, Bedirli A, Kerem M et al. Comparison of free jejunal graft with gastric pull-up reconstruction after resection of hypopharyngeal and cervical esophageal carcinoma. Dis Esophagus 2008;21(4):340-5.

68. Kelley DJ, Wolf R, Shaha AR et al. Impact of clinicopathologic parameters on patient survival in carcinoma of the cervical esophagus. Am J Surg 1995;170(5):427-31.

69. al-Sarraf M, Martz K, Herskovic A et al. Progress report of combined chemoradiotherapy versus radiotherapy alone in patients with esophageal cancer: an intergroup study. J Clin Oncol 1997;15(1): 277-84.

70. Wang S, Liao Z, Chen Y et al. Esophageal cancer located at the neck and upper thorax treated with concurrent chemoradiation: a single-institution experience. J Thorac Oncol 2006;1(3):252-9.

71. Gkika E, Gauler T, Eberhardt W et al. Long-term results of definitive radiochemotherapy in locally advanced cancers of the cervical esophagus. Dis Esophagus 2014;27(7):678-84. 
72. Triboulet JP, Mariette C, Chevalier D, Amrouni H. Surgical management of carcinoma of the hypopharynx and cervical esophagus: analysis of 209 cases. Arch Surg 2001;136(10):1164-70.

73. Jiang $\mathrm{M}, \mathrm{He} \mathrm{X}, \mathrm{Wu} \mathrm{D}$ et al. Reconstruction techniques for hypopharyngeal and cervical esophageal carcinoma. J Thorac Dis 2015;7(3):449-54.

74. Wang HW, Chu PY, Kuo KT et al. A reappraisal of surgical management for squamous cell carcinoma in the pharyngoesophageal junction. J Surg Oncol 2006;93(6):468-76.

75. Tu L, Sun L, Xu Y et al. Paclitaxel and cisplatin combined with intensitymodulated radiotherapy for upper esophageal carcinoma. Radiat Oncol 2013;8:75.

76. Ma JB, Song YP, Yu JM et al. Feasibility of involved-field conformal radiotherapy for cervical and upperthoracic esophageal cancer. Onkologie 2011;34(11):599-604.

77. Wang SL, Liao Z, Liu H et al. Intensity-modulated radiation therapy with concurrent chemotherapy for locally advanced cervical and upper thoracic esophageal cancer. World J Gastroenterol 2006;12(34): 5501-8.

78. Conroy T, Galais MP, Raoul JL et al. Definitive chemoradiotherapy with FOLFOX versus fluorouracil and cisplatin in patients with oesophageal cancer (PRODIGE5/ACCORD17): final results of a randomised, phase 2/3 trial. Lancet Oncol 2014;15(3):305-14.

79. Crosby $\mathrm{T}$, Hurt CN, Falk $\mathrm{S}$ et al. Chemoradiotherapy with or without cetuximab in patients with oesophageal cancer (SCOPE1): a multicentre, phase 2/3 randomised trial. Lancet Oncol 2013;14(7): 627-37.

80. Bleiberg H, Conroy T, Paillot B et al. Randomised phase II study of cisplatin and 5-fluorouracil (5-FU) versus cisplatin alone in advanced squamous cell oesophageal cancer. Eur J Cancer 1997;33(8): 1216-20.

81. Ruppert BN, Watkins JM, Shirai K et al. Cisplatin/irinotecan versus carboplatin/paclitaxel as definitive chemoradiotherapy for locoregionally advanced esophageal cancer. Am J Clin Oncol 2010;33(4): 346-52.

82. Minsky BD, Pajak TF, Ginsberg RJ et al. INT 0123 (Radiation Therapy Oncology Group 94-05) phase III trial of combined-modality therapy for esophageal cancer: high-dose versus standard-dose radiation therapy. J Clin Oncol 2002;20(5):1167-74.

83. Zhang $\mathrm{P}, \mathrm{Xi} \mathrm{M}$, Zhao $\mathrm{L}$ et al. Clinical efficacy and failure pattern in patients with cervical esophageal cancer treated with definitive chemoradiotherapy. Radiother Oncol 2015;116(2): 257-61.

84. Cunningham D, Allum WH, Stenning SP et al. Perioperative chemotherapy versus surgery alone for resectable gastroesophageal cancer. N Engl J Med 2006;355(1):11-20.

85. van Hagen P, Hulshof MC, van Lanschot JJ et al. Preoperative chemoradiotherapy for esophageal or junctional cancer. N Engl J Med 2012;366(22):2074-84.

86. Blom RL, Sosef MN, Nap $M$ et al. Comparison of two neoadjuvant chemoradiotherapy regimens in patients with potentially curable esophageal carcinoma. Dis Esophagus 2014;27(4):380-7.

87. Ilson DH, Moughan J, Suntharalingam M et al. RTOG 0436: a phase III trial evaluating the addition of cetuximab to paclitaxel, cisplatin, and radiation for patients with esophageal cancer treated without surgery. J Clin Oncol 2014;32:5s (Suppl): abstr 4007.

88. Dutton SJ, Ferry DR, Blazeby JM et al. Gefitinib for oesophageal cancer progressing after chemotherapy (COG): a phase 3, multicentre, double-blind, placebo-controlled randomised trial. Lancet Oncol 2014; 15(8):894-904.

89. Lorenzen S, Schuster T, Porschen R et al. Cetuximab plus cisplatin-5-fluorouracil versus cisplatin-5fluorouracil alone in first-line metastatic squamous cell carcinoma of the esophagus: a randomized phase II study of the Arbeitsgemeinschaft Internistische Onkologie. Ann Oncol 2009;20(10):1667-73.

90. Waddell T, Chau I, Cunningham D et al. Epirubicin, oxaliplatin, and capecitabine with or without panitumumab for patients with previously untreated advanced oesophagogastric cancer (REAL3): a randomised, open-label phase 3 trial. Lancet Oncol 2013;14(6):481-9.

91. Fu WH, Wang LH, Zhou ZM et al. Comparison of conformal and intensitymodulated techniques for simultaneous integrated boost radiotherapy of upper esophageal carcinoma. World J Gastroenterol 2004;10(8):1098-102.

92. Cao CN, Luo JW, Gao L et al. Intensity-modulated radiotherapy for cervical esophageal squamous cell carcinoma: clinical outcomes and patterns of failure. Eur Arch Otorhinolaryngol 2016;273(3):741-7. 
93. Zhang Z, Liao Z, Jin J et al. Dose-response relationship in locoregional control for patients with stage IIIII esophageal cancer treated with concurrent chemotherapy and radiotherapy. Int J Radiat Oncol Biol Phys 2005;61(3):656-64.

94. Sun DR. Ten-year follow-up of esophageal cancer treated by radical radiation therapy: analysis of 869 patients. Int J Radiat Oncol Biol Phys 1989;16(2):329-34.

95. Hulshof MCCM. A randomised trial of dose escalation in definitive chemoradiotherapy for patients with oesophageal cancer. http://www.trialregister.nl/trialreg/admin/rctview.asp?TC=3532 (4 May 2016, date last accessed).

96. Fenkell L, Kaminsky I, Breen S et al. Dosimetric comparison of IMRT vs. 3D conformal radiotherapy in the treatment of cancer of the cervical esophagus. Radiother Oncol 2008;89(3):287-91.

97. Zhu WG, Zhou K, Yu CH et al. Efficacy analysis of simplified intensity-modulated radiotherapy with high or conventional dose and concurrent chemotherapy for patients with neck and upper thoracic esophageal carcinoma. Asian Pac J Cancer Prev 2012;13(3):803-7.

98. Yin Y, Chen J, Xing L et al. Applications of IMAT in cervical esophageal cancer radiotherapy: a comparison with fixed-field IMRT in dosimetry and implementation. J Appl Clin Med Phys 2011;12(2): 3343.

99. Ma $\mathrm{P}$, Wang $\mathrm{X}, \mathrm{Xu} \mathrm{Y}$ et al. Applying the technique of volume-modulated arc radiotherapy to upper esophageal carcinoma. J Appl Clin Med Phys 2014;15(3):4732.

100. Zhao KL, Ma JB, Liu G et al. Three-dimensional conformal radiation therapy for esophageal squamous cell carcinoma: is elective nodal irradiation necessary? Int J Radiat Oncol Biol Phys 2010;76(2):446-51.

101. Liu M, Zhao K, Chen Y, Jiang GL. Evaluation of the value of ENI in radiotherapy for cervical and upper thoracic esophageal cancer: a retrospective analysis. Radiat Oncol 2014;9:232.

102. Li M, Liu Y, Fan B, Yu J. Determining the lymph node clinical target volume of upper esophageal carcinoma with computed tomography. Arch Biol Sci 2013;65(3):821-7.

103. Li M, Liu Y, Xu L et al. Computed tomography-based distribution of involved lymph nodes in patients with upper esophageal cancer. Curr Oncol 2015;22(3):e178-82.

104. Van De Voorde L, Larue RT, Pijls M et al. A qualitative synthesis of the evidence behind elective lymph node irradiation in oesophageal cancer. Radiother Oncol 2014;113(2):166-74.

105. Fukada J, Shigematsu N, Ohashi T et al. Pericardial and pleural effusions after definitive radiotherapy for esophageal cancer. J Radiat Res 2012;53(3):447-53.

106. Timon CV, Toner M, Conlon BJ. Paratracheal lymph node involvement in advanced cancer of the larynx, hypopharynx, and cervical esophagus. Laryngoscope 2003;113(9):1595-9.

107. Jones AS, Roland NJ, Hamilton J et al. Malignant tumours of the cervical oesophagus. Clin Otolaryngol Allied Sci 1996;21(1):49-53.

108. Schieman C, Wigle DA, Deschamps C et al. Salvage resections for recurrent or persistent cancer of the proximal esophagus after chemoradiotherapy. Ann Thorac Surg 2013;95(2):459-63.

109. Mariette C, Triboulet JP. Which treatment for squamous cell carcinoma of the pharyngoesophageal junction? J Surg Oncol 2006;94(3):175-7.

110. Fearon K, Strasser F, Anker SD et al. Definition and classification of cancer cachexia: an international consensus. Lancet Oncol 2011;12(5):489-95. 


\section{Supplemental material}

\section{Data Section 4.1}

Literature search strategy

\section{Pubmed}

1. Cervical esophageal cancer [Title/Abstract]

2. Cervical esophageal carcinoma [Title/Abstract]

3. Cancer of the cervical esophagus [Title/Abstract]

4. Cervical oesophageal cancer [Title/Abstract]

5. Cervical oesophageal carcinoma [Title/Abstract]

6. Cancer of the cervical oesophagus [Title/Abstract]

7. Proximal esophageal cancer [Title/Abstract]

8. Proximal esophageal carcinoma [Title/Abstract]

9. Cancer of the proximal esophagus [Title/Abstract]

10. Proximal oesophageal cancer [Title/Abstract]

11. Proximal oesophageal carcinoma [Title/Abstract]

12. Cancer of the proximal oesophagus [Title/Abstract]

13. Upper esophageal cancer [Title/Abstract]

14. Upper esophageal carcinoma [Title/Abstract]

15. Cancer of the upper esophagus [Title/Abstract]

16. Upper oesophageal cancer [Title/Abstract]

17. Upper oesophageal carcinoma [Title/Abstract]

18. Cancer of the upper oesophagus [Title/Abstract]

19. High esophageal carcinoma [Title/Abstract]

20. High esophageal cancer [Title/Abstract]

21. High oesophageal carcinoma [Title/Abstract]

22. High oesophageal cancer [Title/Abstract]

23. 1 or 2 or 3 or 4 or 5 or 6 or 7 or 8 or 9 or 10 or 11 or 12 or 13 or 14 or 15 or 16 or 17 or 18 or 19 or 20 or 21 or 22

24. Incidence

25. Incidence [Mesh Terms]

26. Epidemiology

27. Epidemiology [Mesh Terms]

28. 24 or 25

29. 26 or 27

30. Etiology 
31. Etiology [Subheading] [Mesh Terms]

32. 30 or 31

33. Risk factors

34. Risk factors [Mesh Terms]

35. 33 or 34

36. Diagnostics

37. Treatment

38. Therapy

39. Therapy [Subheading]

40. 37 or 38 or 39

41. Chemoradiation

42. Chemoradiotherapy

43. 41 or 42

44. Targeted therapy

45. Molecular targeted therapy [Mesh Terms]

46. 44 or 45

47. Survival rate

48. Survival rate [Mesh Terms]

49. 47 or 48

50. Toxicity

51. Toxicity [Subheading] [Mesh Terms]

52. 50 or 51

53. 23 AND (28 OR 29 OR 32 OR 35 OR 36 OR 40 OR 43 OR 46 OR 49 OR 52)

\section{Histology}

1. Esophageal cancer [Title/Abstract]

2. Oesophageal cancer [Title/Abstract]

3. Esophageal carcinoma [Title/Abstract]

4. Oesophageal carcinoma [Title/Abstract]

5. Cancer of the esophagus [Title/Abstract]

6. Cancer of the oesophagus [Title/Abstract]

7. 1 or 2 or 3 or 4 or 5 or 6

8. Histopathology

9. Squamous dysplasia

10. Precancerous condition

11. Precancerous lesion

12. 7 AND 8 AND 9 AND 10 AND 11 


\section{Web of Science}

(Cervical esophageal cancer OR cervical esophageal carcinoma OR cancer cervical esophagus OR cervical oesophageal cancer OR cervical oesophageal carcinoma OR cancer cervical oesophagus OR proximal esophageal cancer OR proximal esophageal carcinoma OR cancer proximal esophagus OR proximal oesophageal cancer OR proximal oesophageal carcinoma OR cancer proximal oesophagus OR upper esophageal cancer OR upper esophageal carcinoma OR cancer of upper esophagus OR upper oesophageal cancer OR upper oesophageal carcinoma OR cancer of upper oesophagus AND (incidence OR epidemiology OR etiology OR risk factors OR diagnostics OR treatment OR therapy OR chemoradiation OR chemoradiotherapy OR targeted therapy OR molecular targeted therapy OR survival rate OR toxicity)) [Title]

\section{Histology}

1. Esophageal cancer [Title]

2. Oesophageal cancer [Title]

3. Esophageal carcinoma [Title]

4. Oesophageal carcinoma [Title]

5. Cancer of the esophagus [Title]

6. Cancer of the oesophagus [Title]

7. 1 or 2 or 3 or 4 or 5 or 6

8. Histopathology

9. Squamous dysplasia

10. 7 AND 8 AND 9

\section{Embase}

((Cervical esophageal cancer OR cervical esophageal carcinoma OR cancer of the cervical esophagus OR cervical oesophageal cancer OR cervical oesophageal carcinoma OR cancer of cervical oesophagus OR proximal esophageal cancer OR proximal esophageal carcinoma OR cancer of proximal esophagus OR proximal oesophageal cancer OR proximal oesophageal carcinoma OR cancer of proximal oesophagus OR upper oesophageal cancer OR upper oesophageal carcinoma OR cancer of the upper oesophagus) AND (incidence OR epidemiology OR etiology OR risk factors OR diagnostics OR treatment OR therapy OR chemoradiation OR chemoradiotherapy OR targeted therapy OR molecular targeted therapy OR survival rate OR toxicity)) [Abstract] 


\section{Histology}

1. Esophageal cancer

2. Esophageal carcinoma

3. Cancer of the esophagus

4. Oesophageal cancer

5. Oesophageal carcinoma

6. Cancer of the oesophagus

7. 1 or 2 or 3 or 4 or 5 or 6

8. Histopathology

9. Squamous dysplasia

10. 7 AND 8 AND 9 


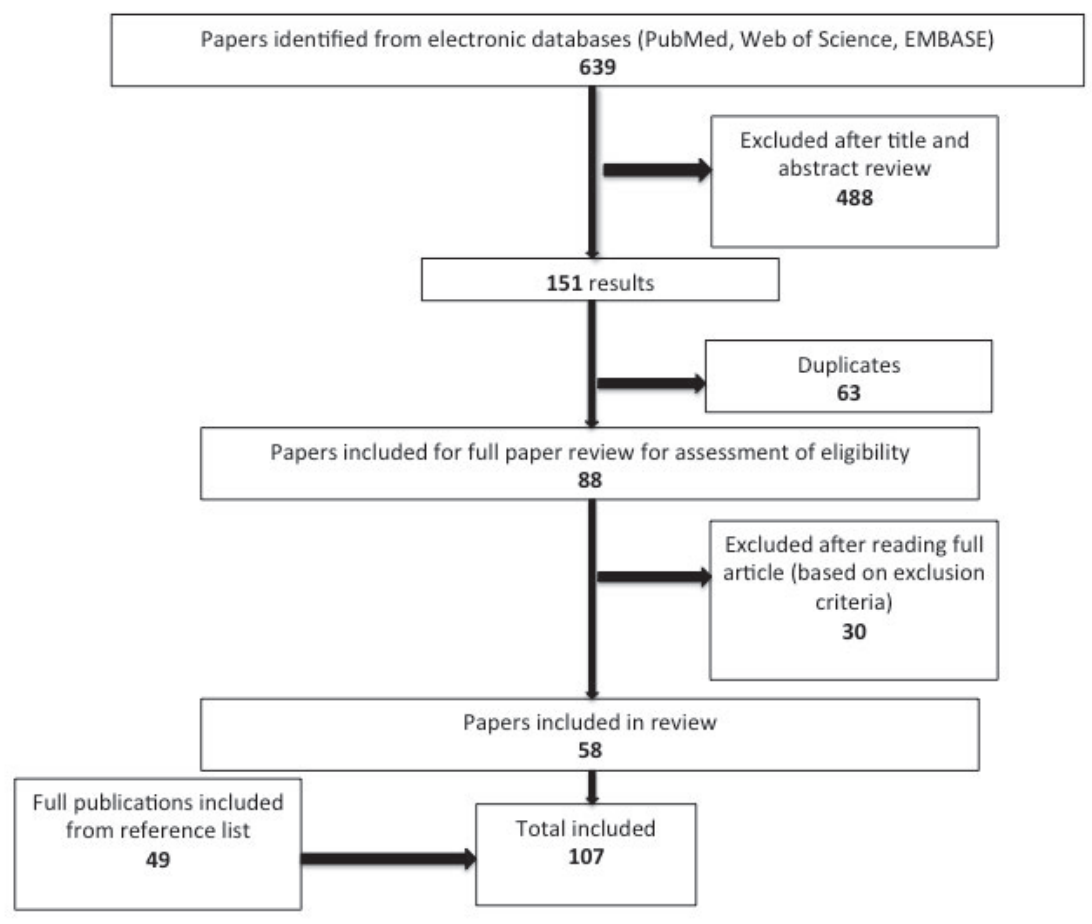

Figure S4.1 Flowchart literature search

Table S4.1 TNM staging $\left(7^{\text {th }}\right.$ edition) of esophageal squamous cell cancer $(\mathrm{SCC})^{1}$

\begin{tabular}{ll}
\hline Primary tumor $(T)^{\text {a }}$ & Primary tumor cannot be assessed \\
Tx & No evidence of primary tumor \\
T0 & High-grade dysplasia \\
Tis & Tumor invades lamina propria, muscularis mucosae or submucosa \\
T1 & Tumor invades lamina propria or muscularis mucosae \\
\multicolumn{1}{c}{ T1a } & Tumor invades submucosa \\
T1b & Tumor invades muscularis propria \\
T2 & Tumor invades adventitia \\
T3 & Tumor invades adjacent structures \\
T4 & Resectable tumor invading pleura, pericardium or diaphragm \\
T4a & Unresectable tumor invading adjacent structures, such as aorta, vertebral body, \\
T4b & trachea, etc. \\
& Regional lymph node(s) cannot be assessed \\
Regional lymph nodes (N) & \\
Nx & No regional lymph node metastasis \\
N0 & Metastasis in 1-2 regional lymph nodes \\
N1 & Metastasis in 3-6 regional lymph nodes \\
N2 & Metastasis in seven or more regional lymph nodes \\
N3 &
\end{tabular}


Table S4.1 (continued)

\begin{tabular}{|c|c|c|c|c|c|}
\hline \multicolumn{6}{|c|}{ Distant metastasis (M) } \\
\hline \multicolumn{2}{|l|}{ MO } & \multicolumn{4}{|c|}{ No distant metastasis } \\
\hline \multicolumn{2}{|l|}{ M1 } & \multicolumn{4}{|c|}{ Distant metastasis } \\
\hline \multicolumn{6}{|c|}{ Histologic grade (G) } \\
\hline \multicolumn{2}{|l|}{ Gx } & \multicolumn{4}{|c|}{ Grade cannot be assessed - stage grouping as G1 } \\
\hline \multicolumn{2}{|l|}{ G1 } & \multicolumn{4}{|c|}{ Well differentiated } \\
\hline \multicolumn{2}{|l|}{ G2 } & \multicolumn{4}{|c|}{ Moderately differentiated } \\
\hline \multicolumn{2}{|l|}{ G3 } & \multicolumn{4}{|c|}{ Poorly differentiated } \\
\hline \multicolumn{2}{|l|}{ G4 } & \multicolumn{4}{|c|}{ Undifferentiated - stage grouping as G3 squamous } \\
\hline \multicolumn{2}{|c|}{ Squamous cell carcinoma ${ }^{d}$} & & & & \\
\hline Stage & $\mathrm{T}$ & $\mathrm{N}$ & M & Grade & Tumor location $^{\mathrm{e}}$ \\
\hline 0 & Tis (HGD) & NO & Mo & $1, x$ & Any \\
\hline IA & $\mathrm{T} 1$ & NO & MO & $1, x$ & Any \\
\hline \multirow[t]{2}{*}{ IB } & $\mathrm{T} 1$ & NO & MO & $2-3$ & Any \\
\hline & $\mathrm{T} 2-3$ & NO & MO & $1, x$ & Lower, $\mathrm{x}$ \\
\hline \multirow[t]{2}{*}{ IIA } & T2-3 & NO & MO & $1, x$ & Upper, middle \\
\hline & $\mathrm{T} 2-3$ & NO & MO & $2-3$ & Lower, $x$ \\
\hline \multirow[t]{2}{*}{ IIB } & $\mathrm{T} 2-3$ & NO & MO & $2-3$ & Upper, middle \\
\hline & $\mathrm{T} 1-2$ & N1 & MO & Any & Any \\
\hline \multirow[t]{3}{*}{ IIIA } & $\mathrm{T} 1-2$ & N2 & MO & Any & Any \\
\hline & T3 & N1 & MO & Any & Any \\
\hline & T4 & NO & MO & Any & Any \\
\hline IIIB & T3 & N2 & MO & Any & Any \\
\hline \multirow[t]{3}{*}{ IIIC } & $\mathrm{T} 4 \mathrm{a}$ & N1-2 & MO & Any & Any \\
\hline & $\mathrm{T} 4 \mathrm{~b}$ & Any & $\mathrm{MO}$ & Any & Any \\
\hline & Any & N3 & $\mathrm{MO}$ & Any & Any \\
\hline IV & Any & Any & M1 & Any & Any \\
\hline
\end{tabular}

${ }^{a}$ At least maximal dimension of the tumor must be recorded and multiple tumors require the $T(m)$ suffix. ${ }^{b}$ HGD: high-grade dysplasia includes all noninvasive neoplastic epithelia that was formerly called carcinoma in situ, a diagnosis that is no longer used for columnar mucosae anywhere in the gastrointestinal tract. ${ }^{c}$ Number must be recorded for total number of regional nodes sampled and total number of reported nodes with metastasis. ${ }^{d}$ Or mixed histology including a squamous component or NOS. ${ }^{e}$ Location of the primary cancer site is defined by the position of the upper (proximal) edge of the tumor in the esophagus.

\section{Reference}

1. Sobin, L.H., M.K. Gospodarowicz, and C. Wittekind, The TNM Classification of Malignant Tumours, 7th Edition. 2009: Wiley-Blackwell. 336. 



\section{Abstract}

\section{Background}

Proximal esophageal cancer (EC) is commonly treated with definitive chemoradiation (CRT). The radiation dose and type of chemotherapy backbone are still under debate. The objective of this study was to compare the treatment outcomes of contemporary CRT regimens.

\section{Material and methods}

In this retrospective observational cohort study, we included patients with locally advanced squamous cell cancer of the proximal esophagus, from 11 centers in the Netherlands, treated with definitive CRT between 2004 and 2014. Each center had a preferential CRT regimen, based on cisplatin (Cis) or carboplatin-paclitaxel (CP) combined with low ( $\leq 50.4 \mathrm{~Gy}$ ) or high ( $>50.4 \mathrm{~Gy}$ ) dose radiotherapy (RT). Differences in overall survival (OS) between CRT regimens were assessed using a fully adjusted Cox proportional hazards and propensity score (PS) weighted model. Safety profiles were compared using a multilevel logistic regression model.

\section{Results}

Two hundred patients were included. Fifty-four, 39, 95, and 12 patients were treated with Cis-low-dose RT, Cis-high-dose RT, CP-low-dose RT, and CP-high-dose RT, respectively. Median follow-up was 62.6 months (95\% Cl: 47.9-77.2 months). Median OS (21.9 months; 95\% Cl: 16.9-27.0 months) was comparable between treatment groups (logrank $p=0.88$ ), confirmed in the fully adjusted and PS weighted model ( $p>0.05)$. Grades 3-5 acute adverse events were less frequent in patients treated with CP-low-dose RT versus Cis-high-dose RT (OR 3.78; 95\% Cl: 1.31-10.87; $p=0.01$ ). The occurrence of grades 3-5 late toxicities was not different between treatment groups.

\section{Conclusion}

Our study was unable to demonstrate a difference in OS between the CRT regimens, probably related to the relatively small sample size. Based on the superior safety profile, carboplatin and paclitaxel-based CRT regimens are preferred in patients with locally advanced proximal EC. 


\section{Introduction}

Ten percent of all esophageal cancers (ECS) are located in the proximal part of the esophagus, which consists of the cervical and upper thoracic segment. ${ }^{1}$ Proximal EC is challenging to treat due to the vicinity of vital structures including the larynx, cricoid, and trachea, which are frequently infiltrated. Furthermore, patients with proximal EC often have locoregional lymph node metastases at the time of diagnosis. ${ }^{2}$ Most patients with proximal EC are thus being diagnosed at an unresectable stage. In others, surgical treatment would implicate mutilating resections, with a high risk of major complications and an extensive impact on a patient's quality of life. ${ }^{3-5}$

As shown in the Radiation Therapy Oncology Group (RTOG) 85-01 trial, a nonsurgical approach of definitive chemoradiation (CRT) provides a significant survival advantage over monomodality radiotherapy (RT) in patients with EC. ${ }^{6}$ Hence, CRT is the standard treatment modality in patients with proximal EC recommended by the National Comprehensive Cancer Network (NCCN) and European Society for Medical Oncology (ESMO). ${ }^{7,8}$ However, there are no data on the most effective CRT regimen in proximal EC. ${ }^{9}$ Hence, physicians use either established regimens for the treatment of head and neck squamous cell carcinoma (HNSCC) due to similarities in location, histology, and molecular features, ${ }^{10}$ or regimens used in the management of patients with lower EC. ${ }^{9}$ The most frequently used CRT regimen for HNSCC is 66-70 Gy RT, with concurrent cisplatin (Cis) at a minimum cumulative dose of $200 \mathrm{mg} / \mathrm{m}^{2}$ body surface intravenously in a 7-week treatment period. ${ }^{11,12}$

In EC, the radiation dose and type of chemotherapy backbone in CRT are still under debate. In the definitive CRT setting, radiation doses of 50-50.4 Gy are recommended to cancers originating in the esophagus. ${ }^{6-8}$ NCCN guidelines state that higher doses of RT (60-66 Gy) may be appropriate for cancers in the proximal esophagus, although sufficient data to substantiate this statement are lacking. ${ }^{7}$

Chemotherapy schemes containing $\mathrm{Cis}$ and 5-fluorouracil (5-FU) have long been the standard in CRT regimens for EC. ${ }^{6,8,13}$ CRT with paclitaxel plus 5-FU did not improve survival over Cis and 5-FU-based CRT. ${ }^{14}$ The CROSS trial ${ }^{15}$ demonstrated acceptable adverse event rates for carboplatin-paclitaxel (CP)-based pre-operative CRT in patients with EC, with a pathologic complete response rate of $49 \%$ in patients with squamous cell EC, which was higher than previously observed in Cis-5-FU regimens. ${ }^{16-18}$ These results have led to the use of $\mathrm{CP}$ in definitive CRT schedules. ${ }^{19}$

Accordingly, CRT regimens for EC with Cis or CP are recommended by the NCCN and ESMO. ${ }^{7,8}$ Results from a small comparative study in the definitive treatment of EC support implementing CP-based CRT, showing comparable survival and a more favorable safety profile in patients treated with $\mathrm{CP}$ compared with Cis-based CRT. ${ }^{20}$ 
However, this study did not include cervical EC, and only a minority of patients were treated with a radiation dose exceeding $50.4 \mathrm{~Gy}$. We hypothesized that patients with proximal EC treated with CP-based definitive CRT with low-dose RT have the best outcome in terms of adverse events, and comparable survival when compared with Cisbased and high-dose RT schemes.

We conducted a propensity-score weighted study to evaluate overall survival (OS) and safety of four contemporary CRT regimens in patients with proximal EC.

\section{Materials and methods}

This multicenter, retrospective, observational study was conducted in 11 centers in The Netherlands. Patients were eligible if they were 18 years of age or older, diagnosed with squamous cell cancer of the proximal esophagus (i.e. $<24 \mathrm{~cm}$ from incisor teeth ${ }^{21}$ ), stage $\mathrm{CT} 1 \mathrm{~N}+\mathrm{MO}$ or $\mathrm{CT} 2-4 \mathrm{NO}-3 \mathrm{MO}$, and started with CRT treatment with a curative intent, between January 2004 and December 2014. Tumor staging was performed according to the TNM 6th or 7th edition based on date of diagnosis. ${ }^{21,22}$ Patients with supraclavicular lymph node metastasis were included, as these lymph nodes were considered to be locoregional node metastasis. ${ }^{23}$ Patient informed consent was waived by the Medical Ethics Board azM/UM due to the retrospective nature of the study (METC 15-4-012). The study was approved by the scientific committee of the Dutch Upper Gl Cancer Group (DUCG), and the Dutch Head and Neck Oncology Cooperative Group (NWHHT 2017-01). The data that support the findings of this study are available from the corresponding author upon request.

\section{Treatment}

Patients received a CRT regimen consisting of cisplatin (Cis)-based chemotherapy with low (Cis-low-dose RT) or high (Cis-high-dose RT) dose RT, or carboplatin-paclitaxel (CP)based chemotherapy combined with low (CP-low-dose RT) or high (CP-high-dose RT) dose RT.

Cis-based chemotherapy included regimens with Cis $100 \mathrm{mg} / \mathrm{m}^{2}$ (day 1 ) administered at weeks 1, 4, and 7 of RT; Cis $6 \mathrm{mg} / \mathrm{m}^{2}$ daily during the first 25 fractions of RT; Cis $40 \mathrm{mg} / \mathrm{m}^{2}$ weekly during RT; or Cis $75 \mathrm{mg} / \mathrm{m}^{2}$ (day 1) plus $5-\mathrm{FU} 1 \mathrm{~g} / \mathrm{m}^{2}$ (days 1-4) at weeks 1 and 5 of RT with or without two additional courses on weeks 8 and 11 . CP regimens comprise carboplatin AUC2 and paclitaxel $50 \mathrm{mg} / \mathrm{m}^{2}$ administered weekly during the period of RT. 
RT groups were categorized into a low-dose group with a planned radiation dose above 41.4 Gy, as used in neoadjuvant schedules, and not exceeding $50.4 \mathrm{~Gy}$, and a high-dose group with a RT dose above $50.4 \mathrm{~Gy}$, in daily fractions of 1.8-2 Gy. Patients were treated by means of external-beam radiation, usually given with 4-6 MV photon linear accelerators. RT was given by a standard 3 or 4-field technique or by an intensitymodulated radiotherapy (IMRT) or volumetric modulated arc therapy (VMAT) technique depending on availability in the treatment period. Depending on local institutional policies, the Gross Tumor Volume (GTV) of the primary tumor was delineated on the planning-CT and expanded to a Clinical Target Volume (CTV) by a margin of up to $3 \mathrm{~cm}$ in craniocaudal direction. Involved lymph nodes were also delineated in the CT scan and expanded to a CTV. The peri-esophageal area at the level of the CTV was included to ensure inclusion of adjacent draining lymph nodes. In cervical EC (CEC), sometimes Elective Nodal Irradiation (ENI) was added to include parts of the (lower) neck levels. The CTV's were combined and expanded by a margin up to $1 \mathrm{~cm}$ into a Planning Target Volume (PTV). Radiation dose was prescribed to the PTV.

\section{Data collection}

All consecutive patients with proximal esophageal cancer and treated with definitive CRT were identified from the population-based Netherlands Cancer Registry. Next, we collected the data from the medical records of the Radiotherapy institutes and Medical Oncology and Surgical Oncology departments. Patient demographics, tumor characteristics, treatment details, tumor response, and vital status were collected retrospectively from the medical records. Data collection was performed between April 2017 and May 2018.

\section{Outcomes}

The primary endpoint was OS, defined as the period from start date of RT to the date of death from any cause, or censored at the date of last follow-up. Secondary endpoints included safety, and tumor response three months after completing CRT as assessed by the local study investigators by means of clinical investigation and/or imaging. Patients were generally examined in regular follow-up according to national guidelines at 4-8 weeks after completion of CRT, and every three months in the first year, with escalating interval up to five years or until death. Safety was scored by the study investigators using Common Terminology Criteria for Adverse Events (CTCAE) Version 4.0. ${ }^{24}$ Acute toxicity was defined as adverse events occurring during CRT or within 90 days after last radiation dose. Late toxicity was scored if the toxic event appeared at least 90 days after the end of therapy. 


\section{Statistical analyses}

Baseline characteristics were analyzed using the ANOVA test or Kruskal-Wallis test for continuous variables, and the Chi-squared test or Fisher exact test for categorical variables. Median follow-up was estimated using the inverse Kaplan-Meier method. OS was calculated by the Kaplan-Meier method. Differences in OS between the CRT regimens were determined using the logrank test, and univariably and multivariably in Cox proportional hazards regression models. OS analyses were performed based on an intention-to-treat analysis, i.e. all included patients, and a per-protocol analysis, including patients who completed treatment as planned, defined as undergoing all fractions of RT and all cycles of chemotherapy, excluding dose interruption or reductions.

For the multivariable analyses of OS, both a classical model as well as a post hoc propensity score (PS) weighted model were used, because the events per variable ratio was borderline for a classical model, i.e. eight (all variables considered) to twelve (multivariable model). ${ }^{25}$ Confounding factors included in the PS weighted model were age, gender, WHO performance status, comorbidity, cT stage, cN stage, tumor location and tumor length. Variables with $P<0.10$ in the univariable analysis were subsequently selected for the classical Cox regression analysis. Cis-low-dose RT was assigned as reference group, regarded as standard for definitive CRT regimen in EC. ${ }^{8}$ Considering the numbers of covariables, PS weighting was performed to balance the pretreatment covariable distributions of the different treatment groups. First, a PS for each patient was calculated by generalized boosted regression using the same variables as included in the univariable model. Four different stopping rules, based on summary statistics (i.e. maximum or mean) of absolute standardized bias or the Kolmogorov-Smirnov statistic which compare the means or the distributions of the covariates between treatment groups, $^{26,27}$ overlap between the groups, and the balance was investigated. After calculating the PS weights, they were used in a weighted survival analyses to calculate the effect of the different treatments on OS. Because of the small sample size of the CPhigh-dose RT group ( $\mathrm{N}=12$ ), sensitivity analyses were performed excluding this group.

Differences in response and (grades 3-5) adverse events were evaluated using the Chisquare test. Additionally, a multilevel (patients within centers) logistic regression analysis on grades 3-5 acute and late toxicity by definitive CRT regimen was performed, including calendar period and GTV (surrogate for RT field size) on patient level as confounding factors. Since causality of adverse events with either radiotherapy or chemotherapy could not be distinguished in most cases, no separate analysis of toxicity for treatment modality was performed. 


\section{Results}

In total, 200 patients were included. Fifty-four patients (26\%) underwent Cis-low-dose RT, 39 patients (19.5\%) Cis-high-dose RT, 95 patients (47.5\%) CP-low-dose RT, and 12 patients (6\%) CP-high-dose RT. Cis-based therapy was replaced by CP in most sites after 2010 (Supplementary Figure S5.1). Baseline characteristics are presented in Table 5.1. Median age was higher in the CP-low-dose RT group compared with the other groups $(P=0.02)$. Comorbidity frequencies were comparable between treatment groups $(P=0.27)$. Patients in the Cis-high-dose RT group had the lowest probability of completing CRT (59\%). In the CP-low-dose RT group, 93\% of the patients received $50.4 \mathrm{~Gy}$, and $98 \%$ in the Cis-low-dose RT group received $50-50.4$ Gy (data not shown). Six of the 67 patients with an incomplete response underwent salvage surgery.

Table 5.1 Baseline characteristics of 200 consecutive patients with proximal esophageal cancer treated with definitive chemoradiation (2004-2014).

\begin{tabular}{|c|c|c|c|c|c|}
\hline & $\begin{array}{c}\text { Cis-low-dose } \\
\text { RT }\end{array}$ & $\begin{array}{c}\text { Cis-high-dose } \\
\text { RT }\end{array}$ & $\begin{array}{c}\begin{array}{c}\text { CP-low-dose } \\
\text { RT }\end{array} \\
\mathrm{N}=95(47.5 \%)\end{array}$ & $\begin{array}{c}\text { CP-high-dose } \\
\text { RT } \\
\mathrm{N}=12(6 \%)\end{array}$ & $P$ value $^{\text {a }}$ \\
\hline Age at diagnosis & & & & & 0.02 \\
\hline Median, years (range) & $62(35-77)$ & $61(30-81)$ & $66(49-85)$ & $62(44-76)$ & \\
\hline$\geq 70$ years & $6(11 \%)$ & $6(15 \%)$ & $31(33 \%)$ & $3(25 \%)$ & \\
\hline Gender & & & & & 0.27 \\
\hline Male & $38(70 \%)$ & $22(56 \%)$ & $59(62 \%)$ & $10(83 \%)$ & \\
\hline WHO performance status & & & & & 0.55 \\
\hline 0 & $21(39 \%)$ & $12(31 \%)$ & $28(29 \%)$ & $4(33 \%)$ & \\
\hline 1 & $30(56 \%)$ & $20(51 \%)$ & $50(53 \%)$ & $8(67 \%)$ & \\
\hline $2-3$ & $2(4 \%)$ & $2(5 \%)$ & $8(8 \%)$ & 0 & \\
\hline Unknown & $1(2 \%)$ & $5(13 \%)$ & $9(10 \%)$ & 0 & \\
\hline Comorbidity & & & & & 0.27 \\
\hline Any & $30(56 \%)$ & $18(46 \%)$ & $61(64 \%)$ & $7(58 \%)$ & \\
\hline Cardiovascular & $13(24 \%)$ & $11(28 \%)$ & 31 (33\%) & $6(50 \%)$ & \\
\hline Pulmonary & $4(7 \%)$ & $6(15 \%)$ & $7(7 \%)$ & 0 & \\
\hline Previous malignancy & $12(22 \%)$ & $1(3 \%)$ & $23(24 \%)$ & $1(8 \%)$ & \\
\hline None & $24(44 \%)$ & $21(54 \%)$ & $34(36 \%)$ & $5(42 \%)$ & \\
\hline Tumor differentiation grade & & & & & 0.04 \\
\hline G1 & $3(6 \%)$ & $2(5 \%)$ & $4(4 \%)$ & 0 & \\
\hline $\mathrm{G} 2$ & $9(17 \%)$ & $12(31 \%)$ & $33(35 \%)$ & $4(33 \%)$ & \\
\hline G3 & $19(35 \%)$ & $11(28 \%)$ & $14(15 \%)$ & 0 & \\
\hline Gx & $23(43 \%)$ & $14(36 \%)$ & $44(46 \%)$ & $8(67 \%)$ & \\
\hline Clinical T stage & & & & & 0.20 \\
\hline T1-3 & $31(57 \%)$ & $22(56 \%)$ & $63(66 \%)$ & $6(50 \%)$ & \\
\hline T4 & $19(35 \%)$ & $9(23 \%)$ & $26(27 \%)$ & $5(42 \%)$ & \\
\hline Tx & $4(7 \%)$ & $8(21 \%)$ & $6(6 \%)$ & $1(8 \%)$ & \\
\hline
\end{tabular}


Table 5.1 (continued)

\begin{tabular}{|c|c|c|c|c|c|}
\hline & $\begin{array}{c}\begin{array}{c}\text { Cis-low-dose } \\
\text { RT }\end{array} \\
\mathrm{N}=54(26 \%)\end{array}$ & $\begin{array}{c}\begin{array}{c}\text { Cis-high-dose } \\
\text { RT }\end{array} \\
\mathrm{N}=39(19.5 \%)\end{array}$ & $\begin{array}{c}\begin{array}{c}\text { CP-low-dose } \\
\text { RT }\end{array} \\
\mathrm{N}=95(47.5 \%)\end{array}$ & $\begin{array}{c}\text { CP-high-dose } \\
\text { RT }\end{array}$ & $P$ value ${ }^{a}$ \\
\hline Clinical N stage & & & & & 0.47 \\
\hline NO & $17(31 \%)$ & $10(26 \%)$ & $27(28 \%)$ & $6(50 \%)$ & \\
\hline $\mathrm{N}+$ & $35(65 \%)$ & 27 (69\%) & $67(71 \%)$ & $6(50 \%)$ & \\
\hline $\mathrm{Nx}$ & $2(4 \%)$ & $2(5 \%)$ & $1(1 \%)$ & 0 & \\
\hline Tumor location & & & & & 0.03 \\
\hline Cervical (<18 cm) & $15(28 \%)$ & $21(54 \%)$ & $27(28 \%)$ & $4(33 \%)$ & \\
\hline Upper thoracic $(18-24 \mathrm{~cm})$ & $39(72 \%)$ & $18(46 \%)$ & $68(72 \%)$ & $8(67 \%)$ & \\
\hline GTV, $\mathrm{cm}^{3}$ & & & & & 0.11 \\
\hline Median (range) & $34.9(2.4-190.5)$ & $\begin{array}{c}39.5(10.3- \\
130.8)\end{array}$ & $31.5(6.8-142.0)$ & $\begin{array}{c}55.2(29.0- \\
106.0)\end{array}$ & \\
\hline Unknown & $16(30 \%)$ & $11(28 \%)$ & $9(10 \%)$ & $3(25 \%)$ & \\
\hline Radiation dose parameters & & & & & $<0.001$ \\
\hline $\begin{array}{l}\text { Median total radiation } \\
\text { dose applied, Gy (range) }\end{array}$ & $50.4(23.4-50.4)$ & $70.0(12.0-70.0)$ & $50.4(37.8-50.4)$ & $61.6(54-70.0)$ & \\
\hline $\begin{array}{l}\text { Median fraction dose, } \\
\text { Gy (range) }\end{array}$ & $1.8(1.8-2.0)$ & $2.0(1.8-2.8)$ & $1.8(1.8-2.5)$ & $2.0(1.8-2.2)$ & \\
\hline $\begin{array}{l}\text { Median number of applied } \\
\text { fractions (range) }\end{array}$ & $27(13-28)$ & $35(6-35)$ & $28(20-28)$ & $30(28-35)$ & \\
\hline CRT completed as planned & & & & & 0.24 \\
\hline Yes & $44(82 \%)$ & $23(59 \%)$ & $68(72 \%)$ & $10(83 \%)$ & \\
\hline No & $7(13 \%)$ & $14(36 \%)$ & $20(21 \%)$ & $2(17 \%)$ & \\
\hline Unknown & $3(6 \%)$ & $2(5 \%)$ & $7(7 \%)$ & 0 & \\
\hline RT completed as planned & & & & & 0.24 \\
\hline Yes & $53(98 \%)$ & $34(87 \%)$ & 89 (94\%) & $11(92 \%)$ & \\
\hline No & $1(2 \%)$ & $5(13 \%)$ & $5(5 \%)$ & $1(8 \%)$ & \\
\hline Unknown & 0 & 0 & $1(1 \%)$ & 0 & \\
\hline $\begin{array}{l}\text { Chemotherapy completed } \\
\text { as planned }\end{array}$ & & & & & 0.61 \\
\hline Yes & $44(82 \%)$ & $25(64 \%)$ & $69(73 \%)$ & $10(83 \%)$ & \\
\hline No & $7(13 \%)$ & $11(28 \%)$ & $19(20 \%)$ & $2(17 \%)$ & \\
\hline Unknown & $3(6 \%)$ & $3(8 \%)$ & $7(7 \%)$ & 0 & \\
\hline
\end{tabular}

Percentages may not add up to 100 because of rounding. ${ }^{a}$ Continuous variables are calculated with the ANOVA-test or Kruskal-Wallis test. Categorical variables are calculated with the Chi-squared test or Fisher exact test where needed. Cis-low-dose RT: cisplatin-based chemotherapy with low-dose RT; Cis-high-dose RT: cisplatin-based chemotherapy with high-dose RT; CP-low-dose RT: carboplatin/paclitaxel with low-dose RT; CP-high-dose RT: carboplatin/paclitaxel with high-dose RT; GTV: gross tumor volume as delineated on the CT scan used for radiation treatment planning; CRT: chemoradiation; RT: radiotherapy.

\section{Survival}

Median follow-up of all patients was 62.6 months (95\% confidence interval [Cl]: 47.977.2 months). During the study period, 139 deaths occurred including 96 (69\%) due to sequelae of the esophageal tumor, $6(4 \%)$ as a result of toxicity, 18 (13\%) due to other causes, and 19 (14\%) due to unknown causes. Median OS was 21.9 months $(95 \% \mathrm{Cl}$ : 
16.9-27.0 months) for the total population, and 21.9 (95\% Cl: $17.7-26.1$ months), 17.2 (95\% Cl: 0.0-48.1 months), 23.2 (95\% Cl: 15.6-30.8 months), and 15.7 (95\% Cl: 8.3-23.2 months) months in Cis-low-dose RT, Cis-high-dose RT, CP-low-dose RT, and CP-highdose RT groups, respectively (Figure 5.1, $P$ logrank=0.88). Three-year OS rates were $35 \%$ (95\% Cl: $22-48 \%$ ) in the Cis-low-dose RT group compared to $46 \%$ (95\% Cl: $30-61 \%)$, 40\% (95\% Cl: 30-50\%), and 33\% (95\% Cl: 10-59\%), in Cis-high-dose RT, CP-low-dose RT, and CP-high-dose RT group, respectively. Per-protocol analysis showed comparable results (Supplementary Figure S5.2, $P$ logrank=0.76).

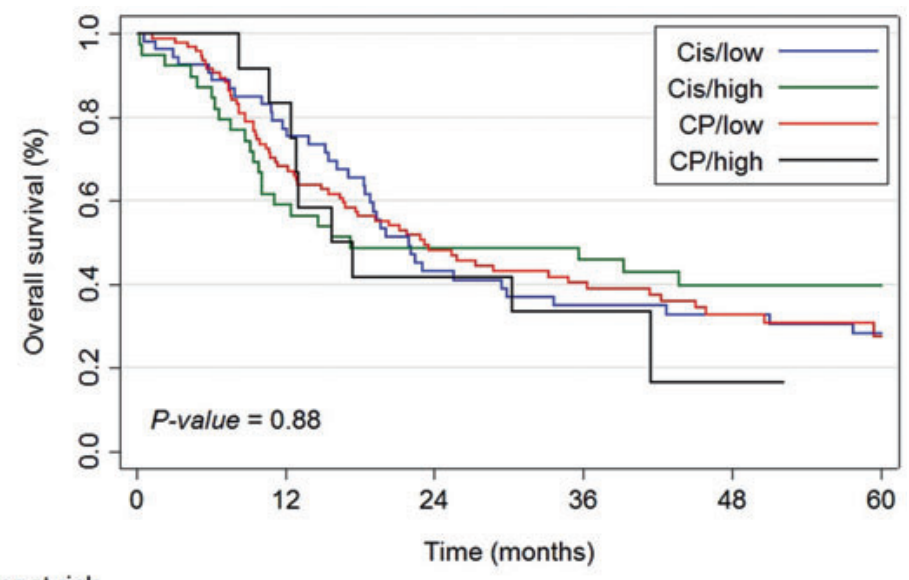

\begin{tabular}{|c|c|c|c|c|c|c|}
\hline \multirow{2}{*}{\multicolumn{7}{|c|}{ Number at risk }} \\
\hline & & & & & & \\
\hline Cis/low & 54 & 40 & 21 & 17 & 15 & 12 \\
\hline Cis/high & 39 & 23 & 18 & 16 & 12 & 9 \\
\hline CP/low & 95 & 63 & 40 & 29 & 18 & 9 \\
\hline $\mathrm{CP} /$ high & 12 & 10 & 5 & 4 & 1 & 0 \\
\hline
\end{tabular}

Figure 5.1 Kaplan-Meier curves for overall survival by treatment, intention-to-treat analysis. Cis/low: cisplatin and low-dose radiotherapy; Cis/high: cisplatin and high-dose radiotherapy; CP/low: carboplatin/paclitaxel and low-dose radiotherapy; CP/high: carboplatin/paclitaxel and highdose radiotherapy.

After correction for potential confounders, no difference in OS between the four treatment schemes was observed (Table 5.2). Male gender, WHO performance status 2-3, unknown $\mathrm{T}$ stage $(\mathrm{Tx})$, and $\mathrm{N}+$ stage were independent unfavorable prognostic factors for OS. OS was significantly higher in patients with tumors located in the upper thoracic segment compared to patients with cervical tumors [hazard ratio (HR) 0.60 , 95\% Cl: 0.42-0.86]. The PS weighted cox regression analysis showed no significant difference in OS between treatment groups. Sensitivity analyses excluding CP-high-dose RT group showed a better balance of the PSs and overlap between the groups, confirming that there were no statistically significant differences in OS. 
Univariable analysis showed no difference in OS between patients treated with Cisbased versus $C P$-based regimens $(P=0.81)$, or between low-dose versus high-dose RT $(P=0.64)$ (data not shown). Both patients with CEC or upper thoracic EC (UTEC) showed comparable OS between treatment groups $(P=0.90$ and $P=0.92$, respectively) (Supplementary Figure S5.3).

Table 5.2 Univariable and multivariable comparison of overall survival by four definitive chemoradiation regimens, and propensity score adjusted for overall survival.

\begin{tabular}{|c|c|c|c|c|c|c|}
\hline & \multicolumn{2}{|c|}{ Univariable } & \multicolumn{2}{|c|}{ Multivariable } & \multicolumn{2}{|c|}{ Propensity score weighted } \\
\hline & HR $(95 \% \mathrm{Cl})$ & $P$ value & $\mathrm{HR}(95 \% \mathrm{Cl})$ & $P$ value & $\mathrm{HR}(95 \% \mathrm{Cl})$ & $P$ value \\
\hline \multicolumn{7}{|l|}{$\begin{array}{l}\text { Definitive chemoradiation } \\
\text { regimen }\end{array}$} \\
\hline Cis-low-dose RT & Ref & & Ref & & Ref & \\
\hline Cis-high-dose RT & $1.05(0.65-1.71)$ & 0.84 & $1.05(0.62-1.79)$ & 0.86 & $1.00(0.57-1.78)$ & 0.99 \\
\hline CP-low-dose RT & $1.03(0.69-1.55)$ & 0.88 & $1.02(0.67-1.56)$ & 0.93 & $1.03(0.68-1.57)$ & 0.87 \\
\hline CP-high-dose RT & $1.33(0.66-2.68)$ & 0.43 & $1.32(0.64-2.72)$ & 0.45 & $1.65(0.83-3.25)$ & 0.15 \\
\hline Age at diagnosis & $1.00(0.98-1.02)$ & 0.93 & - & & NA & \\
\hline \multicolumn{7}{|l|}{ Gender } \\
\hline Male & Ref & & Ref & & NA & \\
\hline Female & $0.78(0.55-1.11)$ & 0.17 & $0.65(0.44-0.97)$ & 0.04 & NA & \\
\hline \multicolumn{7}{|l|}{ WHO performance status } \\
\hline 0 & Ref & & Ref & & NA & \\
\hline 1 & $1.16(0.80-1.68)$ & 0.44 & $1.22(0.83-1.80)$ & 0.32 & NA & \\
\hline $2-3$ & $1.94(0.97-3.87)$ & 0.06 & $2.56(1.18-5.60)$ & 0.02 & NA & \\
\hline Unknown & $1.13(0.57-2.25)$ & 0.73 & $1.57(0.76-3.28)$ & 0.23 & NA & \\
\hline \multicolumn{7}{|l|}{ Comorbidity } \\
\hline No comorbidity & Ref & & & & NA & \\
\hline Comorbidity & $1.04(0.74-1.45)$ & 0.83 & - & & NA & \\
\hline \multicolumn{7}{|l|}{ cT stage } \\
\hline $\mathrm{T} 1-3$ & Ref & & Ref & & NA & \\
\hline $\mathrm{T} 4$ & $1.44(0.99-2.09)$ & 0.06 & $1.35(0.90-2.03)$ & 0.15 & NA & \\
\hline Tx & $1.54(0.89-2.67)$ & 0.13 & $1.85(1.03-3.34)$ & 0.04 & NA & \\
\hline \multicolumn{7}{|l|}{ cN stage } \\
\hline NO & Ref & & Ref & & NA & \\
\hline $\mathrm{N}+$ & $1.32(0.92-1.91)$ & 0.14 & $1.69(1.13-2.53)$ & 0.01 & NA & \\
\hline $\mathrm{Nx}$ & $1.00(0.24-4.15)$ & 1.00 & $0.88(0.21-3.78)$ & 0.87 & NA & \\
\hline \multicolumn{7}{|l|}{ Tumor location } \\
\hline Cervical (<18 cm) & Ref & & Ref & & NA & \\
\hline Upper thoracic $(18-24 \mathrm{~cm})$ & $0.66(0.47-0.94)$ & 0.02 & $0.60(0.42-0.86)$ & 0.006 & NA & \\
\hline \multicolumn{7}{|l|}{ Tumor length } \\
\hline$\leq 5 \mathrm{~cm}$ & Ref & & - & & NA & \\
\hline$>5 \mathrm{~cm}$ & $1.16(0.74-1.80)$ & 0.52 & - & & NA & \\
\hline Obstruction or unknown & $1.37(0.93-2.01)$ & 0.11 & - & & NA & \\
\hline
\end{tabular}

Cis-low-dose RT: cisplatin-based chemotherapy with low-dose RT; Cis-high-dose RT: cisplatin-based chemotherapy with high-dose RT; CP-low-dose; RT: carboplatin/paclitaxel with low-dose RT; CP-high-dose RT: carboplatin/paclitaxel with high-dose RT; NA: not applicable. Bold font indicates significant prognostic factors of overall survival. 


\section{Tumor response}

Response to therapy was available in 196 patients (98\%) (Supplementary Table S5.1). Clinical complete response was achieved in $57 \%, 69 \%, 68 \%$, and $75 \%$ of patients in the Cis-low-dose RT, Cis-high-dose RT, CP-low-dose RT, and CP-high-dose RT group, respectively. The rate of complete response versus incomplete response was not significantly different between the groups $(P=0.72)$. The rate of partial response was comparable for the different regimens, varying between 18 and $25 \%$.

\section{Adverse events}

Grades 3 or 4 acute adverse events occurred in 22 (41\%), 19 (49\%), 21 (22\%), and 5 (42\%) patients in Cis-low-dose RT, Cis-high-dose RT, CP-low-dose RT, and CP-highdose RT group, respectively (Table 5.3). Dysphagia was the main contributor of grades 3 or 4 toxicity in all groups. The incidence of acute renal failure was higher in the Cisgroups compared with the CP-groups. Comparable rates of treatment-related deaths occurred in all four groups. In total, six patients died because of treatment-related adverse events, of which two patients during CRT and the remaining with an interval of 4.4-10.4 months after start of CRT. Three patients died from respiratory problems, one from esophageal stenosis, one from esophageal perforation, and one from esophageal fistulation. The incidence of grades 3-5 acute adverse events was significantly lower in patients treated with CP-low-dose RT compared to patients treated with one of other three regimens $(P=0.01)$. The multivariable multilevel analysis confirmed a significantly better safety profile in terms of acute toxicity of CP-low-dose RT versus Cis-high-dose RT (OR 3.78 (95\% Cl: 1.31-10.87); $P=0.01$ ), and a trend toward a favorable safety profile of CP-low-dose RT versus Cis-low-dose RT ( $P=0.10$, Table 5.4). The occurrence of grades 3-5 late toxicities was not different between treatment groups $(P=0.32)$, confirmed in multivariable analysis (Table 5.4). 


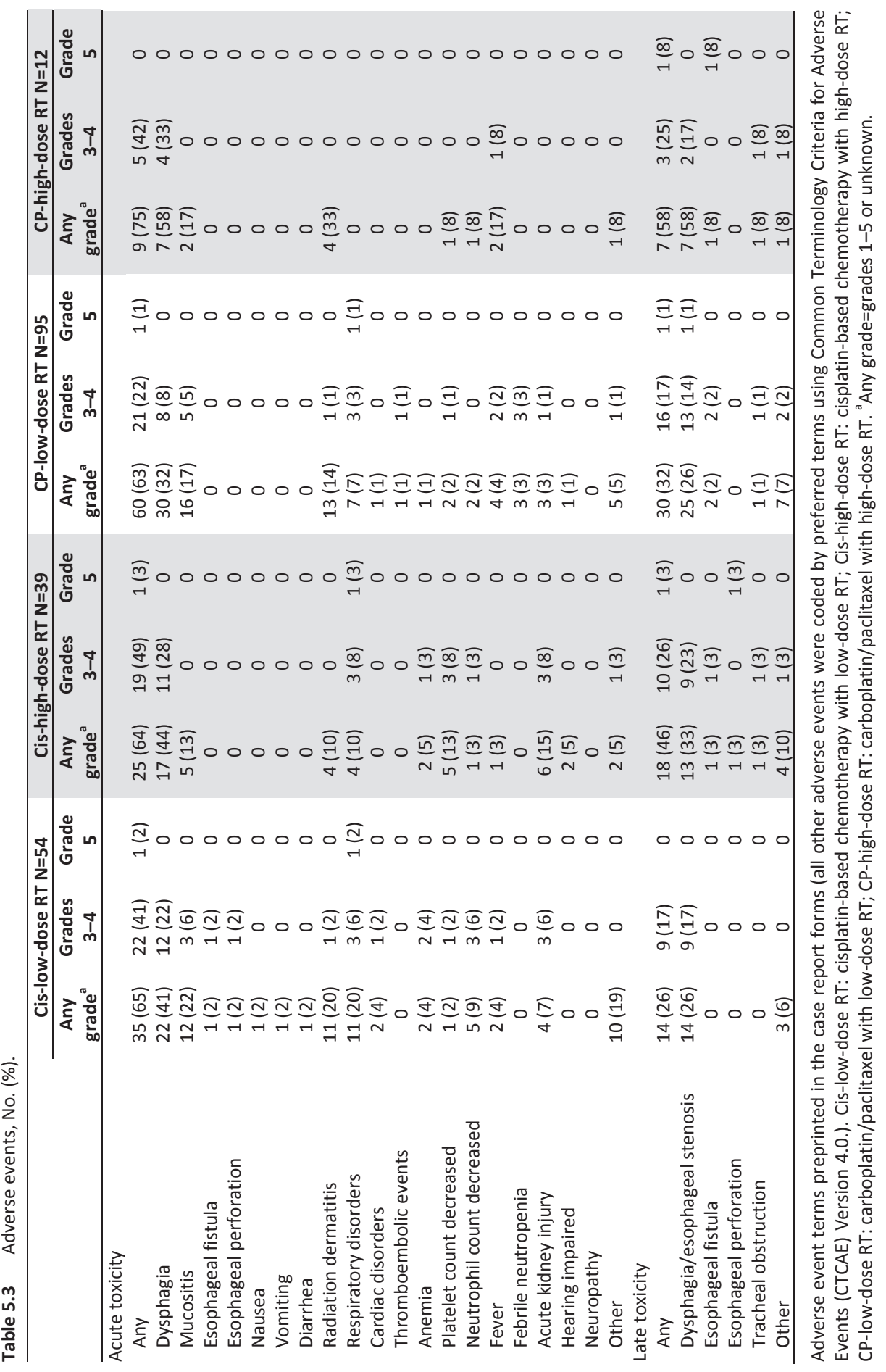


Table 5.4 Multivariable multilevel (patients within centers) analyses of grades 3-5 acute and late toxicity.

\begin{tabular}{|c|c|c|c|c|c|c|}
\hline & \multicolumn{3}{|c|}{ Grades $3-5$ acute tox } & \multicolumn{3}{|c|}{ Grades 3-5 late tox } \\
\hline & $\mathrm{N}(\%)$ & OR $(95 \% \mathrm{Cl})$ & $P$ value & $\mathbf{N}(\%)$ & OR $(95 \% \mathrm{Cl})$ & $P$ value \\
\hline \multicolumn{7}{|c|}{$\begin{array}{l}\text { Definitive chemoradiation } \\
\text { regimen }\end{array}$} \\
\hline Cis-low-dose RT & $23(43)$ & $2.43(0.83-7.08)$ & 0.10 & $9(17)$ & $0.87(0.30-2.53)$ & 0.80 \\
\hline Cis-high-dose RT & $20(51)$ & $3.78(1.31-10.87)$ & 0.01 & $11(28)$ & $1.62(0.58-4.53)$ & 0.36 \\
\hline CP-low-dose RT & $22(23)$ & Ref & & $17(18)$ & Ref & \\
\hline CP-high-dose RT & $5(42)$ & $2.41(0.52-11.1)$ & 0.26 & $4(33)$ & $1.96(0.48-8.03)$ & 0.35 \\
\hline \multicolumn{7}{|l|}{ Period } \\
\hline 2004-2006 & $6(21)$ & Ref & & $5(19)$ & Ref & \\
\hline 2007-2009 & $19(35)$ & 3.03 (0.89-10.35) & 0.08 & $15(29)$ & $1.78(0.52-6.14)$ & 0.36 \\
\hline 2010-2014 & 45 (39) & $5.64(1.66-19.16)$ & 0.01 & $21(18)$ & $1.06(0.30-3.70)$ & 0.92 \\
\hline \multicolumn{7}{|l|}{ GTV (tertiles), $\mathrm{cm}^{3}$} \\
\hline$\leq 25$ & $11(23)$ & Ref & & $4(9)$ & Ref & \\
\hline $26-42$ & $20(40)$ & $2.82(0.99-8.08)$ & 0.05 & $14(29)$ & 3.87 (1.13-13.27) & 0.03 \\
\hline$\geq 43$ & $22(35)$ & $1.77(0.65-4.81)$ & 0.27 & $13(22)$ & $2.64(0.76-9.12)$ & 0.13 \\
\hline Unknown & $17(44)$ & $2.49(0.73-8.45)$ & 0.14 & $10(26)$ & $3.83(0.95-15.46)$ & 0.06 \\
\hline
\end{tabular}

Cis-low-dose RT: cisplatin-based chemotherapy with low-dose RT; Cis-high-dose RT: cisplatin-based chemotherapy with high-dose RT; CP-low-dose RT: carboplatin/paclitaxel with low-dose RT; CP-high-dose RT: carboplatin/paclitaxel with high-dose RT. Bold font indicates significant prognostic factors of toxicity.

\section{Discussion}

Definitive CRT is the current standard of care in patients with proximal EC. ${ }^{7,8}$ Although there seems to be general consensus regarding the need for CRT, there is significant variation in the design of this multimodality therapy. In this study, no statistically significant difference in OS could be determined between four contemporary CRT regimens. A firm conclusion is however not possible due to the small sample size. However, CP showed a better safety profile compared with Cis-based groups.

Limited randomized series on CRT regimens in EC investigated either unknown numbers of proximal EC patients, ${ }^{28}$ or limited numbers of patients with proximal EC. ${ }^{29,30}$ A recent phase 3 trial in patients with EC treated with definitive CRT showed no significant difference in OS between paclitaxel plus 5-FU and Cis plus 5-FU. ${ }^{14}$ This led to the initiation of a phase 3 trial comparing paclitaxel plus cisplatin, CP, and paclitaxel plus 5-FU concurrent with RT for patients with EC (NCT02459457). No randomized trials have been published comparing Cis- versus CP-based CRT schemes in patients with EC. RT dose escalation (64.8 versus $50.4 \mathrm{~Gy}$ ) was evaluated in patients with EC in a randomized trial (INT-0123/RTOG 94-05). ${ }^{28}$ This trial was prematurely stopped when an interim analysis showed a higher treatment-related mortality rate in the high-dose RT arm. Yet, seven of the 11 deaths occurred in patients who actually had received $\leq 50.4 \mathrm{~Gy}$. A recent meta-analysis $(\mathrm{N}=3736)$ including the before mentioned RTOG 94-05 
trial and seven retrospective studies demonstrated better outcomes in patients with squamous cell EC treated with definitive CRT with high dose radiotherapy ( $\geq 60 \mathrm{~Gy}$ ) versus 45-59.4 Gy. ${ }^{31}$ However, this analysis excluded patients with incomplete dosage, receiving $<45 \mathrm{~Gy}$. In the era of modern $\mathrm{RT}$ techniques, dose escalation in CRT for EC has been investigated in 260 patients with EC by the randomized ARTDECO study, including 72 patients (28\%) with proximal EC. Radiation dose escalation up to 61.6 Gy versus $50.4 \mathrm{~Gy}$ to the primary tumor in CP-based CRT did not improve local control and OS. ${ }^{32}$ To the best of our knowledge, this is the largest study comparing Cis- versus CP-based CRT, with RT dose-escalation regimens in patients with proximal EC in a curative treatment approach. OS data in our cohort is consistent with results of previous observational studies in cervical or proximal EC exploring the effects of CRT, with 3-year OS rates of about 35-45\%. ${ }^{33-39}$ Recently, a small retrospective single institutional Korean study exploring the impact of radiation dose escalation on OS showed more favorable 3-year OS rates compared to the results in the current study, with $58 \%$ in the high-dose RT ( $\geq 59.4 \mathrm{~Gy}$ ) and $49 \%$ of patients in the low-dose RT group (<59.4 Gy, $P=0.69){ }^{40}$ However, this study excluded patients who had not completed treatment as planned. In line with our results, an analysis of 789 patients with CEC from the US Cancer Data Base demonstrated no association between radiation dose escalation and improved $0 S^{41}$ of note, they did not provide information on potential confounding factors, such as chemotherapeutic regimens and safety information. Furthermore, one Japanese phase 2 trial $^{42}$ was conducted in 2009-2013 in 30 patients with CEC to evaluate Cis-based high dose RT (60 Gy), demonstrating a remarkable 3-year OS of $67 \%$, compared with $46 \%$ observed in this study. However, this concerned a highly selected patient group with mostly early stage disease and excellent performance status. Interestingly, in this series one-third of the patients underwent salvage surgery. With a comparable complete response rate of $73 \%$, the higher 3 -year OS outcome suggests a possible role for salvage surgery in patients who fail to achieve a complete response.

Our study confirmed previous data concerning impaired treatment compliance in patients treated with Cis-based CRT. Honing et al. ${ }^{20}$ described that only $57 \%$ of patients with EC treated with Cis-based CRT completed treatment, comparable with $59 \%$ of patients treated with Cis-high-dose RT in our cohort. Remarkably, $82 \%$ of the patients in the current study undergoing Cis-low-dose RT were able to complete therapy. To help determine if non-adherence to Cis-high-dose RT was responsible for OS in this group, a separate per-protocol analysis was performed that included only patients who completed the assigned CRT schedule (Supplementary Figure S5.2). Despite this biased analysis, again no survival advantage of the Cis-high-dose RT group could be demonstrated. Premature treatment discontinuation was frequently a result of side effects. Considering this study was unable to provide survival differences between the 
four treatment groups, arguments for treatment choice might be based on the expected adverse event rates.

The safety profile of CP-low-dose RT group was more favorable than that of the Cisbased groups. One in five patients treated with CP-low-dose RT experienced grades 3 or 4 acute adverse events, whereas half of the patients treated in the other three groups did. In agreement, retrospective studies in primarily thoracic EC demonstrated that CPbased CRT was better tolerated compared with Cis-based CRT, again with comparable survival. ${ }^{20,43}$ The reported toxicity rates in the CP-based CRT groups in our study demonstrated higher treatment-related grade 3 or greater toxic event rates, as compared with data from the CP-based CRT group in the randomized neoadjuvant CROSS trial. ${ }^{15}$ Accordingly, we consider these toxicity data to be registered accurately. In addition, multilevel logistic regression showed that higher toxicity rates were registered in patients treated in the more recent years, independent of CRT regimen (Table 5.4). Hence, since CP-based regimens were more common in the contemporary era, and underreporting is expected to be higher in the older years (OR 5.64 (95\% Cl: 1.66-19.16) of grades 3-5 acute toxicity in 2010-2014 versus 2004-2006), the observed difference in toxicity between Cis- and CP-based regimens may in fact be larger than retrospectively observed in this study.

In addition to the more favorable toxicity profile, CP does not require inpatient protective hydration, in contrast to high-dose Cis. ${ }^{44}$ Moreover, health-related costs can be reduced by a shift to outpatient treatment, and as such CP-based regimens may be preferred for everyday clinical practice.

The strength of this study is that we included a relatively large number of patients with a rare disease. Since a randomized controlled trial in a disease with this low incidence is challenging, we provide the second best study design. Moreover, this study collected long-term follow-up data.

The retrospective design of this study is inherent with some limitations. The observational nature of the study makes it sensitive for bias, such as selection bias. However, correction for institution in multilevel logistic regression analysis did not alter the odds of the occurrence of grade 3-5 toxicities per treatment regimen. We were able to realize a fair sample size by including 200 patients with proximal EC. According to the European Society for Medical Oncology Magnitude of Clinical Benefit Scale (ESMOMCBS), a $H R \leq 0.70$ is defined as a clinically meaningful benefit for treatments that are not likely to be curative. ${ }^{45}$ Although in our study, the point estimates of the HR for the different regimens approximates one (suggesting a possible OS difference would be small), the $\mathrm{Cl}^{\prime}$ s include 0.70 , meaning that our study is not powered to state that there is no difference. We invite other institutions and countries to study this question as well, in order to perform a meta-analysis in the future. 
In conclusion, the small sample size of this study restricts a definitive conclusion regarding OS differences between the CRT regimens. Based on the superior safety profile, in addition to a more feasible outpatient implementation, we suggest a CRT regimen with carboplatin and paclitaxel in the curative setting for patients with proximal EC. 


\section{References}

1. van Putten M, de Vos-Geelen J, Nieuwenhuijzen GAP, et al. Longterm survival improvement in oesophageal cancer in the Netherlands. Eur J Cancer. 2018;94:138-47.

2. Grass GD, Cooper SL, Armeson K, et al. Cervical esophageal cancer: a population-based study. Head Neck. 2015;37(6):808-14.

3. Valmasoni M, Pierobon ES, Zanchettin G, et al. Cervical esophageal cancer treatment strategies: a cohort study appraising the debated role of surgery. Ann Surg Oncol. 2018;25(9):2747-55.

4. Takebayashi K, Tsubosa Y, Matsuda S, et al. Comparison of curative surgery and definitive chemoradiotherapy as initial treatment for patients with cervical esophageal cancer. Dis Esophagus. 2017:30(2):1-5.

5. Cao CN, Luo JW, Gao L, et al. Primary radiotherapy compared with primary surgery in cervical esophageal cancer. JAMA Otolaryngol Head Neck Surg. 2014;140(10):918-26.

6. Cooper JS, Guo MD, Herskovic A, et al. Chemoradiotherapy of locally advanced esophageal cancer: long-term follow-up of a prospective randomized trial (RTOG 85-01). Radiation Therapy Oncology Group. JAMA. 1999;281(17):1623-7.

7. National Comprehensive Cancer Network. NCCN GuidelinesVR. NCCN GuidelinesVR \& Clinical Resources 2018. Esophageal and Esophagogastric Junction Cancers (Version 2.2018) 2018 [updated May 22, 2018]. Available from: https://www.nccn.org/professionals/physician_gls/pdf/esophageal.pdf

8. Lordick F, Mariette C, Haustermans K, et al. Oesophageal cancer: ESMO Clinical Practice Guidelines for diagnosis, treatment and follow-up. Ann Oncol. 2016;27(suppl 5):v50-7.

9. Hoeben A, Polak J, Van De Voorde L, et al. Cervical esophageal cancer: a gap in cancer knowledge. Ann Oncol. 2016;27(9):1664-74.

10. The Cancer Genome Atlas Research Network. Integrated genomic characterization of oesophageal carcinoma. Nature. 2017;541(7636):169-75.

11. Pignon JP, Le Maitre A, Maillard E, et al. Meta-analysis of chemotherapy in head and neck cancer (MACH-NC): an update on 93 randomised trials and 17,346 patients. Radiother Oncol. 2009;92(1):4-14.

12. Strojan P, Vermorken JB, Beitler JJ, et al. Cumulative cisplatin dose in concurrent chemoradiotherapy for head and neck cancer: a systematic review. Head Neck. 2016;38(S1):E2151-8.

13. Herskovic A, Martz K, Al-Sarraf M, et al. Combined chemotherapy and radiotherapy compared with radiotherapy alone in patients with cancer of the esophagus. N Engl J Med. 1992;326(24): 1593-8.

14. Chen Y, Ye J, Zhu Z, et al. Comparing paclitaxel plus fluorouracil versus cisplatin plus fluorouracil in chemoradiotherapy for locally advanced esophageal squamous cell cancer: a randomized, multicenter, phase III clinical trial. JCO. 2019;37(20):1695-703.

15. van Hagen $\mathrm{P}$, Hulshof M, van Lanschot JJB, et al. Preoperative chemoradiotherapy for esophageal or junctional cancer. N Engl J Med. 2012;366(22):2074-84.

16. Bosset JF, Gignoux M, Triboulet JP, et al. Chemoradiotherapy followed by surgery compared with surgery alone in squamous-cell cancer of the esophagus. N Engl J Med. $1997 ; 337(3): 161-7$.

17. Tepper J, Krasna MJ, Niedzwiecki D, et al. Phase III trial of trimodality therapy with cisplatin, fluorouracil, radiotherapy, and surgery compared with surgery alone for esophageal cancer: CALGB 9781. JCO. 2008;26(7):1086-92.

18. Lee JL, Park SI, Kim SB, et al. A single institutional phase III trial of preoperative chemotherapy with hyperfractionation radiotherapy plus surgery versus surgery alone for resectable esophageal squamous cell carcinoma. Ann Oncol. 2004;15(6):947-54.

19. Jeene PM, van Laarhoven HWM, Hulshof M. The role of definitive chemoradiation in patients with nonmetastatic oesophageal cancer. Best Practice Res Clin Gastroenterol. 2018;36-37:53-9.

20. Honing J, Smit JK, Muijs CT, et al. A comparison of carboplatin and paclitaxel with cisplatinum and 5fluorouracil in definitive chemoradiation in esophageal cancer patients. Ann Oncol. 2014;25(3):638-43.

21. Greene FL, Balch Cm Haller Dg, et al. AJCC Cancer Staging Manual, 6th edn. New York: Springer-Verlag; 2002.

22. Edge SB. Byrd Dr, Compton CC. The AJCC Cancer Staging Manual. 7th edn. New York: Springer. 2010. 
23. Jeene PM, Versteijne E, van Berge Henegouwen MI, et al. Supraclavicular node disease is not an independent prognostic factor for survival of esophageal cancer patients treated with definitive chemoradiation. Acta Oncologica (Stockholm, Sweden. 2017;56(1):33-8.

24. U.S. Department of Health and Human Services. Common Terminology Criteria for Adverse Events (CTCAE), v4.03; 2009 [cited 2010 Jun 14]. Available from: https://evs.nci.nih.gov/ftp1/CTCAE/ CTCAE_4.03/CTCAE_4.03_2010-06-14_QuickReference_8.5x11.pdf

25. Biondi-Zoccai G, Romagnoli E, Agostoni P, et al. Are propensity scores really superior to standard multivariable analysis?. Contemp Clin Trials. 2011;32(5):731-40.

26. Burgette L, Griffin BA, McCaffrey D. Propensity scores for multiple treatments: a tutorial for the mnps function in the twang package. 2020. Available from: https://cran.r-project.org/web/packages/twang/ vignettes/mnps.pdf

27. McCaffrey DF, Griffin BA, Almirall D, et al. A tutorial on propensity score estimation for multiple treatments using generalized boosted models. Statist Med. 2013;32(19):3388-414.

28. Minsky BD, Pajak TF, Ginsberg RJ, et al. INT 0123 (Radiation Therapy Oncology Group 94-05) phase III trial of combinedmodality therapy for esophageal cancer: high-dose versus standard-dose radiation therapy. J Clin Oncol. 2002;20(5):1167-74.

29. Conroy T, Galais M-P, Raoul J-L, et al. Definitive chemoradiotherapy with FOLFOX versus fluorouracil and cisplatin in patients with oesophageal cancer (PRODIGE5/ACCORD17): final results of a randomised, phase 2/3 trial. The Lancet Oncol. 2014;15(3):305-14.

30. Crosby T, Hurt CN, Falk S, et al. Chemoradiotherapy with or without cetuximab in patients with oesophageal cancer (SCOPE1): a multicentre, phase $2 / 3$ randomised trial. The Lancet Oncol. 2013;14(7):627-37.

31. Luo HS, Huang HC, Lin LX. Effect of modern high-dose versus standard-dose radiation in definitive concurrent chemo-radiotherapy on outcome of esophageal squamous cell cancer: a metaanalysis. Radiat Oncol. 2019;14(1):178.

32. Hulshof M, Geijsen D, Rozema T, et al. A randomized controlled phase III multicenter study on dose escalation in definitive chemoradiation for patients with locally advanced esophageal cancer: ARTDECO study. JCO. 2020;38(4_suppl):281. Abstract 281.

33. Huang SH, Lockwood G, Brierley J, et al. Effect of concurrent high-dose cisplatin chemotherapy and conformal radiotherapy on cervical esophageal cancer survival. Int J Radiat Oncol Biol Phys. 2008;71(3):735-40.

34. Zhang $P, X i M$, Zhao $L$, et al. Clinical efficacy and failure pattern in patients with cervical esophageal cancer treated with definitive chemoradiotherapy. Radiother Oncol. 2015;116(2):257-61.

35. Herrmann E, Mertineit N, De Bari B, et al. Outcome of proximal esophageal cancer after definitive combined chemo-radiation: a Swiss multicenter retrospective study. Radiat Oncol. 2017;12(1):97.

36. Gkika E, Gauler T, Eberhardt W, et al. Long-term results of definitive radiochemotherapy in locally advanced cancers of the cervical esophagus. Dis Esophagus. 2014;27(7):678-84.

37. Yamada K, Murakami M, Okamoto $\mathrm{Y}$, et al. Treatment results of radiotherapy for carcinoma of the cervical esophagus. Acta Oncologica (Stockholm, Sweden). 2006;45(8):1120-5.

38. Uno $\mathrm{T}$, Isobe $\mathrm{K}$, Kawakami $\mathrm{H}$, et al. Concurrent chemoradiation for patients with squamous cell carcinoma of the cervical esophagus. Dis Esophagus. 2007;20(1):12-8.

39. Ludmir EB, Palta M, Zhang X, et al. Incidence and prognostic impact of high-risk HPV tumor infection in cervical esophageal carcinoma. J Gastrointest Oncol. 2014;5(6):401-7.

40. Kim TH, Lee IJ, Kim Jh, et al. High-dose versus standard-dose radiation therapy for cervical esophageal cancer: retrospective singleinstitution study. Head Neck. 2019;41(1):146-53.

41. De B, Rhome R, Doucette J, et al. Dose escalation of definitive radiation is not associated with improved survival for cervical esophageal cancer: a National Cancer Data Base (NCDB) analysis. Dis Esophagus. 2017;30(4):1-10.

42. Zenda S, Kojima T, Kato K, et al. Multicenter phase 2 study of cisplatin and 5-fluorouracil with concurrent radiation therapy as an organ preservation approach in patients with squamous cell carcinoma of the cervical esophagus. Int J Rad Oncol Biol Phys. 2016;96(5):976-84.

43. Blom RL, Sosef MN, Nap M, et al. Comparison of two neoadjuvant chemoradiotherapy regimens in patients with potentially curable esophageal carcinoma. Dis Esophagus. 2014;27(4):380-7. 
44. Ozols RF, Corden BJ, Jacob J, et al. High-dose cisplatin in hypertonic saline. Ann Intern Med. 1984;100(1):19-24.

45. Cherny NI, Sullivan R, Dafni U, et al. A standardised, generic, validated approach to stratify the magnitude of clinical benefit that can be anticipated from anti-cancer therapies: the European Society for Medical Oncology Magnitude of Clinical Benefit Scale (ESMO-MCBS). Ann Oncol. 2017;28(11): 2901-5. 


\section{Supplemental material}

Table S5.1 Response rates, No. (\%).

\begin{tabular}{lcccc}
\hline & $\begin{array}{c}\text { Cis-low-dose RT } \\
(\mathrm{N}=54)\end{array}$ & $\begin{array}{c}\text { Cis-high-dose RT } \\
(\mathrm{N}=39)\end{array}$ & $\begin{array}{c}\text { CP-low-dose RT } \\
(\mathrm{N}=95)\end{array}$ & $\begin{array}{c}\text { CP-high-dose RT } \\
(\mathrm{N}=12)\end{array}$ \\
\hline Objective response & & & & \\
Complete response & $32(59)$ & $27(69)$ & $65(68)$ & $9(75)$ \\
Partial response & $10(19)$ & $7(18)$ & $22(23)$ & $3(25)$ \\
No response & $8(15)$ & $4(10)$ & $5(5)$ & 0 \\
Progressive disease & $1(2)$ & $1(3)$ & $3(3)$ & 0 \\
Not evaluable & $3(6)$ & 0 & 0 & 0 \\
\hline
\end{tabular}

Percentages may not add up to 100 because of rounding. Cis-low-dose RT, cisplatin-based chemotherapy with low-dose RT; Cis-high-dose RT, cisplatin-based chemotherapy with high-dose RT; CP-low-dose RT, carboplatin/paclitaxel with low-dose RT; CP-high-dose RT, carboplatin/paclitaxel with high-dose RT. 

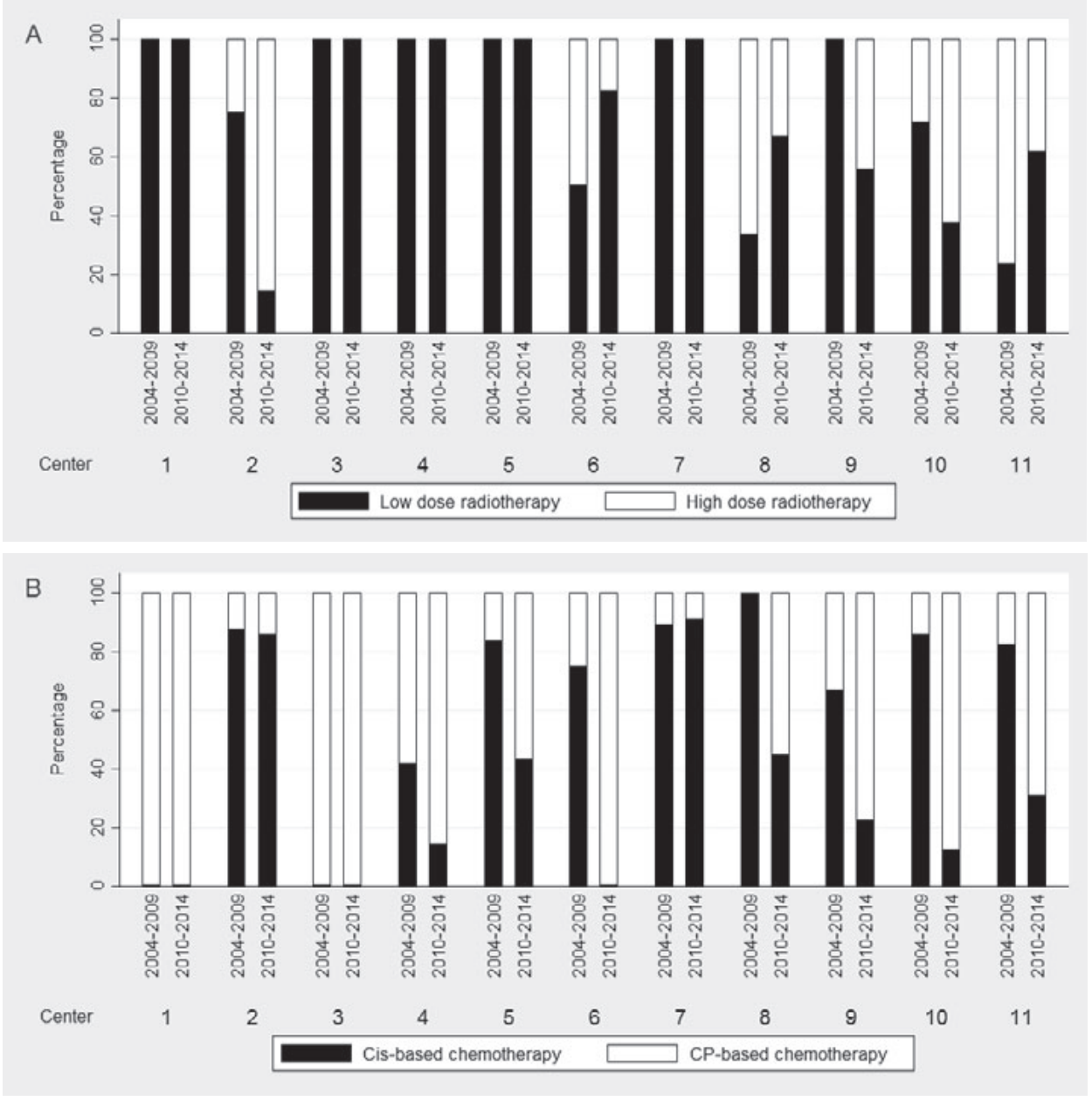

Figure S5.1 Distribution of treatment strategy in the individual centers between 2004 and 2009, and 2010 and 2014. Plots show radiation dose (A) and chemotherapy backbone (B). 


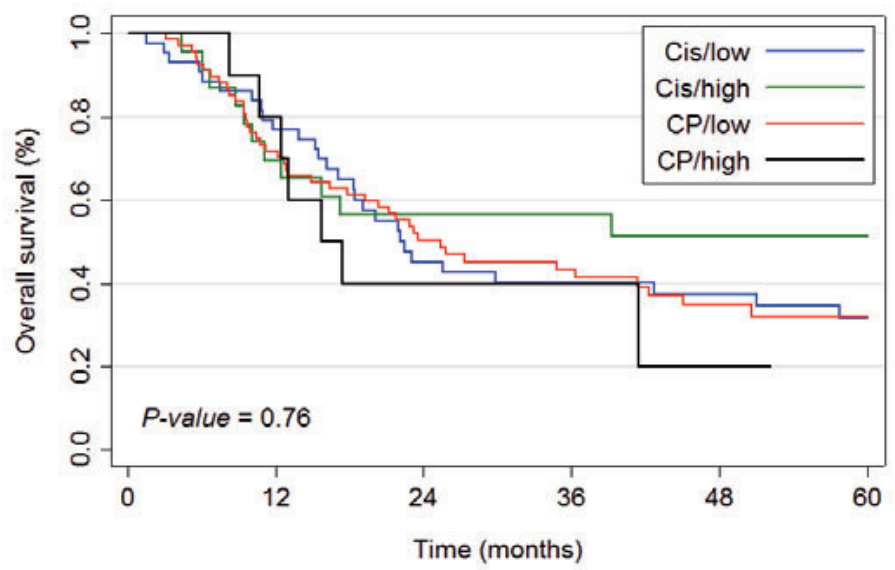

\begin{tabular}{|c|c|c|c|c|c|c|}
\hline \multirow{2}{*}{\multicolumn{7}{|c|}{ Number at risk }} \\
\hline & & & & & & \\
\hline Cis/low & 44 & 33 & 18 & 16 & 14 & 11 \\
\hline Cis/high & 23 & 16 & 12 & 12 & 9 & 7 \\
\hline CP/low & 68 & 48 & 31 & 22 & 13 & 9 \\
\hline CP/high & 10 & 8 & 4 & 4 & 1 & 0 \\
\hline
\end{tabular}

Figure S5.2 Kaplan-Meier curves for overall survival by treatment, per-protocol analysis. Cis/low: cisplatin and low-dose radiotherapy; Cis/high: cisplatin and high-dose radiotherapy; CP/low: carboplatin/paclitaxel and low-dose radiotherapy; CP/high: carboplatin/paclitaxel and highdose radiotherapy 


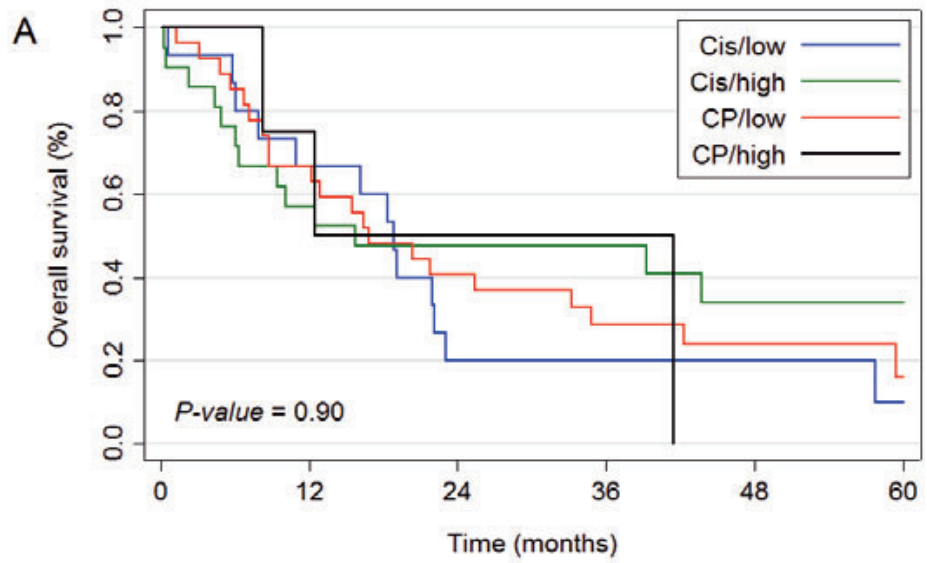

\begin{tabular}{|c|c|c|c|c|c|c|}
\hline \multicolumn{7}{|l|}{ Number at risk } \\
\hline Cis/low & 15 & 10 & 3 & 3 & 2 & 1 \\
\hline Cis/high & 21 & 12 & 9 & 8 & 4 & 2 \\
\hline CP/low & 27 & 18 & 11 & 6 & 5 & 2 \\
\hline CP/high & 4 & 3 & 2 & 2 & 0 & 0 \\
\hline
\end{tabular}

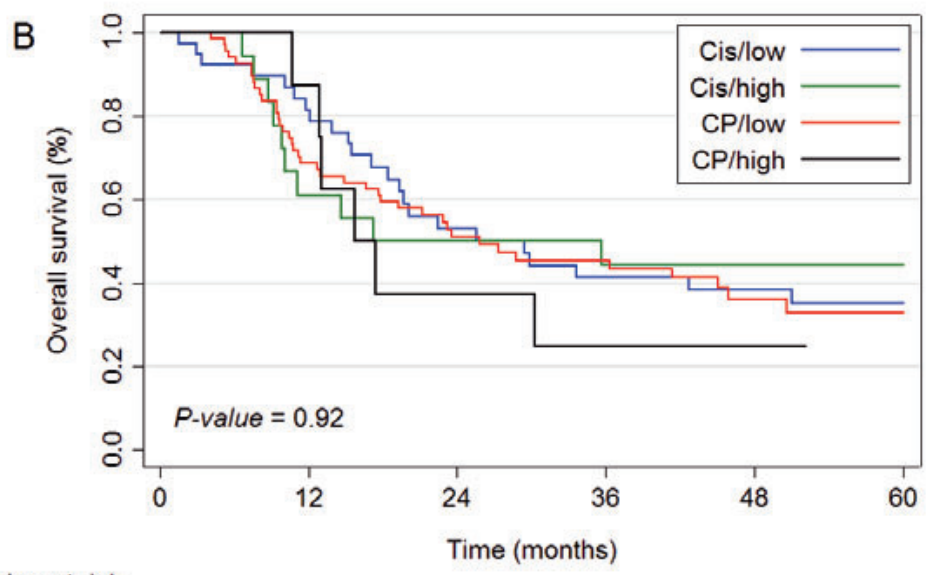

\begin{tabular}{|c|c|c|c|c|c|}
\hline Number at risk & & & & & \\
\hline Cis/low & 39 & 30 & 18 & 14 & 13 \\
\hline Cis/high & 18 & 11 & 9 & 8 & 8 \\
\hline CP/low & 68 & 45 & 29 & 23 & 13 \\
\hline CP/high & 8 & 7 & 3 & 2 & 1 \\
\hline
\end{tabular}

Figure S5.3 Kaplan-Meier curves for overall survival by treatment, in patients with cervical esophageal cancer (A), and upper thoracic esophageal cancer (B). Cis/low: cisplatin and low-dose radiotherapy; Cis/high: cisplatin and high-dose radiotherapy; $\mathrm{CP} /$ low: carboplatin/paclitaxel and low-dose radiotherapy; $\mathrm{CP} /$ high: carboplatin/paclitaxel and high-dose radiotherapy. 


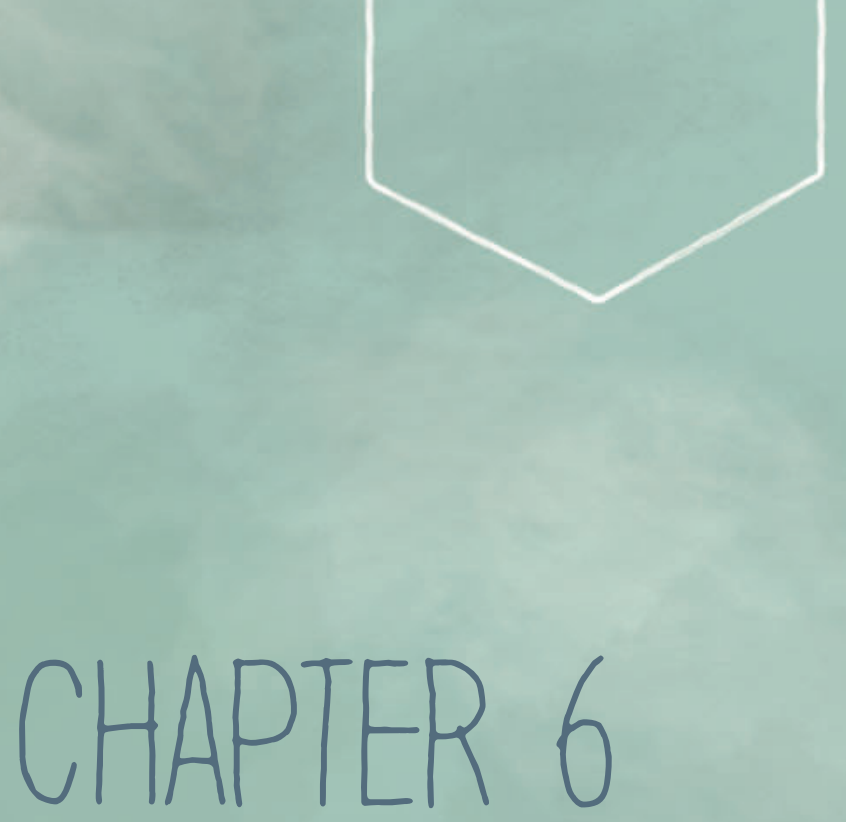

Patterns of recurrence following definitive chemoradiation for patients with proximal esophageal cancer

J. de Vos-Geelen, S.M.E. Geurts, G.A.P. Nieuwenhuijzen, F.E.M. Voncken, J.A. Bogers

P.M. Braam, C.T. Muijs, M.A. de Jong, N. Kasperts, T. Rozema, G.J. Blom,

S.A.W. Bouwense, L.B.J. Valkenburg-van lersel, P.M. Jeene, F.J.P. Hoebers*

V.C.G. Tjan-Heijnen*

*These authors share senior authorship

European Journal of Surgical Oncology. 2021:S0748-7983(21)00084-6 


\section{Abstract}

\section{Introduction}

The aim of this retrospective study was to determine the patterns of recurrence and overall survival (OS) in patients achieving clinical complete response after treatment with definitive chemoradiation (CRT) for proximal esophageal cancer.

\section{Materials and methods}

Patients with proximal esophageal cancer treated with CRT between 2004 and 2014 in 11 centers in the Netherlands were included. OS and progression-free survival (PFS) were calculated using the Kaplan-Meier method. Cumulative incidence of first recurrence (locoregional or distant) and locoregional recurrence (LRR) were assessed using competing risk analyses.

\section{Results}

In 197 of the 200 identified patients, response was evaluated, $133(68 \%)$ showed a complete response. In complete responders, median OS, three-year OS, and PFS were 45.0 months ( $95 \% \mathrm{Cl} 34.8-61.5$ months), $58 \%$ (95\% Cl 48-66), and $49 \%$ (95\% Cl 40-57), respectively. Three- and five-year risk of recurrence were respectively $40 \%(95 \% \mathrm{Cl}$ $31-48)$, and $45 \%$ (95\% Cl 36-54). Three- and five-year risk of LRR were $26 \%(95 \% \mathrm{Cl}$ 19-33), and $30 \%$ (95\% Cl 22-38). Eight of 32 patients with an isolated LRR underwent salvage surgery, with a median OS of 32.0 months ( $95 \% \mathrm{Cl} 6.8$-not reached).

\section{Conclusion}

In patients with a complete response after definitive CRT for proximal esophageal cancer, most recurrences were locoregional and developed within the first three years after CRT. These findings suggest to shorten locoregional follow-up from five to three years. 


\section{Introduction}

Definitive chemoradiation (CRT) is the standard of care for patients with a proximal esophageal squamous cell cancer (SCC), recommended by the National Comprehensive Cancer Network (NCCN), American Society of Clinical Oncology (ASCO), and European Society for Medical Oncology (ESMO) guidelines. ${ }^{1-3}$

Prognosis of proximal esophageal cancer (EC) is poor, providing three-year overall survival (OS) rates in patients treated with CRT of about $35-45 \%{ }^{4-11}$ Our previous retrospective cohort study showed comparable OS between four different CRT regimens including cisplatin or carboplatin and paclitaxel backbones and low ( $\leq 50.4 \mathrm{~Gy}$ ) or high dose (>50.4 Gy) radiotherapy (RT). ${ }^{12}$ Long-term survival is only achieved in complete responders to CRT. ${ }^{7,9,13,14}$ In the absence of clinical complete response (CR), none of the patients were alive at three years following CRT, ${ }^{7,9}$ whereas three-year OS rates were shown to be approximately $25 \%$ in patients treated with salvage surgery for residual or progressive disease. ${ }^{13,14}$ However, additional surgical resection independent of response following CRT was not associated with a survival benefit. ${ }^{14}$

Patterns and treatment of recurrence in complete responders to definitive CRT for proximal EC are currently unknown, hindering evidence-based follow-up and clinical counseling of these patients. Whether or not follow-up after definitive CRT for EC is useful remains controversial. Hence, recommendations by NCCN and ESMO guidelines are inconsistent regarding follow-up strategies and duration of surveillance. ${ }^{1,3}$

The purpose of this study was to determine patterns of recurrence, treatment and OS in patients who achieved CR following definitive CRT for proximal EC.

\section{Materials and methods}

This multicenter, retrospective, observational study was conducted in 11 centers in The Netherlands. Patients were identified in site-specific databases, complemented with the Netherlands Cancer Registry, a population-based cancer registry of all newly diagnosed malignancies in the Netherlands. We identified 200 consecutive patients who underwent definitive CRT for proximal EC, from January 2004 to December $2014 .{ }^{15}$ All patients had histologically confirmed SCC of the proximal esophagus, with maximum distal extension up to $24 \mathrm{~cm}$ of the incisors, in which supraclavicular nodal involvement was allowed. Tumor staging was performed according to the Union for International Cancer Control TNM classification that was valid at the time of diagnosis. Since the TNM classification did not essentially change, no coding was performed to a uniform TNM 
version, except nodal status which was converted into N1 excluding subdivision of $\mathrm{N} 1 / 2 / 3$. Further information on the study protocol was described previously. ${ }^{15}$

Patients were generally examined through physical examination and history taking in regular follow-up according to national guidelines at four to eight weeks after completion of CRT, and every three months in the first year, with escalating interval up to five years or until death. Endoscopy and imaging was performed in case of signs or symptoms of recurrence. No strict imaging protocol for follow-up was established. CR following CRT was defined as no clinical or radiological evidence of locoregional disease three months after completing CRT as defined by the treating physician.

Patient informed consent was waived by the Medical Ethics Board azM/UM due to the retrospective nature of the study (METC 15-4-012). The study was approved by the scientific committee of the Dutch Upper GI Cancer Group (DUCG), and the Dutch Head and Neck Oncology Cooperative Group (NWHHT 2017-01).

\section{Data collection}

Patient demographics, tumor characteristics, treatment details, and vital status were collected retrospectively from the medical records, obtained by trained registry clerks. Data collection took place between April 2017 and May 2018.

\section{Outcomes}

In the total group, we aimed to determine OS stratified by response. In the complete responders, additional endpoints were progression-free survival (PFS), cumulative incidence of first recurrence (locoregional or distant), and cumulative incidence of locoregional recurrence (LRR) as first event. Furthermore, we examined whether potential prognostic factors (age, sex, WHO performance status, comorbidity, clinical lymph node (cN) status, tumor location, gross tumor volume (GTV), and radiation dose) were associated with OS in CR.

LRR was classified as recurrence located at the site of the primary tumor and/or regional lymph nodes, up to supraclavicular nodes. The sites of LRR were assessed in relation to the radiation fields and scored as infield or outfield. Distant recurrence was defined as evidence of disease in any other site. The date of recurrence was taken as the date of confirmed histology (if present) or date of imaging of recurrent disease. Diagnostics and treatment modalities of recurrent disease were assessed. 


\section{Statistical analysis}

Differences between continuous and categorical variables were tested using the MannWitney $U$ and Chi-square test, respectively. OS was calculated from the start of CRT to date of death. For the patients with an isolated LRR, OS was additionally calculated from detection of recurrence. PFS was defined as the start of CRT to the date of recurrence or death. Time to recurrence was calculated from the start of CRT until the occurrence of LRR or distant metastasis, whichever came first, with interoccurring death as competing event. Time to LRR was calculated from the start of CRT to the date of LRR diagnosis, considering interocurring distant metastasis and death as competing events. For all time to event analyses, censoring occurred at last contact. OS and PFS were calculated using the Kaplan-Meier method. Cumulative incidence of recurrence and LRR were assessed using competing risk analyses. Median follow-up was calculated using the inverse Kaplan-Meier method for OS (death censored). A full multivariable model of potential predictors for OS was conducted using Cox regression analysis. Multiple imputation was used for missing data. Presence of multicollinearity was checked using variation inflation factors.

\section{Results}

A total of 200 patients were included, of whom 133 patients (67\%) achieved a complete response (CR), 42 (21\%) a partial response, and 17 (9\%) stable disease following definitive CRT. Five patients (3\%) had progressive disease, and in three patients (2\%) response could not be evaluated.

In complete responders, median age at time of diagnosis was 64 years (range, 42 to 85 years) (Table 6.1). Male sex and good performance status, i.e. WHO 0 or 1 , were predominant. Median radiation dose of the primary treatment was 50.4 Gy. CRT was completed as planned in 106 patients (80\%). Median follow-up was 64.7 months (95\% $\mathrm{Cl}$ 47.8-81.7). 
Table 6.1 Baseline and tumor characteristics of 133 complete responders following chemoradiation for proximal esophageal cancer.

\begin{tabular}{|c|c|c|c|}
\hline \multirow[b]{2}{*}{ Characteristic } & & \multicolumn{2}{|c|}{$\begin{array}{c}\text { Complete } \\
\text { responders } \\
\mathrm{N}=133\end{array}$} \\
\hline & & No. & $\%$ \\
\hline \multirow[t]{2}{*}{ Age } & Median, years (range) & \multicolumn{2}{|c|}{$64(42-85)$} \\
\hline & $\geq 70$ years & 33 & 25 \\
\hline Sex & Male & 82 & 62 \\
\hline \multirow[t]{3}{*}{ WHO performance score } & $0-1$ & 118 & 89 \\
\hline & $2-3$ & 6 & 5 \\
\hline & Unknown & 9 & 7 \\
\hline \multirow[t]{4}{*}{ Pre-diagnostic weight loss } & $<5 \%$ & 55 & 41 \\
\hline & $5-10 \%$ & 25 & 19 \\
\hline & $>10 \%$ & 26 & 20 \\
\hline & Unknown & 27 & 20 \\
\hline \multirow[t]{5}{*}{ Comorbidity } & Any & 75 & 56 \\
\hline & Cardiovascular disease & 40 & 30 \\
\hline & Pulmonary disease & 9 & 7 \\
\hline & Previous malignancy & 23 & 17 \\
\hline & None & 58 & 44 \\
\hline \multirow[t]{2}{*}{ Tumor location } & Cervical $(<18 \mathrm{~cm})$ & 41 & 31 \\
\hline & Upper thoracic $(18-24 \mathrm{~cm})$ & 92 & 69 \\
\hline \multirow[t]{2}{*}{ Tumor length } & Median, cm (range) & \multicolumn{2}{|c|}{$4(1-15)$} \\
\hline & Obstruction or unknown & 38 & 29 \\
\hline \multirow[t]{3}{*}{ Tumor grade } & G1-2 & 41 & 31 \\
\hline & G3 & 28 & 21 \\
\hline & Gx & 64 & 48 \\
\hline \multirow[t]{3}{*}{ Clinical T stage } & cT1-3 & 85 & 64 \\
\hline & cT4 & 35 & 26 \\
\hline & $\mathrm{cTx}$ & 13 & 10 \\
\hline \multirow[t]{3}{*}{ Clinical N stage } & $\mathrm{cNO}$ & 46 & 35 \\
\hline & $\mathrm{cN}+$ & 85 & 64 \\
\hline & $\mathrm{cNx}$ & 2 & 2 \\
\hline \multirow[t]{4}{*}{ Chemoradiation regimen } & Cisplatin, RT >43.2 and $\leq 50.4 \mathrm{~Gy}$ & 32 & 24 \\
\hline & Cisplatin, RT >50.4 Gy & 27 & 20 \\
\hline & Carboplatin, Paclitaxel, RT $>43.2$ and $\leq 50.4$ Gy & 65 & 49 \\
\hline & Carboplatin, Paclitaxel, RT >50.4 Gy & 9 & 7 \\
\hline \multirow[t]{3}{*}{ GTV } & Median, $\mathrm{cm}^{3}$ (range) & \multicolumn{2}{|c|}{$33.0(2.4-119.1)$} \\
\hline & IQR & \multicolumn{2}{|c|}{ 19.0-49.1 } \\
\hline & Unknown & 31 & 23 \\
\hline Radiation dose & Median, Gy (range) & \multicolumn{2}{|c|}{$50.4(48.6-70.0)$} \\
\hline \multirow[t]{3}{*}{ Chemoradiation completed as planned } & Yes & 106 & 80 \\
\hline & No & 21 & 16 \\
\hline & Unknown & 6 & 5 \\
\hline
\end{tabular}

GTV, gross tumor volume: the volume of the macroscopic tumor in $\mathrm{cm}^{3}$ as defined by the tumor-delineation on the RT planning-CT scan; IQR, interquartile range. Percentages may not add up to 100 because of rounding. 


\section{Overall survival}

Median OS was 45.0 months ( $95 \% \mathrm{Cl} 34.8-61.5$ months) and three-year OS was $58 \%$ (95\% Cl 48\%-66\%) (Supplementary Figure S6.1). Neither age, sex, comorbidity, lymph node status, GTV, nor radiation dose were significant prognostic factors for OS, whereas WHO performance status and tumor location were identified as clinically important factors with borderline significance (Table 6.2).

Table 6.2 Multivariable comparison of prognostic factors influencing overall survival in complete responders $(\mathrm{N}=133)$ following chemoradiation for proximal esophageal cancer

\begin{tabular}{|c|c|c|}
\hline & HR (95\% Cl) & $P$ value \\
\hline Age at diagnosis & $1.00(0.97-1.04)$ & 0.84 \\
\hline \multicolumn{3}{|l|}{ Sex } \\
\hline Male & Ref. & \\
\hline Female & $0.67(0.39-1.15)$ & 0.15 \\
\hline \multicolumn{3}{|c|}{ WHO performance status } \\
\hline $0-1$ & Ref. & \\
\hline $2-3$ & $2.62(0.90-7.63)$ & 0.08 \\
\hline \multicolumn{3}{|l|}{ Comorbidity } \\
\hline No & Ref. & \\
\hline Yes & $0.84(0.50-1.40)$ & 0.50 \\
\hline \multicolumn{3}{|l|}{ cN stage } \\
\hline NO & Ref. & \\
\hline $\mathrm{N}+$ & $1.19(0.73-1.96)$ & 0.48 \\
\hline \multicolumn{3}{|l|}{ Tumor location } \\
\hline Cervical & Ref. & \\
\hline Upper thoracic & $0.64(0.38-1.07)$ & 0.09 \\
\hline \multicolumn{3}{|l|}{ GTV (tertiles), $\mathrm{cm}^{3}$} \\
\hline$\leq 25$ & Ref. & \\
\hline $26-42$ & $1.04(0.56-1.94)$ & 0.90 \\
\hline$\geq 43$ & $1.64(0.91-2.97)$ & 0.10 \\
\hline \multicolumn{3}{|c|}{ Radiation dose, Gy } \\
\hline$\leq 50.4$ & Ref. & \\
\hline$>50.4$ & $1.10(0.66-1.82)$ & 0.72 \\
\hline
\end{tabular}

GTV, gross tumor volume: the volume of the macroscopic tumor in $\mathrm{cm}^{3}$ as defined by the tumor-delineation on the radiotherapy planning-CT scan.

\section{Recurrence}

Of the 133 patients with a CR, 58 patients had recurrent disease, of whom 32 (55\%) had an isolated LRR, 19 (33\%) distant metastases only, and seven (12\%) concurrent locoregional and distant recurrences as first site (Figure 6.1).

Three-year PFS was 49\% (95\% Cl 40\%-57\%). Three- and five-year incidences of any recurrence (locoregional or distant) was $40 \%(95 \% \mathrm{Cl} 31 \%-48 \%)$ and $45 \%(95 \% \mathrm{Cl}$ 
$36 \%-54 \%)$ and for $\operatorname{LRR} 26 \%(95 \% \mathrm{Cl} 19-33)$ and $30 \%(95 \% \mathrm{Cl} 22-38)$, respectively (Figure 6.2).

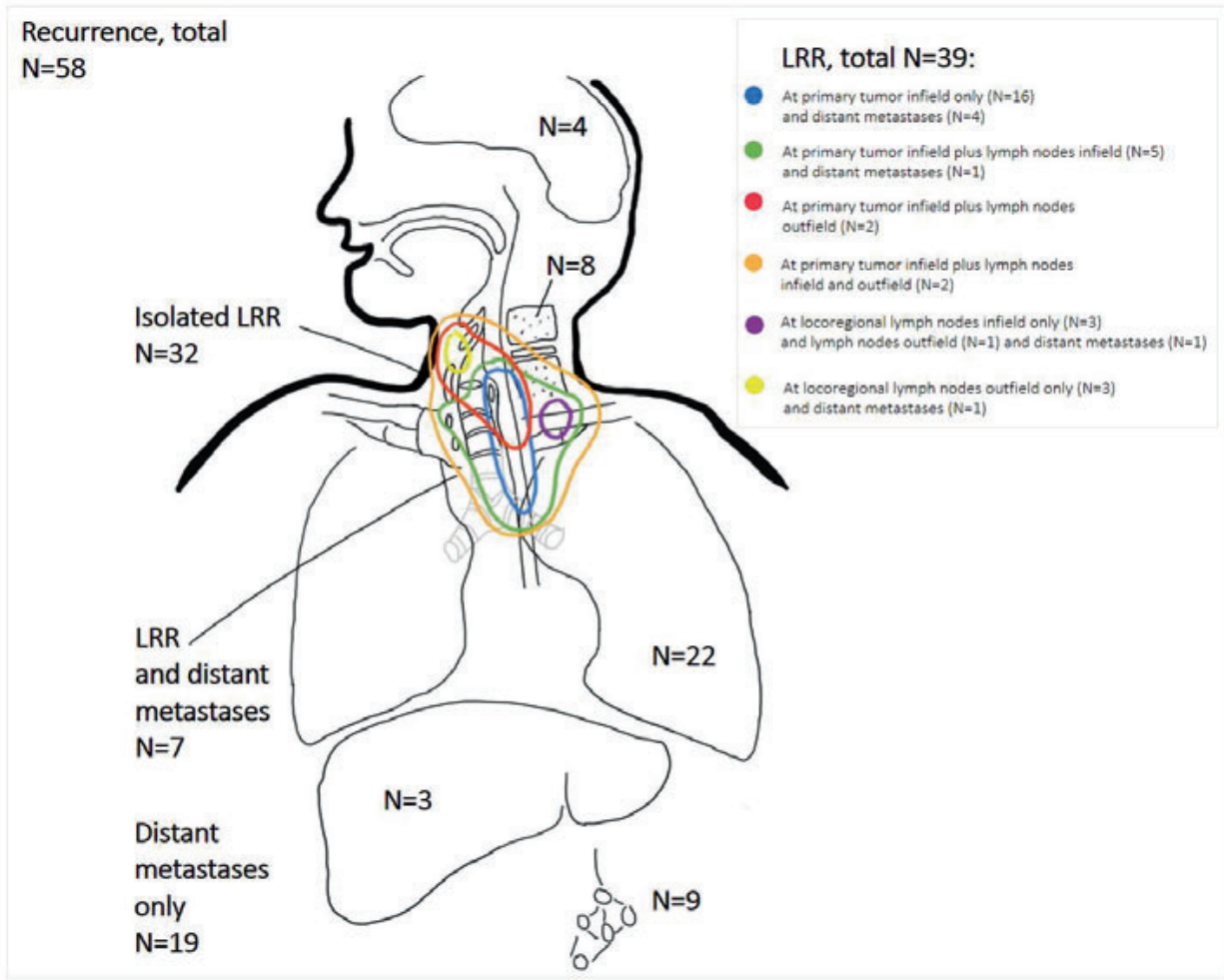

Figure 6.1 Location of first recurrence in complete responders following chemoradiation for proximal esophageal cancer. LRR, locoregional recurrence.

Among the patients with LRR, distribution predominantly showed recurrence primarily infield at the original tumor site, followed by infield at the lymph node site (Figure 6.1). Metastatic disease manifested at a single site in ten patients, and at multiple sites in 16 patients. The lungs were the main site of metastatic disease $(\mathrm{N}=22)$, followed by distant lymph nodes $(\mathrm{N}=9)$, bone $(\mathrm{N}=8)$, brain $(\mathrm{N}=4)$, and liver $(\mathrm{N}=3)$.

Of the patients with LRR, 29 patients $(74 \%)$ were symptomatic at presentation and in 31 patients (80\%) LRR were pathologically confirmed (Supplementary Table S6.1). Fourteen patients (54\%) who developed distant metastasis showed physical complaints. Distant failures were pathologically confirmed in six patients (22\%).

Twenty patients developed a second primary tumor, mainly located in the head and $\operatorname{neck}(\mathrm{N}=7)$, lung $(\mathrm{N}=4)$, and esophagus $(\mathrm{N}=3)$. 
Among the 32 patients with an isolated LRR, 8 (25\%) underwent salvage surgery, 16 (50\%) re-irradiation, $3(9 \%)$ chemotherapy, and 8 (25\%) best supportive care only. Salvage surgery included esophageal resection and gastric conduit $(\mathrm{N}=6)$, cervical lymph node dissection $(\mathrm{N}=1)$, and radiofrequency ablation $(\mathrm{N}=1)$. Of the patients undergoing surgery for their recurrence, four received multimodal treatment with $\mathrm{RT}(\mathrm{N}=3)$ or $\mathrm{CRT}$ $(\mathrm{N}=1)$. Median radiation dose to treat LRR was $30 \mathrm{~Gy}$ (range 12-50.4 Gy).

Median OS of patients undergoing salvage surgery for isolated LRR was 50.6 months (95\% Cl 31.2-70.0, three- and five-year OS 75\% and 30\%) from the start of CRT at primary diagnosis. Median OS from detection of LRR was 32.0 months $(95 \% \mathrm{Cl}$ 6.8-not reached, three- and five-year OS $44 \%$ and $29 \%$ ) for salvage surgery, 8.7 months for patients undergoing re-irradiation with or without chemotherapy, 3.0 months for chemotherapy alone, and 1.5 months for best supportive care only (Supplementary Figure S6.2). At the end of follow-up, five patients had died following salvage surgery, all as a result of recurrent disease. Timing of detection of LRR in patients undergoing salvage surgery compared with those patients with LRR only who were unable to undergo surgery for LRR did not differ (Supplementary Figure S6.3).

In metastatic disease (with or without LRR), three patients (12\%) underwent a metastasectomy (with or without RT). Their median OS from detection of recurrence was 16.0 months. Four patients (15\%) underwent chemotherapy (with or without RT) with a median OS of 7.0 months. A variety of chemotherapeutic agents were administered in recurrent disease, mostly fluoropyrimidine-based. RT only was applied in five patients with a median radiation dose of 22.8 Gy (range 18-39 Gy), demonstrating a median OS of 7.6 months. Median OS for patients not receiving antitumor treatment $(\mathrm{N}=14)$ was 3.5 months.

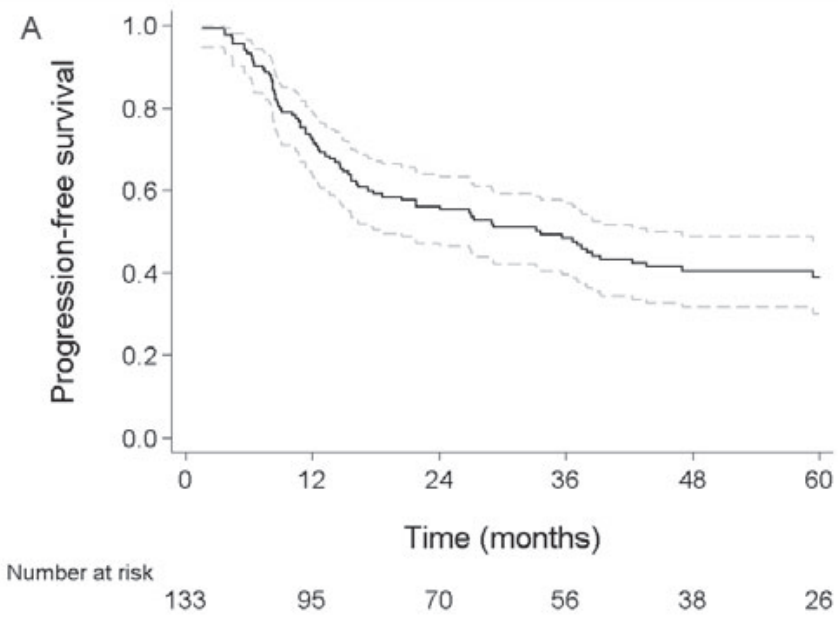



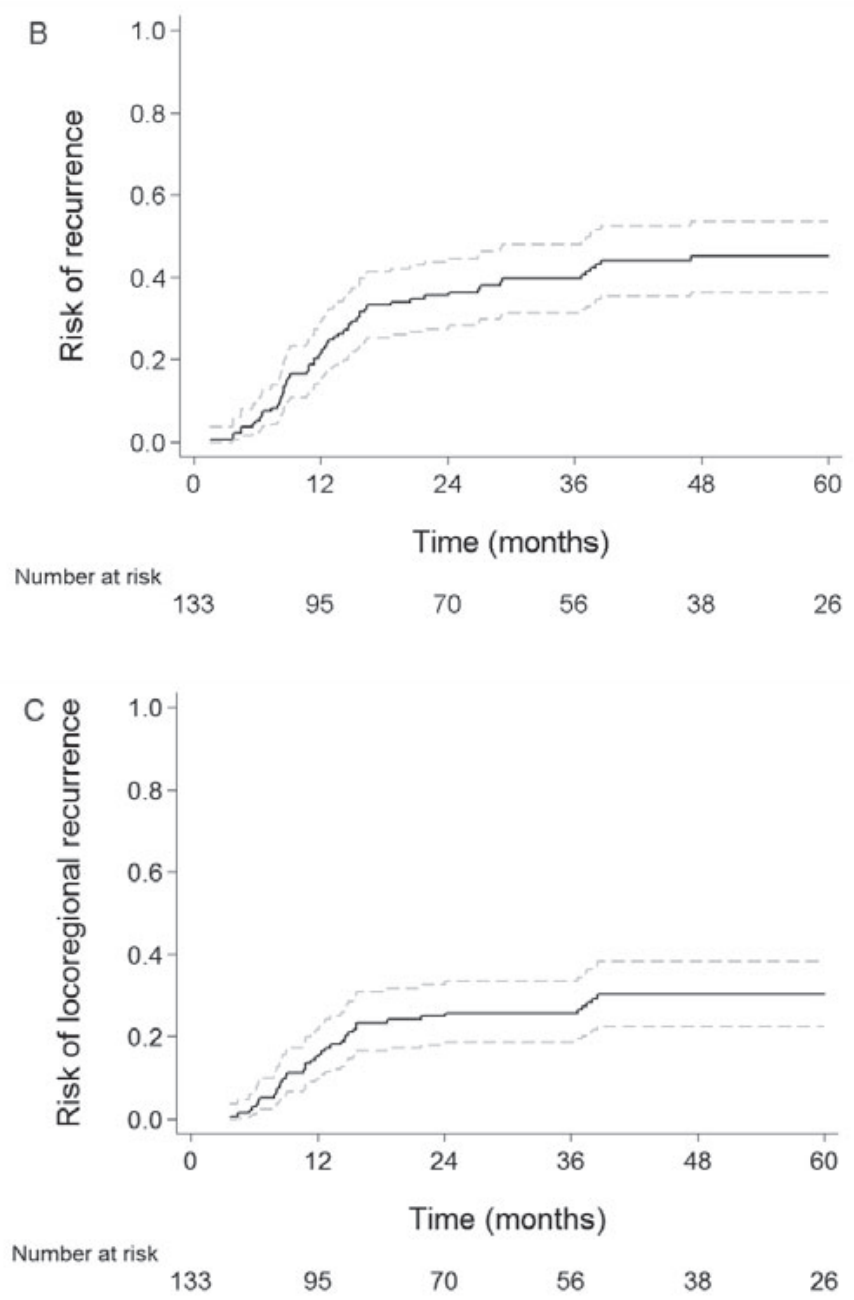

Figure 6.2 Progression-free survival (A), cumulative incidence of recurrence (locoregional or distant) (B), and cumulative incidence of locoregional recurrence as first event (C) for patients with complete response following chemoradiation for proximal esophageal cancer. Dashed lines correspond with the $95 \%$ confidence intervals.

\section{Discussion}

This retrospective cohort study demonstrated that most recurrences in complete responders following CRT for proximal EC were locoregional and occurred mainly in the primary involved tumor field within the first three years. In most cases of LRR local 
therapy was applied, i.e. salvage surgery or second course RT. Only one out of five patients with either a locoregional or distant recurrence received chemotherapy.

To the best of our knowledge, this is the largest cohort reporting the pattern of recurrence in complete responders after CRT for proximal EC, observing a three- and five-year risk of recurrence of $40 \%$ and $45 \%$. Two-thirds of all recurrences were locoregional failures, which was in line with previous cohorts in proximal EC, reporting LRR in 58-84\% of the recurrences after CRT although not specific for $C R, 4,5,8,14,16,17$ except for a small Canadian cohort of complete responders $(\mathrm{N}=38) .{ }^{4}$

The high rate of LRR after CRT emphasizes consideration of improvement in local therapy. However, adjuvant resection after CRT did not prolong survival in cervical EC compared with definitive CRT alone in an Italian cohort study. ${ }^{14}$ Nonetheless, randomized data are lacking.

Locoregional recurrences were mainly within the RT field, suggesting a potential benefit of escalating radiation dose. However, previous studies showed inconsistent results of dose escalation. A recent meta-analysis including ten observational studies $(\mathrm{N}=4918)$, and one small prospective trial $(\mathrm{N}=28)$, suggested that a higher radiation dose to the primary tumor volume was associated with better locoregional failure free survival. ${ }^{18}$ However, the recent phase III dose escalation ARTDECO study in EC randomizing 260 patients $(61 \% \mathrm{SCC})$, demonstrated that radiation dose escalation up to $61.6 \mathrm{~Gy}$ versus 50.4 Gy to the primary tumor did not improve local control. ${ }^{19}$

Salvage surgery in case of an isolated LRR could be considered for highly selected patients. In our study eight out of 32 patients (25\%) with LRR only underwent salvage surgery, of which $44 \%$ were alive at three years after detection of recurrence. These results are comparable with a Japanese phase II trial including five patients (38\%) with LRR of cervical EC who underwent surgery, of which three remained alive for more than three years. ${ }^{13}$ Schieman et al. demonstrated corresponding outcomes, with a threeyear OS rate of $33 \% .{ }^{20}$ The reported long-term survival following salvage surgery was confirmed in retrospective studies including patients with cancers of the esophagus, i.e. proximal, mid or distal, treated with definitive CRT and experiencing a LRR. $^{21,22}$ Moreover, recurrences in the proximal part of the esophagus are even more difficult to treat due to long-term side effects after definitive CRT, e.g. strictures and fistulas. ${ }^{23-25}$ Hence, most patients suffering from a LRR following CRT for proximal EC are unable to undergo salvage surgery. Although a durable survival can be achieved in this group, salvage esophagectomy should be thoughtfully balanced with perioperative morbidity and mortality of such challenging resections by both patients and physicians. ${ }^{21,22}$ The role of re-irradiation in LRR following definitive CRT in EC is controversial. In the current study, re-irradiation was carried out in 16 patients with an isolated LRR, with a median radiation dose of $30 \mathrm{~Gy}$ (range 12-50.4 Gy). Median OS of patients undergoing 
salvage RT was 8.7 months from the point of detection of locoregional disease. Literature on re-irradiation in EC is sparse. Zhou et al. retrospectively analyzed 55 patients with recurrences treated with salvage RT with a median dose of $54 \mathrm{~Gy}$ (range 18-66 Gy), demonstrating a median OS of five months. ${ }^{26}$ A recent Chinese study established long-term survival of 17 months in patients treated with re-irradiation for locoregional recurrent esophageal SCC. ${ }^{27}$ Others found comparable poor outcomes following re-irradiation. ${ }^{28,29}$ Hence, only in selected and highly motivated patients a radical radiotherapeutic approach can be considered, outweighing the significant risks of re-irradiation, e.g. fistulation, stenosis, and vascular blow-out.

Although the minority of initial recurrences in our study were distant, improvements in systemic therapy remain warranted, regarding optimization of systemic cytotoxic effects in recurrent disease, but also for synergistic effects in primary CRT. The implementation of immunotherapy in metastatic EC is to be awaited, after proved safety and efficacy of the ATTRACTION-3, CheckMate-649, and KEYNOTE-590 trials, especially in the subset of programmed death ligand-1 positive tumors. ${ }^{30-32}$ Furthermore, interim analysis of the adjuvant CheckMate-577 trial showed a significantly improved disease-free survival with adjuvant nivolumab compared with placebo in patients with resected EC after neoadjuvant chemoradiation and have not achieved a pathological complete response. ${ }^{33}$ In addition, a phase II study is assessing the efficacy of atezolizumab following definitive CRT to increase CR rate. ${ }^{34}$

In the current study, main metastatic sites were lung and lymph nodes, comparable with the results from smaller observational studies. ${ }^{8,35,36}$ In our cohort, only $15 \%$ of patients developing distant metastases received palliative chemotherapy. This corresponds to historical data in a large cohort of proximal EC, ${ }^{37}$ and reflects the limited high level evidence of palliative systemic therapy in metastatic esophageal $\mathrm{SCC}^{38}$ as well as the frailty of this population.

The approach regarding evaluation of response after CRT has not been established. ESMO guidelines do not include recommendations concerning response evaluation following definitive CRT. ${ }^{3}$ However, the NCCN guideline committee recommends endoscopy and biopsy. ${ }^{1}$ Others have suggested a role for $18 \mathrm{~F}-\mathrm{FDG}$ PET/CT, diffusionweighted $\mathrm{MRI}^{39}$ or molecular biomarkers, such as circulating tumor DNA ${ }^{40}$ for response evaluation, which has to be explored in future studies. The potential benefits of such extensive assessments have to outweigh the impact on either patients and healthcare facilities.

Systematic surveillance strategies after successful definitive treatment for proximal EC remain controversial. We demonstrated that most patients presented with symptoms at the time of recurrence, which was expected since Dutch esophageal and head and neck cancer guidelines, as well as NCCN guidelines, ${ }^{1}$ advice symptom-based follow-up, 
whereas endoscopy and imaging studies are only recommended to be performed on indication. In contrast, ESMO guideline states that a three-month follow-up based on endoscopy, biopsies and CT scan may be recommended in the case of CR to definitive CRT. It might be expected that a more vigorous approach of follow-up will lead to an earlier detection of recurrences. An earlier detection may, in addition, lead to an increased rate of effective salvage interventions. However, associated outcome remains unknown. The usefulness of follow-up in terms of improving survival is limited for early salvage surgery after (failing) definitive CRT. ${ }^{3}$ It would be of great interest to study the influence of the different methods of follow-up on the rate of detection of LRR, and the chances of performing salvage treatment. Particularly in the current era of enhanced surgical procedures in the salvage setting for EC, e.g. endoscopic resections, ${ }^{41}$ robot-assisted minimally invasive esophagectomy, ${ }^{42}$ and the advantages of high volume expertise centers. ${ }^{43,44}$

In the Netherlands, follow-up ends five years post treatment. Duration of follow-up is not clearly specified in ESMO guidelines, whereas NCCN recommends annual follow-up even after five years. The current study demonstrated that most failures were developed within the first three years after CRT. After that point, surveillance for second primary tumors may be of importance, considering the high occurrence of a second SCC due to the close association of alcohol consumption and smoking habits. ${ }^{45}$ Whether early detection and treatment of second primaries improves patient outcomes is currently unknown. Considering the impact of prolonged follow-up might have on patients quality of life and health care costs, we would propose to restrict follow-up to three years following CR after definitive CRT for proximal EC. Unless other factors regarding patients recovery, e.g. repeated dilatations, dietary or psychosocial needs, require continued surveillance. Furthermore, follow-up should be patient tailored in order to warrant patients' preferences.

The strength of our study is that we included a large cohort of patients in this rare disease, with long-term follow-up. The retrospective design of this study is however also inherent with some limitations. Details on applied RT techniques, time to response, subsequent recurrences were not collected. Furthermore, the number of patients with recurrences did not allow us to study independent predictive and prognostic factors for risk of LRR and radiation dose effect on treatment response. In addition, recurrence treatment outcomes should be considered with care, given the low patient numbers. In conclusion, patients with a complete response after definitive CRT for proximal EC demonstrated high rates of infield LRR, suggesting methods to optimize locoregional control are necessary. Salvage treatment of isolated LRR resulted in favorable outcome. Hence, screening for LRR should be optimized. Furthermore, since nearly all 
Chapter 6

recurrences occurred within three years after initial treatment, routine follow-up could be restricted. 


\section{References}

1. Ajani JA, et al. Esophageal and esophagogastric junction cancers, version 2.2019, NCCN clinical practice guidelines in Oncology. J Natl Compr Canc Netw 2019;17:855-883.

2. Shah MA, et al. Treatment of locally advanced esophageal carcinoma: ASCO guideline. J Clin Oncol 2020;38:2677-2694.

3. Lordick F, et al. Oesophageal cancer: ESMO Clinical Practice Guidelines for diagnosis, treatment and follow-up. Ann Oncol 2016;27:v50-v57.

4. Huang $\mathrm{SH}$, et al. Effect of concurrent high-dose cisplatin chemotherapy and conformal radiotherapy on cervical esophageal cancer survival. Int J Radiat Oncol Biol Phys 2008;71:735-740.

5. Zhang P, et al. Clinical efficacy and failure pattern in patients with cervical esophageal cancer treated with definitive chemoradiotherapy. Radiother Oncol: J. Eur. Soc. Therap. Radiol. Oncol. 2015;116: 257-261.

6. Herrmann E, et al. Outcome of proximal esophageal cancer after definitive combined chemo-radiation: a Swiss multicenter retrospective study. Radiat Oncol (London, England) 2017;12:97.

7. Gkika $E$, et al. Long-term results of definitive radiochemotherapy in locally advanced cancers of the cervical esophagus. Dis Esophagus: Off J Int Soc Dis Esophagus 2014;27:678-684.

8. Yamada K, et al. Treatment results of radiotherapy for carcinoma of the cervical esophagus. Acta Oncol (Stockholm, Sweden) 2006;45:1120-1125.

9. Uno T, et al. Concurrent chemoradiation for patients with squamous cell carcinoma of the cervical esophagus. Dis Esophagus: Off J Int Soc Dis Esophagus 2007;20:12-18.

10. Ludmir EB, et al. Incidence and prognostic impact of high-risk HPV tumor infection in cervical esophageal carcinoma. J Gastrointest Oncol 2014;5:401-407.

11. Hoeben A, et al. Cervical esophageal cancer: a gap in cancer knowledge. Ann Oncol 2016;27:1664-1674.

12. de Vos-Geelen J, et al. A national study to assess outcomes of definitive chemoradiation regimens in proximal esophageal cancer. Acta Oncol (Stockholm, Sweden) 2020;59:895-903.

13. Zenda S, et al. Multicenter phase 2 study of cisplatin and 5-fluorouracil with concurrent radiation therapy as an organ preservation approach in patients with squamous cell carcinoma of the cervical esophagus. Int J Radiat Oncol Biol Phys 2016;96:976-984.

14. Valmasoni $\mathrm{M}$, et al. Cervical esophageal cancer treatment strategies: a cohort study appraising the debated role of surgery. Ann Surg Oncol 2018;25:2747-2755.

15. de Vos-Geelen J, et al. A national study to assess outcomes of definitive chemoradiation regimens in proximal esophageal cancer. Acta Oncol (Stockholm, Sweden) 2020;1-9.

16. Zhao $\mathrm{L}$, et al. Patterns of failure and clinical outcomes of definitive radiotherapy for cervical esophageal cancer. Oncotarget 2017;8:21852-21860.

17. Esmati E, et al. Outcomes of definitive chemoradiotherapy for cervical and upper thoracic esophageal cancers: a single-institution experience of a rare cancer. J Gastrointest Canc 2019;50(3):380-385.

18. Xiao L, et al. Do higher radiation doses with concurrent chemotherapy in the definitive treatment of esophageal cancer improve outcomes? A meta-analysis and systematic review. J Canc 2020;11: 4605-4613.

19. Hulshof MCCM, et al. A randomized controlled phase III multicenter study on dose escalation in definitive chemoradiation for patients with locally advanced esophageal cancer: ARTDECO study. J Clin Oncol 2020;38. Abstract 281.

20. Schieman C, et al. Salvage resections for recurrent or persistent cancer of the proximal esophagus after chemoradiotherapy. Ann Thorac Surg 2013;95:459-463.

21. Markar S, et al. Salvage surgery after chemoradiotherapy in the management of esophageal cancer: is it a viable therapeutic option? J Clin Oncol 2015;33:3866-3873.

22. Sudo $\mathrm{K}$, et al. Importance of surveillance and success of salvage strategies after definitive chemoradiation in patients with esophageal cancer. J Clin Oncol 2014;32:3400-3405.

23. Faiz Z, et al. A meta-analysis on salvage surgery as a potentially curative procedure in patients with isolated local recurrent or persistent esophageal cancer after chemoradiotherapy. Eur J Surg Oncol 2019;45:931-940. 
24. Wang S, et al. Esophageal cancer located at the neck and upper thorax treated with concurrent chemoradiation: a single-institution experience. J Thorac Oncol: Off Publ Int Assoc Study Lung Canc 2006;1:252-259.

25. Tu L, et al. Paclitaxel and cisplatin combined with intensity-modulated radiotherapy for upper esophageal carcinoma. Radiat Oncol (London, England) 2013;8:75.

26. Zhou Z, et al. Salvage radiotherapy in patients with local recurrent esophageal cancer after radical radiochemotherapy. Radiat Oncol 2015;10:54.

27. X. Xu X, et al. Evaluating the optimal re-irradiation dose for locally recurrent esophageal squamous cell carcinoma after definitive radiotherapy. Radiat Oncol (London, England) 2019;14:191.

28. Y.S. Kim YS, et al. Re-irradiation of recurrent esophageal cancer after primary definitive radiotherapy. Radiat Oncol J 2012;30:182-188.

29. S. Yamaguchi S, et al. Multimodal approaches including three-dimensional conformal Re-irradiation for recurrent or persistent esophageal cancer: preliminary results. J Radiat Res 2011;52:812-820.

30. K. Kato K, et al. Nivolumab versus chemotherapy in patients with advanced oesophageal squamous cell carcinoma refractory or intolerant to previous chemotherapy (ATTRACTION-3): a multicentre, randomised, open-label, phase 3 trial. Lancet Oncol 2019;20:1506-1517.

31. Moehler M. Nivolumab (NIVO) plus chemotherapy (chemo) versus chemo as first-line (1I) treatment for advanced gastric cancer/gastroesophageal junction cancer (GC/GEJC)/esophageal adenocarcinoma (EAC): first results of the CheckMate 649 study. Ann Oncol 2020;31. Abstract LBA6_PR.

32. Kato K. Pembrolizumab plus chemotherapy versus chemotherapy as first-line therapy in patients with advanced esophageal cancer: the phase 3 KEYNOTE-590 study. Ann Oncol 2020;31. Abstract LBA8_PR.

33. Kelly RJ. Adjuvant nivolumab in resected esophageal or gastroesophageal junction cancer (EC/GEJC) following neoadjuvant chemoradiation therapy (CRT): first results of the CheckMate 577 study. Ann Oncol 2020;31:S1142-S1215.

34. Bando $\mathrm{H}$, et al. TENERGY: multicenter phase II study of Atezolizumab monotherapy following definitive Chemoradiotherapy with 5-FU plus Cisplatin in patients with unresectable locally advanced esophageal squamous cell carcinoma. BMC Canc 2020;20:336.

35. Cao CN, et al. Primary radiotherapy compared with primary surgery in cervical esophageal cancer. JAMA Otolaryngol-- Head \& Neck Surg 2014;140:918-926.

36. Cao C, et al. Definitive radiotherapy for cervical esophageal cancer. Head Neck 2015;37:151-155.

37. de Vos-Geelen J, et al. Trends in treatment and overall survival among patients with proximal esophageal cancer. World J Gastroenterol 2019;25:6835-6846.

38. Janmaat VT, et al. Palliative chemotherapy and targeted therapies for esophageal and gastroesophageal junction cancer. Cochrane Database Syst Rev 2017.

39. Borggreve AS, et al. Preoperative prediction of pathologic response to neoadjuvant chemoradiotherapy in patients with esophageal cancer using (18)F-FDG PET/CT and DW-MRI: a prospective multicenter study. Int J Radiat Oncol Biol Phys 2020;106:998-1009.

40. Azad TD, et al. Circulating tumor DNA analysis for detection of minimal residual disease after chemoradiotherapy for localized esophageal cancer. Gastroenterology 2020;158:494-505.e6.

41. Al-Kaabi A, et al. Salvage endoscopic resection after definitive chemoradiotherapy for esophageal cancer: a Western experience. Gastrointest Endosc 2020;S0016-5107(20)34657-5.

42. Defize IL, et al. ASO author reflections: preoperative selection of cT4b esophageal cancer patients who benefit from a salvage robot-assisted minimally invasive esophagectomy (RAMIE). Ann Surg Oncol 2020.

43. van Putten $M$, et al. Hospital of diagnosis influences the probability of receiving curative treatment for esophageal cancer. Ann Surg 2018;267:303-310.

44. van de Poll-Franse LV, et al. Impact of concentration of oesophageal and gastric cardia cancer surgery on long-term population-based survival. Br J Surg 2011;98:956-963.

45. Mitani S, et al. Risk of second primary malignancies after definitive treatment for esophageal cancer: a competing risk analysis. Canc Med 2020;9:394-400. 


\section{Supplemental material}

Table S6.1 Symptoms and modality of detection of recurrent disease in complete responders $(N=133)$ following chemoradiation for proximal esophageal cancer.

\begin{tabular}{|c|c|c|c|}
\hline & & $\begin{array}{l}\text { Locoregional recurrence } \\
\qquad \begin{array}{c}(\mathrm{N}=39) \\
\mathrm{N}(\%)\end{array}\end{array}$ & $\begin{array}{c}\text { Metastatic disease } \\
(\mathrm{N}=26) \\
\mathrm{N}(\%)\end{array}$ \\
\hline \multicolumn{4}{|c|}{ Symptoms at time of detection recurrence } \\
\hline Yes & & $29(74)$ & $14(54)$ \\
\hline \multicolumn{4}{|c|}{ Modality of detection } \\
\hline & Endoscopy & $14(36)$ & 0 \\
\hline & CT scan & $7(18)$ & $9(35)$ \\
\hline & PET scan & $4(10)$ & $2(8)$ \\
\hline & Ultrasound & $3(8)$ & 0 \\
\hline & Other & 0 & $3(12)^{*}$ \\
\hline & Unknown & $1(3)$ & 0 \\
\hline No & & $7(18)$ & $11(42)$ \\
\hline \multicolumn{4}{|c|}{ Modality of detection } \\
\hline & Endoscopy & $3(8)$ & 0 \\
\hline & CT scan & $2(5)$ & $6(23)$ \\
\hline & PET scan & $2(5)$ & 5 (19) \\
\hline Unk & & $3(8)$ & $1(4)$ \\
\hline \multicolumn{4}{|c|}{ Recurrence pathologically confirmed } \\
\hline Yes & & $31(80)$ & $6(22)$ \\
\hline No & & $8(21)$ & $20(77)$ \\
\hline
\end{tabular}

Percentages may not add up to 100 because of rounding. ${ }^{*} \mathrm{MRI}(\mathrm{N}=2)$ and chest $\mathrm{X}$-ray $(\mathrm{N}=1)$.

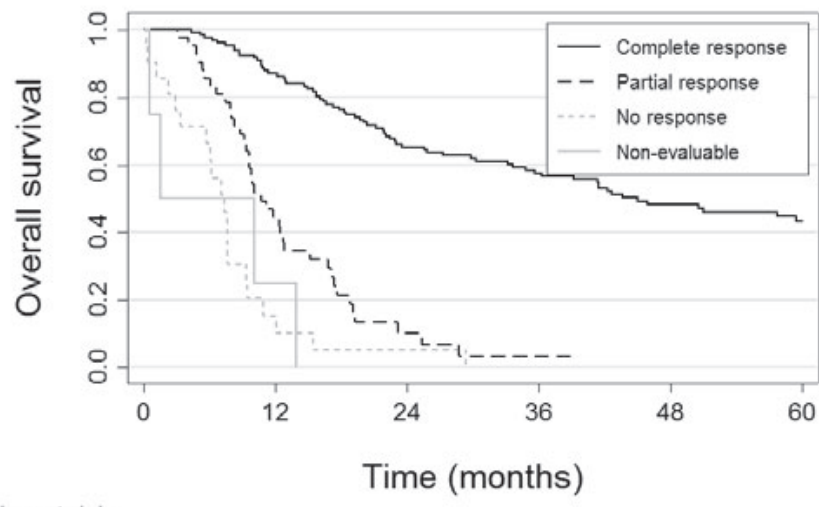

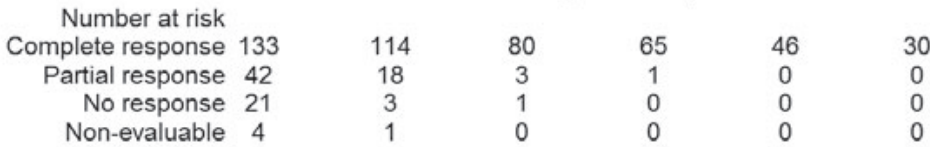

Figure S6.1 Overall survival of 200 patients treated with chemoradiation for proximal esophageal cancer, stratified by treatment response 


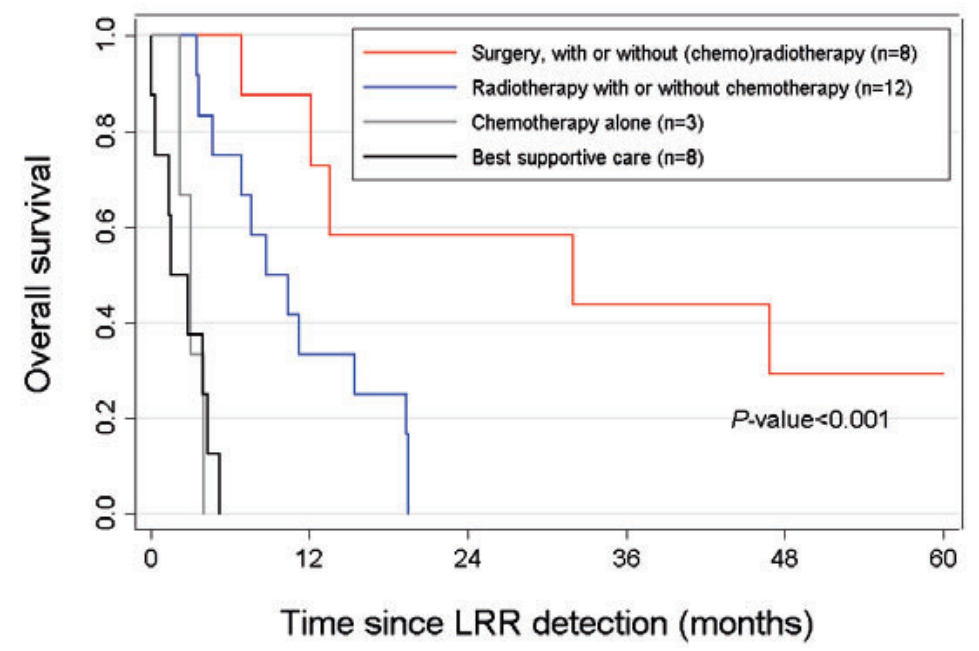

Figure S6.2 Overall survival from date of detection of locoregional recurrence only
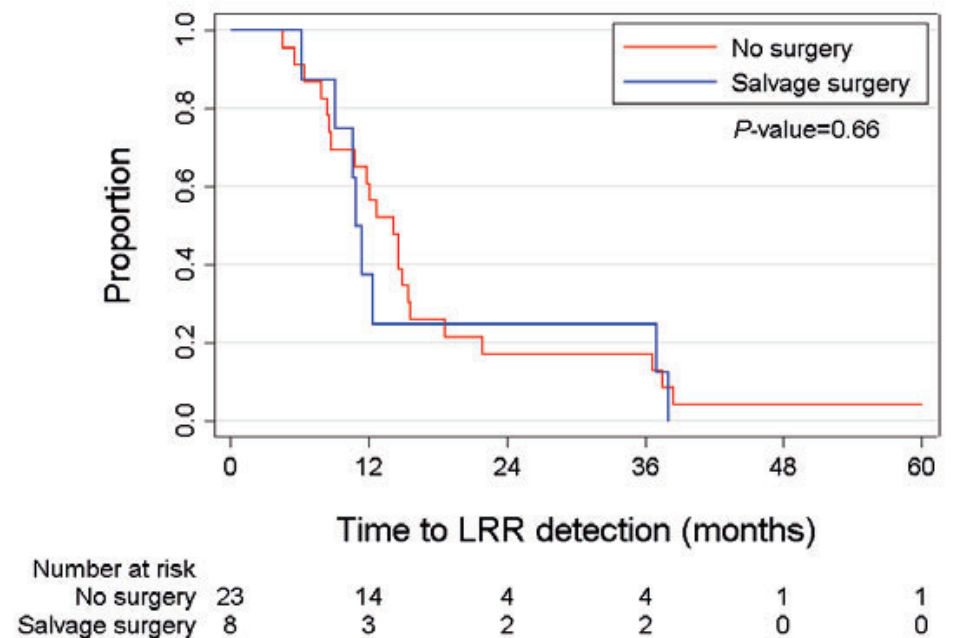

$\begin{array}{ccccc}14 & 4 & 4 & 1 & 1 \\ 3 & 2 & 2 & 0 & 0\end{array}$

Figure S6.3 Timing of detection of locoregional recurrence only, stratified by salvage surgery 




\section{General discussion}

The preeminent objective of physicians involved in the management of esophageal cancer is to improve survival while optimizing patients' quality of life. In the past decade more attention is being paid to involve patients in clinical decision-making in order to warrant patients' preferences. Discussing treatment possibilities, and their potential benefits and burden in respect to patient choices, is more and more integrated in current clinical practice by implementing a decision-making process by the patient and the physician. A prerequisite for performing shared decision-making is the availability of robust data and real-world evidence on treatment choices and outcomes. However, in (proximal) esophageal cancer comprehensive real-world data are scarce. In this thesis we focused on studying stage distribution, trends in treatment, safety data, and survival in patients with esophageal cancer in a nationwide population-based design, with a spotlight on cancers originating in the proximal esophagus.

In this discussion chapter we will elaborate on the findings of the previous sections, providing a framework for guidance of each patient with (proximal) esophageal cancer in daily clinical practice, attaining future perspectives to further improve esophageal cancer outcomes. Our research yielded two main results which are relevant for the counseling of esophageal cancer patients. First of all, we were able to assess the survival in esophageal cancer in a real-world setting. We showed that relative survival of patients with esophageal cancer has improved over the past decades, though modestly. Secondly, by placing the emphasis on proximal esophageal cancer, potential chemoradiation strategies were studied. We indicated a schedule including carboplatin plus paclitaxel as preferred option. Next, we address the implications of our findings for clinical practice and identify topics in the field of (proximal) esophageal cancer that need further interdisciplinary investigation.

\section{Exploring the scope of esophageal cancer: incidence and survival}

Squamous cell cancer and adenocarcinoma of the esophagus are distinct histologic entities, with different pathogenesis, tumor biology, and outcomes. ${ }^{1}$ Historically, squamous cell cancer has been the most common esophageal malignancy. During past decades however, with the tremendous increase in obesity in the Western industrialized population, ${ }^{2}$ adenocarcinomas dominate the field of esophageal cancer, as a result of gastroesophageal reflux disease and subsequent Barrett's esophagus. ${ }^{3} \mathrm{We}$ observed that the incidence of adenocarcinomas increased in the Netherlands from 3 to 10 per 100,000 inhabitants per year in 1989-1994 and 2010-2014, respectively, 
hereby surpassing the rate of esophageal squamous cell cancer. This change in histology dominance corresponds with data from 46,063 patients from the United States (US) diagnosed with esophageal cancer in 1973-2015 using the Surveillance, Epidemiology, and End Results (SEER) program database. ${ }^{4}$ Given the higher impact of adenocarcinomas on society, less attention has been given to esophageal squamous cell cancer in Western countries. Hence, improving quality of care for patients with esophageal squamous cell cancer is even more a major challenge as a consequence of the relatively low incidence. ${ }^{5}$

Using data from the Netherlands Cancer Registry, we showed that there has yet been achieved a survival improvement over the past few decades for the total group of esophageal cancer, as well as for esophageal squamous cell cancer patients, particularly in patients with non-metastatic disease and in the period 2005 to 2014. Five-year relative survival for all patients with esophageal cancer increased from $8 \%$ in 1989-1994 to $22 \%$ in 2010-2014. In patients with non-metastatic esophageal squamous cell cancer relative survival increased threefold, achieving a 5 -year relative survival of $27 \%$ for patients diagnosed between 2010 and 2014.

\section{Treatment strategies in non-metastatic esophageal cancer}

We postulate that various factors have led to the improved survival of non-metastatic esophageal cancer. First, survival may have improved due to better diagnostic procedures, resulting in improved staging and patient selection. With the introduction of high-quality computed tomography (CT) and ${ }^{18}$ fluorodeoxyglucose (FDG) positron emission tomography (PET) scanners, endoscopic and endobronchial ultrasonography, staging has become more precise..$^{6-9}$ We demonstrated that over time, more patients could be staged more accurately, by means of decreasing rates of patients with unknown tumor stages and higher rates of patients with advanced stage disease. Hence, for each individual patient, clinically meaningful treatment possibilities could be depicted in a more careful way, optimizing treatment trajectories for patients with localized cancers, and justifying and discussing palliative options when disease has been diagnosed in an advanced stage. Since the survival of all patients with esophageal cancer increased, the impact of stage migration can only partly explain the increased survival of patients with non-metastatic esophageal cancer.

Second, centralization of surgical care has been associated with a decline in postoperative complications, and improved long-term survival. ${ }^{10-12}$ We demonstrated that the rates of resections being performed in high-volume centers ( $\geq 20$ procedures 
yearly) increased, from one in three resections in 1989-1994 to nearly all in 2010-2014. Furthermore, this concentration might have led to a better preoperative patient selection due to the usage of high-quality diagnostic procedures and associated judgement of a multidisciplinary expertise team. This is, illustrated by an improved survival in both patients with metastatic and non-metastatic disease.

Third, the introduction of chemoradiation has contributed to more curative options and better survival rates. Treatment strategies for patients fit enough for surgery are enhanced by applying neoadjuvant chemoradiation. Moreover, escalating therapeutic options for inoperable patients are being implemented by the introduction of definitive chemoradiation at the expense of radiotherapy alone. Among patients with nonmetastatic esophageal adenocarcinomas, neoadjuvant chemoradiation followed by resection increased from 4\% in 1989-1994 to roughly half of patients in 2010-2014. In contrast, neoadjuvant chemoradiation was only performed in one out of four patients with non-metastatic esophageal squamous cell cancer in the latest time frame. Moreover, definitive chemoradiation was established mainly in non-metastatic squamous cell cancers (31\%; versus 14\% in adenocarcinomas) in 2010-2014. Interestingly, most previous population-based studies examining trends in treatment in non-metastatic esophageal cancer do not provide data on the total group of patients and focus on subgroups, e.g. excluding patients that did not undergo any form of anticancer therapy. Hence, the denominator is incomparable to the population-based studies described in this thesis. A population-based study of the US, using the National Cancer Database, of patients diagnosed with localized esophageal cancer from 2004 to 2011 treated with chemoradiation demonstrated that $73 \%$ of the patients with squamous cell cancer received a definitive schedule, compared with $47 \%$ of the patients with adenocarcinomas treated with chemoradiation. ${ }^{13}$ The higher rates of definitive schedules in squamous cell cancers, in contrast to neoadjuvant strategies, do reflect the presented results in this thesis.

The observational data from the Netherlands Cancer Registry demonstrated in this thesis necessitate critical interpretation. It is essential to recognize the potential sources of bias, e.g. selection bias and confounding by indication. Furthermore interpretation of data may not reflect the actual situation. In the Netherlands Cancer Registry, treatments were categorized. It is clear that a patient who has been treated with surgery preceded by radiotherapy and chemotherapy, has undergone neoadjuvant chemoradiation. However, patients who underwent radiotherapy and chemotherapy without a surgical approach exhibit a miscellaneous population, i.e. patients not being able to undergo a resection following neoadjuvant chemoradiation, patients indeed 
receiving definitive chemoradiation, or patients refusing surgery when a clinical complete response might have been achieved after neoadjuvant chemoradiation.

The presented results, however, accurately illustrate the paradigm shifts in esophageal cancer care based on high-level, i.e. randomized, evidence, demonstrating neoadjuvant chemoradiation in addition to surgery is efficacious in terms of overall survival, presented by Walsh et al. in 1996, followed by the CALGB 9781 and CROSS trial. ${ }^{14-16}$ As of 2008, neoadjuvant chemoradiation has become the standard of care in the Netherlands. Furthermore, the randomized RTOG 85-01 study depicted chemoradiation as favorable treatment regimen compared with radiotherapy alone for patients with locally advanced esophageal cancer, ${ }^{17}$ confirmed by a systematic review by Wong et al. ${ }^{18}$ Considering squamous cell cancers are highly sensitive to chemoradiation, ${ }^{19}$ treatment strategies with chemoradiation omitting surgery afterwards even in potentially resectable squamous cell cancer showed comparable outcome with neoadjuvant chemoradiation followed by surgery. ${ }^{20,21}$ Notably in patients with squamous cell cancer and $\geq 2$ comorbidities or aged 75 years or above, definitive chemoradiation has found common ground and may be the preferred approach. ${ }^{22}$

\section{Implementing chemoradiation: The key to control outcome in cancers originating in the proximal part of the esophagus}

The proximal esophageal section is located in a complex position because it is surrounded by several vital structures, e.g. vessels, nerves, (hypo)pharynx, vocal cords, larynx, and cervical spine in the highly compact area of the neck. When a cancer arises at the specific site of the proximal esophagus, stretching from the upper esophageal sphincter up to roughly $24 \mathrm{~cm}$ (endoscopically) measured from the incisor teeth, invasion of surrounding structures may occur. ${ }^{23}$ We demonstrated that it only comprises a small subset of all esophageal cancer patients: $6-10 \%$ of all esophageal cancers diagnosed between 1989 and 2014 originated from the proximal part. This corresponds with 80 to 133 new cases yearly in the Netherlands. In addition to the challenging location of these cancers, we showed that nowadays most cancers are being diagnosed with a locally advanced stage, i.e. invading adjacent structures (18\%) or locoregional lymph nodes (59\%). Hence, surgical treatment is even more challenging compared with cancers from more distal parts of the esophagus, as it would necessitate extensive mutilating resections with a high risk of major complications and a significant impact on patients' quality of life. 
As pointed out previously, chemoradiation for esophageal squamous cell cancers has been demonstrated to establish equal outcomes to a surgical approach. However, only a minority of the studies included in the aforementioned randomized trials incorporated patients with proximal esophageal cancers, limiting the extrapolation of these findings to the proximal esophagus.

The question remains how this theory affects the mainframe of patients with proximal esophageal cancer. Based on the data from the Netherlands Cancer Registry, we could confirm the beneficial impact of definitive chemoradiation also holds true for proximal esophageal cancer.

Histology of cancers in the proximal esophagus consists predominantly of squamous cell cancer (81\%). Hence, most cancers in the proximal esophagus exhibit a (chemo)radiotherapy-sensitive biology. ${ }^{1}$ We observed that surgery has been abandoned over time, in favor of the implementation of definitive chemoradiation. In 2010-2014, almost half of patients with non-metastatic proximal esophageal cancer were treated with definitive chemoradiation. Furthermore, the appliance of radiotherapy without chemotherapy was reduced by $50 \%$ between 1989 and 2014 . These results are unique for proximal esophageal cancer in literature. When seeking a comparator, a SEER US-population-based study of cervical esophageal cancer showed a similar shift towards non-surgical treatment modalities. ${ }^{24}$ These findings confirm a different approach in the management of proximal esophageal cancer in specific as compared with non-metastatic squamous cell cancers from the lower parts of the esophagus. In the latter group the proportion of patients treated with surgery remained relatively stable between 1989 and 2014, approximately $25 \%$.

In the same time frame, we found an increase in overall survival for patients with nonmetastatic proximal esophageal cancer. In contrast to patients with metastatic esophageal cancer in general, overall survival in patients with metastatic proximal esophageal cancer did not increase. Hence, improvement in outcome of non-metastatic proximal esophageal cancer cannot be explained by stage migration. We were able to establish that progress in outcome was associated with advances in treatment strategies. Considering bias by indication, we hypothesized that patients undergoing a resection might show a superior outcome when compared with definitive chemoradiation. However, this thesis demonstrated comparable long-term overall survival in patients treated with surgery with or without neoadjuvant chemoradiation versus those treated with definitive chemoradiation. These results are consistent with the findings of two observational studies in patients with squamous cell cancer of the 
cervical esophagus, conducted in Italy (2018) and China (2020). ${ }^{25,26}$ Reminiscing the major disadvantage in quality of life of patients undergoing a surgical strategy, i.e. the physical and psychosocial impact of a permanent tracheostomy and loss of normal voice in addition to increased swallowing efforts and transit time, it is justifiable to state that all proximal esophageal squamous cell cancers should be offered definitive chemoradiation.

\section{Constructing a 'solid gold' definitive chemoradiation schedule for patients with proximal esophageal cancer}

In the past few decades various strategies in chemoradiation design for the treatment of localized esophageal cancer (in general) have been described. Cisplatin with or without fluorouracil played an undisputed key role in concurrent chemoradiation schedules in squamous cell cancers of the esophagus, both in neoadjuvant as well as in definitive setting. ${ }^{27}$ Pathological complete response following cisplatin-based chemoradiation for esophageal cancer was achieved in approximately $25-30 \%$ of patients. $^{15,28,29}$ By establishing a pathological complete response rate of $49 \%$ in esophageal squamous cell cancer following neoadjuvant chemoradiation incorporating carboplatin plus paclitaxel and 41.4 Gy radiotherapy in the phase 3 CROSS trial, this scheme was stated as a designated medalist. ${ }^{16}$ In addition to a superior response, this regimen also demonstrated a favorable safety profile. However, up to now, no randomized trials have been published comparing neoadjuvant or definitive chemoradiation schedules with carboplatin plus paclitaxel versus cisplatin backbones. Conroy et al. ${ }^{30}$ randomly assigned patients that had unresectable esophageal cancer or comorbidities that preclude surgery, to receive chemoradiation with either oxaliplatin and fluorouracil with leucovorin (FOLFOX) or cisplatin and fluorouracil. The radiotherapy regimen (a total dose of $50 \mathrm{~Gy}$ ) was the same in both treatment groups. Endoscopic complete response and progression-free survival, as well as the rates of most frequent grade 3 or 4 adverse events, were comparable between the treatment groups. It is therefore tempting to assume one should bet on a carboplatin plus paclitaxel regimen in the contest of definitive chemoradiation schedules.

Furthermore, the most optimal radiation dose in the definitive setting for proximal esophageal cancer is still under debate. Established chemoradiation schedules for the treatment of locally advanced head and neck squamous cell cancer or regimens used in the management of patients with lower esophageal cancer are implemented with 6070 Gy or 50-50.4 Gy, respectively. ${ }^{17,31-34}$ NCCN guidelines state that 60-66 Gy 
radiotherapy may be appropriate for cancers in the proximal esophagus, although sufficient data to substantiate this statement are lacking. ${ }^{33}$

The following main questions therefore arise:

1. Is there a difference in response and survival in patients with proximal esophageal cancer treated with carboplatin plus paclitaxel versus cisplatin-based chemoradiation?

2. How does radiation dose in proximal esophageal cancer affect outcome parameters?

3. Do safety profiles indicate the quarterback?

In this thesis we have sought answers to these questions. We studied 200 patients with locally advanced proximal esophageal squamous cell cancer treated with definitive chemoradiation, categorized in cisplatin and low dose radiotherapy ( $\leq 50 \mathrm{~Gy}$ ), cisplatin and high dose radiotherapy (>50 Gy), carboplatin plus paclitaxel and low dose radiotherapy, and carboplatin plus paclitaxel and high dose radiotherapy. Since a randomized controlled trial in a disease with this low incidence is unlikely to be performed, we provide the second-best study design. Affirming the observational nature makes it sensitive for bias, such as selection bias, all participating centers in the presented comparative effectiveness study in proximal esophageal cancer were predominantly using a single preferential chemoradiation regimen, irrespective of patient's characteristics. As such, patient's exposure to an individual chemoradiation group resembles random assignment, harboring causal inference.

We demonstrated that median overall survival was 21.9 months (95\% Cl: $16.9-27.0$ months) and comparable between the four chemoradiation schedules (logrank $P=0.88$ ), confirmed in the fully adjusted and propensity weighted models ( $P>0.05)$. Three-year overall survival rates were not statistically significantly different, with 35\% (95\% Cl: $22-$ $48 \%$ ) in patients treated with cisplatin and low dose radiotherapy compared with $46 \%$ (95\% Cl: $30-61 \%), 40 \%$ (95\% Cl: $30-50 \%)$, and 33\% (95\% Cl: $10-59 \%)$, in the groups treated with cisplatin and high dose radiotherapy, carboplatin plus paclitaxel and low dose radiotherapy, and carboplatin plus paclitaxel and high dose radiotherapy, respectively. These survival outcomes in our comparative effectiveness study in proximal esophageal cancer correspond with the observed results in previous studies examining definitive chemoradiation schedules, with 3-year overall survival rates of 35$45 \%{ }^{35-41}$ 
In view of the inability to determine a preferred schedule based on survival differences between the four treatment groups, arguments for treatment choice might be based on the recorded toxicity profiles. The incidence of grades 3-5 acute adverse events was significantly lower in patients treated with carboplatin plus paclitaxel and low dose radiotherapy compared with patients treated with a cisplatin-based chemoradiation regimen. One in five patients treated with carboplatin plus paclitaxel and low dose radiotherapy experienced grades 3 or 4 acute adverse events, whereas half of the patients treated in the other three groups did. Hence, we concluded that carboplatin plus paclitaxel is the preferred backbone of definitive chemoradiation in patients with locally advanced proximal esophageal squamous cell cancer. Even though not statistically significant, there was an association of lower grades 3-5 adverse event rates in patients treated with 50.4 Gy radiotherapy versus higher radiation dose, in carboplatin plus paclitaxel regimens.

No data from randomized trials have been published comparing different chemoradiation schemes in patients with proximal esophageal cancer. The limited randomized series on definitive chemoradiation in esophageal cancer exploit either unknown numbers of proximal esophageal cancer, ${ }^{42}$ or restricted rates of patients with proximal esophageal cancer. ${ }^{30,43,44}$ Furthermore, comparisons between definitive or neoadjuvant chemoradiation regimens containing cisplatin and carboplatin plus paclitaxel have only been studied retrospectively. Results from a small Dutch comparative study $(\mathrm{N}=102)$ in the definitive treatment of thoracic esophageal cancer support implementing carboplatin plus paclitaxel in chemoradiation, showing comparable survival and a more favorable toxicity profile when compared with cisplatin-based chemoradiation. ${ }^{45}$ In contrast, a recent Canadian study stated that cisplatin-based chemoradiation was superior to carboplatin plus paclitaxel in the definitive setting of esophageal or gastroesophageal junction cancer, excluding cancers from the cervical esophagus. ${ }^{46}$ They demonstrated favorable outcomes in patients treated with cisplatin-based chemoradiation with superior 3-year overall survival (36 vs. 63\%; $\mathrm{P}=0.001$ ) and disease-free survival ( 0 vs. 41\%; $\mathrm{P}=0.004$ ). However, only 26 patients ( $\mathrm{N}=18$ cisplatin; $\mathrm{N}=8$ carboplatin plus paclitaxel) were included, with imbalanced baseline characteristics, e.g. histology and radiation dose. Furthermore, a low dose cisplatin-based schedule was applied.

This finding corresponds with the conception that high dose cisplatin regimens, as included in our comparative effectiveness study, might be the major contributor to the unfavorable toxicity profile in this treatment group. Dysphagia was the most frequent grade 3 or 4 acute adverse event in all four treatment groups. One out of four patients 
treated with cisplatin-based chemoradiation experienced severe dysphagia, i.e. necessity of tube or parenteral feeding, or hospitalization, in contrast to $8 \%$ of the patients in the carboplatin plus paclitaxel and low dose radiotherapy group.

To evaluate registration bias in this retrospective study, a multivariable multilevel analysis (patients within centers) was performed, and confirmed the encouraging safety profile for patients treated with carboplatin plus paclitaxel and low dose radiotherapy compared with a cisplatin-based regimen. Furthermore, the patients treated with carboplatin plus paclitaxel and low dose radiotherapy in our study demonstrated higher treatment-related grade 3 or greater toxic event rates, as compared with data from the randomized neoadjuvant CROSS-trial. ${ }^{16}$ This is to be expected since the median radiation dose applied in the definitive schedule of carboplatin plus paclitaxel and low dose radiotherapy was 50.4 Gy (93\% of patients underwent 50.4 Gy) in our study, compared with $92 \%$ of patients receiving the full dose of neoadjuvant radiotherapy of $41.4 \mathrm{~Gy}$ in the CROSS-trial. Interestingly, the recent phase 3 ARTDECO trial, $^{47}$ showed exceedingly high rates of grade 3-5 adverse events of $70 \%$ in patients treated with comparable definitive chemoradiation schedule of carboplatin plus paclitaxel and $50.4 \mathrm{~Gy}$ radiotherapy treated for inoperable or unresectable esophageal cancer. This trial included 260 patients of which $61 \%$ were squamous cell cancers and $28 \%(N=73)$ cancers located in the proximal esophagus. The results of the ARTDECO trial suggest that toxicity might be underreported in our cohort of carboplatin plus paclitaxel in combination with low dose radiotherapy. However, it is important to realize the actual toxicity rates in cisplatin-based regimens in the current retrospective study might also be higher than registered considering cisplatin-based therapy was being executed in the earlier years with impaired registration compared with the more recent period as demonstrated in the multilevel analysis.

As a surrogate marker for toxicity, it is of interest to review treatment adherence. The comparative effectiveness study of this thesis demonstrated that patients treated with cisplatin and high dose radiotherapy were frequently unable to adhere to the full treatment scheme (41\%), in accordance to previous data. ${ }^{45}$ Remarkably, the group of patients treated with cisplatin and low dose radiotherapy could largely complete chemoradiation (82\%). This observation underlines the disputed effect of radiation dose escalation on toxicity in definitive schedules in esophageal cancer in general, and proximal esophageal cancer in specific. In our comparative effectiveness study, the impact of radiation dose escalation on safety could not be ruled out since only 12 patients treated with carboplatin plus paclitaxel and high dose radiotherapy were included. The phase 3 ARTDECO trial demonstrated higher rates of grade 3-5 adverse 
events $(86 \%)$ in patients with esophageal cancer treated with radiation dose escalation to 61.6 Gy to the primary tumor compared with $50.4 \mathrm{~Gy}$, which did neither result in an improvement of local tumor control (3-year local progression free survival of $73 \%$ versus $71 \%$, respectively, $\mathrm{P}=0.62$ ) nor in overall survival (3-year overall survival of $40 \%$ versus $41 \%$ respectively, $\mathrm{P}=0.21)^{47}$

These findings correspond with historical data in esophageal cancer in general treated with definitive chemoradiation, which could not establish improvements in local control or survival applying radiation dose escalation. ${ }^{42} \mathrm{~A}$ meta-analysis of Luo et al. ${ }^{48}$ including the aforementioned RTOG 94-05 trial and seven retrospective studies $(\mathrm{N}=3736)$ demonstrated better outcomes in patients with esophageal squamous cell cancer treated with definitive chemoradiation with high dose radiotherapy ( $\geq 60 \mathrm{~Gy}$ ) versus 45 59.4 Gy. A separate meta-analysis was performed by Xiao et al. ${ }^{49}$ which may reflect the real impact of dose-escalation in modern practice as in the ARTDECO trial utilizing CTbased radiation planning techniques. This meta-analysis demonstrated improved 5-year overall survival in patients with esophageal squamous cell cancer treated with radiation dose of $\geq 60$ Gy compared with 50.4 Gy (HR $0.683,95 \% \mathrm{Cl}: 0.561-0.83 ; \mathrm{P}<0.001$ ), without increasing treatment related toxicities $(P>0.05)$. Hence, high level evidence showed conflicting outcome, and thus the optimal radiation dose in definitive schedules in proximal esophageal cancer remains undetermined.

Consequently, a balance should be attempted between dose escalation to potentially optimize cancer treatment, but not pushing the boundaries of tolerance of both chemotherapy and radiotherapy to increase treatment adherence. Notably, post-hoc analysis showed that premature discontinuing chemoradiation is associated with lower complete response rates. It is axiomatic that cure of cancer cannot be achieved without control of the primary tumor site. There have been many studies investigating the relationship between local control and survival in a variety of malignancies, including esophageal cancer. ${ }^{25,38,40,50}$ Most of these studies have shown that cancer patients reaching local response live longer than those who did not. In addition, the current study demonstrated that long-term survival is only seen in patients achieving complete response following definitive chemoradiation, with a 3 -year overall survival rate of $58 \%$ (95\% Cl: 48-66\%), compared with nearly nil for non-complete responders in our study and other retrospective work. ${ }^{38,40}$

Further optimization of outcome and counseling in complete responders should build upon incidence and sites of recurrence. This thesis provides unique evidence of recurrence patterns in patients with proximal esophageal cancer achieving complete 
response following definitive chemoradiation. Our retrospective study in proximal esophageal cancer described most recurrences occurred locoregional, mainly within the treated region of the primary tumor and lymph nodes. Merely one out of three patients with a recurrence experienced distant metastasis only. These observations were in line with previous smaller cohorts in proximal esophageal cancer, reporting locoregional relapses in $58-84 \%$ of the recurrences although not specific for complete responders. ${ }^{25,35,36,39,51,52}$ Remarkably, we found that patients suffering from an isolated locoregional recurrence treated with salvage surgery demonstrated a favorable longterm outcome with nearly half of patients being alive after three years. This group in fact could represent the asset of optimization of locoregional follow-up after definitive chemoradiation in (proximal) esophageal cancer, which is currently controversial.

Systematic surveillance strategies after successful definitive treatment for proximal esophageal cancer are disputed. In our study, most patients presented with symptoms at the time of recurrence. This was expected since Dutch esophageal and head and neck cancer guidelines advice symptom-based follow-up, whereas endoscopy and imaging studies are only recommended to be performed on indication. This is in line with recommendations of the NCCN guideline. ${ }^{53}$ Contrarily, ESMO guideline states a more strict follow-up should be applied, with 3-monthly endoscopy, biopsies and CT scan. ${ }^{34}$ Scarce literature on the legitimacy of follow-up after definitive chemoradiation is published. The usefulness of surveillance in terms of improving survival is limited for early salvage surgery after (failing) definitive chemoradiation. ${ }^{54}$ It would be of great interest to study the influence of the different methods of follow-up on the rate of detection of locoregional recurrence, and the chances of performing salvage treatment. Particularly nowadays, with innovative salvage surgical approaches in esophageal cancer, e.g. endoscopic resections, ${ }^{55}$ robot-assisted minimally invasive procedures, ${ }^{56,57}$ and the advantages of high volume expertise centers. ${ }^{10,58}$

\section{Future perspectives}

This thesis contributes to the assessment and understanding of previously unexplored aspects of outcome in patients with (proximal) esophageal cancer. Research in this rare disease is a challenging and dynamic process. However, findings described in this thesis add to a body of evidence suggesting that definitive chemoradiation is the preferred treatment modality in proximal esophageal cancer, with a backbone of carboplatin plus paclitaxel demonstrating most optimal outcome compared with cisplatin-based regimens. Furthermore, understanding of the patterns of recurrence provides evidence 
for a boost to reevaluate follow-up after definitive chemoradiation in proximal esophageal cancer.

By exploring the most advantageous chemoradiation schedule, we concentrated on survival and safety. Since chemoradiation consists of two separate treatment modalities, it is of interest to study this management as a whole. However, progress in techniques will primarily be explored in the separate methods of radiotherapy and the backbone of chemotherapy or, in a broader context, systemic therapy.

Future studies will need to ascertain the exact role of radiation dose escalation in proximal esophageal cancer, and whether this is related to an effect on local control and survival, without significantly increasing rates of dysphagia, esophageal strictures and fistulas. Hence, protocols involving proton beam therapy and magnetic resonance imaging (MRI)-guided radiotherapy are under development in the definitive setting in esophageal cancer, in order to minimize the volume of organs at risk exposed to radiation. ${ }^{59}$ In the case of proton beam radiotherapy, the unique physical properties of proton irradiation reduce the rates and severity of profound radiotherapy-related toxicities compared with photon radiotherapy. First randomized data have recently been published by Lin et al. ${ }^{60}$ studying proton beam therapy versus intensity-modulated radiation therapy in patients with locally advanced esophageal cancer treated with neoadjuvant or definitive chemoradiation (50.4 Gy) in a phase $2 \mathrm{~B}$, single-institutional, open-label trial. This trial demonstrated a 2.3 times higher total toxicity burden for intensity-modulated radiation therapy compared with proton beam therapy (grades 3-5 adverse events in $64 \%$ versus $54 \%$, respectively), with similar survival in both arms, i.e. 3 -year progression free survival of $51 \%$ and 3 -year overall survival of $45 \%$. However, of the enrolled patients only a minority (3\%) had a proximal esophageal cancer and only $11 \%$ of the included cancers was of squamous cell origin. As such, future research focusing on total toxicity burden of proton beam therapy in definitive chemoradiation schedules for proximal esophageal cancer is warranted. Furthermore, the concept of MRI-guided radiotherapy achieves a superior tumor visualization and allows smaller margins and daily adapted treatment, resulting in lower doses to organs at risk. ${ }^{61,62}$ Subsequent studies will investigate the exact benefit of MRI-guided therapy for the localization of the macroscopic extent of the tumor and real time tumor tracking in esophageal cancer patients.

Contributing to the developments in the field of radiotherapy, optimization of systemic therapy as backbone in concurrent treatment is essential. Combining immunotherapy to radiotherapy might be of interest considering radiotherapy can create a 
proinflammatory tumor microenvironment and increase the T-cell inflamed geneexpression profile, ${ }^{63}$ and achieve a stronger systemic immune response, i.e. the abscopal effect. ${ }^{64}$ In esophageal cancer, future research will have to elucidate this role in combination therapy.

Recent studies of immune checkpoint inhibitors, without radiotherapy, in esophageal cancer have yet shown significant improvements in outcome. CheckMate-649 is the first randomized phase 3 trial in metastatic esophageal cancer demonstrating superior survival of the (programmed cell death-1) PD-1 inhibitor nivolumab in combination with chemotherapy when compared to chemotherapy alone in first-line therapy, with median overall survival of 13.8 versus 11.6 months, respectively (HR 0.80, $\mathrm{P}=0.0002$ ). ${ }^{65}$ Notably, only adenocarcinomas were enrolled in this trial. Results of the CheckMate648 study in esophageal squamous cell cancer are to be awaited. ${ }^{66}$ The KEYNOTE-590 trial, however, included patients with esophageal squamous cell cancer, demonstrating a similar study design as CheckMate-649 with a different PD-1 inhibitor, pembrolizumab. ${ }^{67}$ Pembrolizumab plus chemotherapy improved overall and progression-free survival in patients with esophageal squamous cell cancer, particularly with programmed cell death-ligand 1 (PD-L1) combined positive score (CPS) $\geq 10$, demonstrating median overall survival of 13.9 versus 8.8 months, respectively (HR 0.57 , $\mathrm{P}<0.0001)$.

The feasibility of combining immunotherapy with definitive chemoradiation in esophageal cancer is studied in the TAPESTRY trial (NCT04595149). This single-arm phase 2 study investigates the addition of bintrafusp- $\alpha$, a combined transforming growth factor (TGF)- $\beta$ and PD-L1 inhibitor, to carboplatin plus paclitaxel and 50.4 Gy radiotherapy in patients with non-metastatic unresectable esophageal squamous cell cancer. In head and neck squamous cell cancer, early efficacy data of the combination of pembrolizumab and cisplatin-based chemoradiation support further investigation, demonstrating a 2-year overall survival rate of $97 \%$ including 47 patients (80\%) with TNM stage IVA disease. $^{68}$

In response to the encouraging results from the CheckMate-577 trial, $^{69}$ adjuvant immunotherapy following definitive chemoradiation is investigated. The randomized CheckMate-577 trial showed significantly improved disease-free survival with adjuvant nivolumab compared to placebo in patients with resected esophageal or gastroesophageal junction cancer who have received neoadjuvant chemoradiation and have not achieved a pathological complete response. Adjuvant PD-L1 inhibitor atezolizumab following definitive chemoradiation is being investigated in the 
multicenter phase 2 TENERGY trial. $^{70}$ These observations pose the question whether immunotherapy directly in combination with or following chemoradiation would improve outcome in the definitive setting of patients with proximal esophageal cancer. Importantly, further deduction of patient selection is needed to confine subgroups who benefit from the treatment, e.g. PD-L1 positive (CPS $\geq 5$ or 10) groups and/or microsatellite instable status. Based on the poor prognosis of non-complete responders following definitive chemoradiation, one could postulate adding immunotherapy in these patients would have limited impact on outcome. Moreover, it could be hypothesized that adjuvant immunotherapy would be of interest in patients achieving complete response following definitive chemoradiation.

Howbeit, this proposal necessitates physicians to accurately define response rates soon after completion of definitive chemoradiation. Current practice includes tumor response assessment three months after completion of chemoradiation by means of clinical investigation and/or imaging. The best approach regarding evaluation of response after definitive chemoradiation has not been established and is notoriously inaccurate, since imaging evaluations are hindered by extensive radiation-induced inflammation and fibrosis, which can mimic persistently active or recurrent/progressive disease. ESMO guidelines do not include recommendations concerning response evaluation following definitive chemoradiation. ${ }^{34}$ However, the NCCN guideline committee recommends endoscopy and biopsy. ${ }^{53}$ In contrast to prediction of tumor response in adenocarcinomas, ${ }^{71}$ the accuracy of FDG-PET after completion of definitive chemoradiation for esophageal squamous cell cancer has not undisputedly been established. However, FDG-PET, in addition to endoscopic ultrasonography with biteon-bite biopsies and fine-needle aspiration of suspicious lymph nodes, seems to be the best available imaging tool for response assessment after neoadjuvant chemoradiation in esophageal cancer. ${ }^{72}$ The main contribution of FDG-PET is the detection of interval metastases, whereas accuracy of detecting locoregional residual disease by FDG-PET is poor as shown by the high proportion of false-negative cases. ${ }^{73}$ Novel integrative approaches, e.g. diffusion-weighted $\mathrm{MRI}^{74}$ a radiomics nomogram model, ${ }^{75}$ or circulating tumor DNA, ${ }^{76}$ are to be investigated. Future studies will need to ascertain the exact role of these modalities in the setting of definitive chemoradiation. For the use in clinical practice, a validated prediction model to substantiate outcome in terms of clinical complete response should be explored, containing variables derived from a Delphi procedure.

Separately, aside from optimization of current medical approaches to increase the rate of complete response, therapeutic strategies are to be examined specifically aimed to 
enforce salvage procedures in residual or recurrent disease. Yet, isolated recurrences in the proximal part of the esophagus are difficult to treat, with limited rescue options after definitive chemoradiation and additional side effects including esophageal strictures and fistulas. ${ }^{77}$ In particular, patients without signs of node positive recurrent disease and esophageal stenosis should be selected for an aggressive strategy. ${ }^{78,79}$ However, solid evidence on improved outcome following invasive approaches, as well as validating its safety, is lacking. First, we propose to extend the observational work by inviting additional international institutions to obtain larger numbers of patients undergoing salvage therapies. Next, research should also include prospective evaluation of salvage surgery and reirradiation in residual and locoregional recurrent proximal esophageal cancer, to ascertain whether this exposure should be considered as legitimate treatment option.

To conclude, the increased use of chemoradiation strategies has significantly improved the outcome of non-metastatic (proximal) esophageal cancer patients over the last decades. Whereas the 5 -year relative survival of patients with non-metastatic esophageal squamous cell cancer diagnosed in the Netherlands was only $9 \%$ in the period 1989 to 1994 , it improved to $27 \%$ in the period from 2010 to 2014 . However, more attempts should be made to secure leverage on improved patient outcomes in proximal esophageal cancer. To achieve this goal multidisciplinary collaboration is essential to ultimately further improve quality of life and (counseling of) treatment options to strive for enhanced long-term survival in patients with proximal esophageal cancer. 


\section{References}

1. Siewert JR, Ott K. Are squamous and adenocarcinomas of the esophagus the same disease? Semin Radiat Oncol 2007;17(1):38-44.

2. Ward ZJ, et al. Projected U.S. State-Level Prevalence of Adult Obesity and Severe Obesity. N Engl J Med 2019;381(25):2440-50.

3. Smyth, E.C., et al., Oesophageal cancer. Nat Rev Dis Primers 2017;3:17048.

4. $\mathrm{He} \mathrm{H}$, et al. Trends in the incidence and survival of patients with esophageal cancer: A SEER database analysis. Thorac Cancer 2020;11(5):1121-8.

5. Ferlay J, et al. Global Cancer Observatory: Cancer Today. Lyon, France: International Agency for Research on Cancer. Available from: https://gco.iarc.fr/today (accessed November 23,2020).

6. van Vliet EP, et al. Staging investigations for oesophageal cancer: a meta-analysis. Br J Cancer 2008; 98(3):547-57.

7. Kim TJ, et al. Multimodality assessment of esophageal cancer: preoperative staging and monitoring of response to therapy. Radiographics 2009;29(2):403-21.

8. Findlay JM, et al. Pragmatic staging of oesophageal cancer using decision theory involving selective endoscopic ultrasonography, PET and laparoscopy. Br J Surg 2015;102(12):1488-99.

9. Puli SR, et al. Staging accuracy of esophageal cancer by endoscopic ultrasound: a meta-analysis and systematic review. World J Gastroenterol 2008;14(10):1479-90.

10. van de Poll-Franse LV, et al. Impact of concentration of oesophageal and gastric cardia cancer surgery on long-term population-based survival. Br J Surg 2011;98(7):956-63.

11. Dikken JL, et al. Effect of hospital volume on postoperative mortality and survival after oesophageal and gastric cancer surgery in the Netherlands between 1989 and 2009. Eur J Cancer 2012;48(7):1004-13.

12. Han S, et al. The Volume-Outcome Effect Calls for Centralization of Care in Esophageal Adenocarcinoma: Results From a Large National Cancer Registry. Am J Gastroenterol, 2020.

13. Shao MS, et al. Definitive or Preoperative Chemoradiation Therapy for Esophageal Cancer: Patterns of Care and Survival Outcomes. Ann Thorac Surg 2016;101(6):2148-54.

14. Walsh TN, et al. A comparison of multimodal therapy and surgery for esophageal adenocarcinoma. $\mathrm{N}$ Engl J Med 1996;335(7):462-7.

15. Tepper J, et al. Phase III trial of trimodality therapy with cisplatin, fluorouracil, radiotherapy, and surgery compared with surgery alone for esophageal cancer: CALGB 9781. J Clin Oncol 2008;26(7): 1086-92.

16. van Hagen $\mathrm{P}$, et al. Preoperative Chemoradiotherapy for Esophageal or Junctional Cancer. N Engl J Med 2012;366(22):2074-84.

17. Cooper JS, et al. Chemoradiotherapy of locally advanced esophageal cancer: long-term follow-up of a prospective randomized trial (RTOG 85-01). Radiation Therapy Oncology Group. JAMA 1999;281(17): 1623-7.

18. Wong R, Malthaner R. Combined chemotherapy and radiotherapy (without surgery) compared with radiotherapy alone in localized carcinoma of the esophagus. Cochrane Database Syst Rev 2006;(1): Cd002092.

19. Wolfe WG, et al. Survival of patients with carcinoma of the esophagus treated with combined-modality therapy. J Thorac Cardiovasc Surg 1993;105(4):749-55; discussion 755-6.

20. Stahl $\mathrm{M}$, et al. Chemoradiation with and without surgery in patients with locally advanced squamous cell carcinoma of the esophagus. J Clin Oncol 2005;23(10):2310-7.

21. Bedenne $L$, et al. Chemoradiation followed by surgery compared with chemoradiation alone in squamous cancer of the esophagus: FFCD 9102. J Clin Oncol 2007;25(10):1160-8.

22. Faiz Z, et al. Impact of Age and Comorbidity on Choice and Outcome of Two Different Treatment Options for Patients with Potentially Curable Esophageal Cancer. Ann Surg Oncol 2019;26(4):986-95.

23. Greene FL, et al. AJCC Cancer Staging Manual, 6th Edition. Springer-Verlag New York, 2002.

24. Grass GD, et al. Cervical esophageal cancer: A population-based study. Head Neck 2015;37(6):808-14.

25. Valmasoni M, et al. Cervical Esophageal Cancer Treatment Strategies: A Cohort Study Appraising the Debated Role of Surgery. Ann Surg Oncol 2018;25(9):2747-55. 
26. Chen $\mathrm{P}$, et al. Characterization of 500 Chinese patients with cervical esophageal cancer by clinicopathological and treatment outcomes. Cancer Biol Med 2020;17(1):219-26.

27. Poplin E, et al. Combined therapies for squamous-cell carcinoma of the esophagus, a Southwest Oncology Group Study (SWOG-8037). J Clin Oncol 1987;5(4):622-8.

28. Bosset JF, et al. Chemoradiotherapy followed by surgery compared with surgery alone in squamous-cell cancer of the esophagus. N Engl J Med 1997;337(3):161-7.

29. Berger AC, et al. Complete response to neoadjuvant chemoradiotherapy in esophageal carcinoma is associated with significantly improved survival. J Clin Oncol 2005;23(19):4330-7.

30. Conroy T, et al. Definitive chemoradiotherapy with FOLFOX versus fluorouracil and cisplatin in patients with oesophageal cancer (PRODIGE5/ACCORD17): final results of a randomised, phase $2 / 3$ trial. Lancet Oncol 2014;15(3):305-14.

31. Pignon JP, et al. Meta-analysis of chemotherapy in head and neck cancer (MACH-NC): an update on 93 randomised trials and 17,346 patients. Radiother Oncol 2009;92(1):4-14.

32. Strojan P, et al. Cumulative cisplatin dose in concurrent chemoradiotherapy for head and neck cancer: A systematic review. Head Neck 2016;38(S1):E2151-E2158.

33. National Comprehensive Cancer Network. NCCN Guidelines ${ }^{\circledR}$. NCCN Guidelines ${ }^{\circledR}$ \& Clinical Resources 2018. Esophageal and Esophagogastric Junction Cancers (Version 2.2018). 2018 May 22, 2018; Available from: https://www.nccn.org/professionals/physician_gls/pdf/esophageal.pdf.

34. Lordick F, et al. Oesophageal cancer: ESMO Clinical Practice Guidelines for diagnosis, treatment and follow-up. Ann Oncol 2016;27(suppl 5):v50-7.

35. Huang $\mathrm{SH}$, et al. Effect of concurrent high-dose cisplatin chemotherapy and conformal radiotherapy on cervical esophageal cancer survival. Int J Radiat Oncol Biol Phys 2008;71(3):735-40.

36. Zhang $P$, et al. Clinical efficacy and failure pattern in patients with cervical esophageal cancer treated with definitive chemoradiotherapy. Radiother Oncol 2015;116(2):257-61.

37. Herrmann E, et al. Outcome of proximal esophageal cancer after definitive combined chemo-radiation: a Swiss multicenter retrospective study. Radiat Oncol 2017;12(1):97.

38. Gkika $E$, et al. Long-term results of definitive radiochemotherapy in locally advanced cancers of the cervical esophagus. Dis Esophagus 2014;27(7):678-84.

39. Yamada K, et al. Treatment results of radiotherapy for carcinoma of the cervical esophagus. Acta Oncol 2006;45(8):1120-5.

40. Uno $\mathrm{T}$, et al. Concurrent chemoradiation for patients with squamous cell carcinoma of the cervical esophagus. Dis Esophagus 2007;20(1):12-8.

41. Ludmir EB, et al. Incidence and prognostic impact of high-risk HPV tumor infection in cervical esophageal carcinoma. J Gastrointest Oncol 2014;5(6):401-7.

42. Minsky BD, et al. INT 0123 (Radiation Therapy Oncology Group 94-05) Phase III Trial of CombinedModality Therapy for Esophageal Cancer: High-Dose Versus Standard-Dose Radiation Therapy. Journal of Clinical Oncology 2002;20(5):1167-74.

43. Crosby $\mathrm{T}$, et al. Chemoradiotherapy with or without cetuximab in patients with oesophageal cancer (SCOPE1): a multicentre, phase 2/3 randomised trial. Lancet Oncol 2013;14(7):627-37.

44. Chen Y, et al. Comparing Paclitaxel Plus Fluorouracil Versus Cisplatin Plus Fluorouracil in Chemoradiotherapy for Locally Advanced Esophageal Squamous Cell Cancer: A Randomized, Multicenter, Phase III Clinical Trial. J Clin Oncol 2019;37(20):1695-703.

45. Honing J, et al. A comparison of carboplatin and paclitaxel with cisplatinum and 5-fluorouracil in definitive chemoradiation in esophageal cancer patients. Ann Oncol 2014;25(3):638-43.

46. Jiang DM, et al. Chemoradiotherapy Using Carboplatin plus Paclitaxel versus Cisplatin plus Fluorouracil for Esophageal or Gastroesophageal Junction Cancer. Oncology 2020:1-8.

47. Hulshof MCCM, et al. A randomized controlled phase III multicenter study on dose escalation in definitive chemoradiation for patients with locally advanced esophageal cancer: ARTDECO study. J Clin Oncol 2020; 38: p. Abstract 281.

48. Luo HS, Huang HC, Lin LX. Effect of modern high-dose versus standard-dose radiation in definitive concurrent chemo-radiotherapy on outcome of esophageal squamous cell cancer: a meta-analysis. Radiat Oncol 2019;14(1):178. 
49. Xiao L, et al. Do Higher Radiation Doses with Concurrent Chemotherapy in the Definitive Treatment of Esophageal Cancer Improve Outcomes? A Meta-Analysis and Systematic Review. J Cancer 2020;11(15): 4605-13.

50. Zenda S, et al. Multicenter Phase 2 Study of Cisplatin and 5-Fluorouracil With Concurrent Radiation Therapy as an Organ Preservation Approach in Patients With Squamous Cell Carcinoma of the Cervical Esophagus. Int J Radiat Oncol Biol Phys 2016;96(5):976-84.

51. Zhao L, et al. Patterns of failure and clinical outcomes of definitive radiotherapy for cervical esophageal cancer. Oncotarget 2017;8(13):21852-60.

52. Esmati $\mathrm{E}$, et al. Outcomes of Definitive Chemoradiotherapy for Cervical and Upper Thoracic Esophageal Cancers: a Single-Institution Experience of a Rare Cancer. J Gastrointest Cancer 2019;50(3):380-5.

53. Ajani JA, et al. Esophageal and Esophagogastric Junction Cancers, Version 2.2019, NCCN Clinical Practice Guidelines in Oncology. J Natl Compr Canc Netw 2019;17(7):855-83.

54. Markar S, et al. Salvage Surgery After Chemoradiotherapy in the Management of Esophageal Cancer: Is It a Viable Therapeutic Option? J Clin Oncol 2015;33(33):3866-73.

55. Al-Kaabi A, et al. Salvage endoscopic resection after definitive chemoradiotherapy for esophageal cancer: a Western experience. Gastrointest Endosc, 2020.

56. Defize IL, et al. ASO Author Reflections: Preoperative Selection of cT4b Esophageal Cancer Patients Who Benefit From a Salvage Robot-Assisted Minimally Invasive Esophagectomy (RAMIE). Ann Surg Oncol 2020.

57. Defize IL, et al. Salvage Robot-Assisted Minimally Invasive Esophagectomy (RAMIE) for T4b Esophageal Cancer After Definitive Chemoradiotherapy. Ann Surg Oncol 2020.

58. van Putten M, et al. Hospital of Diagnosis Influences the Probability of Receiving Curative Treatment for Esophageal Cancer. Ann Surg 2018;267(2):303-10.

59. Mitin T, Zietman AL. Promise and pitfalls of heavy-particle therapy. J Clin Oncol 2014;32(26):2855-63.

60. Lin SH, et al. Randomized Phase IIB Trial of Proton Beam Therapy Versus Intensity-Modulated Radiation Therapy for Locally Advanced Esophageal Cancer. J Clin Oncol 2020;38(14):1569-79.

61. Münch S, et al. DVH- and NTCP-based dosimetric comparison of different longitudinal margins for VMAT-IMRT of esophageal cancer. Radiat Oncol 2017;12(1):128.

62. Lips I, et al. SU-E-J-57: MRI-Linac (MRL) Guided Treatment for Esophageal Cancer. Med Phys 2012; 39(6Part6):3665.

63. Weichselbaum RR, et al. Radiotherapy and immunotherapy: a beneficial liaison? Nat Rev Clin Oncol 2017;14(6):365-79.

64. Demaria $S$, et al. lonizing radiation inhibition of distant untreated tumors (abscopal effect) is immune mediated. Int J Radiat Oncol Biol Phys 2004;58(3):862-70.

65. Moehler M. Nivolumab (NIVO) plus chemotherapy (chemo) versus chemo as first-line (1I) treatment for advanced gastric cancer/gastroesophageal junction cancer (GC/GEJC)/esophageal adenocarcinoma (EAC): First results of the CheckMate 649 study. Ann Oncol 2020;31:Abstract LBA6_PR.

66. Ajani J, et al. CheckMate-648: a Randomized Phase 3 Study of Nivolumab Plus Ipilimumab or Nivolumab Combined With Fluorouracil Plus Cisplatin vs Fluorouracil Plus Cisplatin in Patients With Unresectable Advanced, Recurrent, or Metastatic Previously Untreated Esophageal Squamous Cell Carcinoma. ASCOGI Annual Meeting, 2018.

67. Kato K. Pembrolizumab plus chemotherapy versus chemotherapy as first-line therapy in patients with advanced esophageal cancer: The phase 3 KEYNOTE-590 study. Ann Oncol 2020;31:Abstract LBA8_PR.

68. Powell SF, et al. Safety and Efficacy of Pembrolizumab With Chemoradiotherapy in Locally Advanced Head and Neck Squamous Cell Carcinoma: A Phase IB Study. J Clin Oncol 2020;38(21):2427-37.

69. Kelly RJ. Adjuvant nivolumab in resected esophageal or gastroesophageal junction cancer (EC/GEJC) following neoadjuvant chemoradiation therapy (CRT): First results of the CheckMate 577 study. Ann Oncol 2020;31:S1142-215.

70. Bando $\mathrm{H}$, et al. TENERGY: multicenter phase II study of Atezolizumab monotherapy following definitive Chemoradiotherapy with 5-FU plus Cisplatin in patients with unresectable locally advanced esophageal squamous cell carcinoma. BMC Cancer 2020;20(1):336.

71. Lordick F, et al. PET to assess early metabolic response and to guide treatment of adenocarcinoma of the oesophagogastric junction: the MUNICON phase II trial. Lancet Oncol 2007;8(9):797-805. 
72. Rebollo Aguirre AC, et al. 18F-fluorodeoxiglucose positron emission tomography for the evaluation of neoadjuvant therapy response in esophageal cancer: systematic review of the literature. Ann Surg 2009;250(2):247-54.

73. Noordman BJ, et al. Detection of residual disease after neoadjuvant chemoradiotherapy for oesophageal cancer (preSANO): a prospective multicentre, diagnostic cohort study. Lancet Oncol 2018; 19(7):965-74.

74. Borggreve AS, et al. Preoperative Prediction of Pathologic Response to Neoadjuvant Chemoradiotherapy in Patients With Esophageal Cancer Using (18)F-FDG PET/CT and DW-MRI: A Prospective Multicenter Study. Int J Radiat Oncol Biol Phys 2020;106(5):998-1009.

75. Qiu Q, et al. Development and Validation of a Radiomics Nomogram Model for Predicting Postoperative Recurrence in Patients With Esophageal Squamous Cell Cancer Who Achieved pCR After Neoadjuvant Chemoradiotherapy Followed by Surgery. Front Oncol 2020;10:1398.

76. Azad TD, et al. Circulating Tumor DNA Analysis for Detection of Minimal Residual Disease After Chemoradiotherapy for Localized Esophageal Cancer. Gastroenterology 2020;158(3):494-505.e6.

77. Faiz Z, et al. A meta-analysis on salvage surgery as a potentially curative procedure in patients with isolated local recurrent or persistent esophageal cancer after chemoradiotherapy. Eur J Surg Oncol 2019;45(6):931-40.

78. Harada $\mathrm{H}$, et al. Patient selection for salvage surgery after definitive chemoradiotherapy in esophageal squamous cell carcinoma. Langenbecks Arch Surg 2020;405(6):767-76.

79. Zhao K, et al. Efficacy and toxicity of re-irradiation for esophageal cancer patients with locoregional recurrence: a retrospective analysis. Radiat Oncol 2020;15(1):243. 



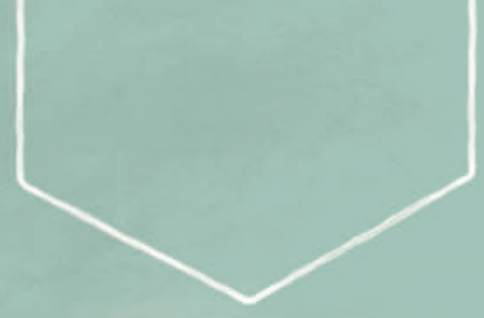

CHAPTER 8

Summary

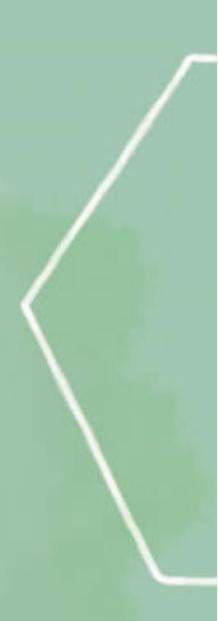





\section{Summary}

The proximal esophagus is the upper segment of the esophagus, consisting of the cervical part starting at the lower part of the cricoid cartilage to the thoracic inlet at approximately $18 \mathrm{~cm}$ from the incisors, and the upper thoracic part from the thoracic inlet to $24 \mathrm{~cm}$ from the incisors (Chapter one). Cancer of the proximal esophagus is an uncommon malignancy, with less than $5 \%$ of all esophageal cancers, ${ }^{1}$ and poses several challenges to combat the current dismal prognosis. Incidence of proximal esophageal cancer in the Netherlands and optimal treatment modality of primary and recurrent disease was unknown. The main aim of this thesis was to investigate incidence and therapeutic patterns for patients with proximal esophageal cancer, in order to optimize patient treatment choices and subsequent outcomes in terms of quality of life and survival.

First, we assessed trends in stage distribution, treatment and its impact on outcome in patients with esophageal cancer in general (Chapter two) and proximal esophageal cancer specifically (Chapter three) diagnosed between 1989 and 2014 in the Netherlands. The aim was to gain more insight through real-life population cohorts, studying the developments in treatment strategies in order to optimize counseling of patients with (proximal) esophageal cancer. For these studies patients with (proximal) esophageal cancer were selected from the Netherlands Cancer Registry. Trends in stage distribution, treatment and survival rates were evaluated. Analyses were stratified by presence of distant metastasis.

In total, 35,760 patients with esophageal cancer were included (Chapter two). Agestandardized incidence rates increased from 5 per 100,000 inhabitants in 1989 to 9 in 2014, whereas mortality rates increased from 5 to 7 per 100,000 inhabitants. The incidence of esophageal adenocarcinoma increased, whereas the new cases with esophageal squamous cell cancer remained relatively stable. The proportion of cancers located in the cervical and upper thoracic part was $<1-3 \%$ and $5-7 \%$, respectively. Due to centralization, rates of resections performed in high-volume hospitals $(\geq 20$ procedures per year) increased from 32\% in 2005 to $92 \%$ in 2014. Neoadjuvant chemoradiation was performed more frequently in patients with non-metastatic esophageal adenocarcinoma and squamous cell cancer, respectively $4 \%$ and $2 \%$ in $2000-2004$ to $43 \%$ and $26 \%$ in $2010-2014$. The use of definitive chemoradiation increased as well, from $8 \%$ in $2000-2004$ to $31 \%$ in $2010-2014$ for non-metastatic esophageal squamous cell cancer, whereas this increase was less prominent for adenocarcinomas (3-14\%). In metastatic disease, patients with adenocarcinomas received chemotherapy more frequently, and with squamous cell cancer underwent 
more frequently radiotherapy and chemotherapy in more recent years. Five-year relative survival increased from $12 \%$ (standard error (SE): $0.9 \%$ ) to $36 \%$ (SE: $0.9 \%$ ) for non-metastatic adenocarcinoma and from 9\% (SE: 0.7\%) to $27 \%$ (SE: $1.2 \%$ ) for nonmetastatic squamous cell cancer over 26 years, particularly in the period 2005-2014. One-year relative survival for metastatic esophageal cancer increased from $15 \%$ (SE: $1.1 \%$ ) to $22 \%$ (SE: $0.7 \%$ ) between 1989 and 2014. We concluded that survival of patients with esophageal cancer improved significantly, which might be attributed to the centralization of surgery and the implementation of (neoadjuvant) chemoradiation.

In 1989-2014, 2,783 patients were diagnosed with proximal esophageal cancer in the Netherlands (Chapter three). In patients with non-metastatic proximal esophageal cancer $(\mathrm{N}=2.194)$, the use of surgery and radiotherapy was substituted by chemoradiation, the latter increasing from $1 \%$ in $1989-1994$ to $49 \%$ in $2010-2014$. Resection without neoadjuvant treatment was performed in $17 \%$ of patients in 1989 1994 and in $2 \%$ of patients in 2010-2014. The proportion of patients treated with neoadjuvant therapy and resection was relatively constant over time, varying between $3 \%$ and $7 \%$. For patients with metastatic disease, only minor variations in treatment were observed, with a slight decrease in radiotherapy use and an increased appliance of chemotherapy and radiotherapy, concurrent or sequential, in $3 \%$ of patients in 1989-1994 and 23\% of patients in 2010-2014. Chemotherapy alone was given to $7 \%$ $12 \%$ of patients in all time periods. Median overall survival of the total population increased from 7.3 months (95\% Cl: 6.4-8.1 months) in 1989-1994, to 9.5 months (95\% Cl: 8.1-10.8 months) in 2010-2014 (logrank $P<0.001)$. In non-metastatic proximal esophageal cancer, five-year overall survival rates improved from 5\% (95\% $\mathrm{Cl}$ : $3 \%-7 \%$ ) in 1989-1994, to 13\% (95\% Cl: 9\%-17\%) in 2010-2014 (logrank $P<0.001)$. In patients with non-metastatic disease, time period effect disappeared after additional inclusion of treatment modality in the multivariable model. All treatment modalities had a statistically significant influence on overall survival compared with no localized treatment $(P<0.001)$. Patients with non-metastatic proximal esophageal cancer treated with surgery with or without neoadjuvant therapy or treated with definitive chemoradiation showed 5-year overall survival rates of $31 \%(95 \% \mathrm{Cl}: 23 \%-40 \%), 21 \%$ (95\% Cl: $16 \%-28 \%)$, and $22 \%(95 \% \mathrm{Cl}: 19 \%-26 \%)$, respectively (logrank $P=0.32)$. In patients with metastatic disease, overall survival did not change significantly over time (logrank $P=0.26$ ). This study showed that overall survival significantly improved in nonmetastatic proximal esophageal cancer, likely to be associated with an increased use of definitive chemoradiation. Treatment patterns and outcome in metastatic disease did not change significantly over time. 
In Chapter four, we present the results of a review of the literature on the diagnosis, treatment options and treatment-related complications of non-metastatic cervical esophageal cancer. Our review identified 107 publications describing a minimum of five patients diagnosed with cancer of the cervical esophagus and treated with curative intent.

We found that cervical esophageal cancer is rare, accounting for $2 \%-10 \%$ of all esophageal cancers. Tobacco and alcohol consumption seemed to be the major risk factors for developing cervical esophageal cancer. Patients with non-metastatic cervical esophageal cancer have a poor prognosis, with a 5-year overall survival of approximately $30 \%$. These tumors are often locally advanced at presentation invading surrounding vital structures, e.g. upper respiratory tract, and are thus frequently unresectable at diagnosis. In other patients with resectable cervical esophageal cancer, surgery would implicate disabling resections including pharyngo-laryngoesophagectomy, with accompanying decline in quality of life. Hence, curative strategies frequently include definitive chemoradiation, adapted by established regimens for lower esophageal or head and neck squamous cell cancer. However, definitive chemoradiation for cervical esophageal cancer is described to be accompanied by severe side-effects and complications. The urgency to progress in the management of cervical esophageal cancer warrants further research to explore which factors and treatment strategies are associated with improved outcomes.

This unchartered territory led to the initiation of a national comparative effectiveness study in proximal esophageal cancer, described in Chapter five. The objective of this study was to compare the treatment outcomes of four contemporary definitive chemoradiation regimens, based on cisplatin (Cis) or carboplatin plus paclitaxel (CP) combined with low ( $\leq 50.4 \mathrm{~Gy}$ ) or high ( $>50.4 \mathrm{~Gy}$ ) dose radiotherapy (RT). We included 200 patients with locally advanced and unresectable squamous cell cancer of the proximal esophagus, from 11 centers in the Netherlands, treated with definitive chemoradiation between 2004-2014. Fifty-four, 39, 95, and 12 patients were treated with Cis-low-dose RT, Cis-high-dose RT, CP-low-dose RT, and CP-high-dose RT, respectively. Clinical complete response was achieved in $57 \%$ to $75 \%$ of patients, whereas the rate of complete response versus incomplete response was not significantly different between the four treatment groups $(P=0.72)$. Median overall survival was 21.9 months (95\% Cl: 16.9-27.0 months) and comparable between treatment groups (logrank $P=0.88$ ), confirmed in the fully adjusted and propensity score weighted model $(P>0.05)$. Three-year overall survival rates were $35 \%(95 \% \mathrm{Cl}$ : $22 \%-48 \%$ ) in the Cis-low-dose RT group compared with $46 \%$ (95\% Cl: $30 \%-61 \%$ ), $40 \%$ (95\% Cl: 30\%-50\%), and 33\% (95\% Cl: 10\%-59\%), in Cis-high-dose RT, CP-low-dose RT, 
and CP-high-dose RT group, respectively. Multivariable analyses showed that the confidence intervals include 0.70 , meaning that our study is not powered to state that there is no difference in survival between the four regimens. But, importantly, the point estimates of the hazard ratio approximate 1.0 for the different regimens, suggesting a possible overall survival difference would be small. Grades 3-5 acute adverse events were more frequent in patients treated with Cis-high-dose (OR 3.78; $P=0.01$ ) or Cis-lowdose (OR 2.43; $P=0.10$ ) versus $C P$-low-dose RT. The occurrence of grades $3-5$ late toxicities was not different between the four treatment groups. This study could not establish a definitive conclusion regarding overall survival differences between the chemoradiation regimens. However, based on the superior safety profile, in addition to a more feasible outpatient implementation, we suggest a chemoradiation regimen with carboplatin and paclitaxel to be standard in the curative setting for patients with locally advanced proximal esophageal cancer.

The national comparative effectiveness study in unresectable proximal esophageal squamous cell cancer was furthermore used to determine the patterns of recurrence and overall survival in patients achieving clinical complete response after treatment with definitive chemoradiation (Chapter six). In 197 of the 200 identified patients, response was evaluated, among which 133 (68\%) showed a complete response. In complete responders, median overall survival, 3-year overall survival, and progressionfree survival were 45.0 months, 58\%, and $49 \%$, respectively. Three- and 5-year risk of recurrence were $40 \%$ and $45 \%$. Three- and 5-year risk of locoregional recurrence were $26 \%$ and $30 \%$. Eight of 32 patients with an isolated locoregional recurrence underwent salvage surgery, with a median overall survival of 32.0 months $(95 \% \mathrm{Cl}$ 6.8-not reached). We concluded that most recurrences after complete response following definitive chemoradiation for unresectable proximal esophageal cancer were locoregional and developed within the first three years after chemoradiation. These findings suggest to enhance and restrict locoregional follow-up during the first three years following chemoradiation. 


\section{Reference}

1. Rice TW, et al. Worldwide esophageal cancer collaboration. Dis Esophagus 2009;22(1):1-8. 



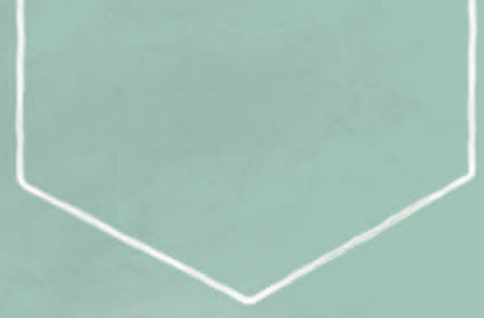

ADDENDUM

Samenvatting

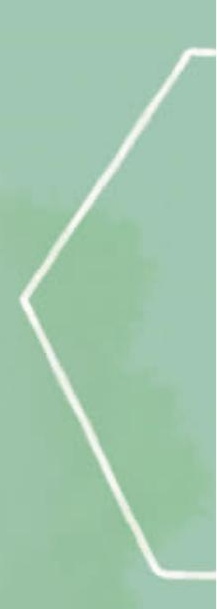





\section{Samenvatting}

In Nederland worden per jaar ongeveer 2500 patiënten met slokdarmkanker gediagnosticeerd. Kanker van het bovenste deel van de slokdarm komt in 1 op de 20 patiënten met slokdarmkanker voor en is derhalve een zeldzame aandoening. Slokdarmkanker kan met veel symptomen gepaard gaan, waaronder moeite of pijn bij het slikken en gewichtsverlies. De hoeksteen van de behandeling van kanker in zijn algemeenheid is chirurgische verwijdering. Bij slokdarmkanker is een operatie echter geen sinecure en kan gepaard gaan met ernstige complicaties. Kanker van het bovenste deel van de slokdarm ligt zeer ongunstig voor een operatieve ingreep door de nabijheid van vele cruciale structuren die noodzakelijk zijn voor een kwalitatief goed bestaan. Met name de overgang van de mondholte naar de stembanden en luchtpijp grenzen aan het bovenste deel van de slokdarm. Een operatie zou derhalve resulteren in een mutilerende situatie waarbij het vermogen tot spreken en slikken onnatuurlijk zal zijn. Daarom is het essentieel om te bestuderen welke behandelopties er zijn voor deze patiënten. Op deze manier kan elke patiënt zo goed mogelijk worden geïnformeerd over de mogelijke behandelopties, risico's op complicaties en verwachte effecten, alvorens tot besluitvorming door een patiënt en de behandelend arts wordt overgegaan.

Dit proefschrift toont dat het aantal patiënten dat in Nederland werd gediagnosticeerd met slokdarmkanker toenam over de tijd, van 5 per 100.000 inwoners per jaar in 19891994 naar 9 per 100.000 inwoners per jaar in 2010-2014. De kans om aan de ziekte te overlijden nam af, waarbij in 1989-1994 maar 1 op de 13 patiënten 5 jaar na de diagnose in leven was, is dit in 2010-2014 gestegen naar 1 op de 4 patiënten. Deze winst is met name te verklaren door de toepassing van een gecombineerde behandeling van chemotherapie en radiotherapie ('chemoradiatie'), zowel vooraf aan een eventuele operatie ('neoadjuvante setting') als bij patiënten die geen operatie kunnen ondergaan ten gevolge van te uitgebreide lokale groei of doordat ze niet fit genoeg worden geacht voor een operatieve ingreep ('definitieve setting'). Daarnaast worden slokdarm operaties vanaf 2006 verricht in een expertisecentrum voor slokdarmkanker om de hoog specialistische chirurgische zorg te bundelen, waarbij in eerdere studies werd gezien dat deze centralisatie bijdraagt aan een betere uitkomst voor de patiënt.

Ook bij patiënten met kanker in het bovenste deel van de slokdarm zagen we een soortgelijke trend in overleving. We zagen dat de chemoradiatie zijn intrede deed, waarbij in 1989-1994 nog maar 1\% van de patiënten met lokale ziekte werd behandeld 
met definitieve chemoradiatie, nam dit toe tot $49 \%$ in $2010-2014$. Gelijktijdig nam de toepassing van operaties en radiotherapie zonder chemotherapie af. Ondanks dat wellicht fittere patiënten een operatie ondergingen, zagen we dat de overleving min of meer gelijk was tussen patiënten die werden behandeld met een operatie, met of zonder neoadjuvante therapie, of met definitieve chemoradiatie, waarbij 1 op de 4 patiënten 5 jaar na de diagnose nog in leven was. Omdat chemoradiatie tot minder ernstige complicaties leidt dan een operatie, is het toepassen van chemoradiatie zonder een operatie op dit moment de beste behandelmodaliteit. Bij patiënten met uitgezaaide kanker vanuit het bovenste deel van de slokdarm werd over de tijd iets meer chemotherapie toegepast, hoewel de overleving hier niet evident door verbeterde.

Chemoradiatie kan uit verschillende soorten (combinaties van) chemotherapie en uiteenlopende doses radiotherapie bestaan. We hebben onderzocht welke combinatie de beste uitkomsten gaf voor patiënten met kanker van het bovenste deel van de slokdarm. Hiervoor vergeleken we 4 behandelgroepen bestaande uit cisplatin chemotherapie met lage dosis radiotherapie ( $\leq 50 \mathrm{~Gy}$ ), cisplatin chemotherapie met hoge dosis radiotherapie (>50 Gy), carboplatin plus paclitaxel chemotherapie en lage dosis radiotherapie of carboplatin plus paclitaxel chemotherapie en hoge dosis radiotherapie. Deze studie toont dat de overleving van patiënten uit alle 4 behandelgroepen vergelijkbaar was. Wel zagen we dat ernstige bijwerkingen duidelijk minder vaak voorkwamen bij 1 van de 4 groepen, namelijk patiënten die werden behandeld met carboplatin plus paclitaxel chemotherapie en lage dosis radiotherapie. Aangezien de kwaliteit van leven enorm beïnvloed kan worden door deze (ernstige) bijwerkingen ligt de voorkeur voor het chemoradiatie schema met de laagste kans op bijwerkingen voor de hand. Tevens wordt deze behandeling (carboplatin-paclitaxel) op de dagverpleging toegediend, in tegenstelling tot (een deel van de) cisplatin behandelingen, waarbij patiënten worden opgenomen en gedurende een etmaal een infuus krijgen ten behoeve van toediening van de chemotherapie.

Bij 133 van de 200 patiënten zagen we dat de kanker van het bovenste deel van de slokdarm volledig leek te verdwijnen door de definitieve chemoradiatie. Deze patiënten hadden een evident betere prognose dan patiënten waarbij nog rest tumor aanwezig was na chemoradiatie. We hebben in dit proefschrift gekeken naar patronen van terugkeer van ziekte bij de groep patiënten waarbij de ziekte volledig verdwenen leek na de chemoradiatie. Ondanks de initieel goede respons op de chemoradiatie, zagen we bij $44 \%$ alsnog terugkeer van ziekte. Het meest frequent keerde de kanker terug in het gebied van de oorspronkelijke tumor, dus in het bestraalde gebied. Behandeling 
van teruggekeerde kanker in dit gebied dient op individueel niveau te worden beoordeeld door patiënt en behandelend arts, waarbij kan worden besloten tot bestraling, chemotherapie, geen anti-tumor behandeling of, in uitzonderlijke gevallen, een operatie. Deze studie toont dat als de kanker terugkeert, dit voornamelijk in de eerste 3 jaar na de behandeling is. Dit heeft tot het voorstel geleid om bij de opvolging na chemoradiatie de aandacht op terugkeer van ziekte in het bestraalde gebied te verbeteren, waarbij er kan worden overwogen om na 3 jaar geen standaard opvolging meer te verrichten, tenzij dit op basis van andere factoren, bijvoorbeeld slokdarmoprekkingen, diëtetiek of psychosociale begeleiding, noodzakelijk wordt geacht. 



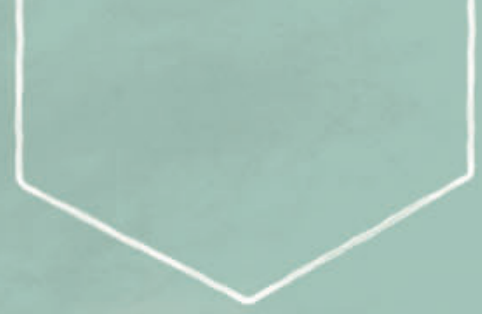

Impact paragraph

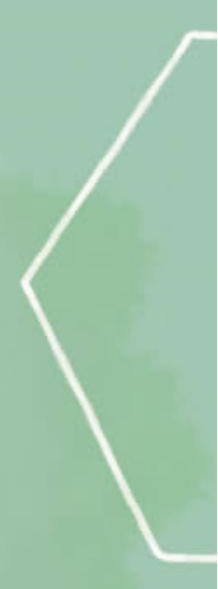





\section{Impact paragraph}

In this thesis, we explored a number of scientific questions in an attempt to provide answers for clinical problems which may be encountered in everyday practice in (proximal) esophageal cancer. In this chapter, the relevance of the results described in this thesis and their scientific and social impact will be discussed.

\section{Reinforced real-world data}

Esophageal cancer is the seventh leading type of cancer worldwide (572.034 new cases in 2018), and tenth in the Netherlands (2.456 new cases in 2018). ${ }^{1}$ Although the absolute number of deaths has decreased, esophageal cancer covers the sixth place in cancer-related mortality globally and in the Netherlands. ${ }^{1}$ Over the past decades, several developments in esophageal cancer care have been established, such as the implementation of neoadjuvant chemoradiation, ${ }^{2,3}$ definitive chemoradiation, ${ }^{4}$ and centralization of care in the Netherlands. ${ }^{5}$ Cancer of the proximal esophagus is a distinct and rare entity. Due to its location, i.e. adjacent vital structures, the treatment approach of these cancers differs from cancers from lower parts of the esophagus, by predominantly performing non-surgical therapy. In addition, patients with proximal esophageal cancer are frequently excluded from esophageal trial participation and, as a result, no separate high level evidence has been achieved. Hence, research data from large populations in Western countries are necessary to optimize patient counseling in the Netherlands. This thesis has added value to clinical practice as it provides insights in the characteristics of proximal esophageal cancer patients, their treatment options, and it offers real-world survival data.

Overall, outcome of patients with (proximal) esophageal has improved over the past decades. We revealed that the broad implementation of combined modality treatment with chemoradiation was associated with this progress. We found that in proximal esophageal cancer, outcome in patients treated with surgery, with or without neoadjuvant therapy, was comparable with patients treated with the non-surgical strategy of definitive chemoradiation. Concerning high morbidity rates and decreased quality of life associated with the surgical procedures for proximal esophageal cancer, it is essential to focus on the multimodality treatment of chemoradiation, appreciating patients' quality of life but yet maintaining survival prospects. 


\section{Enhanced chemoradiation strategies}

Accordingly, this thesis focused on the identification of an optimal chemoradiation regimen for patients with proximal esophageal cancer. By performing a comparative effectiveness study of four contemporary chemoradiation schedules, we provided relevant information regarding risks of toxicity, and concerns of non-adherence mainly caused by adverse events. Furthermore, we demonstrated a suboptimal outcome based on high rates of locoregional residual disease or recurrence, with limited salvage treatment options.

Superiority of carboplatin plus paclitaxel versus cisplatin in definitive chemoradiation schedules for the treatment of proximal esophageal cancer could not be established in terms of overall survival. However, the toxicity profile was significantly better in patients treated with carboplatin plus paclitaxel compared with cisplatin. Hence, we concluded that carboplatin plus paclitaxel-based chemoradiation should be regarded as the standard of care in proximal esophageal cancer. This statement was supported by the Dutch Upper GI Cancer Group (DUCG) and the National Working Group Head Neck Cancer (NWHHT), following national scientific discussion sessions. In December 2020, a survey during a DUCG meeting following the presentation of our study results, demonstrated that 22 out of 24 Dutch physicians involved in esophageal cancer treatment, implemented carboplatin plus paclitaxel in chemoradiation for proximal esophageal cancer nowadays. This is a significant increase compared with $53 \%$ of the patients included in our study being treated with carboplatin plus paclitaxel between 2004 and 2014, enrolled from 11 centers in the Netherlands. The decision to implement carboplatin plus paclitaxel based regimens is strengthened by the conveniences and reduced direct healthcare costs associated with a shift towards outpatient treatment and lower numbers of high grade adverse events expected to minimize treatmentrelated hospitalization days, contributing to economic gain.

More importantly, patients will benefit directly from the substantial reduction of toxicities of carboplatin plus paclitaxel compared with cisplatin-based backbone used in chemoradiation. Specifically, in a disease like (proximal) esophageal cancer with this poor outcome it is essential that patients maintain the best achievable quality of life during treatment. This includes as little as possible hospitalization days for treatment and/or due to serious treatment-related side effects.

Various strategies have been addressed in the 'Future perspectives' paragraph for further optimization of chemoradiation. We are awaiting efficacy data of proton therapy, MRI guided radiotherapy, and immunotherapy in definitive chemoradiation schedules for esophageal cancer. However, in other cancers, the implementation of 
these innovative treatment options are subject of debate to balance high quality health care programs and keeping health care budget within limits, in order to maintain accessibility of care for the total population.

\section{Treatment counseling}

Several aspects have been explored in our studies that may help to optimize quality of patient care. We offer input to improve patient counseling in esophageal cancer, and implement the most optimal chemoradiation schedule in proximal esophageal cancer. Particularly in patients with resectable proximal esophageal cancer, the provided information is crucial for treatment counseling. For each individual patient, clinically meaningful treatment possibilities can be depicted in a more careful way. By discussing potential treatment options, higher satisfaction rates of patients in terms of awareness of side effects and survival outcome are obtained, considering patient values, treatment preferences and restrain psychological distress. ${ }^{6}$ Hence, as a result narrowing the perception-reality gap. It is known that treatment tolerance and adherence amongst patients is highest when patients are extensively informed of the risks of the distinct treatment trajectories. ${ }^{7}$

\section{Follow-up after initial curative treatment}

In this thesis, we further explored outcome of the subgroup of patients with the best perspective, i.e. clinical complete responders following chemoradiation. We showed that most recurrences in this subset of patients with proximal esophageal cancer occurred within the radiation field and within the first three years after primary definitive chemoradiation therapy. Whether or not follow-up after definitive chemoradiation for esophageal cancer is useful remains controversial. Hence, recommendations by NCCN and ESMO guidelines are inconsistent regarding follow-up strategies and duration of surveillance. ${ }^{8,9}$ Considering the burden of prolonged followup on patients quality of life and health care costs, we state that restricting follow-up to three years following definitive chemoradiation for proximal esophageal cancer is to be considered. Unless other factors regarding patients recovery, e.g. repeated dilatations, dietary or psychosocial needs, require continued surveillance. It would be of great interest to study the influence of different novel methods of follow-up on the timing and rate of detection of residual disease or locoregional recurrence, e.g. diffusionweighted magnetic resonance imaging $(\mathrm{MRI}),{ }^{10}$ a radiomics nomogram model, ${ }^{11}$ or 
circulating tumor DNA. ${ }^{12}$ In addition, benefits and strains of salvage treatments should further be addressed, reinforcing quality of life. Better pre-selection of patients will lead to less (avoidable) burden of invasive strategies for patients and their multidisciplinary expertise team.

Furthermore, research aiming to establish the effect of surveillance for early detection of second primary tumors may be of importance, considering the high occurrence of a second squamous cell cancer due to the close association of alcohol and smoking disposition. $^{13}$

To optimize awareness amongst physicians in esophageal cancer care, the findings of this thesis were presented at the scientific meetings of DUCG and NWHHT, and at the national congress of the Netherlands Medical Oncology Working group (NVMO). Moreover, it is proposed to insert a separate paragraph in the national guideline of esophageal cancer treatment, highlighting the therapeutic options and their burden in patients with proximal esophageal cancer.

The preceding aspects delineate that further research in (proximal) esophageal cancer is not only crucial from a patients' point of view by providing progress in treatment and subsequent outcome, but also has the potential to result in an economic and societal benefit. Accordingly, we consider the results of our research as a step forward in esophageal cancer patient care. 


\section{References}

1. Ferlay, J., et al., Global Cancer Observatory: Cancer Today. Lyon, France: International Agency for Research on Cancer. Available from: https://gco.iarc.fr/today (accessed November 23, 2020).

2. Tepper, J., et al., Phase III trial of trimodality therapy with cisplatin, fluorouracil, radiotherapy, and surgery compared with surgery alone for esophageal cancer: CALGB 9781. J Clin Oncol, 2008. 26(7): p. 1086-92.

3. van Hagen, P., et al., Preoperative Chemoradiotherapy for Esophageal or Junctional Cancer. New England Journal of Medicine, 2012. 366(22): p. 2074-2084.

4. Cooper, J.S., et al., Chemoradiotherapy of locally advanced esophageal cancer: long-term follow-up of a prospective randomized trial (RTOG 85-01). Radiation Therapy Oncology Group. Jama, 1999. 281(17): p. 1623-7.

5. Dikken, J.L., et al., Effect of hospital volume on postoperative mortality and survival after oesophageal and gastric cancer surgery in the Netherlands between 1989 and 2009. European Journal of Cancer, 2012. 48(7): p. 1004-1013.

6. Stiggelbout, A.M., et al., Shared decision making: really putting patients at the centre of healthcare. Bmj, 2012. 344: p. e256.

7. LeBlanc, T.W., 'Shared decision-making, preferences, risk-tolerance, and the cancer patient experience'. Expert Review of Quality of Life in Cancer Care, 2017. 2(6): p. 275-277.

8. Lordick, F., et al., Oesophageal cancer: ESMO Clinical Practice Guidelines for diagnosis, treatment and follow-up. Ann Oncol, 2016. 27(suppl 5): p. v50-v57.

9. Ajani, J.A., et al., Esophageal and Esophagogastric Junction Cancers, Version 2.2019, NCCN Clinical Practice Guidelines in Oncology. J Natl Compr Canc Netw, 2019. 17(7): p. 855-883.

10. Borggreve, A.S., et al., Preoperative Prediction of Pathologic Response to Neoadjuvant Chemoradiotherapy in Patients With Esophageal Cancer Using (18)F-FDG PET/CT and DW-MRI: A Prospective Multicenter Study. Int J Radiat Oncol Biol Phys, 2020. 106(5): p. 998-1009.

11. Qiu, Q., et al., Development and Validation of a Radiomics Nomogram Model for Predicting Postoperative Recurrence in Patients With Esophageal Squamous Cell Cancer Who Achieved pCR After Neoadjuvant Chemoradiotherapy Followed by Surgery. Front Oncol, 2020. 10: p. 1398.

12. Azad, T.D., et al., Circulating Tumor DNA Analysis for Detection of Minimal Residual Disease After Chemoradiotherapy for Localized Esophageal Cancer. Gastroenterology, 2020. 158(3): p. 494-505.e6.

13. Mitani, S., et al., Risk of second primary malignancies after definitive treatment for esophageal cancer: A competing risk analysis. Cancer Med, 2020. 9(1): p. 394-400. 



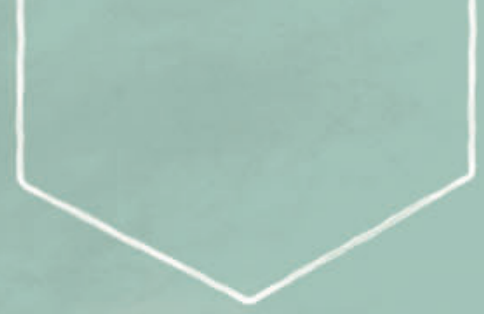

List of publications

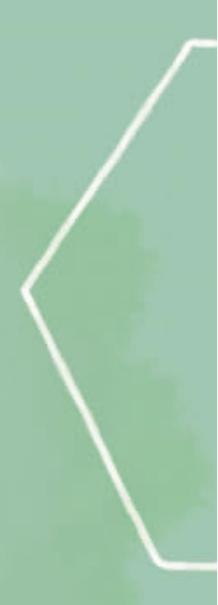





\section{List of publications}

Wi-1

Kelly RJ, Ajani JA, Kuzdzal J, Zander T, Van Cutsem E, Piessen G, Mendez G, Feliciano J, Motoyama S, Lièvre A, Uronis H, Elimova E, Grootscholten C, Geboes K, Zafar S, Snow S, Ko AH, Feeney K, Schenker M, Kocon P, Zhang J, Zhu L, Lei M, Singh P, Kondo K, Cleary JM, Moehler M; CheckMate 577 Investigators. Adjuvant Nivolumab in Resected Esophageal or Gastroesophageal Junction Cancer. N Engl J Med. 2021 Apr 1;384(13):1191-1203.

Janssen QP, van Dam JL, Bonsing BA, Bos H, Bosscha KP, Coene PPLO, van Eijck CHJ, de Hingh IHJT, Karsten TM, van der Kolk MB, Patijn GA, Liem MSL, van Santvoort HC, Loosveld OJL, de VosGeelen J, Zonderhuis BM, Homs MYV, van Tienhoven G, Besselink MG, Wilmink JW, Groot Koerkamp B; Dutch Pancreatic Cancer Group. Total neoadjuvant FOLFIRINOX versus neoadjuvant gemcitabine-based chemoradiotherapy and adjuvant gemcitabine for resectable and borderline resectable pancreatic cancer (PREOPANC-2 trial): study protocol for a nationwide multicenter randomized controlled trial. BMC Cancer. 2021 Mar 23;21(1):300.

de Jong EJ, Geurts SM, van der Geest LG, Besselink MG, Bouwense SA, Buijsen J, Dejong C, Heij LR, Koerkamp BG, de Hingh IH, Hoge C, Kazemier G, van Laarhoven HW, de Meijer VE, Mohammad NH, Strijker M, Timmermans KC, Valkenburg-van lersel LB, Wilmink H, Tjan-Heijnen VC, de Vos-Geelen J; Dutch Pancreatic Cancer Group (DPCG). A population-based study on incidence, treatment, and survival in ampullary cancer in the Netherlands. Eur J Surg Oncol. 2021:S0748-7983(21)00119-0.

Strijker M, van Veldhuisen E, van der Geest LG, Busch OR, Bijlsma MF, Haj Mohammad N, Homs MY, van Hooft JE, Verheij J, de Vos-Geelen J, Wilmink JW, Steyerberg EW, Besselink MG, van Laarhoven HW; Dutch Pancreatic Cancer Group. Readily available biomarkers predict poor survival in metastatic pancreatic cancer. Biomarkers. 2021 Mar 5:1-15.

de Vos-Geelen J, Geurts SME, Nieuwenhuijzen GAP, Voncken FEM, Bogers JA, Braam PM, Muijs CT, de Jong MA, Kasperts N, Rozema T, Blom GJ, Bouwense SAW, Valkenburg-van lersel LBJ, Jeene PM, Hoebers FJP, Tjan-Heijnen VCG. Patterns of recurrence following definitive chemoradiation for patients with proximal esophageal cancer. Eur J Surg Oncol. 2021:S07487983(21)00084-6.

Brada LH, Walma MS, van Dam RM, de Vos-Geelen J, de Hingh IH, Creemers GJ, Liem MS, Mekenkamp LJ, de Meijer VE, de Groot DJA, Patijn GA, de Groot JWB, Festen S, Kerver ED, Stommel MWJ, Meijerink MR, Bosscha K, Pruijt JF, Polée MB, Ropela JA, Cirkel GA, Los M, Wilmink JW, Haj Mohammad N, van Santvoort HC, Besselink MG, Molenaar IQ; Dutch Pancreatic 
Cancer Group. The treatment and survival of elderly patients with locally advanced pancreatic cancer: A post-hoc analysis of a multicenter registry. Pancreatology. 2020:S1424-3903(20)30845-0.

Tan X, Sivakumar S, Bednarsch J, Wiltberger G, Kather JN, Niehues J, de Vos-Geelen J, Valkenburg-van lersel L, Kintsler S, Roeth A, Hao G, Lang S, Coolsen ME, den Dulk M, Aberle MR, Koolen J, Gaisa NT, Olde Damink SWM, Neumann UP, Heij LR. Nerve fibers in the tumor microenvironment in neurotropic cancer-pancreatic cancer and cholangiocarcinoma. Oncogene. 2021;40(5):899-908.

Walma MS, Brada LJ, Patuleia SIS, Blomjous JG, Bollen TL, Bosscha K, Bruijnen RC, Busch OR, Creemers GJ, Daams F, van Dam R, Festen S, Jan de Groot D, Willem de Groot J, Mohammad NH, Hermans JJ, de Hingh IH, Kerver ED, van Leeuwen MS, van der Leij C, Liem MS, van Lienden KP, Los M, de Meijer VE, Meijerink MR, Mekenkamp LJ, Nederend J, Nio CY, Patijn GA, Polée MB, Pruijt JF, Renken NS, Rombouts SJ, Schouten TJ, Stommel MWJ, Verweij ME, de Vos-Geelen J, de Vries JJJ, Vulink A, Wessels FJ, Wilmink JW, van Santvoort HC, Besselink MG, Molenaar IQ, Dutch Pancreatic Cancer Group. Treatment strategies and clinical outcomes in consecutive patients with locally advanced pancreatic cancer: A multicenter prospective cohort. Eur J Surg Oncol. 2020:S0748-7983(20)31033-7.

Hermans BCM, de Vos-Geelen J, Derks JL, Latten L, Liem IH, van der Zwan JM, Speel EM, Dercksen MW, Dingemans AC. Unique Metastatic Patterns in Neuroendocrine Neoplasms of Different Primary Origin. Neuroendocrinology. 2020 Nov 23.

van Dongen JC, Suker M, Versteijne E, Bonsing BA, Mieog JSD, de Vos-Geelen J, van der Harst E, Patijn GA, de Hingh IH, Festen S, Ten Tije AJ, Busch OR, Besselink MG, van Tienhoven G, Groot Koerkamp B, van Eijck CHJ; Dutch Pancreatic Cancer Group. Surgical Complications in a Multicenter Randomized Trial Comparing Preoperative Chemoradiotherapy and Immediate Surgery in Patients With Resectable and Borderline Resectable Pancreatic Cancer (PREOPANC Trial). Ann Surg. 2020 Nov 12.

Latenstein AEJ, Dijksterhuis WPM, Mackay TM, Beijer S, van Eijck CHJ, de Hingh IHJT, Molenaar $I Q$, van Oijen MGH, van Santvoort HC, de van der Schueren MAE, de Vos-Geelen J, de Vries JHM, Wilmink JW, Besselink MG, van Laarhoven HWM; Dutch Pancreatic Cancer Group. Cachexia, dietetic consultation, and survival in patients with pancreatic and periampullary cancer: $A$ multicenter cohort study. Cancer Med. 2020;9(24):9385-9395.

Mackay TM, Latenstein AEJ, Bonsing BA, Bruno MJ, van Eijck CHJ, Groot Koerkamp B, de Hingh IHJT, Homs MYV, van Hooft JE, van Laarhoven HW, Molenaar IQ, van Santvoort HC, Stommel MWJ, de Vos-Geelen J, Wilmink JW, Busch OR, van der Geest LG, Besselink MG. Nationwide compliance with a multidisciplinary guideline on pancreatic cancer during 6-year follow-up. Pancreatology. 2020;20(8):1723-1731. 
Mackay TM, Latenstein AEJ, Sprangers MAG, van der Geest LG, Creemers GJ, van Dieren S, de Groot JB, Groot Koerkamp B, de Hingh IH, Homs MYV, de Jong EJM, Molenaar IQ, Patijn GA, van de Poll-Franse LV, van Santvoort HC, de Vos-Geelen J, Wilmink JW, van Eijck CH, Besselink MG, van Laarhoven HWM; Dutch Pancreatic Cancer Group. Relationship Between Quality of Life and Survival in Patients With Pancreatic and Periampullary Cancer: A Multicenter Cohort Analysis. J Natl Compr Canc Netw. 2020;18(10):1354-1363.

Dijksterhuis WPM, Verhoeven RHA, Pape M, Slingerland M, Haj Mohammad N, de Vos-Geelen J, Beerepoot LV, van Voorthuizen T, Creemers GJ, Lemmens VEPP, van Oijen MGH, van Laarhoven HWM. Hospital volume and beyond first-line palliative systemic treatment in metastatic oesophagogastric adenocarcinoma: A population-based study. Eur J Cancer. 2020;139:107-118.

Martens B, Wildberger JE, Hendriks BMF, Van Kuijk SMJ, Nijssen EC, Peters NHGM, de VosGeelen J, Mihl C. A Solution for Homogeneous Liver Enhancement in Computed Tomography: Results From the COMpLEx Trial. Invest Radiol. 2020;55(10):666-672.

Reinders MTM, van Meer S, Burgmans MC, de Jong KP, Klümpen HJ, de Man RA, Ramsoekh DS, Sprengers D, Tjwa ETTL, de Vos-Geelen J, van Erpecum KJ, van der Geest LGM; Dutch Hepatocellular \& Cholangiocarcinoma Group (DHCG). Trends in incidence, diagnosis, treatment and survival of hepatocellular carcinoma in a low-incidence country: Data from the Netherlands in the period 2009-2016. Eur J Cancer. 2020;137: 214-223.

Belkouz A, Wilmink JW, Haj Mohammad N, Hagendoorn J, de Vos-Geelen J, Dejong CHC, Homs MYV, Groot Koerkamp B, van Gulik TM, van Oijen MGH, Punt CJA, Klümpen H. Advances in adjuvant therapy of biliary tract cancer: an overview of current clinical evidence based on phase II and III trials. Crit Rev Oncol Hematol. 2020;151:102975.

Groen JV, Stommel MWJ, Sarasqueta AF, Besselink MG, Brosens LAA, van Eijck CHJ, Molenaar IQ, Verheij J, de Vos-Geelen J, Wasser MN, Bonsing BA, Mieog JSD; Dutch Pancreatic Cancer Group. Surgical Management and Pathological Assessment of Pancreatoduodenectomy With Venous Resection: An International Survey Among Surgeons and Pathologists. HPB (Oxford). 2020;S1365$182 \times(20) 30142-8$.

de Vos-Geelen J, Hoebers FJP, Geurts SME, Hoeben A, de Greef BTA, Voncken FEM, Bogers JA, Braam PM, Muijs CT, de Jong MA, Kasperts N, Rozema T, Jeene PM, Blom GJ, van Dieren JM, Hulshof MCCM, van Laarhoven HWM, Grabsch HI, Lemmens VEPP, Tjan-Heijnen VCG, Nieuwenhuijzen GAP. A national study to assess outcomes of definitive chemoradiation regimens in proximal esophageal cancer. Acta Oncol. 2020;59(8):895-903.

Mackay TM, Smits FJ, Latenstein AEJ, Bogte A, Bonsing BA, Bos H, Bosscha K, Brosens LAA, Hol L, Busch ORC, Creemers GJ, Curvers WL, den Dulk M, van Dieren S, van Driel LMJW, Festen S, van 
Geenen EJM, van der Geest LG, de Groot DJA, de Groot JWB, Haj Mohammad N, Haberkorn BCM, Haver JT, van der Harst E, Hemmink GJM, de Hingh IH, Hoge C, Homs MYV, van Huijgevoort NC, Jacobs MAJM, Kerver ED, Liem MSL, Los M, Lubbinge H, Luelmo SAC, de Meijer VE, Mekenkamp L, Molenaar IQ, van Oijen MGH, Patijn GA, Quispel R, van Rijssen LB, Römkens TEH, van Santvoort HC, Schreinemakers JMJ, Schut H, Seerden T, Stommel MWJ, Ten Tije AJ, Venneman NG, Verdonk RC, Verheij J, van Vilsteren FGI, de Vos-Geelen J, Vulink A, Wientjes C, Wit F, Wessels FJ, Zonderhuis B, van Werkhoven $\mathrm{CH}$, van Hooft JE, van Eijck CHJ, Wilmink JW, van Laarhoven HWM, Besselink MG; Dutch Pancreatic Cancer Group. Impact of nationwide enhanced implementation of best practices in pancreatic cancer care (PACAP-1): a multicenter stepped-wedge cluster randomized controlled trial. Trials. 2020;21(1):334.

Rolfo C, Isambert N, Italiano A, Molife LR, Schellens JHM, Blay JY, Decaens T, Kristeleit R, Rosmorduc O, Demlova R, Lee MA, Ravaud A, Kopeckova K, Learoyd M, Bannister W, Locker G, de Vos-Geelen J. Pharmacokinetics and safety of olaparib in patients with advanced solid tumours and mild or moderate hepatic impairment. Br J Clin Pharmacol. 2020;86(9):1807-1818.

Versteijne E, Suker M, Groothuis K, Akkermans-Vogelaar JM, Besselink MG, Bonsing BA, Buijsen J, Busch OR, Creemers GM, van Dam RM, Eskens FALM, Festen S, de Groot JWB, Groot Koerkamp B, de Hingh IH, Homs MYV, van Hooft JE, Kerver ED, Luelmo SAC, Neelis KJ, Nuyttens J, Paardekooper GMRM, Patijn GA, van der Sangen MJC, de Vos-Geelen J, Wilmink JW, Zwinderman $\mathrm{AH}$, Punt CJ, van Eijck $\mathrm{CH}$, van Tienhoven G; Dutch Pancreatic Cancer Group. Preoperative Chemoradiotherapy Versus Immediate Surgery for Resectable and Borderline Resectable Pancreatic Cancer: Results of the Dutch Randomized Phase III PREOPANC Trial. J Clin Oncol. 2020;38(16):1763-1773.

Dijksterhuis WPM, Verhoeven RHA, Meijer SL, Slingerland M, Haj Mohammad N, de Vos-Geelen J, Beerepoot LV, van Voorthuizen T, Creemers GJ, van Oijen MGH, van Laarhoven HWM. Increased assessment of HER2 in metastatic gastroesophageal cancer patients: a nationwide population-based cohort study. Gastric Cancer. 2020;23(4):579-590.

Beijers AJM, Bonhof CS, Mols F, Ophorst J, de Vos-Geelen J, Jacobs EMG, van de Poll-Franse LV, Vreugdenhil G. Multicenter randomized controlled trial to evaluate the efficacy and tolerability of frozen gloves for the prevention of chemotherapy-induced peripheral neuropathy. Ann Oncol. 2020;31(1):131-136.

Belkouz A, de Vos-Geelen J, Mathôt RAA, Eskens FALM, van Gulik TM, van Oijen MGH , Punt CJA, Wilmink JW, Klümpen HJ. Efficacy and safety of FOLFIRINOX as salvage treatment in advanced biliary tract cancer: an open-label, single arm, phase 2 trial. Br J Cancer. 2020;122(5):634-639.

Latenstein AEJ, Mackay TM, Creemers GJ, van Eijck CHJ, de Groot JW, Haj Mohammad N, Homs MYV, van Laarhoven HWM, Molenaar IQ, Ten Tije BJ, de Vos-Geelen J, Besselink MG, van der 
Geest LGM, Wilmink JW, Dutch Pancreatic Cancer Group. Implementation of contemporary chemotherapy for patients with metastatic pancreatic ductal adenocarcinoma: a populationbased analysis. Acta Oncol. 2020; 59(6):705-712..

de Vos-Geelen J, Geurts SME, van Putten M, Valkenburg-van lersel LBJ, Grabsch HI, Haj Mohammad N, Hoebers FJP, Hoge CV, Jeene PM, de Jong EJM, van Laarhoven HWM, Rozema T, Slingerland M, Tjan-Heijnen VCG, Nieuwenhuijzen GAP, Lemmens VEPP. Trends in treatment and overall survival among patients with proximal esophageal cancer. World J Gastroenterol 2019; 25(47): 6835-6846.

Latenstein AEJ, van der Geest LGM, Bonsing BA, Groot Koerkamp B, Haj Mohammad N, de Hingh IHJT, de Meijer VE, Molenaar IQ, van Santvoort HC, van Tienhoven GJ, Verheij J, Vissers PAJ, de Vos-Geelen J, Busch ORC, van Eijck CHJ, van Laarhoven HWM, Besselin MG, Wilmink JW for the Dutch Pancreatic Cancer Group. Nationwide trends in incidence, treatment and survival of patients with resected and non-resected pancreatic ductal adenocarcinoma. Eur J Cancer. 2020;125:83-93.

Jones RL, Ratain MJ, O’Dwyer PJ, Siu LL, Jassem J, Medioni J, DeJonge M, Rudin C, Sawyer M, Khayat D, Awada A, de Vos-Geelen J, Evans TRJ, Obel J, Brockstein B, DeGreve J, Baurain JF, Maki R, D'Adamo D, Dickson M, Undevia S, Geary D, Janisch L, Bedard PL, Abdul Razak AR, Kristeleit R, Vitfell-Rasmussen J, Walters I, Kaye SB, Schwartz G. Phase 2 Randomized Discontinuation Trial of Brivanib in Patients with Advanced Solid Tumors. Eur J Cancer. 2019;120:132-139.

Abbema DV, Vissers PAJ, de Vos-Geelen J, Lemmens V, Janssen-Heijnen ML, Tjan-Heijnen VCG. Survival benefits of treatment strategies in breast cancer and colorectal cancer patients: comparison between older and younger cancer patients. Cancers (Basel). 2019;11(9). pii: E1239.

Aarnoutse R, Ziemons J, Penders J, Rensen SS, de Vos-Geelen J, Smidt ML. The Clinical Link between Human Intestinal Microbiota and Systemic Cancer Therapy. Int J Mol Sci. 2019;20(17). pii: E4145.

Mackay TM, Smits FJ, Roos D, Bonsing BA, Bosscha K, Busch OR, Creemers GJ, van Dam RM, van Eijck CHJ, Gerhards MF, de Groot JWB, Groot Koerkamp B, Haj Mohammad N, van der Harst E, de Hingh IHJT, Homs MYV, Kazemier G, Liem MSL, de Meijer VE, Molenaar IQ, Nieuwenhuijs VB, van Santvoort HC, van der Schelling GP, Stommel MWJ, Ten Tije AJ, de Vos-Geelen J, Wit F, Wilmink JW, van Laarhoven HWM, Besselink MG. The risk of not receiving adjuvant chemotherapy after surgical resection of pancreatic ductal adenocarcinoma: a nationwide analysis. HPB (Oxford). 2020;22(2):233-240.

Dijksterhuis WPM, Verhoeven RHA, Slingerland M, Haj Mohammad N, de Vos-Geelen J, Beerepoot LV, van Voorthuizen T, Creemers GJ, van Oijen MGH, van Laarhoven HWM. Heterogeneity of first-line palliative systemic treatment in synchronous metastatic 
esophagogastric cancer patients: a real-world evidence study. Int J Cancer. 2020;146(7):18891901.

Mokadem I, Dijksterhuis W, van Putten M, Heuthorst L, de Vos-Geelen J, Haj Mohammad N, Nieuwenhuijzen GAP, van Laarhoven HWM, Verhoeven RHA. Recurrence after Preoperative Chemotherapy and Surgery for Gastric Adenocarcinoma: A Multicenter Study. Gastric Cancer. 2019;22(6):1263-1273.

Strijker M, Belkouz A, van der Geest LG, van Gulik TM, van Hooft JE, de Meijer VE, Haj Mohammad N, de Reuver PR, Verheij J, de Vos-Geelen J, Wilmink JW, Groot Koerkamp B, Klümpen HJ, Besselink MG; Dutch Pancreatic Cancer Group. Treatment and Survival of Resected and Unresected Distal Cholangiocarcinoma: A Nationwide Study. Acta Oncol. 2019;58(7):10481055.

Rolfo C, de Vos-Geelen J, Isambert N, Molife LR, Schellens J, De Grève J, Blay J-Y, Dirix L, Grundtvig-Sørensen P, Jerusalem G, Leunen K, Mau-Sørensen PM, Plummer R, Learoyd M, Bannister W, Fielding A, Ravaud A. Pharmacokinetics and safety of olaparib in patients with advanced solid tumors and renal impairment. Clin Pharmacokinet. 2019;58(9):1165-1174.

van Hilst J, de Rooij T, van den Boezem PB, Bosscha K, Busch OR, van Duijvendijk P, Festen S, Gerhards MF, de Hingh IH, Karsten TM, Kazemier G, Lips DJ, Luyer MD, Nieuwenhuijs VB, Patijn GA, Stommel MW, Zonderhuis BM, Daams F, Besselink MG; Dutch Pancreatic Cancer Group. Laparoscopic versus open pancreatoduodenectomy for pancreatic or periampullary tumours (LEOPARD-2): a multicentre, patient-blinded, randomised controlled phase $2 / 3$ trial. HPB (Oxford). 2019;21(7):857-864.

Keikes L, de Vos-Geelen J, de Groot JWB, Punt CJA, Simkens LHJ, Trajkovic-Vidakovic M, Portielje JEA, Vos AH, Beerepoot LV, Hunting CB, Koopman M, van Oijen MGH. Implementation, participation and satisfaction rates of a web-based decision support tool for patients with metastatic colorectal cancer. Patient Educ Couns. 2019;102(7): 1331-1335.

van Erning FN, Mackay TM, van der Geest LGM, Groot Koerkamp B, van Laarhoven HWM, Bonsing BA, Wilmink JW, van Santvoort HC, de Vos-Geelen J, van Eijck CHJ, Busch OR, Lemmens VE, Besselink MG; Dutch Pancreatic Cancer Group. Association of the location of pancreatic ductal adenocarcinoma (head, body, tail) with tumor stage, treatment, and survival: a population-based analysis. Acta Oncol. 2018;57(12):1655-1662.

Van Abbema D, van den Akker M, Tjan-Heijnen VCG, Hoeben A, Kleijnen J, van den Berkmortel F, de Vos-Geelen J, Buntinx F, Janssen-Heijnen M. Patient- and tumor-related predictors of chemotherapy intolerance in older cancer patients: a systematic review. J Geriatr Oncol. 2019;10(1):31-41. 
van der Pol J, de Vos-Geelen J, Bucerius J, Mitea C, van der Leij C. Uncomplicated 90Y Selective Internal Radio Therapy in a Patient With Hepatocellular Carcinoma After Arterial and Portal Vein Embolizations. Clin Nucl Med. 2018;43(3):180-182.

van Putten M, de Vos-Geelen J, Nieuwenhuijzen GAP, Siersema PD, Lemmens VEPP, Rosman C, van der Sangen MJC, Verhoeven RHA. Long-term survival improvement in esophageal cancer in the Netherlands. Eur J Cancer. 2018;94:138-147.

Coebergh van den Braak RRJ, van Rijssen LB, van Kleef JJ, Vink GR, Berbee $M$, van Berge Henegouwen MI, Bloemendal HJ, Bruno MJ, Burgmans MC, Busch ORC, Coene PPLO, Coupé VMH, Dekker JWT, van Eijck CHJ, Elferink MAG, Erdkamp FLG, van Grevenstein WMU, de Groot JWB, van Grieken NCT, de Hingh IHJT, Hulshof MCCM, ljzermans JNM, Kwakkenbos L, Lemmens VEPP, Los M, Meijer GA, Molenaar IQ, Nieuwenhuijzen GAP, de Noo ME, van de Poll-Franse LV, Punt CJA, Rietbroek RC, Roeloffzen WWH, Rozema T, Ruurda JP, van Sandick JW, Schiphorst AHW, Schipper H, Siersema PD, Slingerland M, Sommeijer DW, Spaander MCW, Sprangers MAG, Stockmann HBAC, Strijker M, van Tienhoven G, Timmermans LM, Tjin-A-Ton MLR, van der Velden AMT, Verhaar MJ, Verkooijen HM, Vles WJ, de Vos-Geelen J, Wilmink JW, Zimmerman DDE, van Oijen MGH, Koopman M, Besselink MGH, van Laarhoven HWM; Dutch Pancreatic Cancer Group, Dutch Upper GI Cancer Group and PLCRC working group. Nationwide comprehensive gastrointestinal cancer cohorts: the 3P initiative. Acta Oncologica. 2018;57(2):195-202.

Aarnoutse R, de Vos-Geelen J, Penders J, Boerma E-J, Warmerdam F, Goorts B, Olde Damink S, Soons Z, Rensen S, Smidt M. Study protocol on the role of intestinal microbiota in colorectal cancer treatment: a pathway to personalized medicine 2.0. Int J Colorectal Dis. 2017;32(7):10771084.

Van Abbema D, van Vuuren A, van den Berkmortel F, van den Akker M, Deckx L, Buntinx F, van Kampen R, Lambooij E, de Boer M, de Vos-Geelen J, Tjan-Heijnen VC. Functional status decline in older breast and colorectal cancer patients after cancer treatment: A prospective cohort study. J Geriatr Oncol. 2017;8(3):176-184.

Heldens AF, Bongers BC, de Vos-Geelen J, van Meeteren NL, Lenssen AF. Reply to: Exercising patient-centredness in prehabilitation programs. Eur J Surg Oncol. 2017;43(2):511-512.

Munasinghe W, Stodtmann S, Tolcher A, Calvo E, Gordon M, Jalving M, de Vos-Geelen J, et al. Effect of Veliparib (ABT-888) on Cardiac Repolarization in Patients with Advanced Solid Tumors: A Randomized, Placebo-Controlled Crossover Study. Cancer Chemother Pharmacol. 2016;78(5):1003-1011

Heldens AFJM, Bongers BC, de Vos-Geelen J, van Meeteren NLU, Lenssen AF. Feasibility of a physical exercise training program during neoadjuvant chemoradiotherapy in individual patients with rectal cancer. Eur J Surg Oncol. 2016;42(9):1322-30. 
Dirix L, Swaisland H, Verheul HMW, Rottey S, Leunen K, Jerusalem G, Rolfo C, Nielsen D, Molife LR, Kristeleit R, de Vos-Geelen J, et al. Effect of itraconazole and rifampin on the pharmacokinetics of olaparib in patients with advanced solid tumors: results of two Phase I openlabel studies. Clin Ther. 2016;38(10):2286-2299.

Hoeben A, Polak J, van de Voorde L, Hoebers F, Grabsch HI, de Vos-Geelen J. Cervical esophageal cancer: a gap in cancer knowledge. Ann Oncol. 2016;27(9):1664-74.

Versteijne E, van Eijck CHJ, Punt CJA, Suker M, Zwinderman KAH, Dohmen MAC, Groothuis KBC, Busch ORC, Besselink MGH, de Hingh IHJT, ten Tije BJA, Patijn GA, Bonsing BA, de Vos-Geelen J, Klaase JM, Festen S, Boerma D, Erdmann JI, Molenaar IQ, der Harst E, van der Kolk MB, Rasch CRN, van Tienhoven G, for the Dutch Pancreatic Cancer Group (DPCG). Preoperative radiochemotherapy versus immediate surgery for resectable and borderline resectable pancreatic cancer: a Dutch randomized controlled multicenter trial (PREOPANC trial). Trials. 2016;17(1):127.

Van De Voorde L, Houben R, Damen P, Van den Boogaard J, Vanneste B, Lammering G, Dejong C, de Vos-Geelen J, Buijsen J, Öllers M, Berbée M, Lambin P. Image-guided stereotactic ablative radiotherapy for the liver: a safe and effective treatment. Eur J Surg Oncol. 2015;41(2):249-56.

de Vos-Geelen J, Fearon $\mathrm{KCH}$, Schols AMW. The energy balance in cancer cachexia revisited. Curr Opin Clin Nutr Metab Care. 2014;17(6):509-14.

Dingemans AMC, de Vos-Geelen J, Slangen R, Schols AMW. Phase II drugs that are currently in development for the treatment of cachexia. Expert Opin Investig Drugs. 2014;23(12):1655-69.

\section{WN}

Dijksterhuis WPM, Verhoeven RHA, Slingerland M, Haj Mohammad N, de Vos-Geelen J, Beerepoot LV, van Voorthuizen T, Creemers GJ, van Oijen MGH, van Laarhoven HWM. Praktijkvariatie in de palliatieve eerstelijns systemische behandeling bij het gemetastaseerd oesofagus- en maagcarcinoom. Nederlands Tijdschrift voor Oncologie 2020;17:58-65.

Wilmink JW, de Vos-Geelen J, Busch ORC. Nieuw richtlijn pancreascarcinoom. Nederlands Tijdschrift voor Oncologie 2019;16:317-318.

Belkouz A, Wilmink JW, Haj Mohammad N, Hagendoorn J, de Vos-Geelen J, De jong CHC, Homs MYV, Groot Koerkamp B, van Gulik TM, Punt CJA, Klümpen H. New developments in the adjuvant treatment of biliary tract cancer. Nederlands Tijdschrift voor Oncologie 2019;16:24-31. 
PLCRC researchteam. Prospective Dutch CRC cohort: an infrastructure for clinical studies on colorectal cancer. Nederlands Tijdschrift voor Oncologie 2018;15(2):60-63.

Dutch Pancreatic Cancer Group. New developments in the treatment of pancreatic cancer. Nederlands Tijdschrift voor Geneeskunde 2016;160:D538.

de Vos-Geelen J, Sanders KJC, Schols AMWJ, Dingemans AMC. [Pharmaceutical treatment options in cancer cachexia]. Nederlands Tijdschrift voor Oncologie 2016;13(3):72-80.

Jansen RLH, de Vos-Geelen J. [Adjuvant chemotherapy in patients with rectal cancer.] Nederlands Tijdschrift voor Oncologie 2013;10(6):241-2.

Sobczak C, de Vos-Geelen J, Bemelmans MHA, Thissen MRTM, Soetekouw PMMB. [Widespread metastatic melanoma, or not?] Nederlands Tijdschrift voor Dermatologie en Venereologie 2012;22(6):348-351. 



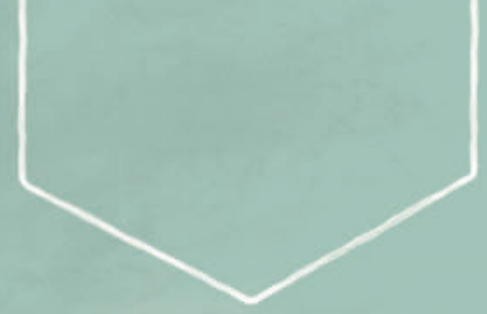

Dankwoord

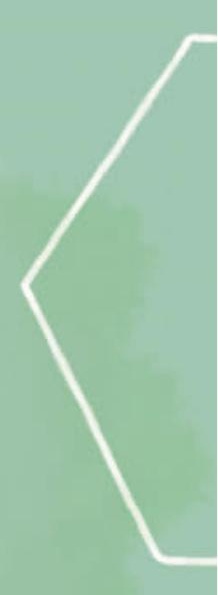





\section{Dankwoord}

Ik ben dankbaar dat ik werkzaam mag zijn in het mooiste en meest intrigerende vakgebied dat er bestaat, waarbij ik een mooie kans krijg om mij te mogen ontwikkelen op wetenschappelijk gebied. Uit de grond van mijn hart dank ik alle patiënten die ik mag begeleiden voor de continue motivatiebron die zij voor mij vormen om te blijven zoeken naar een beter bestaan voor patiënten met kanker.

Er zijn vele mensen die hebben bijgedragen aan de totstandkoming van dit proefschrift, die ik graag allen wil bedanken.

Ik dank mijn begeleiders voor hun inspirerende rol en alle mogelijkheden die zij voor mij hebben gecreëerd, de co-auteurs voor de prettige samenwerking en alle patiënten die hebben bijgedragen aan de studies van dit onderzoek.

Ik wil mijn naaste collegae bedanken voor de fijne samenwerking en de kansen die zij mij hebben gegeven om me te kunnen focussen op mijn onderzoek. In het bijzonder dank ik degenen met wie ik dagelijks mag samenwerken, die altijd tijd creëren om te brainstormen, een kritische blik te leveren en die klaar stonden om werkzaamheden over te nemen als ik bezig was met mijn promotieonderzoek.

Dank aan mijn lieve vrienden, die een frisse visie genereren op alles wat belangrijk is in het leven. Ik prijs mezelf gelukkig met jullie.

Ik ben heel dankbaar voor mijn lieve familie voor hun support en in het bijzonder mijn lieve (schoon)ouders, door wie ik me onbezorgd heb kunnen ontplooien en die altijd voor ons klaar staan.

Oneindige steun, geduld en vertrouwen om mij verder te ontwikkelen, krijg ik van de allerliefsten om mij heen, mijn hartveroverende Saar, Sebastiaan en Roos, en mijn man Cees, de allerleukste man die er bestaat. 



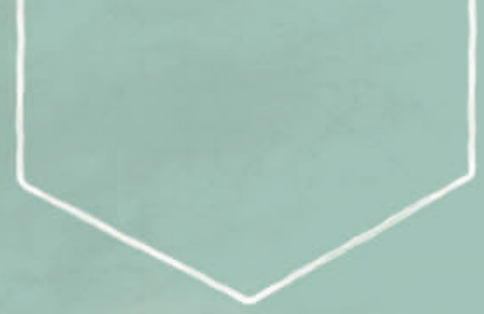

Curriculum vitae

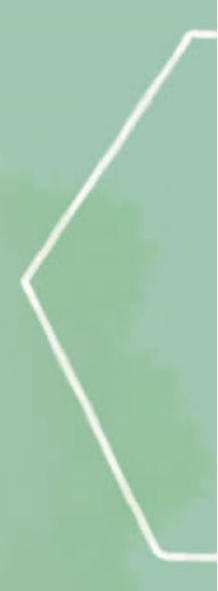





\section{Curriculum vitae}

Judith de Vos-Geelen was born in Maastricht in 1981, where she grew up together with her parents and sister Anouk. She completed her secondary education at Montessori College Maastricht (Dutch equivalent of the Grammar school). In 1999, she started her medical training at the Maastricht University. In 2002 she performed an internship at the Universiti Sains Malaysia, Kota Bharu, Malaysia, and in 2005 at the University of Queensland, Brisbane, Australia. After graduating in 2005, she started as resident in Internal Medicine at VieCuri Medical Center Venlo (supervision dr. A.J. Luik). In 2009, she continued her residency at the Maastricht University Medical Center (supervision prof. dr. C.D.A. Stehouwer and prof. dr. R.P. Koopmans), and onwards a differentiation in Medical Oncology (supervision prof. dr. V.C.G. Tjan-Heijnen). In 2012, she started working as a staff member at the department of Medical Oncology of the Maastricht University Medical Center with special expertise in gastrointestinal cancer. In addition to patient care and student teaching, she started translational and clinical research with several projects in the field of gastrointestinal cancer, of which this thesis is one of the results (supervision prof. dr. V.C.G. Tjan-Heijnen, dr. G.A.P. Nieuwenhuijzen, dr. S.M.E. Geurts, and dr. F.J.P. Hoebers). Between 2015 and 2019 she was medical manager of the multidisciplinary group of upper gastrointestinal and hepatopancreatobiliary cancers at the Maastricht University Medical Center. From 2014 onwards she is deputy head trainer of the fellowship Medical Oncology at the Maastricht University Medical Center. Using her experience as member of the scientific committee of the Dutch Pancreatic Cancer Group (DPCG), board member of the Dutch Hepatocellular \& Cholangiocarcinoma Group (DHCG), and representative in the writing committees of the Dutch Guideline for pancreatic cancer and the Dutch Guideline for hepatocellular cancer, she aims at standardization and uniform data collection to allow for optimal selection of treatment, and personalization of patient decision making. She will continue focusing her research on gastrointestinal cancer. She is currently (co-) supervising PhD candidates E.J.M. de Jong ('Treatment and outcomes of peri-ampullary cancers'), and R. Aarnoutse ('The role of intestinal microbiota in cancer treatment: a pathway to new therapeutic options').

She lives in Roermond with her husband Cees de Vos and their three children Saar, Sebastiaan, and Roos. 
